Florida International University FIU Digital Commons

11-10-2016

\title{
Investigation of Low Reynolds Number Flow and Heat Transfer of Louvered Surfaces
}

Pradeep R. Shinde

Florida International University, pshin001@fiu.edu

DOI: 10.25148 /etd.FIDC001195

Follow this and additional works at: https://digitalcommons.fiu.edu/etd

Part of the Aerodynamics and Fluid Mechanics Commons, Automotive Engineering Commons, Energy Systems Commons, and the Heat Transfer, Combustion Commons

\section{Recommended Citation}

Shinde, Pradeep R., "Investigation of Low Reynolds Number Flow and Heat Transfer of Louvered Surfaces" (2016). FIU Electronic Theses and Dissertations. 3038.

https://digitalcommons.fiu.edu/etd/3038 


\title{
FLORIDA INTERNATIONAL UNIVERSITY \\ Miami, Florida
}

\section{INVESTIGATION OF LOW REYNOLDS NUMBER FLOW AND HEAT TRANSFER OF LOUVERED SURFACES}

\author{
A dissertation submitted in partial fulfillment of the \\ requirements for the degree of \\ DOCTOR OF PHILOSOPHY \\ in \\ MECHANICAL ENGINEERING
}

By

Pradeep Ramesh Shinde 
To: Interim Dean Ranu Jung

College of Engineering and Computing

This dissertation, written by Pradeep Ramesh Shinde, and entitled Investigation of Low Reynolds Number Flow and Heat Transfer of Louvered Surfaces, having been approved in respect to style and intellectual content, is referred to you for judgment.

We have read this dissertation and recommend that it be approved.

Shekhar Bhansali

Chad Bowers

Yiding Cao

George Dulikravich

Cheng-Xian Lin, Major Professor

Date of Defense: November 10, 2016

The dissertation of Pradeep Ramesh Shinde is approved.

Interim Dean Ranu Jung College of Engineering and Computing

Andrés G. Gil

Vice President for Research and Economic Development and Dean of the University Graduate School

Florida International University, 2016 
(C) Copyright 2016 by Pradeep Ramesh Shinde

All rights reserved. 


\section{DEDICATION}

I dedicate this thesis to my parents, my girlfriend Annie, and my friends. Without their patience, understanding, support, and most of all love, the completion of this work would not have been possible. 


\section{ACKNOWLEDGMENTS}

I wish to thank the members of my committee for their support, patience, and good humor. Their gentle but firm direction has been most appreciated. Prof. Shekhar Bhansali has been particularly helpful in guiding me toward a quantitative radiative heat transfer analysis. I appreciate his guidance on public communication development. Prof. Yiding Cao's guidelines on the fundamental knowledge and fault finding during the course of the study, in addition to his suggestion on simplified correlation development, was of tremendous value. Prof. Dulikravich's direction throughout the course of numerical investigation has added a profound value to the present work. I sincerely appreciate his readiness to the guidance and several suggestions on the fundamental understanding of the computational fluid dynamic studies.

The current research is the part and also the outcome of the ASHRAE (American Society of Heating, Refrigeration, and Air-Conditioning Engineers) sponsored project awarded to my major professor, Dr. Cheng-Xian Lin. Dr. Chad Bowers is one of the members of the project monitoring committee from ASHRAE technical committee TC8.4 (2012-2014) team. His input was impetus throughout the project and my dissertation work. His motivation for the investigation of flow behavior has pushed the part of this work towards the improvement of fundamental understanding. Finally, I would like to thank my major professor, Dr. Cheng-Xian Lin, for providing an opportunity for me to work on the project, his support for my degree, push towards the attention to details, and challenging continuously towards innovative thinking. 
I would also like to extend my thanks to the members of American Society of Heating, Refrigeration, and Air-Conditioning Engineers (ASHRAE) project committee, for their very helpful discussions and suggestions during the project. I am also grateful for the financial support of a Florida International University Dissertation Year Fellowship for this study. 
ABSTRACT OF THE DISSERTATION

\title{
INVESTIGATION OF LOW REYNOLDS NUMBER FLOW AND HEAT TRANSFER \\ OF LOUVERED SURFACES
}

\author{
by \\ Pradeep Ramesh Shinde \\ Florida International University, 2016 \\ Miami, Florida \\ Professor Cheng-Xian Lin, Major Professor
}

This study focuses on the investigation of flow behavior at low Reynolds numbers by the experimental and numerical performance testing of micro-channel heat exchangers. An experimental study of the heat transfers and pressure drop of compact heat exchangers with louvered fins and flat tubes was conducted within a low air-side Reynolds number range of $20<R e_{L p}<225$. Using an existing low-speed wind tunnel, 26 sample heat exchangers of corrugated louver fin type, were tested. New correlations for Colburn $j$ and Fanning friction $\mathrm{f}$ factor have been developed in terms of non-dimensional parameters. Within the investigated parameter ranges, it seems that both the $\mathrm{j}$ and $\mathrm{f}$ factors are better represented by two correlations in two flow regimes (one for $\operatorname{Re}_{L p}=20-80$ and one for $\operatorname{Re}_{L p}=80-$ 200) than a single regime correlation in the power-law format. The results support the conclusion that airflow and heat transfer at very low Reynolds numbers behaves differently from that at higher Reynolds numbers. The effect of the geometrical parameters on the heat exchanger performance was investigated. 
The numerical investigation was conducted for further understanding of the flow behavior at the range of experimentally tested Reynolds number. Ten different heat exchanger geometries with varied geometrical parameters obtained for the experimental studies were considered for the numerical investigation. The variations in the louver angle were the basis of the selection. The heat transfer and pressure drop performance was numerically investigated and the effect of the geometrical parameters was evaluated. Numerical results were compared against the experimental results. From the comparison, it is found that the current numerical viscous laminar models do not reflect experimentally observed transitional two regime flow behavior from fin directed to the louver directed at very low Reynolds number ranging from 20 to 200 .

The flow distribution through the fin and the louver region was quantified in terms of flow efficiency. The flow regime change was observed at very low Reynolds number similar to the experimental observations. However, the effect of two regime flow change does not reflect on the thermal hydraulic performance of numerical models. New correlations for the flow efficiency $\eta$ have developed in terms of non-dimensional parameters. 


\section{TABLE OF CONTENTS}

CHAPTER

PAGE

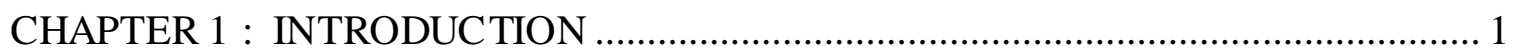

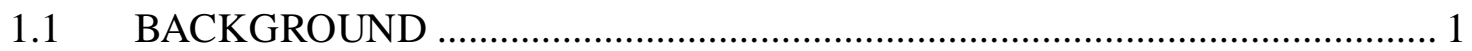

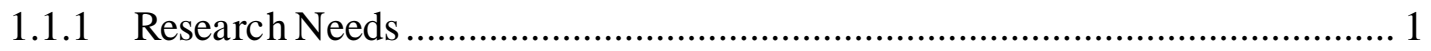

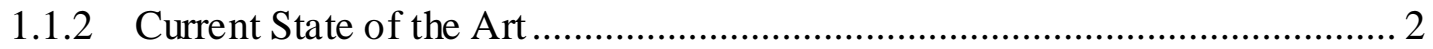

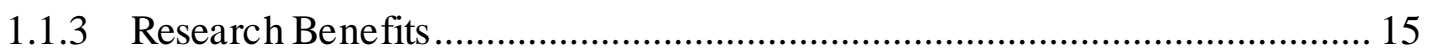

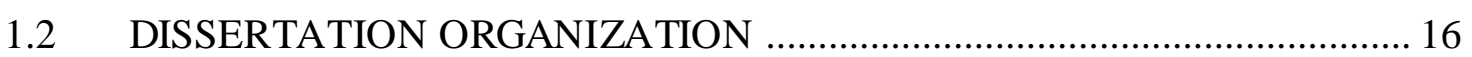

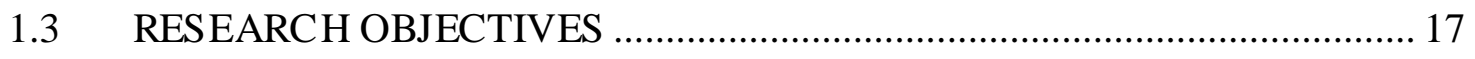

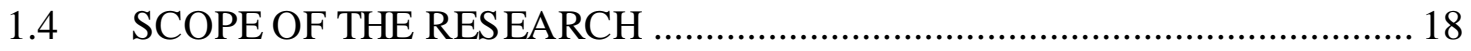

PART I - EXPERIMENTAL INVESTIGATION ................................................ 19

CHAPTER 2 : EXPERIMENTAL FACILITIES, MEASUREMENTS, AND

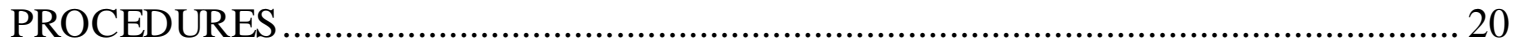

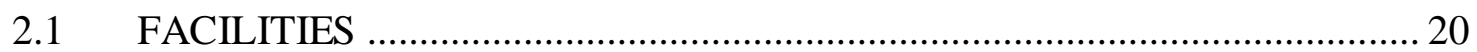

2.1.1 Two-Stage Air Flow Measurement Configuration .................................... 21

2.1.2 Precision Water Temperature Control .................................................. 24

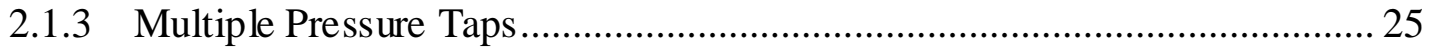

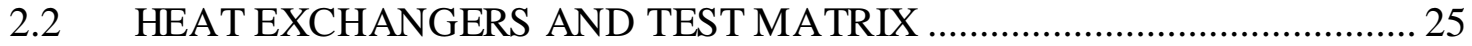

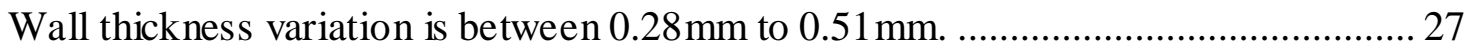

$2.1 \quad$ INSTRUMENTATION ........................................................................ 28

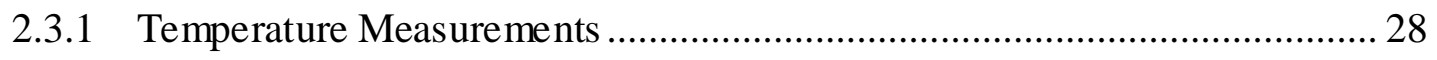

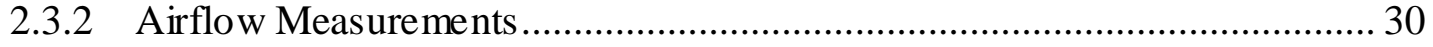

2.3.3 Air Pressure Drop Measurements ........................................................... 31

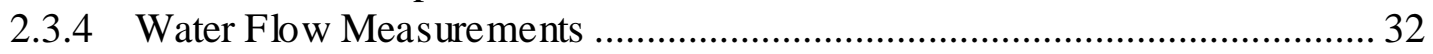

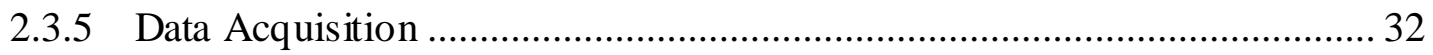

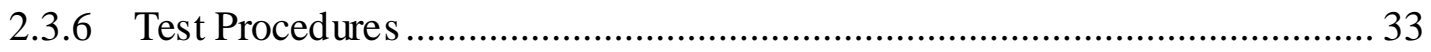

CHAPTER 3 : DATA REDUCTION AND EXPERIMENTAL VERIFICATION ........ 38

3.1 FLUID PROPERTIES CALCULATIONS ................................................. 38

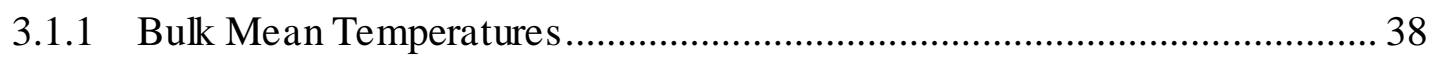

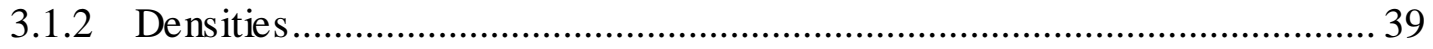

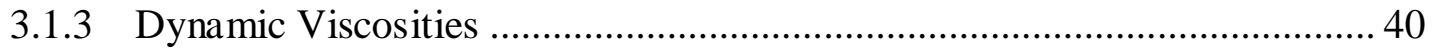

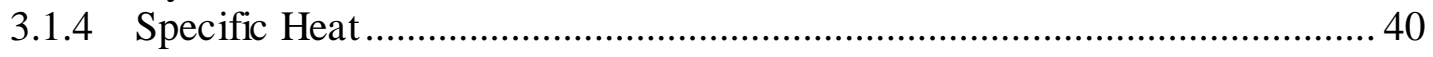

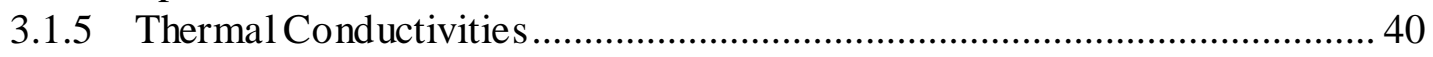

3.2 DIMENSIONLESS PARAMETERS CALCULATIONS .............................. 41

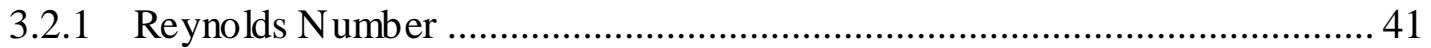

3.2.2 Prand tl Number ............................................................................... 42

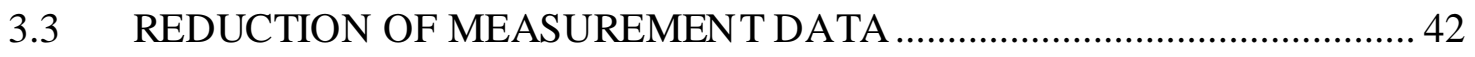

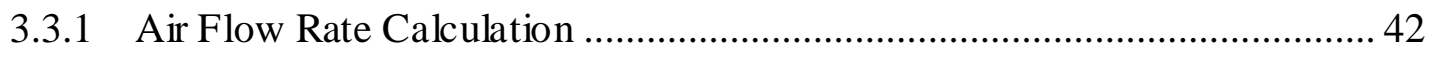

3.3.2 Water Flow Rate Calculation ............................................................ 44

3.3.3 Heat Transfer Rate Calculation Using Enthalpy Method ........................... 44 


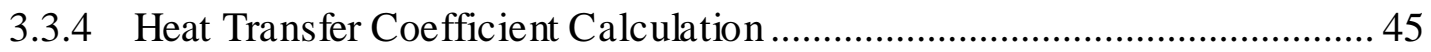

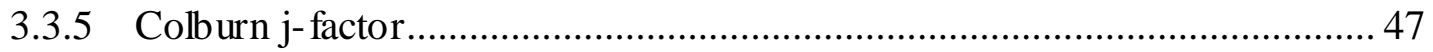

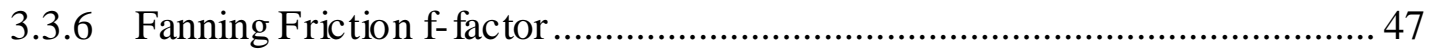

3.4 EXPERIMENTAL VERIFIC ATION ………............................................. 47

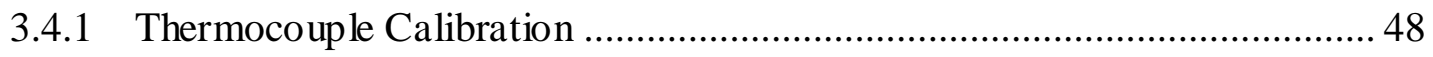

3.4.2 Heat Balance Tests and Radiation Losses .................................................. 51

3.4.3 Repeatability Tests .............................................................................. 54

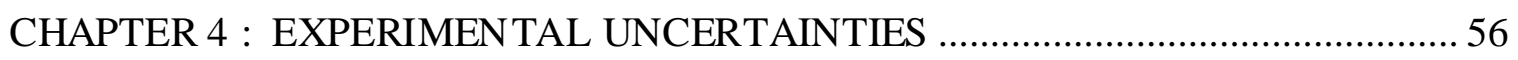

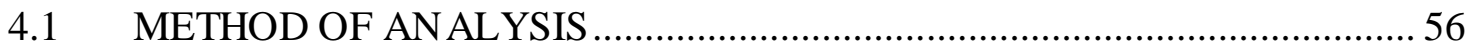

4.2 UNCERTAINTES IN THE EXPERIMENTAL TESTING ……...................57

4.3 UNCERTAITIES IN $R_{L} P, j$-factor, AND $f$-factor ........................................... 59

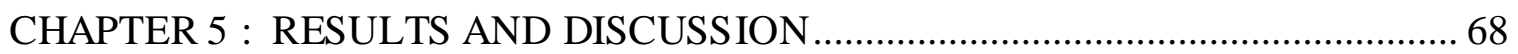

5.1 HEAT TRANSFER COEFFICIENT $h_{o}$ AND PRESS URE DROP $\Delta P \ldots \ldots \ldots \ldots . . . .68$

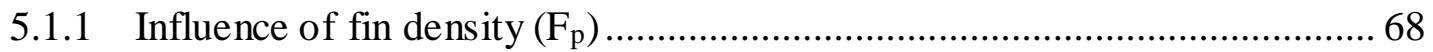

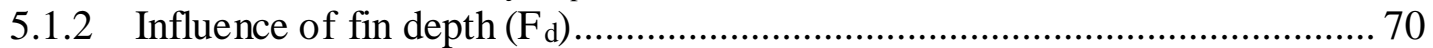

5.1.3 Influence of fin height $(\mathrm{H})$ and tube height $\left(\mathrm{D}_{\mathrm{m}}\right)$........................................ 73

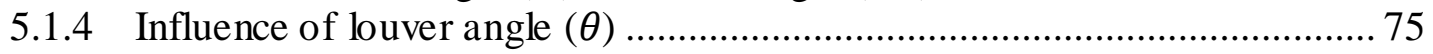

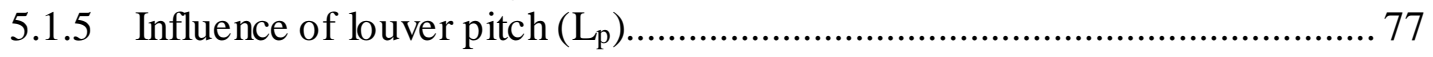

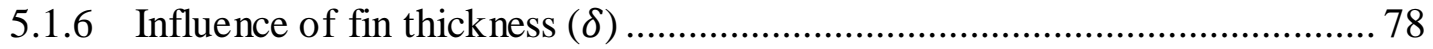

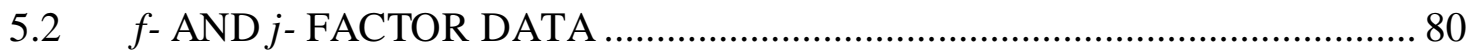

5.2.2 General Observations about the $\mathrm{j}$ and f Factors .......................................... 80

5.2.3 Discussions about the Two Flow Regime Phenomena .................................. 93

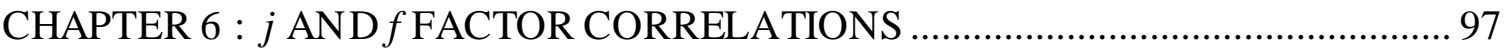

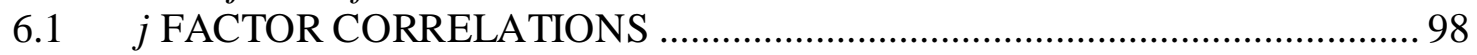

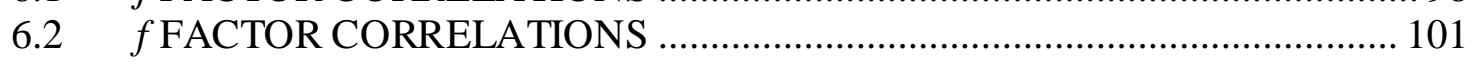

6.3 SIMPLIFIED CORRELATIONS ………............................................... 103

6.4.1 Importance of Variables Test ...................................................................... 104

6.4.2 Simplified Correlations of $\mathrm{j}$ and $\mathrm{f}$ Factors for Two Flow Regime ............... 106

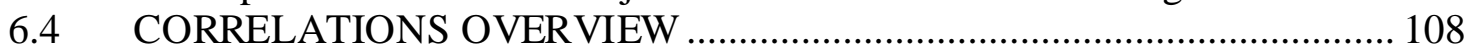

6.4.1 Comparison of Experimental Data with Available Correlations ................. 108

6.4.2 Additional Comments on the j- and f-Factor Correlations .......................... 109

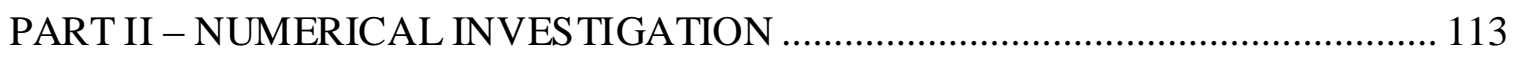

CHAPTER 7 : NUMERICAL METHODOLOGIES ………........................................ 114

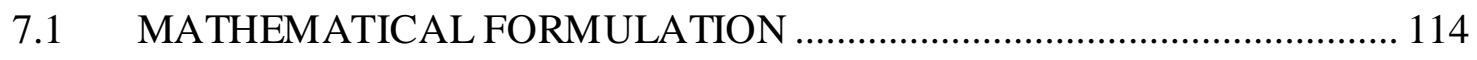

7.2 GEOMETRICAL DETAILS ………………….................................... 115

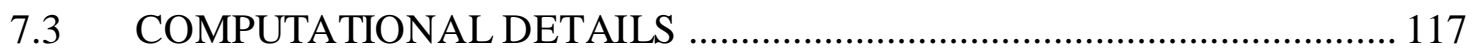

7.4 NUMERICAL DATA REDUCTION .................................................. 118

7.4.1 Colburn j-factor and Friction f-factor ...................................................... 118

7.4.2 Flow Angle and Flow Efficiency ............................................................ 120

7.5 NUMERICAL VALIDATION OF THE SIMULATION MODELS .............. 121 


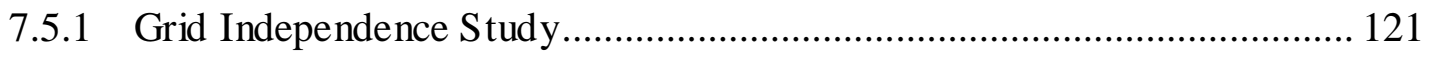

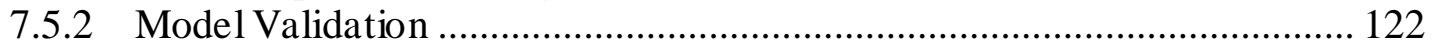

7.5.3 Flow Angle Measurement Validation..................................................... 125

CHAPTER 8 : RESULTS AND DISCUSSION ....................................................... 128

8.1 HEAT TRANSFER COEFFICIENT $h_{o}$ AND PRESSURE DROP $\Delta P \ldots \ldots \ldots . .128$

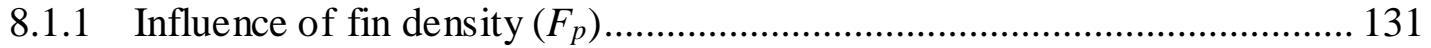

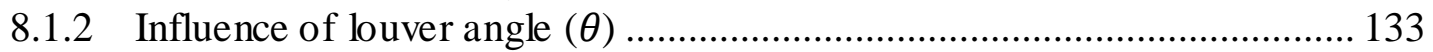

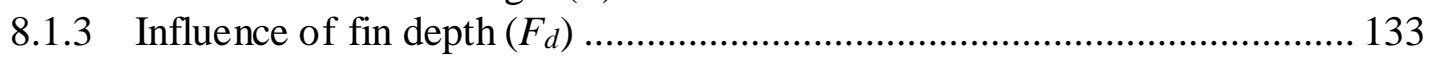

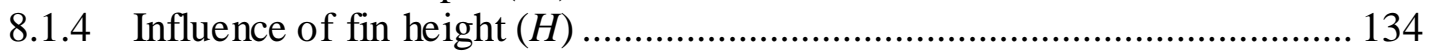

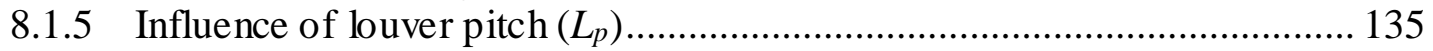

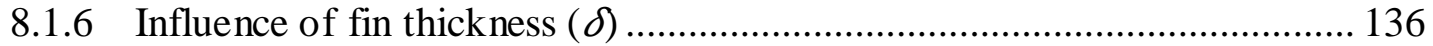

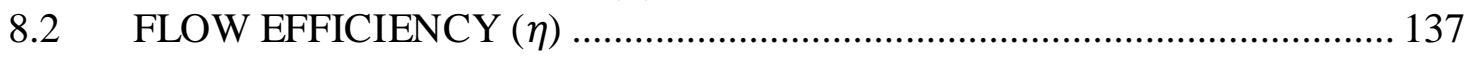

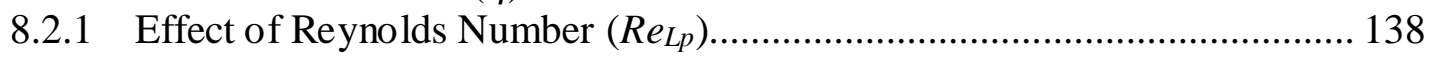

8.2.2 Combined Effect of Louver Angle $(\theta)$ and Thickness to Louver Pitch

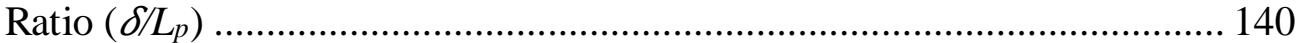

8.2.3 Effect of Louver to Fin Pitch Ratio $\left(L_{p} / F_{p}\right)$.......................................... 140

8.2.4 Prediction of Flow Efficiency .................................................................. 140

8.3 COMPARISON BETWEEN EXPERIMENTAL AND NUMERICAL

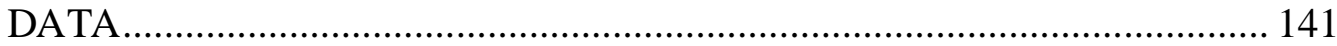

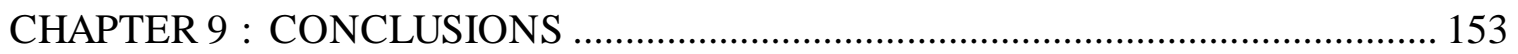

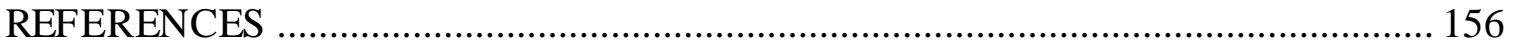

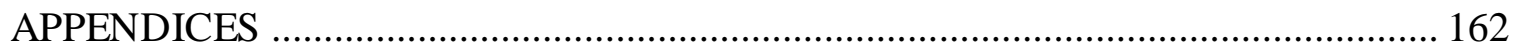

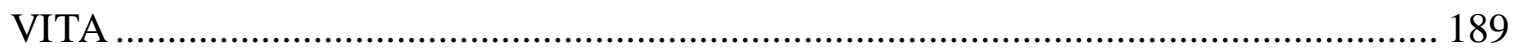




\section{LIST OF TABLES}

TABLE

PAGE

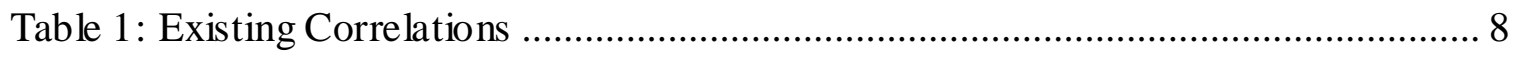

Table 2. Airflow Pressure Drop Limits ..................................................................... 23

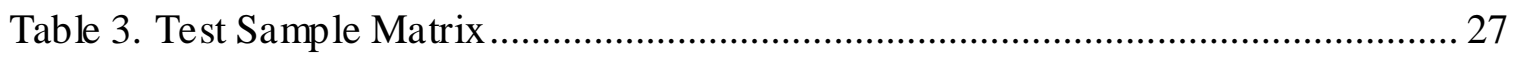

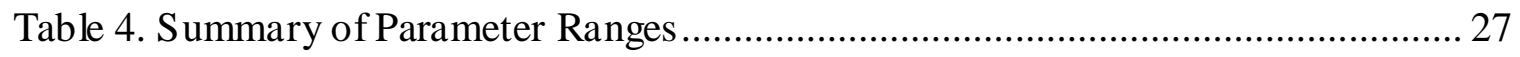

Table 5. Precisions of the Meas urement Instruments ............................................. 28

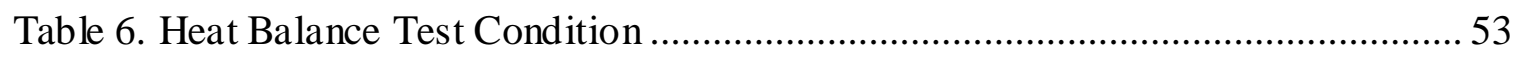

Table 7. Uncertainties of ReLp, j-factor, and f-factor for a Typical Heat Exchanger

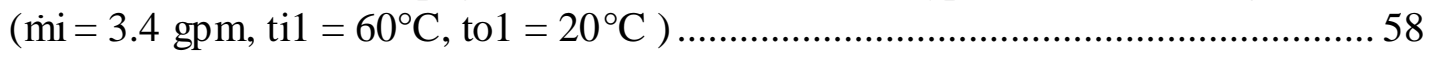

Table 8. Uncertainties of ReLp, j-factor, and f-factor for a Typical Heat Exchanger (Based on Test Data for Sample \#1) ................................................................5

Table 9. Comparisons with Uncertainties in Selected Literature ................................ 59

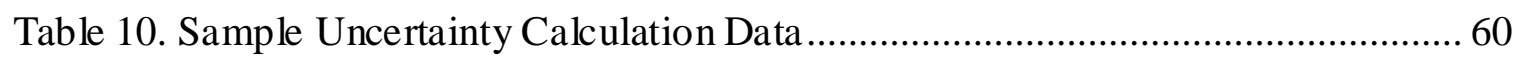

Table 11: Percentage of the Total Data Falling Within the Specified Deviation ........... 109

Table 12: Comparison of Proposed Correlations ................................................... 111

Table 13. Dimensional details of the louvered fins studied ..................................... 116

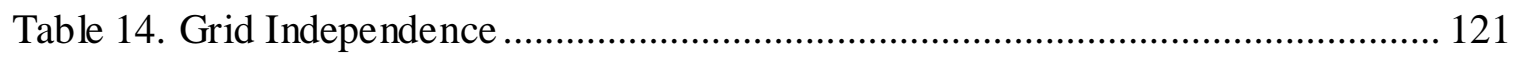

Table 15. Comparison of computed and referenced experimental $j$ and $f$ factor........... 125 


\section{LIST OF FIGURES}

FIGURE

PAGE

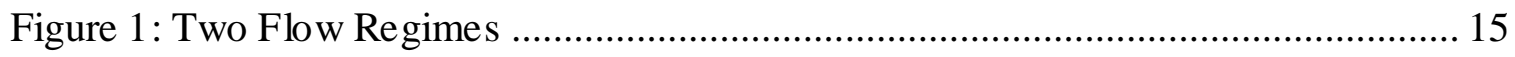

Figure 2. Close Loop Wind Tunnel Apparatus Schematic .......................................... 21

Figure 3. Modified Open Loop Wind Tunnel Apparatus Schematic ............................. 22

Figure 4. Section A-A Top View of Figure 3 ................................................... 23

Figure 5. Upgraded Wind Tunnel Apparatus......................................................... 23

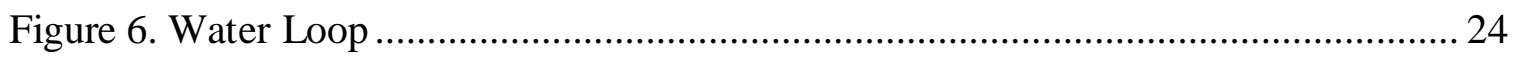

Figure 7. Geometrical Parameters of MCHX; (a) side view along the flow depth and tube cross-section, (b) frontal view perpendicular to flow depth, (c) fin cross-

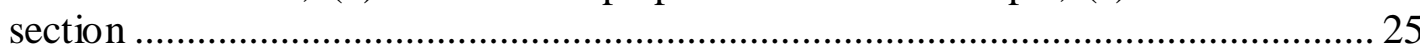

Figure 8. Typical Microchannel Heat Exchanger Test Sample ..................................... 26

Figure 9. Schematic of Thermocouple Locations for Air Temperature Measurement ..... 29

Figure 10. Measuring Stations for Temperature and Pressure Sensors .......................... 29

Figure 11. Digital Differential Pressure Manometer ................................................. 30

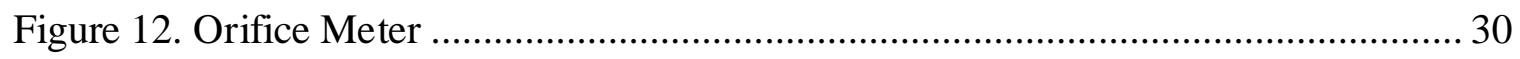

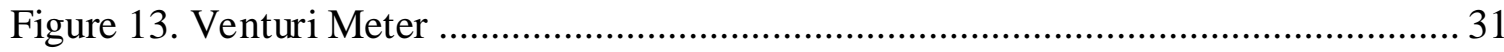

Figure 14. Very Low Range Digital Differential Pressure Manometer ......................... 31

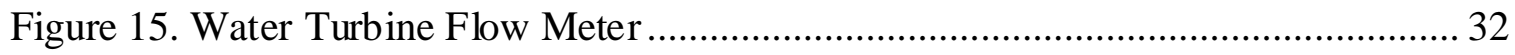

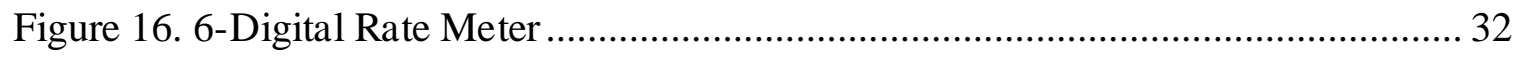

Figure 17. Schematic of Data Acquisition System ................................................. 33

Figure 18. Air Inlet Temperature Sensors Stability Check ........................................ 34

Figure 19. Air Outlet Temperature Sensors Stability Check ..................................... 35

Figure 20. Water Inlet and Outlet Temperature Sensors Stability Check ........................ 36 
Figure 21. Schematic of Calibration Setup .................................................................... 49

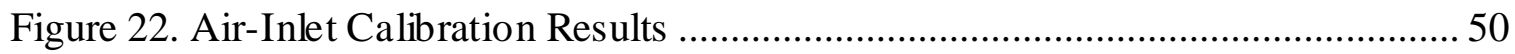

Figure 23. Air-Inlet Calibration Error ................................................................... 50

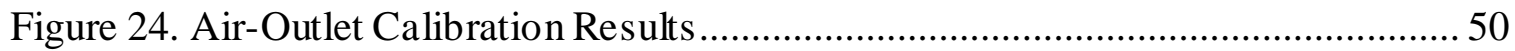

Figure 25. Air-Outlet Calibration Error ...................................................................... 50

Figure 26. Heat Balance Errors and Radiation Losses ................................................. 53

Figure 27. Repeatability Test for Sample \#1 ………….............................................. 54

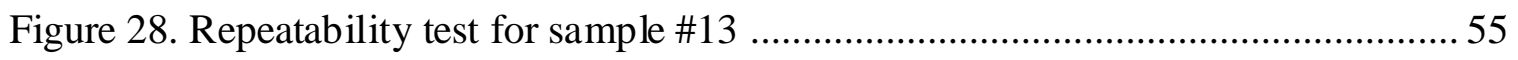

Figure 29. Uncertainty in Reynolds Number based on Louver pitch .............................. 60

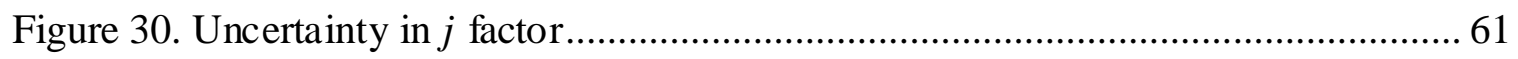

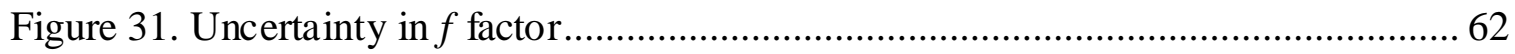

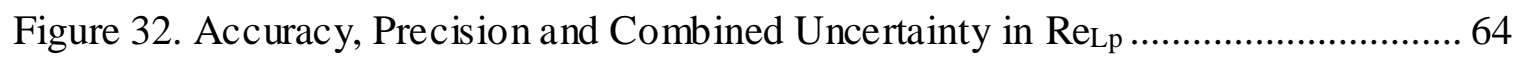

Figure 33. Accuracy, Precision and Combined Uncertainty in $j$ factor ........................... 65

Figure 34. Accuracy, Precision and Combined Uncertainty in $f$ factor ............................. 65

Figure 35. Variations of heat transfer coefficients and pressure drop with fin density and Reynolds number, Sample \#16, and \#17 ............................................................. 69

Figure 36. Variations of heat transfer coefficient and pressure drop with fin depth and Reynolds number; (a) Sample \#12 and \#15, (b) Sample \#14 and \#17 ..................... 70

Figure 37. Variations of heat transfer coefficient and pressure drop with fin height and Reynolds number; (a) Sample \#14, and \#15, (b) Sample \#11, and \#12, and (c) Sample \#9 and \#18

Figure 38. Variations of heat transfer coefficient and pressure drop with louver angle and Reynolds number; Sample \#7 and \#11 ........................................................... 76

Figure 39. Variations of heat transfer coefficient and pressure drop with louver pitch and Reynolds number; Sample \#24 and \#25. 
Figure 40. Variations of heat transfer coefficient and pressure drop with fin thickness and Reynolds number; Sample \#4 and \#8

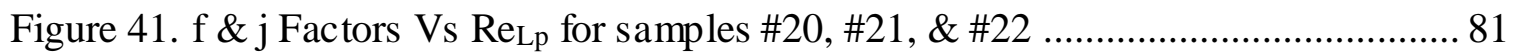

Figure 42. f \& j factors Vs $\operatorname{Re}_{\mathrm{Lp}}$ for samples \#23 \& \#24 ............................................ 82

Figure 43. f \& j Factors Vs $\operatorname{Re}_{\mathrm{Lp}}$ for samples \#5, \& \#6 .............................................. 83

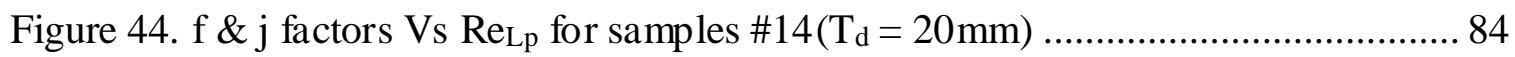

Figure 45. f \& j Factors Vs ReLp for samples \#12 $\left(\mathrm{T}_{\mathrm{d}}=16 \mathrm{~mm}\right)$ and \#15 $\left(\mathrm{T}_{\mathrm{d}}=20 \mathrm{~mm}\right) .85$

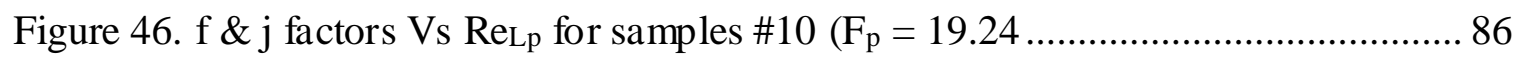

Figure 47. f \& j Factors Vs Re $\mathrm{Lp}_{\mathrm{p}}$ for samples $\# 7\left(\theta=20^{\circ}, \mathrm{D}_{\mathrm{m}}=2 \mathrm{~mm}\right)$ and $\# 11(\theta=$

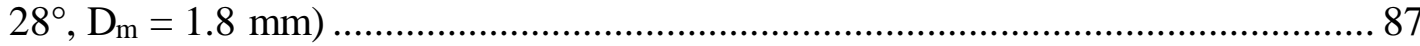

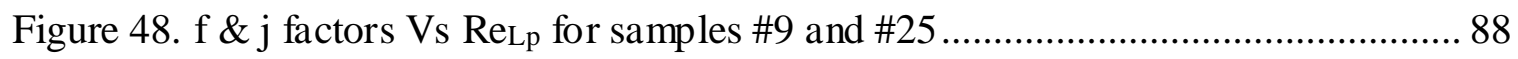

Figure 49. f \& j Factors Vs ReLp for samples \#4, \#8, and \#26 ....................................... 89

Figure 50. f \& j factors Vs $\operatorname{Re}_{\mathrm{Lp}}$ for samples \#1 and \#13 ......................................... 90

Figure 51. f \& j Factors Vs $\operatorname{Re}_{\mathrm{Lp}}$ for samples \#2, and \#3 ............................................ 91

Figure 52. f \& j factors Vs $\operatorname{Re}_{\mathrm{Lp}}$ for samples \#18 and \#19...................................... 92

Figure 53. f \& j factors Vs Re Lp $_{\text {for }}$ foll the samples ................................................ 93

Figure 54. Comparison of Experimental Data and Correlation for $\mathrm{j}$ Factor

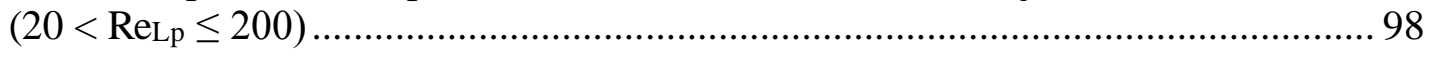

Figure 55. Comparison of Experimental Data and Correlation for $\mathrm{j}$ Factor

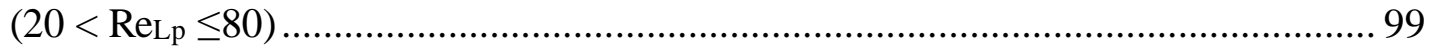

Figure 56. Comparison of Experimental Data and Correlation for $\mathrm{j}$ Factor $\left(80<\operatorname{Re}_{\mathrm{Lp}} \leq 200\right)$ 100

Figure 57. Comparison of Experimental Data and Correlation for f Factor $\left(20<\operatorname{Re}_{\mathrm{Lp}} \leq 80\right)$. 101

Figure 58. Comparison of Experimental Data and Correlation for f Factor $\left(20<\operatorname{Re}_{\mathrm{Lp}} \leq 80\right)$ 102 
Figure 59. Comparison of Experimental Data and Correlation for f Factor $\left(80<\operatorname{Re}_{\mathrm{Lp}} \leq 200\right)$ 103

Figure 60. Analysis of principal components in $\mathrm{j}$-factor for $20<\operatorname{Re}_{\mathrm{Lp}} \leq 80$. 104

Figure 61. Covariance of the two principal components representing the dataset 105

Figure 62. Correlated Simplified j Factor vs. Experimental j Factor $\left(20<\operatorname{Re}_{\mathrm{Lp}} \leq 80\right)$.. 106

Figure 63. Computational Domain 116

Figure 64. Air-side Subdivided Computational Domain: (a) 3-D View (b) Top View .. 117

Figure 65. Effect of Cell Size on Heat Exchanger Performance Parameters 122

Figure 66. Performance Parameters for Laminar and Turbulent Models 124

Figure 67. (a) Computed Flow Efficiency for $\theta=28^{\circ}$ Vs. predicted by Webb and Trauger (1991) and Achaichia \& Cowell (1988).(b) Flow Efficiency Vs. Reynolds Number for $\theta=30^{\circ}$ Webb and Trauger (1991).

Figure 68. Velocity (m/s) contours for (a) $\operatorname{Re}_{L p}=25$, (b) $\operatorname{Re}_{L p}=100$, (c) $\operatorname{Re}_{L p}=200$ for Sample\#1

Figure 69. Temperature (K) contours for (a) $\operatorname{Re}_{L p}=25$, (b) $\operatorname{Re}_{L p}=100$, (c) $\operatorname{Re}_{L p}=200$ for Sample\#1

Figure 70. Pressure (Pa) contours for (a) ReLp = 25, (b) ReLp = 100, (c) ReLp $=200$ for Sample\#1 129

Figure 71. Pressure drop $(\mathrm{Pa})$ across the louvered fin 130

Figure 72. Effect of fin density $\left(F_{p}\right)$ on heat transfer coefficient $\left(h_{o}\right) \ldots \ldots \ldots \ldots \ldots \ldots \ldots \ldots \ldots \ldots \ldots \ldots \ldots \ldots . . . . . . .132$

Figure 73. Effect of louver angle $(\theta)$ on heat transfer coefficient $\left(h_{o}\right) \ldots \ldots \ldots \ldots \ldots \ldots \ldots \ldots \ldots . . . . . . . . . . . . .132$

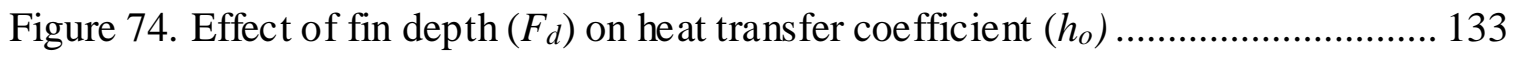

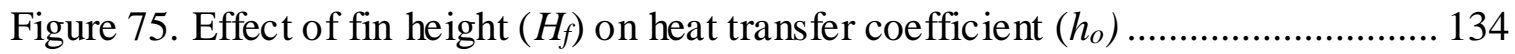

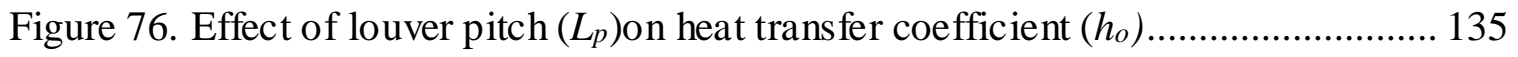

Figure 77. Effect of fin thickness $(\delta)$ on heat transfer coefficient $\left(h_{o}\right) \ldots \ldots \ldots \ldots \ldots \ldots \ldots \ldots \ldots . . . . . . . . . .136$ 
Figure 78. $\eta$ vs. $\operatorname{Re}_{L p}$ (a) All Numerically Tested Samples (b) Effect of $L_{p} / F_{p}$ (c) Combined Effect of $\theta$ and $\delta / L_{p}$ 139

Figure 79. Numerical vs Experimental $\mathrm{j}$ and f Factors For Sample\#1 ............................ 143

Figure 80. Numerical vs Experimental j and f Factors For Sample\#2 ........................... 144

Figure 81. Numerical vs Experimental j and f Factors For Sample\#5 ........................... 145

Figure 82. Numerical vs Experimental j and f Factors For Sample\#7 ............................ 146

Figure 83. Numerical vs Experimental j and f Factors For Sample\#11 ......................... 147

Figure 84. Numerical vs Experimental j and f Factors For Sample\#15 ......................... 148

Figure 85. Numerical vs Experimental j and f Factors For Sample\#19 ......................... 149

Figure 86. Numerical vs Experimental j and f Factors For Sample\#24 ......................... 150

Figure 87. Numerical vs Experimental j and f Factors For Sample\#25 ......................... 151

Figure 88. Numerical vs Experimental j and f Factors For Sample\#26 ......................... 152 


\section{NOMENCLATURE}

$A_{b} \quad$ Airside surface area of tube, $\mathrm{m}^{2}$

$A_{c} \quad$ Minimum free flow area, $\mathrm{m}^{2}$

$A_{f} \quad$ Total fin surface area, $\mathrm{m}^{2}$

$A_{\text {fr }} \quad$ Frontal area, $\mathrm{m}^{2}$

$A_{i} \quad$ Waterside total surface area, $\mathrm{m}^{2}$

$A_{o} \quad$ Airside total surface area, $\mathrm{m}^{2}$

$A_{w} \quad$ Tube wall area, $\mathrm{m}^{2}$

C Heat capacity, $\mathrm{W} / \mathrm{K}$

$c_{p} \quad$ Specific heat at constant pressure, J/(kg.K)

$D_{m} \quad$ Tube height, $\mathrm{m}$

$f \quad$ Fanning friction factor, dimensionless

$F_{d} \quad$ Fin depth, m

$F_{p} \quad$ Fin pitch, m

FS Full Scale

$G_{c} \quad$ Mass flux of air at minimum free flow velocity, $\mathrm{kg} /\left(\mathrm{m}^{2} . \mathrm{sec}\right)$

$H_{f} \quad$ Fin height, $\mathrm{m}$

$h_{i} \quad$ Water side heat transfer coefficient, $\mathrm{W} /\left(\mathrm{m}^{2} . \mathrm{K}\right)$

$h_{0} \quad$ Air side heat transfer coefficient, $\mathrm{W} /\left(\mathrm{m}^{2} . \mathrm{K}\right)$

j Colburn factor, dimensionless

$K_{c} \quad$ Entrance loss coefficient

$K_{e} \quad$ Exit loss coefficient 


\begin{tabular}{|c|c|}
\hline$k_{f}$ & Thermal conductivity of fin material, W/ $(\mathrm{m} . \mathrm{K})$ \\
\hline$k_{w}$ & Thermal conductivity of wall material, W/ (m.K) \\
\hline$l_{f}$ & The fin length, $\mathrm{m}$ \\
\hline$L_{l}$ & Louver length, m \\
\hline$L_{p}$ & Louver pitch, m \\
\hline$\dot{m}$ & Mass flow rate, $\mathrm{kg} / \mathrm{s}$ \\
\hline$N T U$ & Number of transfer units, dimensionless \\
\hline Pun & Precision uncertainty \\
\hline$\dot{q}$ & Heat transfer rate, $\mathrm{W}$ \\
\hline$\dot{Q}$ & Volume flow rate, $\mathrm{m}^{3} / \mathrm{s}$ \\
\hline $\operatorname{Re}_{D h}$ & Reynolds number based on hydraulic diameter, dimensionless \\
\hline $\operatorname{Re}_{L p}$ & Reynolds number based on louver pitch, dimensionless \\
\hline rms & Root mean sqaure \\
\hline $\mathrm{Sm}$ & Mean Standard Deviation \\
\hline$T$ & Temperature, $\mathrm{K}$ \\
\hline$T_{d}$ & Tube depth, m \\
\hline$U A$ & Overall thermal conductance, $\mathrm{W} / \mathrm{K}$ \\
\hline$V_{c}$ & Minimum free flow velocity, $\left(\dot{Q}_{o} / A_{c}\right) \mathrm{m} / \mathrm{sec}$ \\
\hline
\end{tabular}

Greek Symbols:

$\delta_{f} \quad$ Fin thickness, m

$\delta_{w} \quad$ Tube wall thickness; average, $\mathrm{m}$ 


$\begin{array}{ll}\varepsilon_{s} & \text { Overall surface effectiveness, dimensionless } \\ \alpha & \text { Flow angle, }\left(^{\circ}\right) \\ \beta & \text { Thermal expansion coefficient, } \mathrm{K} \\ \theta & \text { Louver angle, }\left(^{\circ}\right) \\ \eta & \text { Flow efficiency, dimensionless } \\ \eta_{f} & \text { Fin efficiency, dimensionless } \\ \Delta P & \text { Pressure drop, Pa } \\ \Delta T & \text { Temperature difference, } \mathrm{K} \\ \varepsilon & \text { Effectiveness of the heat exchanger, dimensionless } \\ \sigma & \text { Contraction factor, } A_{c} / A_{f r} \\ \rho_{o m} & \text { Air density at bulk mean temperature, } \mathrm{kg} / \mathrm{m}^{3} \\ \mu_{\text {om }} & \text { Dynamic viscosity at bulk mean temperature, } \mathrm{kg} /(\mathrm{m} . \mathrm{s}) \\ v_{o} & \text { Viscosity, } \mu_{o m} /\left(\rho_{o m},\right)^{2} / \mathrm{s}\end{array}$

Subscripts:

$\begin{array}{ll}1,2 & \text { inlet and outlet, respectively } \\ \text { A/f } & \text { area per fin } \\ \text { avg } & \text { average } \\ \text { b } & \text { base } \\ \text { cs } & \text { cross sectional } \\ \text { d } & \text { depth } \\ \text { f } & \text { fin }\end{array}$




\begin{tabular}{|c|c|}
\hline flow & Flow \\
\hline $\mathrm{H}$ & height \\
\hline $\mathrm{i}$ & water side \\
\hline $\mathrm{k}$ & variable \\
\hline $\mathrm{kb}$ & Kim and Bullard \\
\hline 1 & length \\
\hline $\mathrm{m}$ & mean \\
\hline $\max$ & maximum \\
\hline $\mathrm{mc}$ & micro channel \\
\hline $\min$ & minimum \\
\hline$n$ & number \\
\hline o & air side \\
\hline $\mathrm{S}$ & surface \\
\hline $\mathrm{W}$ & wall \\
\hline we & wetted \\
\hline
\end{tabular}

Superscript:

n index

Units:

gpm gallons per minute

in wc inches of water column 


\section{CHAPTER 1: INTRODUCTION}

\subsection{BACKGROUND}

\subsubsection{Research Needs}

Compact heat exchangers are widely used in commercial and residential air conditioning systems. These heat exchangers with multi-louver fins and flat tubes typically have oval tube minor dimensions from $0.8 \mathrm{~mm}$ to $3 \mathrm{~mm}$. This type of design offers several advantages to reducing air-side thermal resistance (Webb, R. L., Jung 1992): a) smaller wake region behind the tube thus not reducing heat transfer downstream; b) lower profile drag due to smaller projected frontal area of flat tube vs. conventional round tube; c) overall increased air-side heat transfer coefficient and conductance value.

Reducing the air-side thermal resistance, by use of multi-louver fins and flat tubes, for air-cooled heat exchangers can effectively improve performance. From the literature and also as outlined in ASHRAE 1535-TRP report submitted by Shinde and Lin (2016), the available heat transfer and friction factor correlations for louvered surfaces are only valid at high Reynolds number based on louver pitch $L_{p}(\operatorname{ReLp}>100)$. At low Reynolds number (ReLp<100), a concise and accurate correlation is not available. As energy efficiency becomes increasingly vital, this type of data for compact heat exchanger is urgently needed to help facilitate the design of more efficient air conditioning systems. This need is also driven by the design of low-noise heat exchanger and microchannel heat exchanger both operated at low air flow rates. Development of heat transfer and friction factor correlations can provide engineers a better physical understanding of the role of louver fin dimens ions associated with the flow and thermal transition phenomena at low Reynolds numbers. 


\subsubsection{Current State of the Art}

\subsubsection{Experimental Studies}

Compact heat exchangers with louvered fins have been investigated extensively in the past. Researchers have carried out both experimental and computational studies to understand the underlying fluid flow and heat transfer characteristics. For heat exchanger designs, the performance data, such as Fanning friction factor $\mathrm{f}$ and Colburn factor $\mathrm{j}$, for the louvered surfaces have become widely available over past 25 years. Most of the useful correlations were obtained by experimental methods. Davenport (1983), Achaichia and Cowell (1988), Kajino, M., and Hiramatsu (1987), Huihua and Xuesheung (1989), Aoki et al. (1989), Webb and Trauger (1991), Sunden and Svantesson (1992), Webb, R. L., Jung (1992), Chang, Y. J., and Wang (1994, and 1997), Jeon and Lee (2001), Lyman et al. (2002), Kim \& Bullard (2002); Kim et al. (2000, and 2003), Tafti et al. (2004), Sanders and Thole (2005, and 2006), Dong et al. (2007), Qi et al. (2007), Tang et al. (2009), Li and Wang (2010) and $\mathrm{Li}$ et al. (2011) have all performed experiments to quantify performance for louvered fin surfaces of compact heat exchangers, and studied the effects of geometrical parameters on the heat exchanger performance. Huihua \& Xuesheng (1989), Webb \& Trauger (1991), Jeon and Lee (2001) and Lyman et al. (2002) performed the experimental studies on the scaled-up models with the scale factor of more than 10 , whereas the rest of the studies are conducted as full-scale experiments.

Davenport (1983) tested 32 samples of the nonstandard variant of the flat tube and corrugated louvered fins and developed $\mathrm{j}$ and f factor correlations for the range of Reynolds number from 300 to 4000 , based on louver pitch. The reported j-factor correlations were claimed to be representing $95 \%$ of the experimental within $\pm 6 \%$. 
Achaichia \& Cowell (1988) confirmed the findings of the Davenport and provided the insights on the effects of geometrical parameters such as fin pitch, tube pitch, louver pitch, and louver angle on the heat transfer and pressure drop characteristics of flat tube and louvered plate fin surfaces. The authors described unusual flow structure (flattening behavior) at low Reynolds number due to the limitations in the instrumentation. The authors also proposed the correlations for heat transfer and friction using data bank and reported the variation of the Stanton number and the friction factor as a function of the Reynolds number. They conducted the tests on 15 samples and covered the range of Reynolds number from 150 to 3000, based on louver pitch.

Kajino, M., and Hiramatsu (1987) investigated the relationship between the flow alignment and the geometrical parameters of automotive heat exchangers using a dye-line flow visualization techniques for high Reynolds number. They found the turbulent flow behavior for the Reynolds number at around 1300 and reported that the flow remains laminar and steady below the Reynolds number of 1300. Webb \& Trauger (1991) performed flow visualization study similar to Kajino, M., Hiramatsu (1987), on 10:1 scaled-up louver fin geometry and studied the influence of the geometrical parameters and the Reynolds number on the flow structure. The authors proposed the correlations to predict the flow efficiency as a function of Reynolds number and for the range of Reynolds number 400 to 4000 , based on louver pitch.

Huihua \& Xuesheng (1989) conducted the experimental study on the scaled-up experimental model of louver fin geometry with various louver angle and pitches. They reported that with the increase in oblique angle and plate length, both, the intensity of heat transfers and the pressure drop increases. Aoki et al. (1989) conducted the experimental 
study on louver fin geometries and explained the heat transfer coefficients distribution in the louvered arrays and fin geometries. They reported that with the increase in fin pitch, the heat transfer coefficient decreases. Sunden and Svantesson (1992) studied the louver fin heat exchanger geometries and proposed $\mathrm{j}$ and $\mathrm{f}$ factor correlations. Rugh et al. (1992) conducted the experiments on louvered fin surfaces and investigated the effect of high fin density on heat transfer performance for the range of Reynolds number from 150 to 300 . Other studies on scaled-up models were performed by Jeon and Lee (2001), and Lyman et al. (2002) found a method for evaluating the spatially resolved louver heat transfer coefficients.

Webb, R. L., and Jung (1992) tested six louvered-fin brazed aluminum compact heat exchanger cores and compared the heat exchanger performance against the plate-fin and spine-fin geometries. In their findings, they reported that the brazed aluminum heat exchangers outperform the 12 fins per inch plate-fin and 18 fins per inch spine-fin heat exchangers by $90 \%$ higher heat transfer for only $25 \%$ increase in pressure drop and $44 \%$ higher heat transfer for $10 \%$ decrease in pressure drop, respectively.

Chang et al. (1994) tested 18 samples of louvered fin heat exchanger geometries with several geometrical parameters such as tube width, louver length, louver pitch and fin pitch, and fin height for the range of Reynolds number from 200 to 2600 . They investigated the heat transfer and pressure drop performance of the heat exchanger in the form of $j$ and $f$ factor and reported the correlations within $\pm 10 \%$ and $\pm 15 \%$, respectively. A monumental study was undertaken by Chang, Y. J., and Wang (1997); and Wang et al. (2000) to consolidate all of the previous test data from the previous 20 years and generated an enormous database of 91 multi-louvered heat exchanger samples with flat tubes for 
producing a generalized heat transfer correlation. This correlation for $\mathrm{j}$ and $\mathrm{f}$-factors is referred to as the Chang and Wang correlation and is currently the most widely used correlation for predicting air-side resistance and pressure drop for heat exchangers with louvered fins. Kim and Bullard (2002) examined the heat transfer and pressure drop characteristics of multi-louvered fin heat exchangers on 45 different louver fin geometries for the range of Reynolds number from 100 to 600, based on louver pitch. They informed the decrease in heat transfer with the reduction in flow depth and reported the heat transfer and pressure drop characteristics in terms of $\mathrm{j}$ and $\mathrm{f}$ factor with an rms error of $\pm 14.5 \%$ and $\pm 7 \%$, respectively. Kim et al. (2002) has since conducted an additional study for dry and wet surfaces and proposed new $\mathrm{j}$ and f-factor correlations within $\pm 16.9 \%$ and $\pm 13.6 \%$, respectively. However, these were based on a much smaller data set of 30 samples and parameter range, for the Reynolds number from 80 to 300 and the ratio of $F_{p} / L_{p}<1$.

Tafti et al. (2004) studied the performance of multi-louvered fins and evaluated the effects of the fin pitch, louver thickness, louver angle and Reynolds number on flow efficiency and reported strong dependence of the flow efficiency on geometrical parameters, especially at low Reynolds number. Sanders and Thole (2006) conducted tests on the 20:1 scaled-up model of louvered fin compact heat exchanger for the $\mathrm{F}_{\mathrm{p}} / \mathrm{Lp}_{\mathrm{p}}=0.76$ and louver angle equal to $27^{\circ}$ for the range of Reynold number between 230 and 1016 . They reported $39 \%$ heat transfer augmentation associated with $23 \%$ friction factor increment.

Recently, Dong et al. (2007) investigated 20 types of the multi-louvered fin and flat tube heat exchangers and developed general correlations for both $\mathrm{j}$ and $\mathrm{f}$ factors using a larger ratio of the fin to louver pitches $\mathrm{Fp}_{\mathrm{p}} / \mathrm{Lp}$ as compared to that by Kim and Bullard (2002). 
They conducted the experiments for the range of Reynolds number from 200 to 2500, based on louver pitch and reported the characteristics of heat transfer and pressure drop in the form of $\mathrm{j}$ and $\mathrm{f}$ factors within $\pm 10 \%$ and \pm 12 , respectively. They also found that fin length and fin pitch has significant effects on the heat transfer and pressure drop as a function of Reynolds number.

Qi et al. (2007) examined heat transfer and pressure drop of a heat exchanger with corrugated louvered fins by investigating the effect of geometrical parameters such as flow depth, tube pitch, louver angle, the number of louvers, and the ratio of fin pitch and fin thickness. They found that significant effect of the flow depth, the number of louvers, and the ratio of fin pitch and fin thickness on the thermal hydraulic performance of the louvered fin geometry. Tang et al. (2009) studied air-side heat transfer of five kinds of finned tube geometries such as crimped spiral-fin, plain-fin, slit-fin, fin with delta-wing longitudinal vortex generators and mixed-fins for the range of Reynolds number from 4000 to 10000 . $\mathrm{Li}$ and Wang (2010) conducted the experimental study on the air-side thermal hydraulic performance of seven brazed aluminum heat exchangers with multi-region louver fins and flat tubes for the range of Reynolds number from 400 to 1600 , based on louver pitch. They reported $88.2 \%$ the experimental heat transfer data in terms of $\mathrm{j}$ factor within $\pm 10 \%$ and $83.3 \%$ of the experimental pressure drop data in terms of $\mathrm{f}$ factor within $\pm 20 \%$, respectively. Along with the experimental test data from seven louver fin heat exchanger geometries, they also reported the general correlations for $\mathrm{j}$ and $\mathrm{f}$ factors combined with interrelated test data from the literature. Li et al. (2011) examined 11 heat exchangers with multi-louvered fin, wavy fin, and integrated fins for the range of Reynolds number from 150 to 1350 , based on fin collar outside hydraulic diameter. They reported the thermal 
hydraulic performance of the heat exchangers as $\mathrm{j}$ and $\mathrm{f}$ factors within $\pm 10 \%$ and $\pm 12 \%$, respectively. Table 1 (on next page) shows the $f$ and $j$ correlations developed in the past by various researchers. As can be seen from the table, the number of parameters used in the correlations varies from researcher to researchers. Never the less, most of the correlations for $\mathrm{j}$ and $\mathrm{f}$ factors are in the format of power law.

A careful evaluation of the previous research indicates that the existing correlations of the $\mathrm{j}$ and $\mathrm{f}$ factors are valid for high Reynolds numbers in the range of 100 to 1000 . Jacobi et al. (2005) have proposed a modified j-factor correlation (as compared to that by Chang, and Wang (1997)) designed to account for curve changing at low Reynolds numbers and recognize optimal louver-fin-pitch design. This correlation was based on test data within a Reynolds number range from 40 to 370 . However, the data available for the lower ReLp range was very limited (less than 3 data points when Relp $<100$ ). Also, the focus of Jacobi et al. (2005) was to generate a single range correlation. A friction factor correlation was also not proposed. Another example of the previous study is Aoki et al. (1989), where very limited data points were used in low ReLprange. Within a range of ReLp $=60-700$, their heat transfer data are correlated in terms of Nusselt number $(\mathrm{Nu})$ in a power law format: $\mathrm{Nu}=0.87 \operatorname{ReLp}_{\mathrm{p}} \operatorname{Pr}^{1 / 3}$, when $\mathrm{F}_{\mathrm{p}}=1 \mathrm{~mm}$ and $\theta=35^{\circ}$. However, within the range of $\operatorname{ReLp}_{\mathrm{p}}<100$, only two data points are available.

\subsubsection{Numerical Studies}

From the literature, it is seen that more experimental work has been conducted on the thermal hydraulic performance of compact heat exchangers with varied geometrical types, including the louver fin geometries, before the end of $20^{\text {th }}$ century. After the beginning of the $21^{\text {st }}$ century, more work is conducted using numerical investigation methods. 
Table 1: Existing Correlations

\begin{tabular}{|c|c|c|c|}
\hline Authors & Correlations & $\mathbf{R e}_{L p}$ & Comments \\
\hline $\begin{array}{l}\text { Davenport } \\
\text { (1983) }\end{array}$ & $\begin{array}{l}j=0.249 \operatorname{Re}_{L p}^{-0.42} L_{h}^{0.33}\left(\frac{L_{l}}{H}\right)^{1.1} H^{0.26} \\
f=5.47 \operatorname{Re}_{L p}^{-0.72} L_{h}^{0.37}\left(\frac{L_{l}}{H}\right)^{0.89} L_{p}^{0.2} H^{0.23} \quad \text { for } 70<\operatorname{Re}<900 \\
f=0.494 \operatorname{Re}_{L p}^{-0.39} L_{h}^{0.33}\left(\frac{L_{l}}{H}\right)^{1.1} H^{0.26} \quad \text { for } 1000<\operatorname{Re}<4000\end{array}$ & $300-4000$ & $\begin{array}{l}f \text { developed for } \\
\operatorname{Re}=70-4000 .\end{array}$ \\
\hline $\begin{array}{l}\text { Achaichia } \\
\& \text { Cowell } \\
(1988)\end{array}$ & $\begin{array}{l}\mathrm{St}=1.54 \operatorname{Re}_{L p}^{-0.57}\left(\frac{F}{L}\right)^{-0.19}\left(\frac{T}{L}\right)^{-0.11}\left(\frac{H}{L}\right)^{-0.15} \\
f=0.895 f_{A}^{1.07} F^{-0.22} L^{0.25} T^{0.26} H^{0.33}, \quad f_{A}=596 \operatorname{Re}_{L}^{\left(0.318 \log R e_{L}-2.25\right)} \\
150<\operatorname{Re}<3000 \\
f=10.4 \operatorname{Re}_{L}^{-1.17} F^{-0.05} L^{1.24} H^{0.25} T^{0.83} \text { for } \operatorname{Re}<150\end{array}$ & $\begin{array}{l}150- \\
3000\end{array}$ & $\begin{array}{l}\text { Plate-and-tube } \\
\text { louver fin. } T \text { : } \\
\text { tube transverse } \\
\text { pitch. } 4 \text { data } \\
\text { points } \quad \text { when } \\
\text { Re<150. }\end{array}$ \\
\hline $\begin{array}{l}\text { Webb \& } \\
\text { Jung } \\
(1992)\end{array}$ & $\begin{array}{l}j=0.7728 \operatorname{Re}_{D}^{-0.491} \\
f=30.96 \operatorname{Re}_{D}^{-0.428} \text { for } \sigma \leq 0.4 \\
f=27.88 \operatorname{Re}_{D}^{-0.454} \text { for } \sigma \geq 0.4\end{array}$ & $\begin{array}{l}V_{\text {air }}=72 \\
-\quad 975 \\
\mathrm{~m} / \mathrm{min}\end{array}$ & $\begin{array}{l}\text { Spine fin. } \sigma \text { is } \\
\text { contraction } \\
\text { ratio, } D \text { is } \\
\text { hydraulic } \\
\text { diameter. }\end{array}$ \\
\hline $\begin{array}{l}\text { Chang et } \\
\text { al. (1994) }\end{array}$ & $\begin{array}{l}j=0.291 \operatorname{Re}_{L p}^{-0.589} \varepsilon^{0.438} \\
f=0.805 \operatorname{Re}_{L p}^{-0.514}\left(F_{p} / L_{p}\right)^{-0.72} \cdot\left(H / L_{p}\right)^{-1.22}\left(L_{l} / L_{p}\right)^{1.97}\end{array}$ & $100-700$ & $\begin{array}{l}\text { Fanning factor, } \varepsilon \\
=A_{o} / A_{t o}: 7-12\end{array}$ \\
\hline $\begin{array}{l}\text { Chang \& } \\
\text { Wang } \\
(1997)\end{array}$ & $j=\operatorname{Re}_{L_{p}}^{-0.49}\left(\frac{\theta}{90}\right)^{0.27}\left(\frac{F_{p}}{L_{p}}\right)^{-0.14}\left(\frac{F_{l}}{L_{p}}\right)^{-0.29}\left(\frac{T_{d}}{L_{p}}\right)^{0.23}\left(\frac{L_{l}}{L_{p}}\right)^{0.68}\left(\frac{T_{p}}{L_{p}}\right)^{-0.28}\left(\frac{\delta}{L_{p}}\right)^{-0.05}$ & $\begin{array}{l}100- \\
3000\end{array}$ & $\begin{array}{l}91 \text { samples. } f \text { not } \\
\text { provided. }\end{array}$ \\
\hline $\begin{array}{l}\text { Chang et } \\
\text { al. }(2000)\end{array}$ & $\begin{array}{l}f=f 1 * f 2 * f 3 \\
f 1=14.39 \operatorname{Re}_{L_{p}}^{\left(-\frac{0.805 F_{p}}{F_{l}}\right)}\left(\log _{\mathrm{e}}\left(1.0+\left(F_{p} / L_{p}\right)\right)\right)^{3.04}, \operatorname{Re}_{L_{p}}<150\end{array}$ & $<5000$ & $j$ not provided. \\
\hline
\end{tabular}




\begin{tabular}{|c|c|c|c|}
\hline & $\begin{aligned} & f 1=4.97 \operatorname{Re}_{L_{p}}^{0.6049-1.064 / \theta^{0.2}}\left(\log _{\mathrm{e}}\left(\left(F_{p} / L_{p}\right)^{0.5}+0.9\right)\right)^{-0.527}, 150<\operatorname{Re}_{L_{p}}<5000 \\
& f 2=\left(\log _{\mathrm{e}}\left(\left(\delta / F_{p}\right)^{0.48}+0.9\right)\right)^{-1.435}\left(D_{h} / L_{p}\right)^{-3.01}\left(\log _{\mathrm{e}}\left(0.5 \operatorname{Re}_{L_{p}}\right)\right)^{-3.01}, \\
& f 2=\left(\left(D_{h} / L_{p}\right) \log _{\mathrm{e}}\left(0.3 \operatorname{Re}_{L_{p}}\right)\right)^{-2.966}\left(F_{p} / L_{l}\right)^{-0.7931\left(T_{p} / T_{h}\right)}, \\
& 150<\operatorname{Re}_{L_{p}}<5000 \\
& f 3=\left(F_{p} / L_{l}\right)^{-0.308}\left(F_{d} / L_{l}\right)^{-0.308}\left(e^{-\frac{0.1167 T_{p}}{D_{m}}}\right) \theta^{0.35}, \operatorname{Re}_{L_{p}}<150 \\
& f 3=\left(T_{p} / D_{m}\right)^{-0.0446} \log _{\mathrm{e}}\left(1.2+\left(L_{p} / F_{p}\right)^{1.4}\right)^{-3.553} \theta^{-0.477}, 150<\operatorname{Re}_{L_{p}}<5000\end{aligned}$ & & \\
\hline $\begin{array}{l}\text { Kim \& } \\
\text { Bullard } \\
(2002)\end{array}$ & $\begin{array}{l}j=\operatorname{Re}_{L p}^{-0.487}\left(\frac{L_{\alpha}}{90}\right)^{0.257}\left(\frac{F_{p}}{L_{p}}\right)^{-0.13}\left(\frac{H}{L_{p}}\right)^{-0.29}\left(\frac{F_{d}}{L_{p}}\right)^{-0.235}\left(\frac{L_{1}}{L_{p}}\right)^{0.68}\left(\frac{T_{p}}{L_{p}}\right)^{-0.279}\left(\frac{\delta_{f}}{L_{p}}\right)^{-0.05} \\
f=\operatorname{Re}_{L p}^{-0.781}\left(\frac{L_{\alpha}}{90}\right)^{0.444}\left(\frac{F_{p}}{L_{p}}\right)^{-1.682}\left(\frac{H}{L_{p}}\right)^{-1.22}\left(\frac{F_{d}}{L_{p}}\right)^{0.818}\left(\frac{L_{1}}{L_{p}}\right)^{1.97}\end{array}$ & $100-600$ & $F_{p} / L_{p}<1$ \\
\hline $\begin{array}{l}\text { Kim \& } \\
\text { Bullard } \\
(2002)\end{array}$ & $\begin{array}{l}j=\operatorname{Re}_{L p}^{-0.512}\left(\frac{L_{\alpha}}{90}\right)^{0.25}\left(\frac{F_{p}}{L_{p}}\right)^{-0.171}\left(\frac{H}{L_{p}}\right)^{-0.29}\left(\frac{F_{d}}{L_{p}}\right)^{-0.248}\left(\frac{L_{l}}{L_{p}}\right)^{0.68}\left(\frac{T_{p}}{L_{p}}\right)^{-0.275}\left(\frac{\delta_{f}}{L_{p}}\right)^{-0.05} \\
f=\operatorname{Re}_{L p}^{-0.798}\left(\frac{L_{\alpha}}{90}\right)^{0.395}\left(\frac{F_{p}}{L_{p}}\right)^{-2.635}\left(\frac{H}{L_{p}}\right)^{-1.22}\left(\frac{F_{d}}{L_{p}}\right)^{0.823}\left(\frac{L_{l}}{L_{p}}\right)^{1.97}\end{array}$ & $80-300$ & $\begin{array}{l}F_{p} / L_{p}<1 \\
\text { For dry and wet } \\
\text { surfaces. }\end{array}$ \\
\hline $\begin{array}{l}\text { Jacobi et } \\
\text { al. (2005) }\end{array}$ & $\begin{array}{l}j=\frac{a R e_{L p}^{b}}{R e_{L p}^{b}+d} \\
\frac{j_{m \square \text { dified }}}{j_{\text {Chang\&Wang }}}=\frac{1.1 \operatorname{Re}_{L p} \cosh \left(0.4\left[\left(\frac{F_{p}}{L_{p}}\right)-1\right]\right)}{\operatorname{Re}_{L p}+24-3\left(\frac{F_{p}}{L_{p}}\right)}\end{array}$ & $40-370$ & $\begin{array}{l}a, b, c, d \text { depends } \\
\text { on specimen. } \\
\text { jChang\& Wang is the } \\
j \text { proposed by } \\
\text { Chang and } \\
\text { Wang (1997). }\end{array}$ \\
\hline
\end{tabular}




\begin{tabular}{|c|c|c|c|}
\hline $\begin{array}{l}\text { Dong et al. } \\
\text { (2007a \& } \\
\text { b) }\end{array}$ & $\begin{array}{l}j=0.26712 \operatorname{Re}_{L_{p}}^{-0.1944}\left(\frac{L_{a}}{90}\right)^{0.257}\left(\frac{F_{p}}{L_{p}}\right)^{-0.5177}\left(\frac{F_{h}}{L_{p}}\right)^{-1.9045}\left(\frac{L_{h}}{L_{p}}\right)^{1.7159}\left(\frac{L_{d}}{L_{p}}\right)^{-0.2147}\left(\frac{\delta}{L_{p}}\right)^{-0.05} \\
f=-0.54486 \operatorname{Re}_{L_{p}}^{-0.3068}\left(\frac{L_{a}}{90}\right)^{0.444}\left(\frac{F_{p}}{L_{p}}\right)^{-0.9925}\left(\frac{F_{h}}{L_{p}}\right)^{0.5448}\left(\frac{L_{h}}{L_{p}}\right)^{-0.2003}\left(\frac{L_{d}}{L_{p}}\right)^{-0.0688}\end{array}$ & $\begin{array}{l}200- \\
2500\end{array}$ & $F_{p} / L_{p}>1$ \\
\hline $\begin{array}{l}\text { Li \& Wang } \\
\text { (2010) }\end{array}$ & $\begin{array}{l}j=0.0883 \operatorname{Re}^{-0.289} N^{0.092}\left(\frac{L_{a}}{L_{p}}\right)^{2.019}\left(\frac{F_{p}}{L_{p}}\right)^{-0.293}\left(\frac{F_{h}}{L_{p}}\right)^{0.366}\left(\frac{L_{h}}{L_{p}}\right)^{-0.073}\left(\frac{L_{d}}{L_{p}}\right)^{-0.327}\left(\frac{\delta}{L_{p}}\right)^{-1.548} \\
f=0.0171 \operatorname{Re}^{-0.437} N^{0.41}\left(\frac{L_{a}}{L_{p}}\right)^{2.4}\left(\frac{F_{p}}{L_{p}}\right)^{-0,776}\left(\frac{F_{h}}{L_{p}}\right)^{0.062}\left(\frac{L_{h}}{L_{p}}\right)^{0.334}\left(\frac{L_{d}}{L_{p}}\right)^{0.157}\left(\frac{\delta}{L_{p}}\right)^{-3.313}\end{array}$ & $\begin{array}{l}400- \\
1600\end{array}$ & $\begin{array}{l}7 \text { samples. } \\
\text { Multi-region } \\
\text { louvers. } L_{a}= \\
28^{\circ}, L_{p}=1.2, F_{p} \\
=2.8 \mathrm{~mm} . \mathrm{N} \text { : } \\
\text { number of } \\
\text { louver regions }\end{array}$ \\
\hline $\begin{array}{lrr}\mathrm{Li} & \text { et } & \text { al. } \\
(2011) & \end{array}$ & $\begin{array}{l}j=0.2162 \operatorname{Re}_{D c}^{-0.351}\left(\frac{F_{d}}{D c}\right)^{-0.875}\left(\frac{H}{D c}\right)^{0.426}\left(\frac{F_{p}}{D c}\right)^{-0.543}\left(\frac{\delta}{D c}\right)^{0.12} \\
f=0.4183 \operatorname{Re}_{D c}^{-0.506}\left(\frac{F_{d}}{D_{c}}\right)^{0.69}\left(\frac{H}{D_{c}}\right)^{1.382}\left(\frac{F_{p}}{L_{p}}\right)^{-1.837}\left(\frac{\delta}{L_{p}}\right)^{0.062}\end{array}$ & $\begin{array}{l}150- \\
1500\end{array}$ & $\begin{array}{l}11 \text { samples. } D c \\
\text { was not defined, } \\
\text { but seems } D_{h} \text {, } \\
\text { the hydraulic } \\
\text { diameter }\end{array}$ \\
\hline
\end{tabular}


Asako and Faghri (1987) numerically investigated the thermal hydraulic performance of the corrugated duct for the range of Reynolds number from 100 to 1500, by applying laminar flow model to the 2D geometry. Patel et al. (1991) numerically investigated the laminar boundary layer over the wavy wall. Three-dimensional numerical investigations conducted by Jang et al. (1996) for the fluid flow and heat transfer over a multi-row plate fin and tube heat exchanger studied staggered and in-line configuration of tube rows. They conducted the investigation for the range of Reynolds number from 60 to 900 and reported up to $27 \%$ higher heat transfer and $25 \%$ higher pressure drop performance of staggered arrangement over the in-line arrangement. Yang et al. (1997) numerically studied the transitional flow in a periodic fully developed 2D corrugated duct for the range of Reynolds number from 100 to 2500 by applying low Reynolds number turbulent model. They reported that the predicted transitional Reynolds number is lower than the value for a parallel plate duct. The heat transfers and fluid flow in the automotive radiator were modelled by McNab et al. (1998) and reported 54\% and 33\% variations between the computational and experimental results for the $\mathrm{j}$ and $\mathrm{f}$ factors for laminar flow regime. Whereas for the turbulent flow regime, these variations were within 17\%. 2D and 3D numerical investigations on flow and heat transfer for louvered fin arrays in compact heat exchangers were conducted by Atkinson et al. (1998). They reported the total heat transfer results from the 3D simulations were in better agreement with the experimental observations. In the study of compact heat exchangers, Springer \& Thole (1999) made detailed flow field measurements in the entry region of several louvered fin geometries, whereby the louver angle, the ratio of fin pitch to louver pitch, and Reynolds number were all varied. Tsai et al. (1999) conducted 3-D numerical investigation on wavy fin heat 
exchanger for the study of flow and thermal fields. Flow transition from steady to unsteady flow in a multi-louvered fin array was investigated by Tafti et al. (2000) for the range of Reynolds number from 400 to 1300 and found the flow instability for the Reynolds number greater than 1000. They also reported for the Reynolds number of 1300; the flow still found to be unstable.

The Air-side performance of fin and tube heat exchangers with circular and oval configurations were numerically investigated by Leu et al. (2001) and reported dropped in pressure with the increase in the louver angle, and both heat transfer and frictional performance increase with louver length. Cui and Tafti (2002) conducted a computational study of flow and heat transfer in a three-dimensional multi-louvered fin. They found that the heat transfer is high in the transition region. Due to the flat landing of the louvers, 50 percent improvement in the tube surface heat transfer is achieved compared to the angled louver that extends to the tube surface. Tiwari et al. (2003) performed a computational study on flat plate oval tube heat exchangers with delta winglet and reported the increase in heat transfer with increasing number of inline winglets. Ebeling \& Thole (2004) conducted both experimental and computational studies on straight louvers with no transition at the tube wall-louver interface. They reported higher heat transfer performance of the analyzed configuration over the conventional flat plate configuration.

Panse (2005) investigated the heat transfer and flow friction characteristics on plain fin configuration with six different multi-row models and revealed that the number of tube rows plays a vital part in the overall heat exchanger performance. Hsieh \& Jang (2006) investigated the effect of louver angles on thermal hydraulic performance using 3D numerical analysis. Malapure et al. (2007) has numerically investigated three-dimensional 
flow and heat transfer over louvered fins in compact heat exchangers considering conjugate heat transfer and fin resistance. They found that both Stanton number and friction factor decrease with the increase in fin pitch. However, the simulation results of Stanton number and friction factor are not in agreement with the experimental results at low Reynolds number. A comparative study of circular tube louver fin heat exchanger with its counterpart of plate fin heat exchangers was numerically performed by Čarija \& Franković (2008). Tang et al. (2009) performed numerical optimization of experimentally investigated fin and tube heat exchangers and showed that numerically optimized vortex-generator fin can offer better heat transfer performance than slit fin. Jang \& Tsai (2011) applied 3D model and a simplified conjugate gradient method to find the optimal louver angle of a fin heat exchanger for a range of Reynolds number from 100 to 500. Cheng et al. (2012) investigated heat transfer characteristics and flow structure of fin and tube heat exchanger with delta winglet vortex generators using $3 \mathrm{D}$ numerical simulations for the range of Reynolds number from 600 to 2000, based on tube collar diameter. They reported with the increase in angle of attack, both heat transfer and pressure drop increases. They also found $71 \%$ increase in heat transfer coefficient with the pressure drop penalty of up to $98 \%$ with vortex generators as compared to the plate fin geometry. Another louver angle and louver pitch optimization study for a louvered fin and tube heat exchanger with a simplified conjugate gradient method was conducted by Jang and Chen (2013). Ryu et al. (2014) conducted parametric study and optimization to improve the performance of corrugated louver fin and reported the louver fin performance in terms of $J F$ factor. They found 14$32 \%$ increase in $J F$ factor of the optimal model. Jang and Chen (2015) conducted another 
optimization study on heat transfer performance with and without louver fin heat exchanger using 3D laminar fluid flow with conjugate gradient method.

\subsubsection{Flow Regime Variations at Low Reynolds Number}

The lack of credible correlations, i.e. $\mathrm{j}$ and f-factors, in the low Reynolds number range is further complicated by the fact that the heat transfer and pressure drop are much more sensitive to lower air flow rates than higher air flow rates. At low Reynolds numbers, it has been discussed by several researchers that there might be a transition regime from louver directed to fin directed flow (Sahnoun and Webb (1992); Hiramatsu et al. (1990)) as presented in Figure 1. This transition depends on both the Reynolds number and geometrical parameters, such as the ratio of fin pitch to louver pitch, $\mathrm{F}_{\mathrm{p}} / \mathrm{L}_{\mathrm{p}}$. In general, when $\operatorname{Re}_{\mathrm{Lp}}$ is low, and $\mathrm{F}_{\mathrm{p}} / \mathrm{L}_{\mathrm{p}}$ is high, the gap between adjacent louvers is blocked, and the flow is in the direction of the fin, named as fin directed flow in the Figure. At higher $\operatorname{Re}_{\mathrm{Lp}}$ and lower $F_{p} / L_{p}$ the boundary layers are thinner, and the flow is almost aligned with the louvers, named as fin directed flow in the Figure. However, this phenomenon is not well captured by any of the existing correlations.

Having said that, the authors would like to point out that the concept of two regimes, i.e. fin directed flow and louver directed flow, has been a controversial subject in the literature. Davenport (1980) conjectured that a flattening behavior (actually "wavy" in their work) of the experimental Stanton number curve as Reynolds number decreased, was due to this same two-regime effect. The author observed that thickening of the boundary layer and hence flow bypassing the louvers increases with the reduction in the Reynolds number. He first noted that at low Reynolds number, the flow tends to align with the gap between the fins. As the Reynolds number increases, the flow starts aligning in the direction of 
louvers. Since it was reported it has been a subject, discussed and argued by researchers from different perspectives (Achaichia and Cowell 1988). For example, Shah and Webb (1983) claimed that such flattening or wavy behavior of the Stanton number curve is due to experimental error. Therefore, the new experimental study of heat transfers and pressure drops using specifically instrumented facilities along with the numerical study of the thermal hydraulic performance and especially for the flow field analysis is required to advance the state-of-the-art.

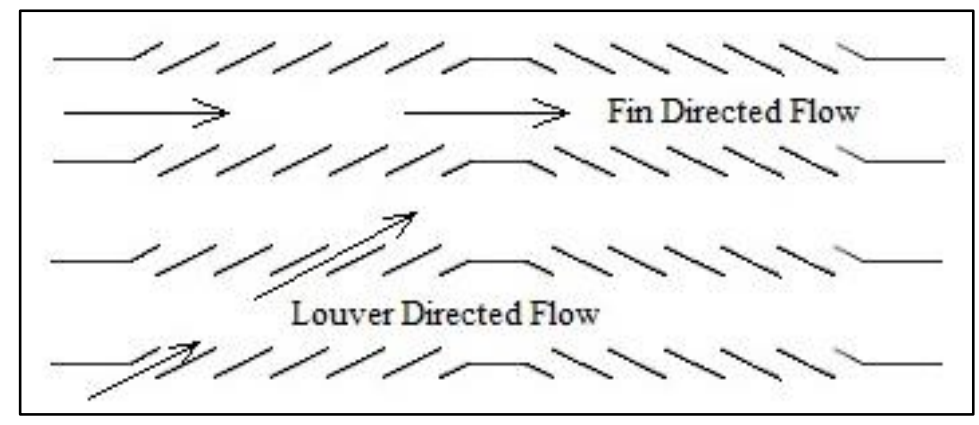

Figure 1: Two Flow Regimes

\subsubsection{Research Benefits}

In this endeavor, an experimental study is carried out to investigate the heat transfer and friction factor of compact heat exchangers with louvered fins and flat tubes at different low-air-side Reynolds numbers.

The data, correlations or guidelines obtained from this undertaking will partially fill up a knowledge gap in the compact heat exchanger at low air-side Reynolds numbers. They can be used to adequately design more efficient heat exchangers in air conditioning systems, freezer, and refrigeration applications.

The industries which design large refrigerant to air condensers, especially residential $\mathrm{A} / \mathrm{C}$ and commercial rooftop applications will benefit from this work. Other industries 
which design medium temp (refrigeration) and low temp (freezer) vapor compression systems will be affected, and will benefit from the development of dry (frost-free) correlations. Automotive heat exchanger manufacturers could also benefit from this work by applying it to the automotive condenser at idling conditions. Heat exchanger manufacturers who supply OEM customers or system manufacturers will also be affected since larger coils are needed to meet the higher efficiency ratings required in industry. It is estimated that over $50 \%$ of the society members could be aided by having such a correlation available for use in their heat exchanger design tools. If lower airflow off-peak conditions begin to be regulated more closely, even more members could benefit from this work. After successful completion of the work, such correlations could be implemented by ASHRAE members immediately.

\subsection{DISSERTATION ORGANIZATION}

The present study is narrated in two parts in this report. PART-I which describes the experimental investigation and starts with Chapter 2 in which, the experimental facilities, instrumentation, and procedures used over the course of the study are discussed. This is followed by the data reduction, and experimental verification in Chapter 3, and then experimental uncertainty estimates in Chapter 4. Chapter 5 evaluates the thermal hydraulic performance of the brazed-aluminum louver fin heat exchangers and the flow behavior at low Reynolds number. In Chapter 6, novel correlations for the $\mathrm{j}$ and $\mathrm{f}$ factors are presented.

PART-II depicts the numerical investigation and comprises of two chapters. Chapter 7 describes the numerical methodology followed during the study. This includes mathematical formulations, geometrical and computational details, numerical data 
reduction and validations. Chapter 8 explains the effect of geometrical parameters on the thermal hydraulic performance of the numerically tested geometries, evaluates the $\mathrm{j}$ and $\mathrm{f}$ factors in comparison with the experimental findings. At the end of the report, Chapter 9 provides the conclusions of the current research findings, followed by the supporting appendices.

\subsection{RESEARCH OBJECTIVES}

The primary objective of this research mission is to develop air-side heat transfer and pressure drop correlations for high-performance compact heat exchangers under low air velocity conditions or at low Reynolds numbers.

The research problem has the following facets:

1. To conduct a literature review to investigate similar work that's already been completed. Upgrade the test facility as per the research need. Develop the test matrix based on the variation of heat exchanger geometrical parameters. Acquire the heat exchanger samples.

2. Conduct the experimental testing and acquire the data.

3. Reduce the experimental results to develop new heat transfer and pressure drop correlations for the low Reynolds number flow from 20 to 200.

4. With consideration of the effects of flow rarefaction, re-investigate the experimental data and provide the accurate and concise correlations for heat transfer and pressure drop characteristics at low Reynolds number from 20 to 200 based on louver pitch. 
5. To investigate numerically, the heat transfers and pressure drop characteristics of the flow through compact heat exchangers and provide the comparison with experimental results.

This study is part of the ASHRAE sponsored technical research project on air to refrigerant heat transfer equipment conducted under the guidance of technical committee TC8.4. As a part of the ASHRAE-funded project, experimental testing's of the microchannel heat exchangers have been carried out in the wind tunnel equippedexperimental facility in the Mechanical and Materials Engineering Department at Florida International University.

\subsection{SCOPE OF THE RESEARCH}

The scope of the research includes experimental, and numerical investigation of highperformance compact heat exchangers and develop airside heat transfer and pressure drop correlations for Low Reynolds Number Flow condition. The investigation of the curre nt study will partially fill the knowledge gap in compact heat exchangers at low Reynolds numbers and benefit industries such as automotive, HVAC, refrigeration and air conditioning, and in the design and manufacturing of the high-performance heat exchanger equipment. It is expected that the outcome of this work will be heat transfer and pressure drop correlations that ASHRAE members can use to predict HVAC\&R components and system performance better. The current study will also benefit Micro Electro Mechanical Systems (MEMS) industry in the application of electronics cooling and microfluidic

devices, biomedical application devices for micro-flow transport such as bioreactors, radial chambers, parallel plate cell perfusion chamber, and many others. 


\section{PART I - EXPERIMENTAL INVESTIGATION}




\section{CHAPTER 2 : EXPERIMENTAL FACILITIES, MEASUREMENTS, AND PROCEDURES}

\section{$2.1 \quad$ FACILITIES}

This section provides an overview of the test facilities used in this study. The subsection "Instrumentation" provides detailed descriptions of instrument precisions or accuracies.

Typical low-speed wind tunnel equipped research laboratory at FIU Engineering Center is utilized to test the microchannel heat exchanger samples. The wind tunnel has a $0.6096 \mathrm{~m}$ long rectangular test section of cross section $0.635 \times 0.457 \mathrm{~m}$ on edge. Figure 2 illustrates the general design layout of the apparatus. Single-phase, 115/230V-AC centrifugal fan of $1.5-\mathrm{kW}$, and 1750-RPM powered the wind tunnel. The fan provides a maximum speed in the test section (with no blockage) of about $6 \mathrm{~m} / \mathrm{s}$ and a Reynolds number per meter of up to about 400,000 (based on the tunnel's hydraulic diameter). The tunnel can be operated as a closed loop system or as an open loop by the opening or closing of the loop connect valve (No. 17) as shown in the Figure. By changing the inlet and outlet valves (No. 1 and No. 16) the air flow rate is controlled. Before the test section (No. 10), a flow straightener and an air pre-heater are installed. The original wind tunnel has one circular developing section accompanied with venturi meter for airflow measurement through the tunnel.

The present study is to measure the heat transfer and pressure drops at very low Reynolds numbers based on louver pitch $\left(20<\operatorname{Re}_{\mathrm{Lp}}<200\right)$. At such low Reynolds number range, relatively more accurate or reasonable measuring systems are employed as compared to the requirements for higher Reynolds number range. 


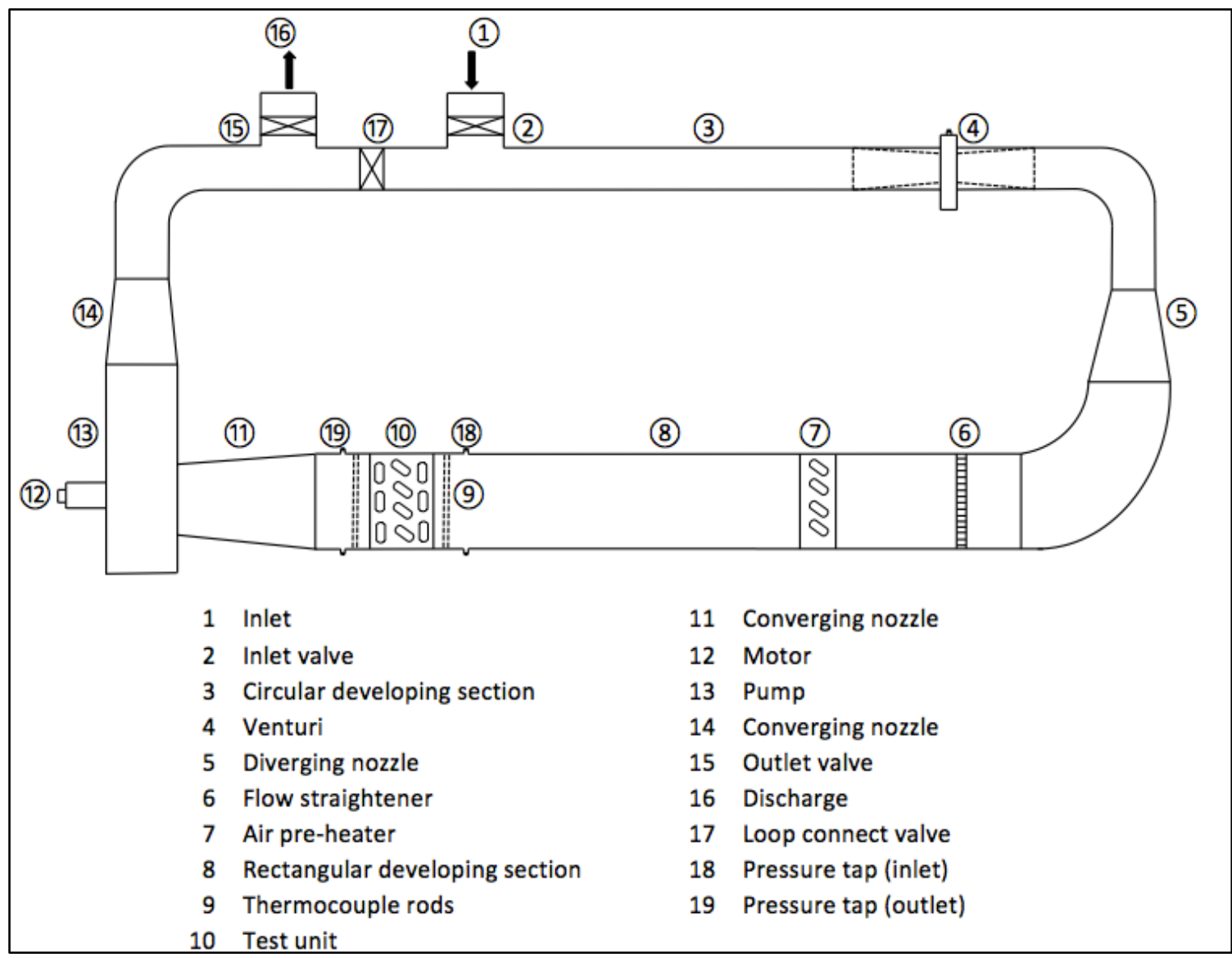

Figure 2. Close Loop Wind Tunnel Apparatus Schematic

Considering the availability of the laboratory instruments and the capability of the existing facilities, we have made a few modifications to the system. Here are three significant changes made during the course of the study:

\subsubsection{Two-Stage Air Flow Measurement Configuration}

Existing apparatus setup was designed to measure the pressure drop through venturi meter of range 0 to 2.6466 in of $\mathrm{H} 2 \mathrm{O}$ for the airflow of $3000 \mathrm{scfm}$. This was leading to very high errors at the lower pressure drop measurements. To increase the accuracy of the measurements; apparatus is then modified to an open loop system as shown in the 
schematics of Figure 3 Modified Open Loop Wind Tunnel Apparatus. Modifications made to the system by replacing 12 -inch 24 -gauge round duct with an elbow joint to that of two 12-inch 24-gauge round ducts with Tee joint. Modified two-stage wind tunnel apparatus is accompanied with venturi meter in one duct while orifice meter in another duct, which is portrayed in the schematics of Figure 3 and Figure 4. Figure 5 shows the upgraded wind tunnel apparatus.

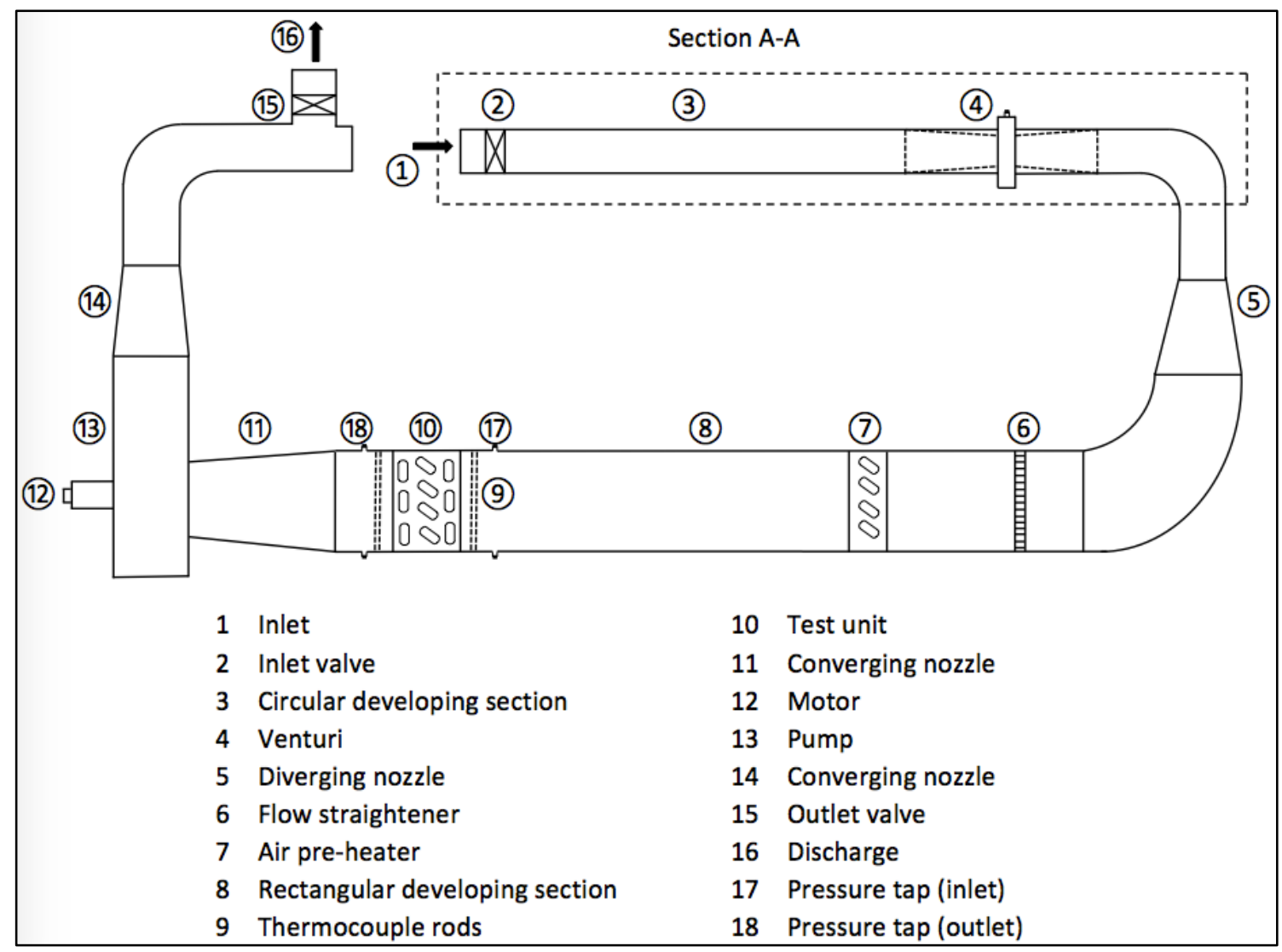

Figure 3. Modified Open Loop Wind Tunnel Apparatus Schematic

The pressure drop measurement in the modified apparatus setup in each side is listed in Table 2 Airflow Pressure Drop Limits, below. 
Table 2. Airflow Pressure Drop Limits

\begin{tabular}{c|c}
\hline Measurement Device Side & Pressure Drop (in of $\mathrm{H}_{2} \mathrm{O}$ ) \\
\hline Venture meter & 2.6466 at $3000 \mathrm{scfm}$ \\
Orifice meter & 172.37 at $2200 \mathrm{scfm}$ \\
\hline
\end{tabular}

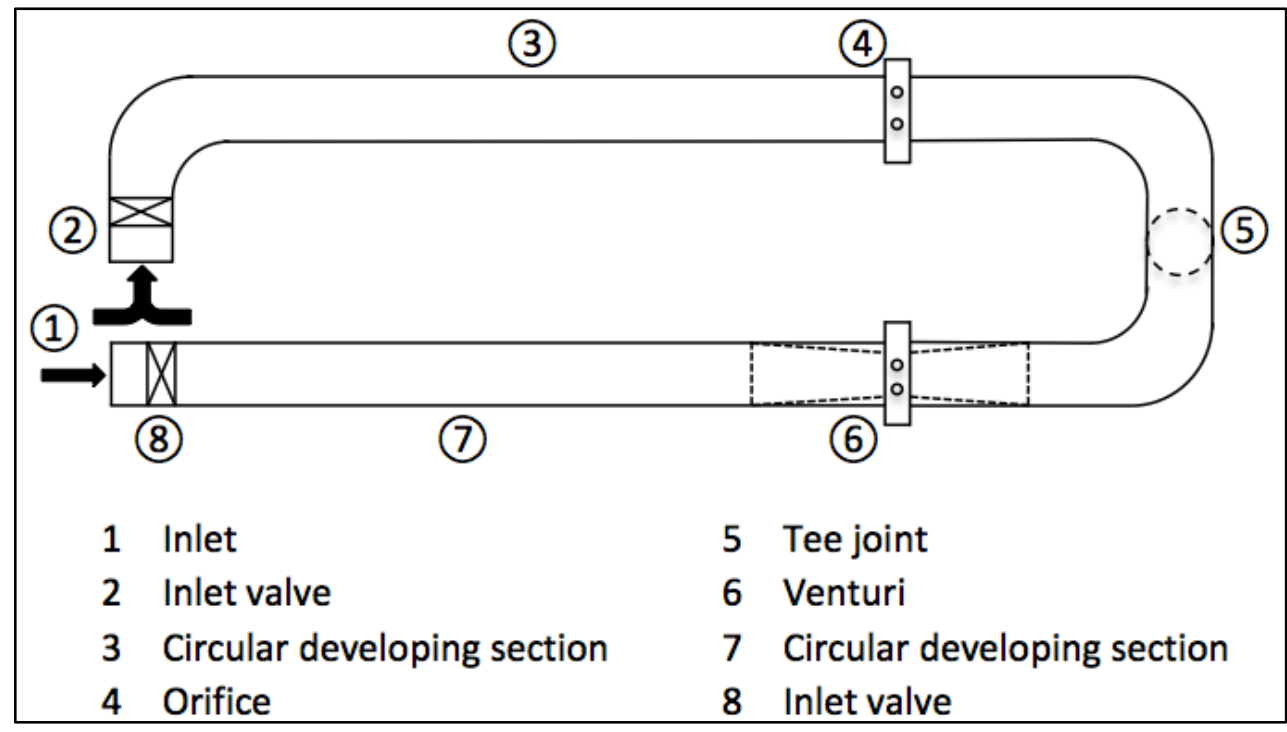

Figure 4. Section A-A Top View of Figure 3.

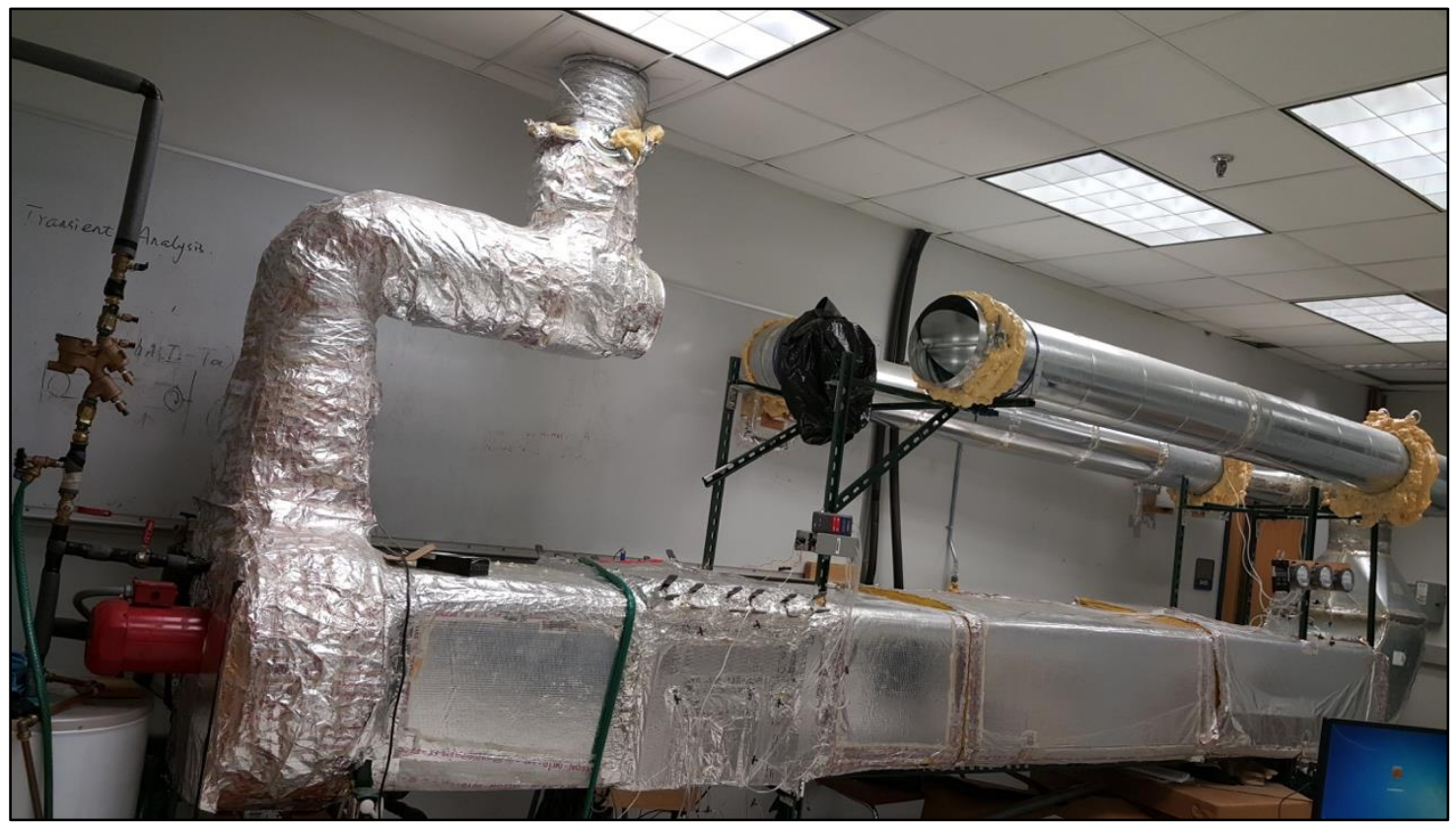

Figure 5. Upgraded Wind Tunnel Apparatus 
The measured pressure drop is ultimately used to calculate the air flow rates. With existing fan power, the modified setup was able to use orifice side for the measurement of medium to lower airflow rates with greater accuracies, whereas venturi side for the measurement of medium to higher airflow rates within the range of the experiments of this study. The modified setup adds an additional drop in the system.

\subsubsection{Precision Water Temperature Control}

On the water side, the developed close loop system has a 45 -gallon water tank furnis hed with a standard $4.5 \mathrm{~kW}$ heater. To minimize the water temperature variation and provide a backup heating system during the testing, a precision tankless heater, model TX027-3R, was installed. The water heater can operate up to $27 \mathrm{~kW}$ keeping temperature change less than $1^{\circ} \mathrm{F}$. Figure 6 shows the schematic of water loop with the tankless heater (No. 2). Also shown in the Figure are the relative locations of heat exchangers, water pump, as well as measuring stations.

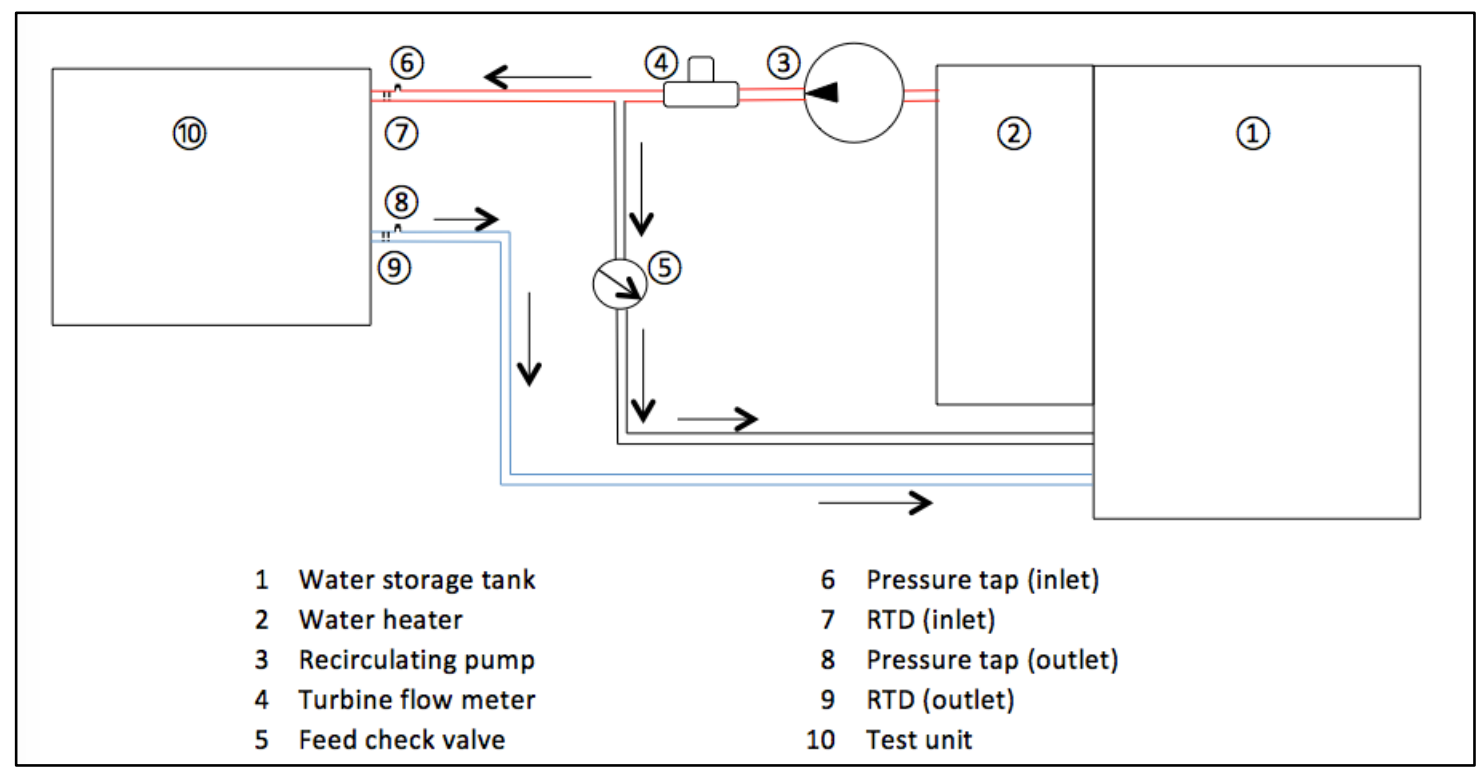

Figure 6. Water Loop 


\subsubsection{Multiple Pressure Taps}

To improve the accuracy of pressure drop measurements across the heat exchangers, we have used multiple pressure taps before and after the test samples, instead of one. The subsection of "Instrumentation" provides the details about the multiple pressure tap locations.

\subsection{HEAT EXCHANGERS AND TEST MATRIX}

The test samples were brazed aluminum microchannel heat exchangers (MCHX) with flat tube louvered fin geometry, similar to the ones tested by Chang et al. (1994).

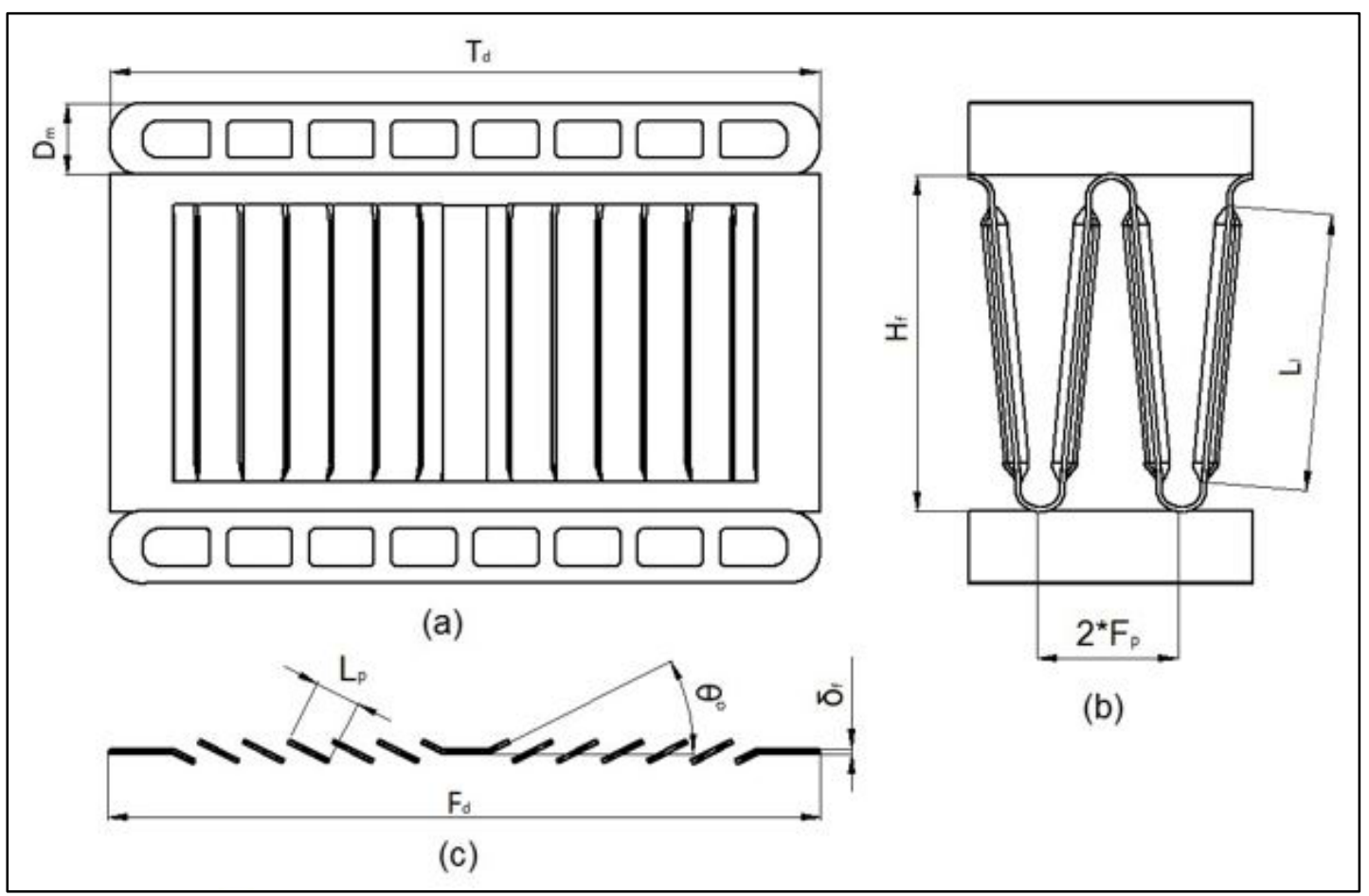

Figure 7. Geometrical Parameters of MCHX; (a) side view along the flow depth and tube cross-section, (b) frontal view perpendicular to flow depth, (c) fin cross-section

Figure 7 represents the definitions of the key geometrical parameters for the flat tube, louver, and fins, as well as the MCHX assembly. Although there are other types of louver 
fin heat exchangers as reported in Chang and Wang (1997), this study focused on the "corrugated louvers" with near triangular or rectangular channels for airflows.

The test samples were commercially available and obtained from several manufacturers in the United States, Europe, and Asia who were able to provide the geometrical details or design drawing of the heat exchangers. Figure 8 is a picture of a typical sample tested in this study. This tested geometry has $18 \mathrm{~mm}$ depth of fin array in the flow direction, 8.58 $\mathrm{mm}$ fin height, $7.11 \mathrm{~mm}$ louver length, $27^{\circ}$ louver angle, $14 \mathrm{~mm}$ fin pitch, and $1.14 \mathrm{~mm}$ louver pitch. Test sample core size is $609.4 \times 356.8 \mathrm{~mm}$.

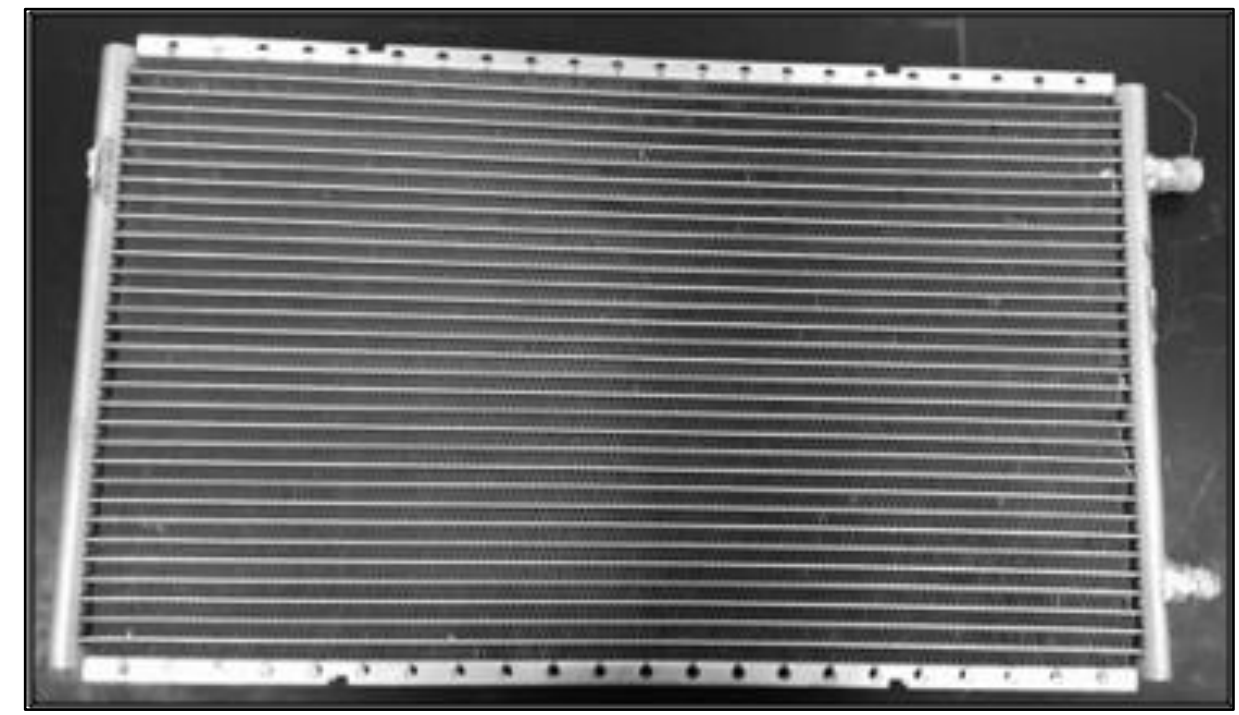

Figure 8. Typical Microchannel Heat Exchanger Test Sample

Table 3 is the test sample matrix developed for this study based on the availability of the MCHXs on the market. A total of 26 heat exchanger samples were tested. The test sample matrix covered fairly wide parametric ranges for fin pitch, fin height, fin thickness, louver pitch, louver angle, louver length, tube depth, and fin depth. In place of supplier's company names, codes were used to maintain the confidentiality. Table 4 summarize s the ranges for each parameter. 
Table 3. Test Sample Matrix

\begin{tabular}{|c|c|c|c|c|c|c|c|c|c|c|}
\hline $\begin{array}{c}\text { Geom. } \\
\text { No. }\end{array}$ & $\begin{array}{c}F_{p} \\
(\boldsymbol{F P I})\end{array}$ & $\begin{array}{c}\boldsymbol{H}_{f} \\
(\mathbf{m m})\end{array}$ & $\begin{array}{c}\delta \\
(\mathrm{mm})\end{array}$ & $\begin{array}{c}L_{p} \\
(\mathbf{m m})\end{array}$ & $\begin{array}{c}L_{l} \\
(\mathrm{~mm})\end{array}$ & $\begin{array}{c}D_{m} \\
(\mathrm{~mm})\end{array}$ & $\begin{array}{c}T_{d} \\
(\mathrm{~mm})\end{array}$ & $\begin{array}{c}F_{d} \\
(\mathbf{m m})\end{array}$ & $\begin{array}{c}\theta \\
\left({ }^{\circ}\right)\end{array}$ & Co. \\
\hline 1 & 14 & 8.58 & 0.13 & 1.14 & 7.11 & 1.83 & 18 & 18 & 27 & U1 \\
\hline 2 & 20.3 & 10 & 0.1 & 1.14 & 6.75 & 1.75 & 25 & 25 & 25 & E1 \\
\hline 3 & 20 & 8 & 0.1 & 0.9 & 6.5 & 1.5 & 30 & 30 & 27 & E1 \\
\hline 4 & 23 & 8 & 0.08 & 1 & 6.6 & 1.8 & 12 & 12 & 28 & $\mathrm{C} 1$ \\
\hline 5 & 20.3 & 8 & 0.08 & 1 & 6.6 & 1.8 & 12 & 12 & 28 & $\mathrm{C} 1$ \\
\hline 6 & 18 & 8 & 0.08 & 1 & 6.6 & 1.8 & 12 & 12 & 28 & $\mathrm{C} 1$ \\
\hline 7 & 20.3 & 8 & 0.1 & 1 & 6.6 & 2 & 16 & 16 & 20 & $\mathrm{C} 1$ \\
\hline 8 & 23 & 8 & 0.1 & 1 & 6.6 & 2 & 16 & 16 & 28 & $\mathrm{C} 1$ \\
\hline 9 & 21.17 & 8 & 0.1 & 1 & 6.6 & 2 & 16 & 16 & 28 & $\mathrm{C} 1$ \\
\hline 10 & 19.24 & 8 & 0.1 & 1 & 6.6 & 2 & 16 & 16 & 28 & $\mathrm{C} 1$ \\
\hline 11 & 20.3 & 8 & 0.1 & 1 & 6.6 & 1.8 & 16 & 16 & 28 & $\mathrm{C} 1$ \\
\hline 12 & 20.3 & 7.5 & 0.1 & 1 & 6.2 & 2 & 16 & 16 & 28 & $\mathrm{C} 1$ \\
\hline 13 & 14.94 & 8 & 0.1 & 1.3 & 6.6 & 2 & 20 & 20 & 34 & $\mathrm{C} 1$ \\
\hline 14 & 20.3 & 8 & 0.1 & 1 & 6.6 & 2 & 20 & 20 & 28 & $\mathrm{C} 1$ \\
\hline 15 & 20.3 & 7.5 & 0.1 & 1 & 6.2 & 2 & 20 & 20 & 28 & $\mathrm{C} 1$ \\
\hline 16 & 14.94 & 8 & 0.1 & 1 & 6.6 & 2 & 26 & 26 & 28 & $\mathrm{C} 1$ \\
\hline 17 & 20.3 & 8 & 0.1 & 1 & 6.6 & 2 & 26 & 26 & 28 & $\mathrm{C} 1$ \\
\hline 18 & 21.17 & 5.6 & 0.1 & 1 & 6.6 & 1.4 & 16 & 16 & 28 & $\mathrm{C} 1$ \\
\hline 19 & 14 & 8 & 0.17 & 1.14 & 5.97 & 2.03 & 25.4 & 25.4 & 30 & U2 \\
\hline 20 & 12 & 9.45 & 0.15 & 2.44 & 7.87 & 4.19 & 26.92 & 26.92 & 28 & U3 \\
\hline 21 & 9 & 9.45 & 0.15 & 2.44 & 7.87 & 4.19 & 26.92 & 26.92 & 28 & U3 \\
\hline 22 & 7 & 9.45 & 0.15 & 2.44 & 7.87 & 4.19 & 26.9 & 26.9 & 28 & U3 \\
\hline 23 & 11 & 7.4 & 0.1 & 1.02 & 5.97 & 1.6 & 25.6 & 28 & 27 & U4 \\
\hline 24 & 14 & 7.4 & 0.1 & 1.02 & 5.97 & 1.6 & 25.6 & 28 & 27 & U4 \\
\hline 25 & 15 & 7.4 & 0.1 & 1 & 6.0 & 1.6 & 25.6 & 28 & 27 & U4 \\
\hline 26 & 18 & 7.4 & 0.1 & 1.02 & 5.97 & 1.6 & 26.6 & 28 & 27 & U4 \\
\hline
\end{tabular}

Table 4. Summary of Parameter Ranges

\begin{tabular}{c|c|c|c|c|c|c|c|c}
\hline $\begin{array}{c}\boldsymbol{F}_{\boldsymbol{p}} \\
(\boldsymbol{F P I})\end{array}$ & $\begin{array}{c}\boldsymbol{H}_{\boldsymbol{f}} \\
(\mathbf{m m})\end{array}$ & $\begin{array}{c}\boldsymbol{\delta} \\
(\mathbf{m m})\end{array}$ & $\begin{array}{c}\boldsymbol{L}_{\boldsymbol{p}} \\
(\mathbf{m m})\end{array}$ & $\begin{array}{c}\boldsymbol{L}_{\boldsymbol{l}} \\
(\mathbf{m m})\end{array}$ & $\begin{array}{c}\boldsymbol{D}_{\boldsymbol{m}} \\
(\mathbf{m m})\end{array}$ & $\begin{array}{c}\boldsymbol{T}_{\boldsymbol{d}} \\
(\mathbf{m m})\end{array}$ & $\begin{array}{c}\boldsymbol{F}_{d} \\
(\mathbf{m m})\end{array}$ & $\begin{array}{c}\boldsymbol{\theta} \\
\left({ }^{\circ}\right)\end{array}$ \\
\hline $7-21.17$ & $5.6-10$ & $0.08-0.17$ & $0.9-2.44$ & $5.97-7.87$ & $1.5-4.19$ & $12-30$ & $12-30$ & $20-34$ \\
\hline
\end{tabular}

Wall thickness variation is between $0.28 \mathrm{~mm}$ to $0.51 \mathrm{~mm}$. 


\section{$2.1 \quad$ INSTRUMENTATION}

This section briefly describes the various measurement and control devices installed throughout the experimental setup. Table 5 provides the summary of the instrumental precisions for the measurement of temperatures, flow rates, and pressure drops on air and water sides.

Table 5. Precisions of the Measurement Instruments

\begin{tabular}{|c|c|c|c|}
\hline Parameter & Instrument/Method & Range & Precision/Error \\
\hline \multirow{2}{*}{$\begin{array}{l}\text { Air-side } \\
\text { Temperature }\end{array}$} & Thermocouple Calibration & $0-100{ }^{\circ} \mathrm{C}$ & $\pm 0.1{ }^{\circ} \mathrm{C}$ \\
\hline & $\begin{array}{l}\text { T-type Thermocouple } \\
\text { Precision* }\end{array}$ & $0-100{ }^{\circ} \mathrm{C}$ & $\pm 0.03{ }^{\circ} \mathrm{C}$ \\
\hline $\begin{array}{l}\text { Water-side } \\
\text { Temperature }\end{array}$ & $\begin{array}{l}\text { T-type Thermocouple Probe } \\
\text { Precision* }\end{array}$ & $0-100{ }^{\circ} \mathrm{C}$ & $\pm 0.03{ }^{\circ} \mathrm{C}$ \\
\hline $\begin{array}{l}\text { Air-side Pressure } \\
\text { Drop } \\
\text { (at Test Section) }\end{array}$ & $\begin{array}{l}\text { HHP-103 Manometer } \\
\text { (Differential Pressure } \\
\text { Transducer) }\end{array}$ & $0-10.4$ in wc & $\pm 0.2 \% \mathrm{FS}$ \\
\hline \multirow{2}{*}{$\begin{array}{l}\text { Air-side Volume } \\
\text { Flow Rate }\end{array}$} & $\begin{array}{l}\text { Orifice: 477A Digital } \\
\text { Manometer }\end{array}$ & $0-335 \mathrm{scfm}$ & $\pm 0.1 \% \mathrm{FS}$ \\
\hline & $\begin{array}{l}\text { Venturi: 477A Digital } \\
\text { Manometer }\end{array}$ & $\begin{array}{l}260-885 \\
\text { scfm }\end{array}$ & $\pm 0.1 \% \mathrm{FS}$ \\
\hline
\end{tabular}

*Based on 1090 samples

\subsubsection{Temperature Measurements}

Thermocouple grid is applied to measure the air temperatures at the inlet (before the heat exchanger) and outlet (after the heat exchanger) to take into account the possibility of non-uniform measurements. T-type thermocouple wire from Omega Engineering Inc. is then used to manufacture the thermocouple connections in-house in Seismic Lab at Florida International University for the measurement of air temperature at inlet and outlet of the 
test section. Nine thermocouples used before the heat exchanger and 25 thermocouples after the heat exchanger. Figure 9 illustrates the locations of these thermocouples. Whereas, Figure 10 shows the temperature measuring stations.

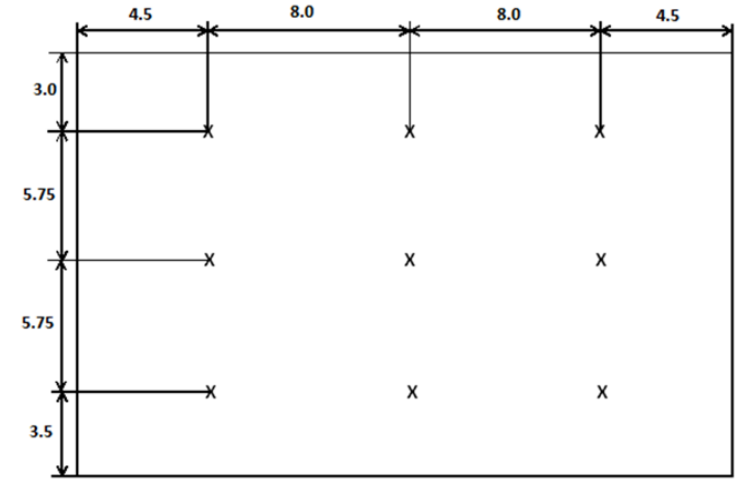

(a) before heat exchanger

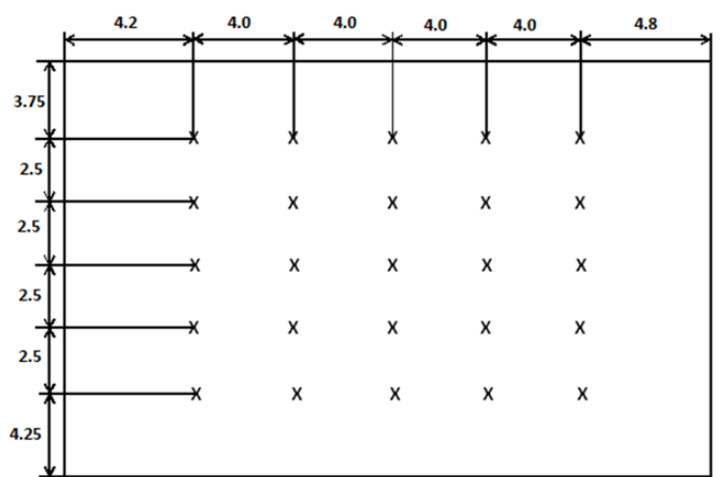

(b) after the heat exchanger Figure 9. Schematic of Thermocouple Locations for Air Temperature Measurement

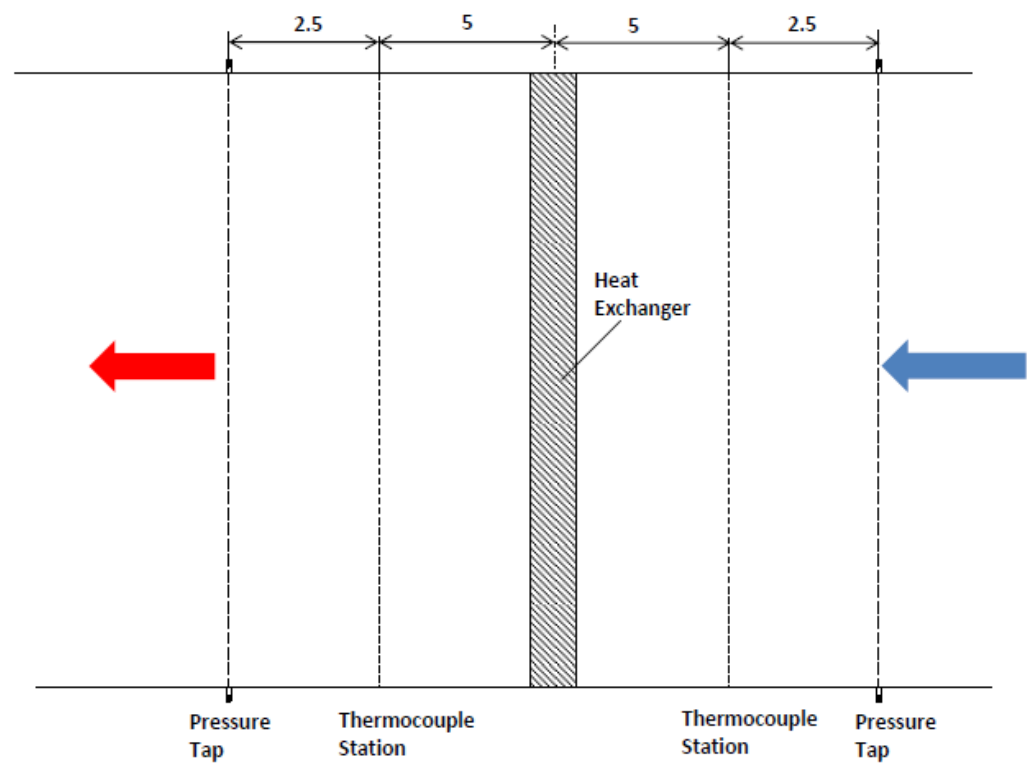

Figure 10. Measuring Stations for Temperature and Pressure Sensors

On the waterside temperature measurement, at the inlet and outlet, T-type thermocouple probes from Omega Engineering Inc. are used with one on each location of the connection tubes of the heat exchangers. 
A thermometer of $0.1{ }^{\circ} \mathrm{C}$ precision (NIST Traceable) was used to calibrate the air-side thermocouples. The calibration details of the air-side thermocouples are listed in chapter 3. Both the inlet and the exit temperature of the water were measured by two pre-calibrated T-type thermocouple probes with the precision of $0.1{ }^{\circ} \mathrm{C}$.

\subsubsection{Airflow Measurements}

The static pressure difference across the orifice meter as well as the venturi meter was used to estimate the air volumetric flow rate. This section just describes the instrumentation; next chapter gives more details about the volumetric flow rate calculations on both sides (orifice and venturi meter). The pressure difference across the orifice or venturi meter was measured by handheld digital differential pressure manometer Dwyer series $477 \mathrm{~A}$ as seen in Figure 11. The operating range of the manometer is between 0 to 4982 Pascal (0 to 20 inches of $\mathrm{H} 2 \mathrm{O}$ ) with an accuracy of $\pm 4.982 \mathrm{~Pa}(0.02$ inches of $\mathrm{H} 2 \mathrm{O})$.

Both the orifice (Figure 12) and venturi meters (Figure 13) are pre-calibrated by the instrument manufacturers based on NIST standards.

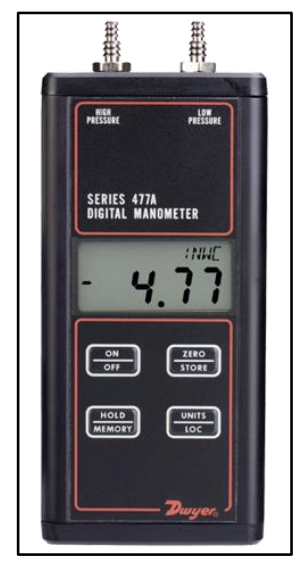

Figure 11. Digital Diffe re ntial Pressure Manometer

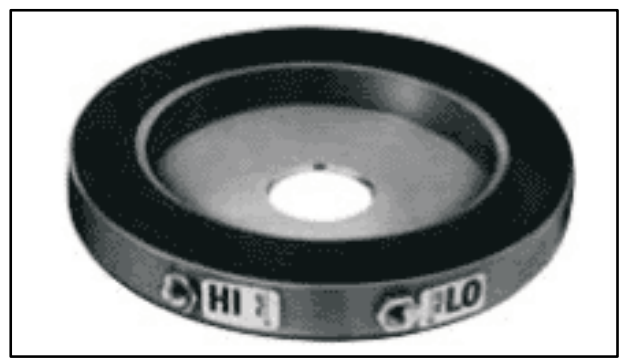

Figure 12. Orifice Meter 


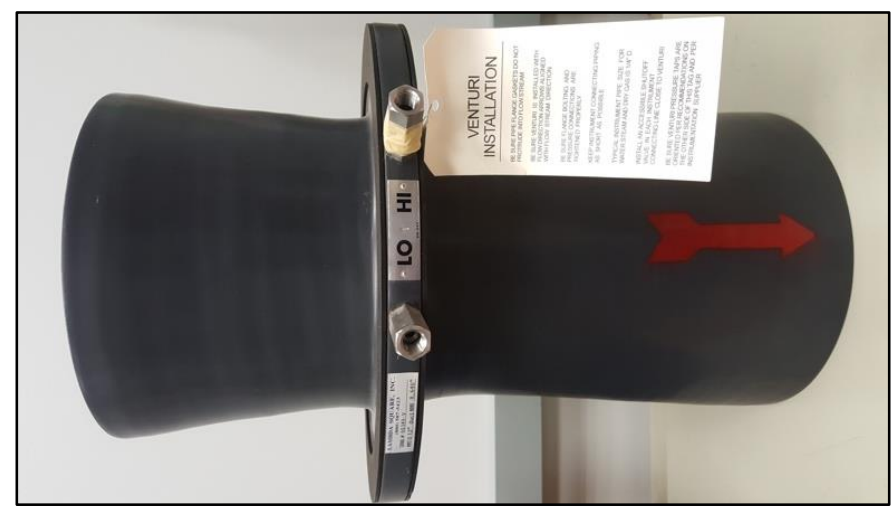

Figure 13. Venturi Meter

\subsubsection{Air Pressure Drop Measurements}

Since, the airflow range in the experiment is very low; the pressure drop measurements across the test unit are also very low. This leads to the use of high resolution, and high accuracy measuring device for the pressure drop measurement. A very low digital manometer from Omega Engineering Inc. model HHP-103 was used to measure the static pressure drop across the test unit during the heating experiment as seen in Figure 14. The operating range of the manometer is between 0 to 2501 Pascal $\left(0\right.$ to 10.04 inch $\left.\mathrm{H}_{2} \mathrm{O}\right)$ with an accuracy of $\pm 5.002 \mathrm{~Pa}\left(0.02008\right.$ inch $\left.\mathrm{H}_{2} \mathrm{O}\right)$.

Pressure taps are installed on the four sides of the test section before and after the heat exchangers. Figure 10 depicts the locations of measuring stations for the pressure taps.

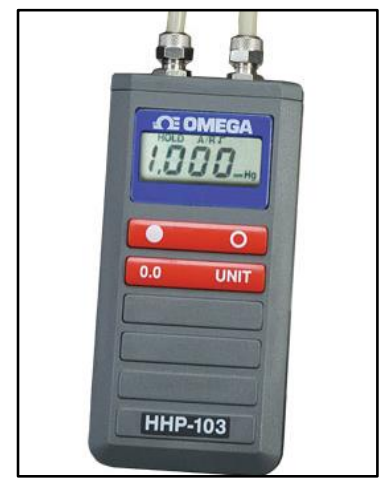

Figure 14. Very Low Range Digital Differential Pressure Manometer 


\subsubsection{Water Flow Measurements}

The liquid turbine flow meter from Omega Engineering Inc. model FTB 1425 as seen in Figure 15 was used to measure the water-side volumetric flow rate. The operating range of the flow meter is between 2.8 to 28 LPM ( 0.75 to 7.5 GPM) with an accuracy of $\pm 1 \%$ of the reading. The measurements from the turbine flow meter were displayed on 6-digit rate meter from Omega Engineering Inc. model DPF701 as seen in Figure 16. The accuracy of the rate meter is $0.01 \%$ of the flow rate $\pm 1 \frac{1}{2}$ LSD (Least Significant Digit).

The flow meter was pre-calibrated by the manufacturer based on NIST standard.

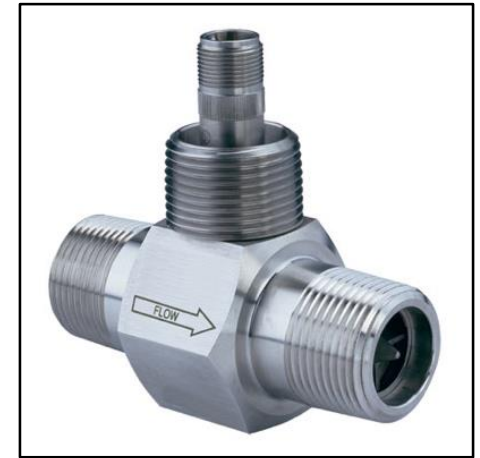

Figure 15. Water Turbine Flow Meter

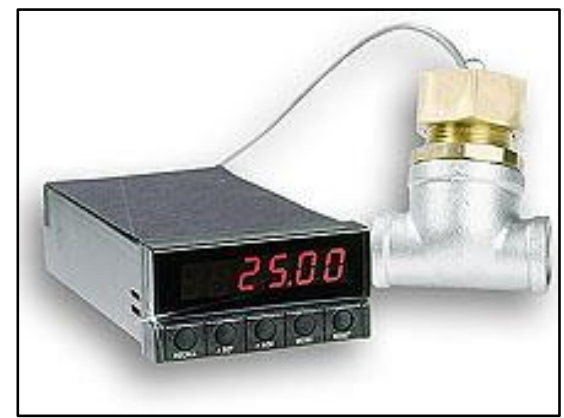

Figure 16. 6-Digital Rate Meter

\subsubsection{Data Acquisition}

National Instruments cDAQ-9174, 32-bit, CompactDAQ data acquisition unit was employed to record the transients associated with temperature monitoring of 25 thermocouple junctions on airside measurements and two thermocouple probes on waterside measurements. The chassis possessed four slots for modules out of which three were used - two of NI 9213 16-ch TC, 24-bit C Series Modules, and one NI 9211 4-Ch \pm 80 mV, $14 \mathrm{~S} / \mathrm{s}, 24-B i t$ Thermocouple Differential Analog Input Module. The calibration standard used for this instrument is ASTM E230-87. 
The output of the data acquisition unit was fed into the Desktop computer via USB-2 interface bus. National Instruments LabVIEW software controlled the PC-based data acquisition system.

Figure 17 below is a schematic portraying the data acquisition system with signal input into the NI 9211 and NI 9213 modules.

As mentioned earlier, the Dwyer Instruments Series 477A Digital Manometer used for the differential pressure measurement in the measurement of airflow, whereas the differential pressure across the test unit was recorded using Omega's HHP103 digital manometer. These pressure measurement data are saved on the computer directly.

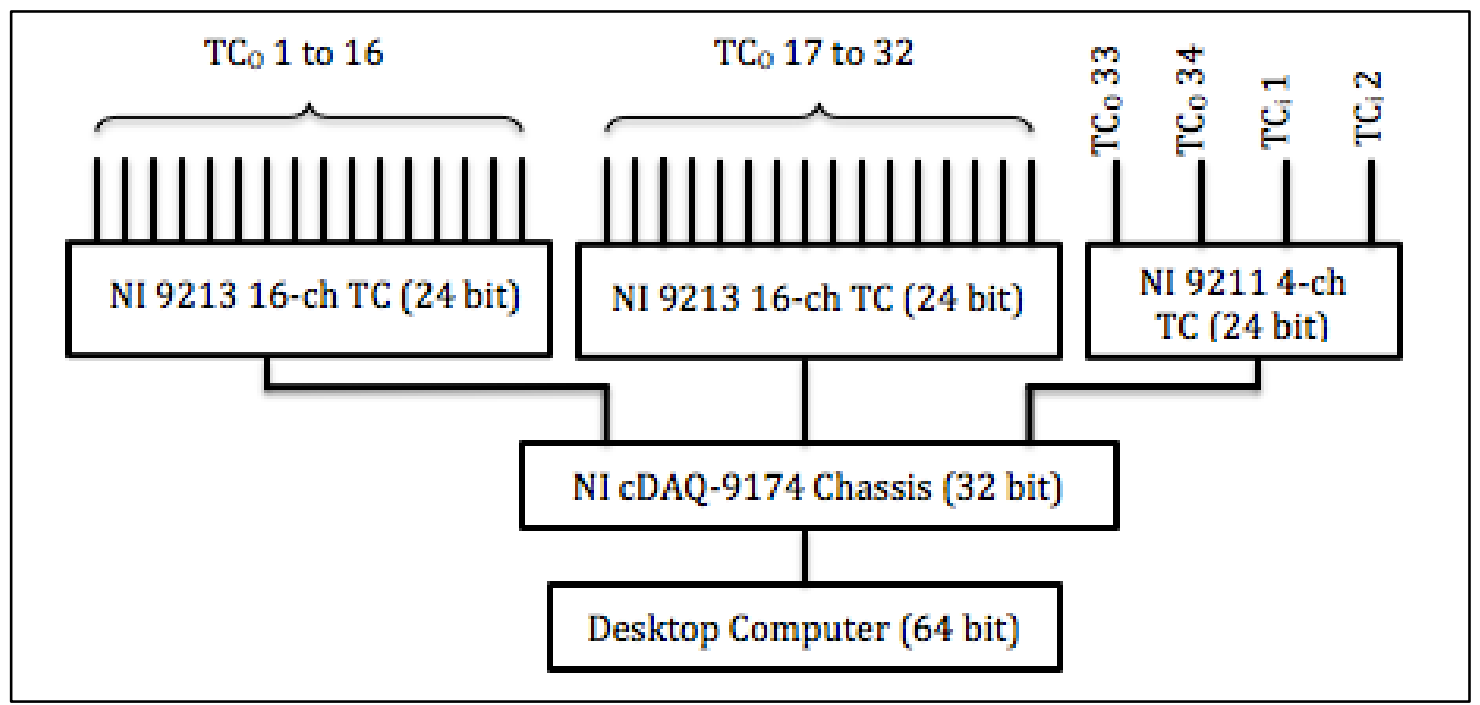

Figure 17. Schematic of Data Acquisition Sys tem

\subsubsection{Test Procedures}

All experimental tests were conducted with the test sample initially in dry condition. All of the test samples were bought new unused from the manufacturer. The repeated test samples were drained and dried at room temperature for at least two days or more inside 
the laboratory. The test sample then installed into the test apparatus. The water was stored, heated and maintained at around $50^{\circ} \mathrm{C}\left(122^{\circ} \mathrm{F}\right)$ with $\pm 5^{\circ} \mathrm{C}\left( \pm 5^{\circ} \mathrm{F}\right)$ accuracy specified by the manufacturer in the household water heater with the storage tank. As explained earlier in the section 2.1.2, the water was fed to the test sample via precision tankless heater (TX027-3R) with the variation in the temperature at inlet less than $1^{\circ} \mathrm{F}$. Water loop system was pressurized with hot water, and the air relief valves were operated manually to remove the air out of the system. Hot water is then pumped through the test sample with the flow rate in between 1GPM to 4GPM. Depends on the liquid side flow area of the test sample, flow rate varies. Once again air relief valves were operated manually to remove any trapped air inside the system. The fan was then turned on, and the air stream in the wind tunnel was set to the desired test condition. Test run for the stability check was started. Once the wind tunnel and the water loop both reached the steady state conditions, the experiments were conducted. This period of the stability can be observed in Figure 18-20.

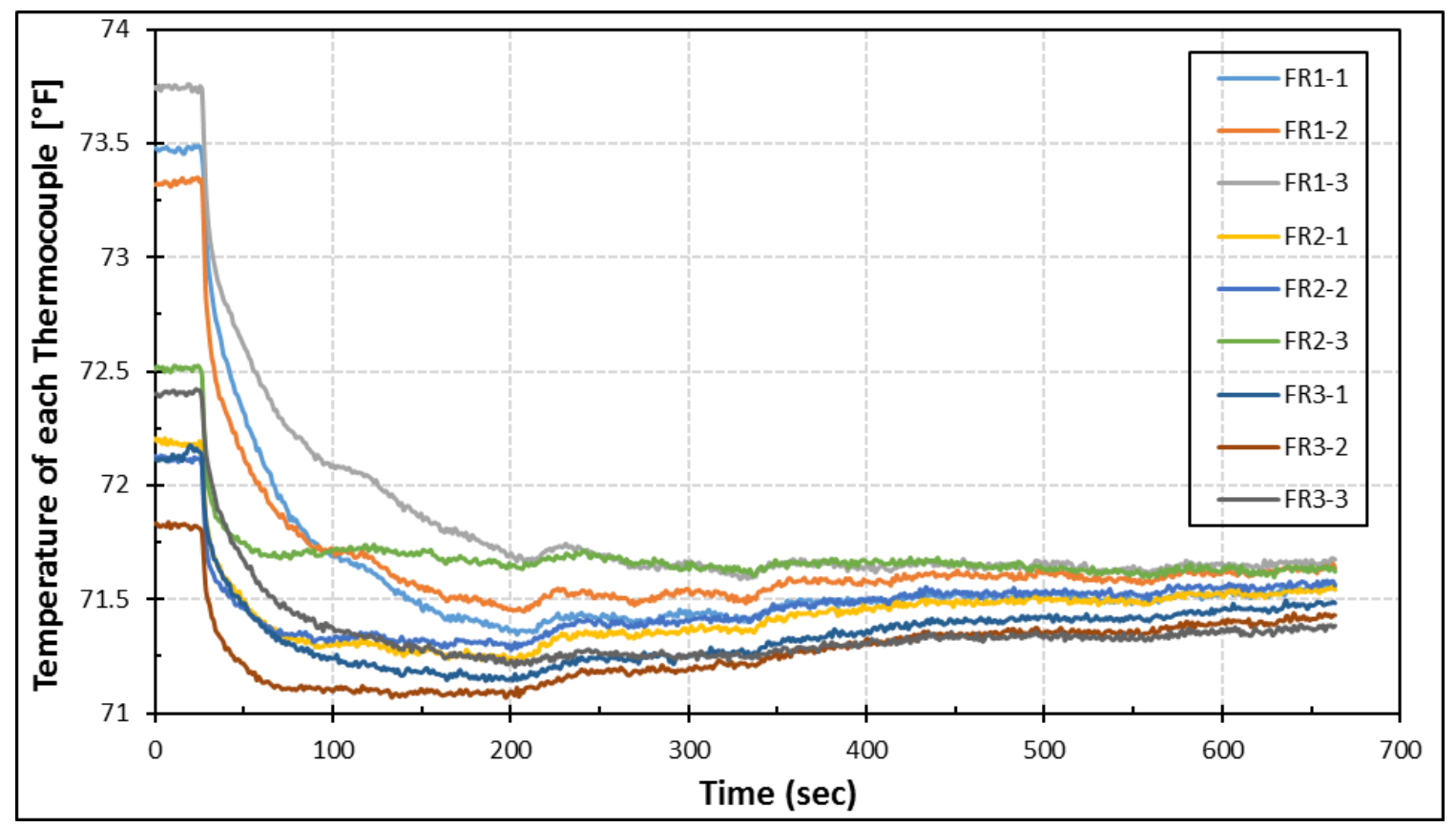

Figure 18. Air Inlet Temperature Sensors Stability Check 
After the stability check, the readings from the manual readers for airflow, pressure drop across test unit and water flow rate measurements were recorded as initial readings. At each reading, three sample readings have collected with an interval of 5 seconds.

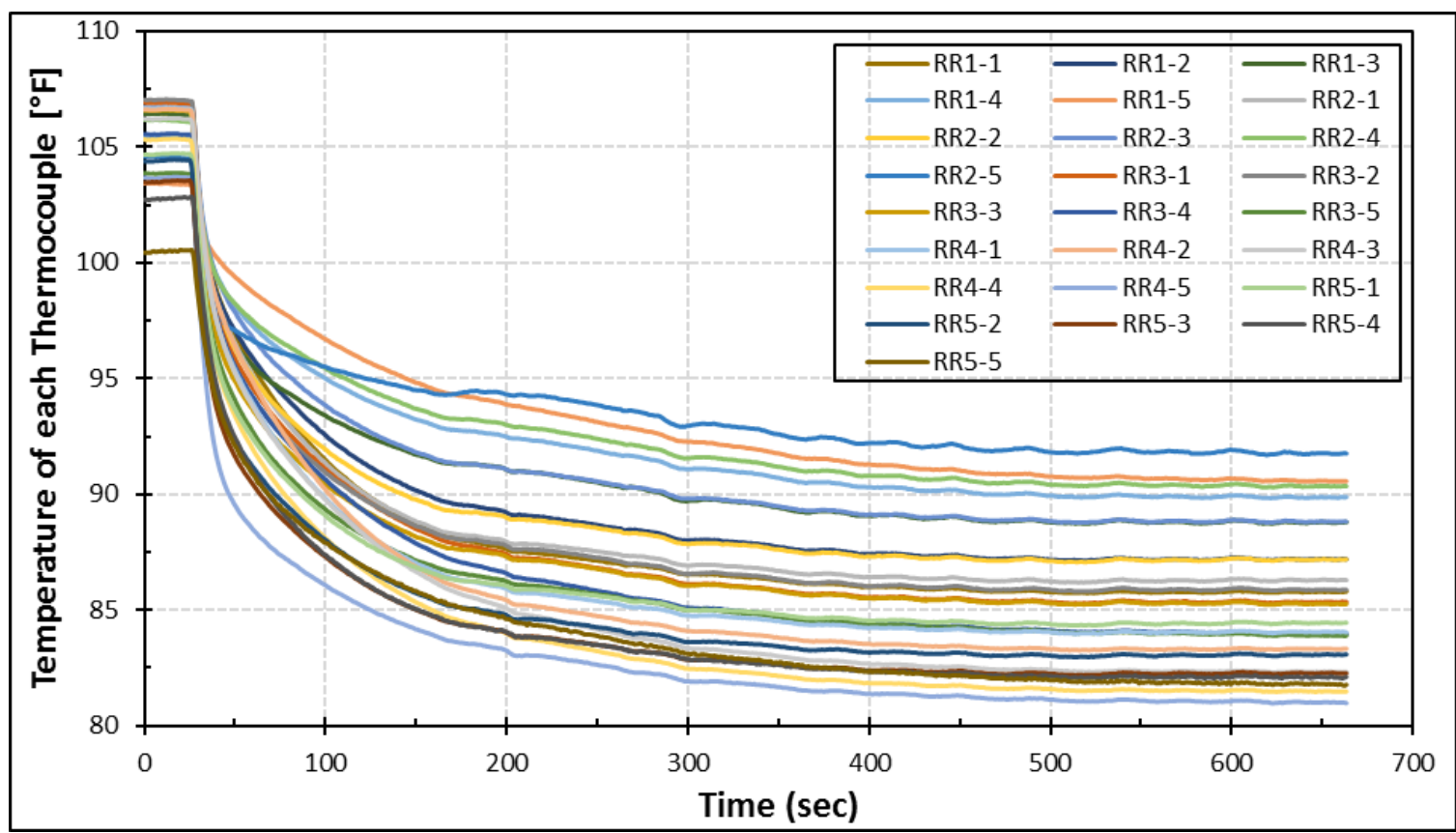

Figure 19. Air Outlet Temperature Sens ors Stability Check

This data recording procedure for the manual readings from the readers is kept constant throughout the experimentation for all of the test samples. Then the test run was initiated by maintaining the test conditions constant for the entire test run. The readings from the manual readers were recorded every 5 minutes from the start to end of the test run. The inlet and outlet temperatures on both airside as well as waterside were recorded and monitored through a data acquisition system. Using data acquisition system data have been registered for thirty-minute test time with a 1.1-second interval. 


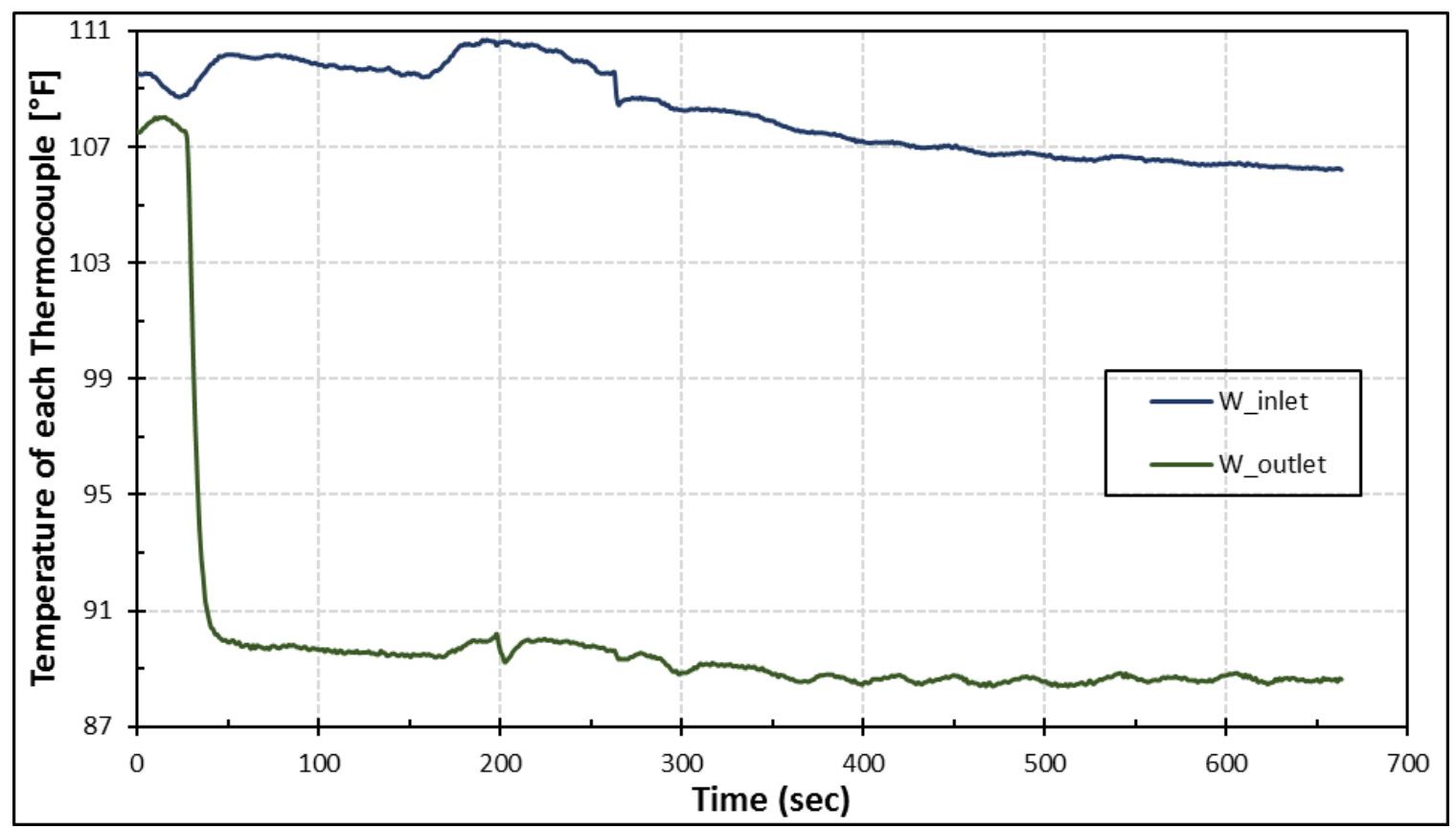

Figure 20. Water Inlet and Outlet Temperature Sensors Stability Check

Final averaged values obtained for each measurement of temperature as well as pressure drop was used for further data reduction. After the end of each successful test run, the air stream in the wind tunnel was set to the next desired test condition. Again the stability check was performed, and the process was repeated. Test runs were conducted for the range of airstreams on venturi meter side as well as on orifice meter side to cover the range of Reynolds numbers ranging from 25 to 200. For each sample test, the measurements were recorded with an interval of 10 was used for the Reynolds number ranging from 25 to 75 , and with an interval of 25 for the rest of the measurements.

While conducting the test run, only one side of air flow stream was used at a time, either venturi side or an orifice side, whereas the remaining side was sealed tight for any air leaks. The procedure was repeated from the very beginning till the end for every newly installed test sample stepwise. 
For each sample's test, the procedures can be divided into the following seven steps:

1. Water pre-heating: The water in the storage tank is first pre-heated to about $80^{\circ} \mathrm{C}$. This water process usually takes about an hour.

2. Water pump is turned on to circulate the water through the heat exchanger.

3. Fan-motor unit is turned on to move the airflow in the wind tunnel.

4. The control valve is adjusted to achieve the desired air flow rates.

5. Let the system stabilize for about $15-30 \mathrm{~min}$. This is monitored by the data acquisition system to ensure the curves of temperature and pressure vs. time are flatting or no noticeable change

6. Repeat step $4 \& 5$ for another air flow rate until the collection of all data points. Depending on the flow rates, either venturi or orifice flow meter will be used.

7. Save data ad turn off the system.

At least ten minutes of steady state data is required to ensure steady data logging conditions. Stability in the heat exchanger inlet fluid temperature measurement of around $0.02{ }^{\circ} \mathrm{C}$ per minute of sample also means a standard deviation, as suggested by EPRI TR107397 (1998).

Data were recorded for thirty-minute test time with 1.1 -second interval. Final average values obtained for each temperature as well as pressure drop measurement are used for further data reduction using the procedures to be described in the chapter "Data Reduction".

Fiberglass material was used to insulate the wind tunnel. The energy balance between the water side and the air side was less than 5\% in most of the experiments (over 90\%). At very low Reynolds numbers $\left(\operatorname{Re}_{\mathrm{Lp}}<50\right)$, the maximum heat balance is less than $10-15 \%$ 


\section{CHAPTER 3 : DATA REDUCTION AND EXPERIMENTAL VERIFICATION}

This chapter discusses the data reduction for the performance parameters and verification of the experimental measurements, in details. The heat transfer performance was evaluated over various fin geometries, and tube arrays, thermo-physical characteristics of hot and cold fluids i.e. water and air respectively, and flow conditions. The heat transfer rate of the microchannel heat exchanger was computed using the enthalpy method, for both air and waterside. Airside heat transfers coefficient was obtained using the effectiveness NTU method. The airside heat transfer and pressure drop characteristics are presented in terms of Colburn- $\mathrm{j}$ factor and friction- $\mathrm{f}$ factor respectively. Air properties are calculated based on ASHRAE Fundamentals Handbook (2013). These methods of estimating the heat transfer and pressure drop characteristics will be discussed in more detail later in this chapter. In the last section of the chapter experimental verification is provided.

\subsection{FLUID PROPERTIES CALCULATIONS}

\subsubsection{Bulk Mean Temperatures}

Bulk mean temperatures i.e. arithmetic mean of the inlet and outlet temperatures are used to evaluate the fluid properties.

\subsubsection{Water Bulk Mean Temperature}

The water bulk mean temperature is calculated using Equation (1).

$$
T_{i m}=\frac{T_{i 1}+T_{i 2}}{2}
$$




\subsubsection{Air Bulk Mean Temperature}

Air bulk mean temperature is calculated using Equation (2).

$T_{o m}=\frac{T_{o 1}+T_{o 2}}{2}$

where,

$T_{o 1}=\frac{\sum_{1}^{9} T_{F i}}{9}$

$T_{o 2}=\frac{\sum_{1}^{25} T_{R i}}{25}$

\subsubsection{Wall Bulk Mean Temperature}

Wall bulk mean temperature is calculated using Equation (5).

$T_{w m}=\frac{T_{i m}+T_{o m}}{2}$

\subsubsection{Densities}

\subsubsection{Water Density}

The temperature-dependent water density is estimated using Equation (6) as shown below.

$$
\rho_{i}=1000-0.0178\left|T_{i m}\left({ }^{\circ} \mathrm{C}\right)-4\left({ }^{\circ} \mathrm{C}\right)\right|^{1.7}
$$

\subsubsection{Air Density}

Ideal gas law is used to estimate the temperature dependent air density at atmospheric pressure as shown in Equation (7). 


$$
\rho_{o}=\frac{P}{R T_{o m}}
$$

\subsubsection{Dynamic Viscosities}

Temperature dependent dynamic viscosity of water and air are estimated using the Equations (8) and (9) respectively.

$$
\begin{aligned}
& \mu_{i}=0.001788 e^{\left(-1.704-5.306\left(\frac{273 K}{T_{i m} K}\right)+7.003\left(\frac{273 K}{T_{i m} K}\right)^{2}\right)} \\
& \mu_{o}=1.71 \times 10^{-5}\left(\frac{T_{o m} K}{273 K}\right)^{0.7}
\end{aligned}
$$

\subsubsection{Specific Heat}

Temperature dependent specific heat of water and air are estimated using the Equations (10) and (11) respectively.

$$
\begin{aligned}
& C_{p_{i}}=(1000 / 18.02)\left(92.053-0.039953 T_{i m}-.00021103 T_{i m}{ }^{2}\right. \\
&+\left.5.3469 \times 10^{-7} T_{i m}{ }^{3}\right) \\
& C_{p_{o}}=\frac{8.314}{28.97}( 3.653-1.337 \times 10^{-3} T_{o m}+3.294 \times 10^{-6} T_{o m}{ }^{2}-1.913 \\
&\left.\times 10^{-9} T_{o m}{ }^{3}+0.2763 \times 10^{-12} T_{o m}{ }^{4}\right)
\end{aligned}
$$

\subsubsection{Thermal Conductivities}

Temperature dependent thermal conductivity of water and air are estimated using the Equations (12) and (13) respectively. 


$$
\begin{aligned}
& k_{i}=\left(-0.2758+0.004612 T_{i m}-5.5391 \times 10^{-6} T_{i m}{ }^{2}\right) \\
& k_{o}=\frac{2.495 \times 10^{-3} T_{o m}{ }^{3 / 2}}{194 K+T_{o m}}
\end{aligned}
$$

\subsubsection{Test Sample Thermal Conductivity}

Wall thermal resistance is taken into account to estimate the airside overall heat transfer coefficient, which depends on the thermal conductivity of the wall material. All the samples tested throughout the experimentation are made of Aluminum. Therefore, the temperature dependent thermal conductivity of Aluminum is estimated using the Equation (14).

$$
k_{w}=\left(228.2103+0.0578 T_{w m}-8.6806 \times 10^{-5} T_{w m}{ }^{2}\right)
$$

\subsection{DIMENSIONLESS PARAMETERS CALCULATIONS}

\subsubsection{Reynolds Number}

Waterside Reynolds number is evaluated based on water properties, velocity through the tubes and tube side hydraulic diameter $D_{h_{i}}$ as shown in Equation (15).

$$
R e_{D_{h}, i}=\frac{\rho_{i} V_{i} D_{h_{i}}}{\mu_{i}}
$$

Airside Reynolds number is evaluated based on air properties, the minimum free flow velocity of air and the Louver pitch of the fin as shown in Equation (16).

$$
R e_{L_{P}}=\frac{\rho V_{c} L_{P}}{\mu}
$$




\subsubsection{Prandtl Number}

The fluid properties dependent Prandtl number for water and air are as shown in Equations (17) and (18) respectively.

$$
\begin{aligned}
& \operatorname{Pr}_{i}=\frac{\mu_{i} C_{p_{i}}}{k_{i}} \\
& \operatorname{Pr}_{o}=\frac{\mu_{o} C_{p_{o}}}{k_{o}}
\end{aligned}
$$

\subsection{REDUCTION OF MEASUREMENT DATA}

As mentioned earlier, the data reduction in the experiment is mainly to investigate the heat transfer and pressure drop performance of the microchannel heat exchangers. Several parameters used, needs to be estimated, i.e. mass flow rate, heat transfer rate, and overall heat transfer coefficient.

\subsubsection{Air Flow Rate Calculation}

Air mass flow rate is calculated using air volumetric flow rate utilizing two measuring meters Orifice meter and Venturi meter as mentioned earlier. The static pressure difference measured across the respective air flow meter was used to estimate the volumetric airflow rate.

\subsubsection{Orifice Meter}

The volumetric flow rate through the orifice meter in the experiment was calculated using the Equation (19) as a function of measured static pressure difference across the orifice $\left(\Delta P_{\text {ori }}\right)$ installed in the tunnel. 
$\dot{Q}_{o}=K_{o r i} * A_{2} * \sqrt{2 * \Delta P_{o r i} / \rho_{o m}}$

The Flow coefficient $\left(K_{\text {ori }}\right)$ is a function of discharge coefficient $\left(C_{\text {ori }}\right)$ and the Beta ratio of the orifice $\left(\beta_{\text {ori }}\right)$ as seen in Equation (20). Whereas, the Beta ratio of the orifice is the ratio of the orifice bore diameter to the duct inside diameter as seen in Equation (21).

$$
\begin{aligned}
& K_{\text {ori }}=C_{d, \text { ori }} / \sqrt{1-\beta_{\text {ori }}^{4}}=\frac{0.6011}{\sqrt{1-0.3^{4}}}=0.60355 \\
& \beta_{\text {ori }}=d / D=\frac{0.09144}{0.3048}=0.3
\end{aligned}
$$

\subsubsection{Venturi Meter}

The volumetric flow rate as a function of measured static pressure difference through the venturi meter $\left(\Delta P_{\mathrm{ven}}\right)$ installed in the tunnel was estimated using the Equation (22).

$$
\dot{Q}_{o}=K_{v e n} * A_{2} * \sqrt{2 * \Delta P_{v e n} / \rho_{o m}}
$$

The venturi meter Flow coefficient $\left(K_{v e n}\right)$ is a function of discharge coefficient $\left(C_{v e n}\right)$ and the Beta ratio of the venturi meter $\left(\beta_{v e n}\right)$ as seen in Equation (23). Whereas, the Beta ratio of the venturi meter is the ratio of the venturi throat diameter to the duct inside diameter as seen in Equation (24).

$$
\begin{aligned}
& K_{\text {ven }}=C_{d, v e n} / \sqrt{1-\beta_{\text {ven }}{ }^{4}}=\frac{0.985}{\sqrt{1-0.723^{4}}}=1.152 \\
& \beta_{\text {ven }}=d / D=\frac{0.219456}{0.3048}=0.72
\end{aligned}
$$

The mass flow rate $\left(\dot{m}_{o}\right)$ is calculated by using the volumetric flow rate $\left(\dot{Q}_{o}\right)$ and air density at bulk mean temperature $\left(\rho_{o m}\right)$ as shown in Equation (25).

$$
\dot{m}_{o}=\dot{Q}_{o} * \rho_{o m}
$$




\subsubsection{Water Flow Rate Calculation}

The waterside mass flow rate $\left(\dot{m}_{l}\right)$ is calculated by using the measured volumetric flow rate $\left(\dot{Q}_{i}\right)$ of water and water density at bulk mean temperature $\left(\rho_{i m}\right)$ as shown in Equation (26).

$\dot{m}_{\iota}=\dot{Q}_{i} * \rho_{i m}$

\subsubsection{Heat Transfer Rate Calculation Using Enthalpy Method}

The heat transfer rate on waterside as well as airside was calculated for the test sample through enthalpy method as shown in Equation (27) and (28) respectively.

$$
\begin{aligned}
& \dot{q}_{o}=\dot{m}_{o} c_{p, o} \Delta T_{o} \\
& \dot{q}_{i}=\dot{m}_{\iota} c_{p, i} \Delta T_{i}
\end{aligned}
$$

Average values of measurement variables, airside inlet, and outlet temperatures, and waterside inlet and outlet temperatures, are used for the calculation of $\dot{\mathrm{q}}_{\mathrm{o}}$ and $\dot{\mathrm{q}}_{\mathrm{i}}$. The mathematical average of $\dot{\mathrm{q}}_{\mathrm{o}}$ and $\dot{\mathrm{q}}_{\mathrm{i}}$ is used to calculate airside heat transfer coefficient.

$$
\dot{\mathrm{q}}_{\mathrm{avg}}=\frac{\left(\dot{\mathrm{q}}_{\mathrm{o}}+\dot{\mathrm{q}}_{\mathrm{i}}\right)}{2}
$$

The heat exchanger effectiveness was calculated using maximum possible heat transfer from the heat exchanger based upon hot water and cold air heat exchange system.

$$
\dot{\mathrm{q}}_{\max }=\mathrm{C}_{\min }\left(\mathrm{T}_{\mathrm{i} 1}-\mathrm{T}_{\mathrm{o} 1}\right)
$$

where,

$$
\begin{aligned}
& C_{\text {min }}=\dot{m}_{\iota} c_{p, i} \text { if } \dot{m}_{\iota} c_{p, i}<m_{o} c_{p, o} \\
& C_{\text {min }}=\dot{m}_{o} c_{p, o} \text { if } \dot{m_{o}} c_{p, o}<m_{\iota} c_{p, i}
\end{aligned}
$$




\subsubsection{Heat Transfer Coefficient Calculation}

\subsubsection{Overall Heat Transfer Calculation Using Effectiveness-NTU method}

To provide heat transfer characteristics of test samples; Effectiveness-NTU method is used to determine the airside overall heat transfer, UA (Incroprea and DeWitt (2000)). The $U A$ product was calculated using the effectiveness- $N T U$ method for both streams unmixed

cross-flow arrangement. Approximate expression for effectiveness- $N T U$ is (McQuiston et al. (2005)):

$$
\varepsilon=1-\exp \left[\frac{N T U^{0.22}}{C_{r}}\left\{\exp \left(-C_{r} N T U^{0.78}\right)-1\right\}\right]
$$

where,

$$
\begin{aligned}
& \varepsilon=\frac{\dot{q}_{a v g}}{\dot{q}_{\text {max }}} \\
& C_{r}=\frac{C_{\text {min }}}{C_{\text {max }}} \\
& U A=C_{\text {min }} N T U
\end{aligned}
$$

\subsubsection{Waterside Heat Transfer Coefficient}

For the turbulent flow of water inside the flat tubes, the Dittus-Boelter equation (Incroprea and DeWitt (2000)) is adopted.

$$
h_{i}=\left(\frac{k_{i}}{D_{h_{i}}}\right) 0.023\left(R e_{D_{h}, i}\right)^{0.8}\left(P r_{i}\right)^{n}
$$

where,

$$
\begin{aligned}
& n=0.3 \text { for } T_{\text {wall }}<T_{\text {bulk }} \\
& n=0.4 \text { for } T_{\text {bulk }}<T_{\text {wall }}
\end{aligned}
$$


The overall surface effectiveness $\left(\varepsilon_{s}\right)$ can be evaluated using equation (38).

$\varepsilon_{s}=1-\frac{A_{f}}{A_{o}}\left(1-\eta_{f}\right)$

where,

$A_{o}=A_{b}+A_{f}$

$\eta_{f}=\frac{\tanh \left(m l_{f}\right)}{m l_{f}}$

The fin efficiency is determined using the method defined in Kays \& London (1984).

$$
\begin{aligned}
& m=\sqrt{\frac{2 h_{o}}{k_{f} \delta_{f}}\left(1+\frac{\delta_{f}}{f_{d}}\right)} \\
& l_{f}=\frac{H}{2}-\delta_{f}
\end{aligned}
$$

\subsubsection{Airside Heat Transfer Coefficient}

Assuming zero waterside fouling resistance; airside heat transfer coefficient was calculated by subtracting the water-side and wall resistances from the total thermal resistance. Therefore,

$$
\frac{1}{\varepsilon_{s} h_{o} A_{o}}=\frac{1}{U A}-\frac{1}{h_{i} A_{i}}+\frac{\delta_{w}}{k_{w} A_{w}}
$$

Solving equation (25) for $h_{o}$ yields

$$
h_{o}=\frac{1}{\varepsilon_{s} A_{o}}\left(\frac{1}{U A}-\frac{1}{h_{i} A_{i}}+\frac{\delta_{w}}{k_{w} A_{w}}\right)^{-1}
$$




\subsubsection{Colburn j-factor}

The airside heat transfer characteristic is presented in the form of Colburn $\mathrm{j}$-factor and can be calculated as follows:

$$
j=\frac{h_{o}}{G_{c} c_{p, o}} P r_{o}{ }^{2 / 3}
$$

where,

$$
G_{c}=\rho_{o m} V_{c}
$$

\subsubsection{Fanning Friction f-factor}

Pressure drop equation described by Kays and London (1984), is used to calculate the heat exchanger core Fanning friction factor as follows:

$$
\begin{gathered}
f=\frac{A_{c}}{A_{o}} \frac{\rho_{o m}}{\rho_{o 1}}\left[\frac{2 \rho_{o 1} \Delta P}{G_{c}{ }^{2}}-\left(K_{c}+1-\sigma^{2}\right)-2\left(\frac{\rho_{o 1}}{\rho_{o 2}}-1\right)\right. \\
\left.+\left(1-\sigma^{2}-K_{e}\right) \frac{\rho_{o 1}}{\rho_{o 2}}\right]
\end{gathered}
$$

The entrance and exit loss coefficients $\left(\mathrm{K}_{\mathrm{c}}\right.$ and $\left.\mathrm{K}_{\mathrm{e}}\right)$ were evaluated for triangular ducts at $\operatorname{Re}_{\mathrm{D}_{\mathrm{h}}}=\infty$ from Kays and London (1984).

\subsection{EXPERIMENTAL VERIFICATION}

The verifications on the instrumentation accuracy, signal processing, and data recording were conducted through three steps. The first step was performing air-side thermocouple calibrations. Additionally, the tests were used to estimate the total thermal 
resistance and the heat losses (heat gain) employed in the measurement of the heat transfer rate as explained in the previous chapter.

The second step of experimental validation was the heat balance tests and the radiation losses. These tests were performed on all of the test samples and were intended to verify that the heat transfer measured by the enthalpy method on the air-side as well as water-side was the same. Whereas, the third step of experimental validation was the repeatability tests. The repeatability tests were performed on two heat exchanger samples. These tests were intended to verify the stability of the test facility and i the instruments utilized during the course of the study.

\subsubsection{Thermocouple Calibration}

Thermocouple connections to the DAQ system and further to the computer is explained in Chapter 2. A similar setup was used to record the thermocouple readings and then compared with the NIST Traceable blue spirited precision thermometer of the range -1 to $101^{\circ} \mathrm{C}$, and the accuracy of $0.1^{\circ} \mathrm{C}$. The schematic of the experimental setup for the calibration is as shown in Figure 21. The reference temperatures were maintained at room temperature, and temperatures around $40^{\circ} \mathrm{C}$ and $80^{\circ} \mathrm{C}$, for the calibration testings. This range of reference temperatures (from room temperature to $80^{\circ} \mathrm{C}$ ) was considered because of the apparent estimates of the variations in the measurements of air temperature measurements during the experimentation at standard atmospheric conditions. As per the documentations of the National Instruments NI9211, and NI9213 thermocouple modules, the modules by themselves incorporate the cold junction compensation, eliminating the 
variations in the measurement during the experiments caused by the drifts in the surrounding temperature.

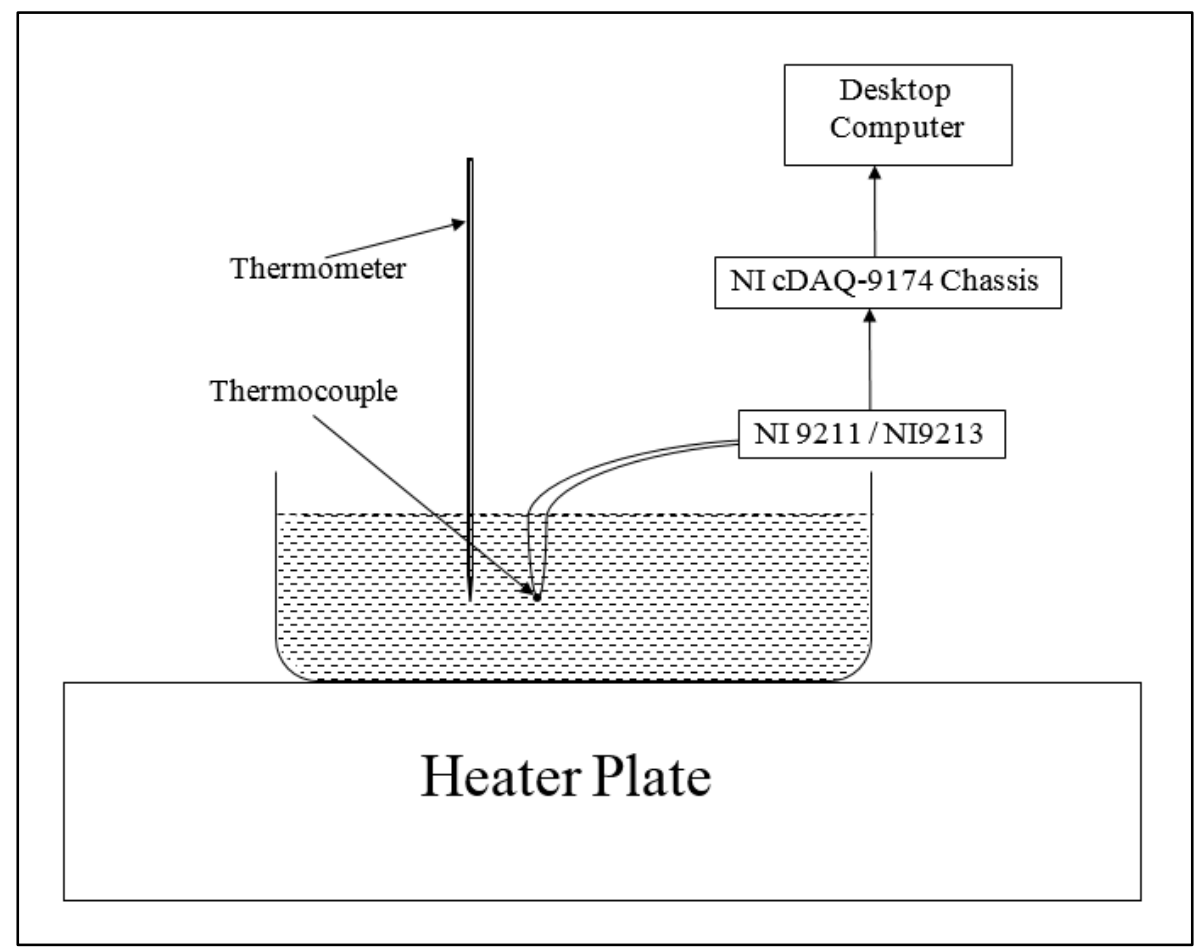

Figure 21. Sche matic of Calibration Setup

Figure 22 and Figure 24 shows the calibration results for all the thermocouple sensors used for the air temperature measurement at inlet and outlet of the test section. On the other hand, Figure 23 and Figure 25 shows the absolute errors detected in the temperature measurements for the respective thermocouple sensors. The Maximum absolute error is found at the higher temperature of about $80^{\circ} \mathrm{C}$, which is $3.8^{\circ} \mathrm{C}$ in case of $\mathrm{TC} 08$ and $1.32^{\circ} \mathrm{C}$ in case of TC12. From the Figures, it is also seen that the variation in the absolute error decreases with the reduction in the measurement temperature up to about $40^{\circ} \mathrm{C}$. Thereafter slightly increase in the errors are recorded when the measurement temperature declines to room temperature. The average minimum absolute error is found to be about $0.1^{\circ} \mathrm{C}$ at $40^{\circ} \mathrm{C}$ 
inclusive of all thermocouple sensors. During the experimentation, the actual air-side temperatures are measured between $20^{\circ} \mathrm{C}$ and $41^{\circ} \mathrm{C}$ where the absolute errors are at their minimum. The coefficients of equation $\mathrm{b} 0$, and $\mathrm{b} 1$ used to find the actual temperature on air-side.

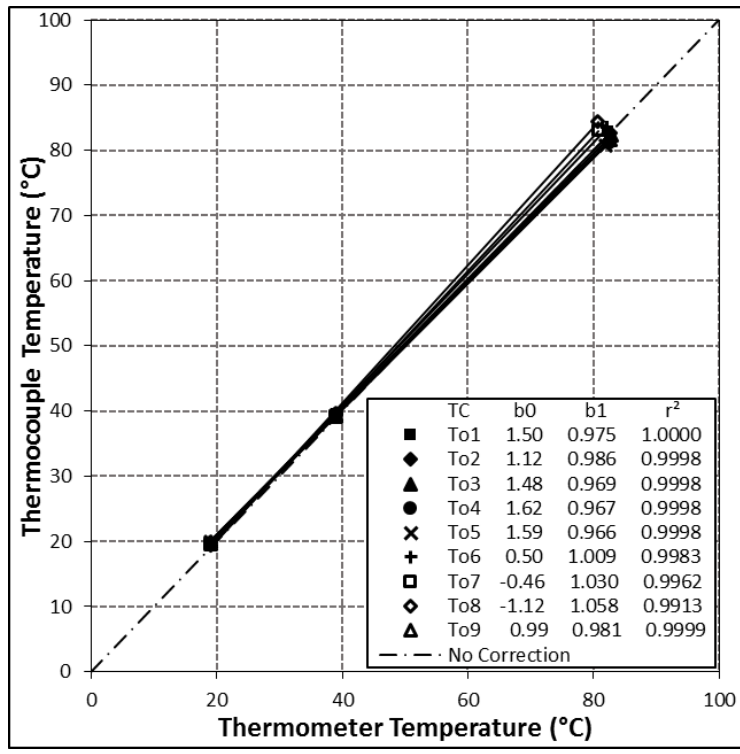

Figure 22. Air-Inlet Calibration Results

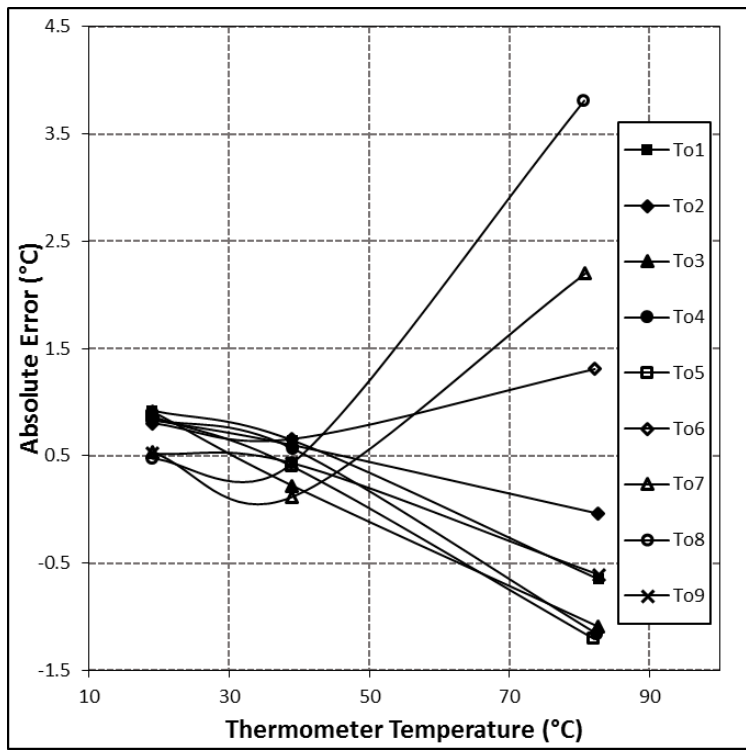

Figure 23. Air-Inlet Calibration Error

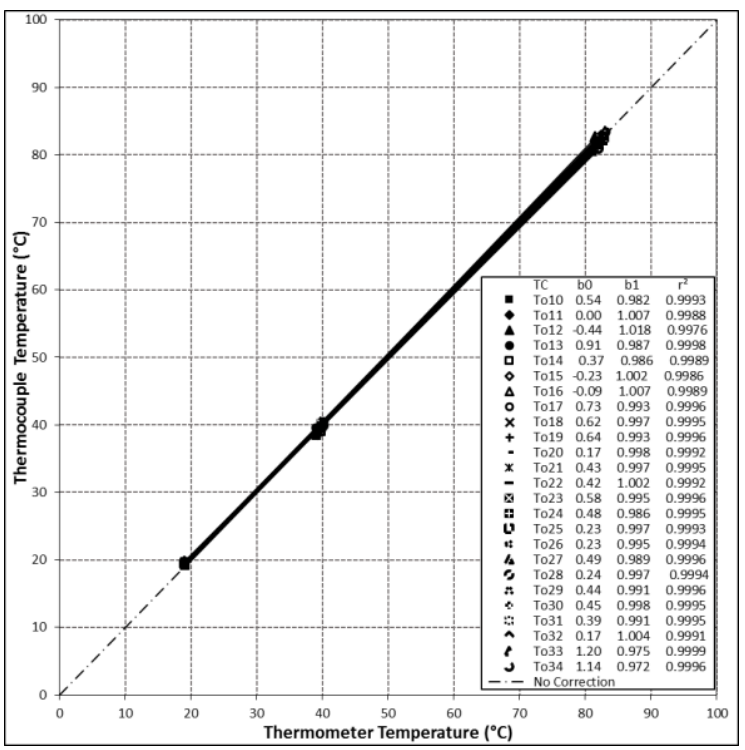

Figure 24. Air-Outlet Calibration Results

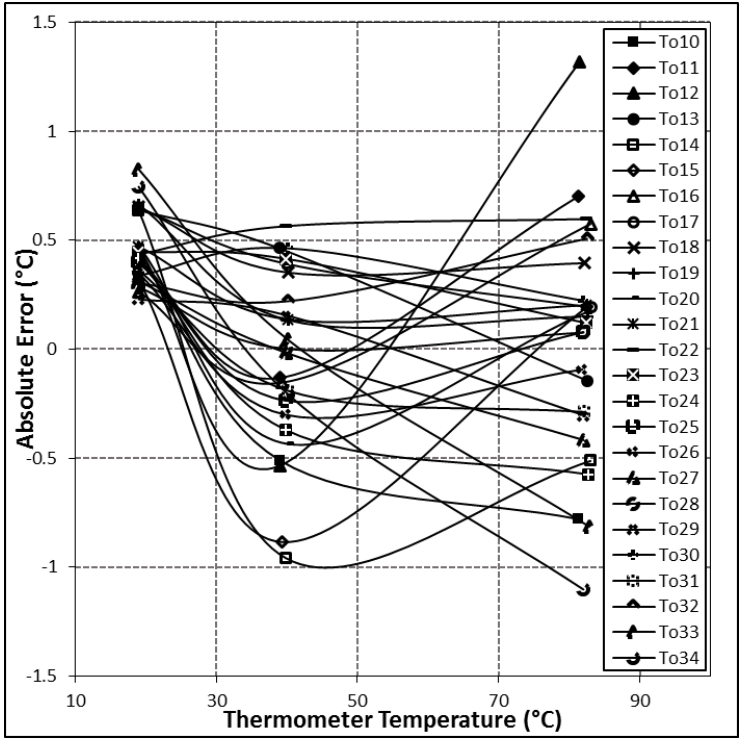

Figure 25. Air-Outlet Calibration Error 
The maximum uncertainty based on precision in the thermocouple calibration is found out to be $0.1^{\circ} \mathrm{C}$ by using the equations from 48 to 50 , as shown below.

$$
\begin{aligned}
& \mathrm{S}_{\mathrm{m}}=\sqrt{\frac{\sum_{k=1}^{N}\left(X_{k}-\bar{X}\right)^{2}}{(N-1)}} \\
& \mathrm{P}_{\mathrm{un}}= \pm 2 \mathrm{~S}_{\mathrm{m}} \\
& W T=\sqrt{\left(\mathrm{P}_{\mathrm{un}}\right)^{2}+\left(\mathrm{B}_{\mathrm{err}}\right)^{2}}
\end{aligned}
$$

For $95 \%$ confidence interval.

\subsubsection{Heat Balance Tests and Radiation Losses}

\subsubsection{Heat Balance Tests}

Heat balance test for the experimental measurement validation is reported on test sample\#3 as an example. The heat balance was calculated using Equation (51) shown below.

$$
\text { Heat Balance }(\%)=\frac{q_{\text {water-side }}-q_{\text {air-side }}}{q_{\text {water-side }}} \times 100 \%
$$

Heat balance test in the early stage of the study is important because it can be used as one of the tool to evaluate the accuracy of heat transfer measurements. By passing hot water through, the test sample was heated and then cooled down by blowing air over it. The air temperature at the inlet of the test sample was kept at the ambient temperature approximately at 18 to $24^{\circ} \mathrm{C}\left(64.4\right.$ to $\left.75.2^{\circ} \mathrm{F}\right)$ by not conditioning the air inside the wind tunnel. Once the test had reached steady state condition, the test was continued for half an hour, recording the data. The heat balance test was conducted on all the samples. The calculation of heat transfer rate for both water-side and air-side are explained in detail in the previous section for data reduction. 


\subsubsection{Thermal Radiation Losses}

The present study of water to air heat transfer comprises water-side convection, wall conduction, and air-side convection. Enthalpy-based heat balance study gives a clear understanding of the losses occurred during the experimentation. The sources of these losses can be from instrumentation, measurement practices, or system generated. To locate and categorize the sources of errors or losses in the experimentations it is important to study the losses due to the radiation in the wind tunnel system. It is also known fact that all the bodies with the temperature greater than absolute zero emit thermal radiation. This makes further investigation of thermal radiation losses imperative. As mentioned in chapter two, the wind tunnel system was insulated externally; therefore, the radiation losses from the outside of the system were neglected. Hence, the thermal radiation between the heat exchanger unit and the internal wall of the wind tunnel apparatus only was considered. Also, due to the complex orientation of the heat exchanger geometrical parameters with respect to the walls of the wind tunnel system, the directional dependence of the radiation was neglected from the study.

Radiation losses test for the experimental measurement validation is reported on test sample\#3 as an example. The radiation losses were calculated using Equation (52) whereas the percentage contribution of the radiation losses was calculated using Equation (53) as shown below.

$$
\begin{aligned}
& q_{r}=\sigma_{\text {stef }} A_{o} \varepsilon_{\text {emiss }}\left(T_{i}^{4}-T_{\text {wall }}{ }^{4}\right) \\
& q_{r}(\%)=\frac{q_{r}}{q_{i}} \times 100 \%
\end{aligned}
$$


The test conditions considered for the thermal radiation modeling are shown in Table 6 below.

Table 6. Heat Balance Test Condition

\begin{tabular}{l|c}
\hline \multicolumn{1}{c|}{ Test Condition } & Set Point \\
\hline$\sigma_{\text {stef }}$ & $5.67 \times 10^{-8} \mathrm{~W} / \mathrm{m}^{2} \mathrm{k}^{4}$ \\
$\varepsilon_{\text {emiss }}$ & 0.255 \\
$T_{i}$ & Water Inlet Temperature \\
$T_{\text {wall }}$ & Air Inlet Temperature \\
\hline
\end{tabular}

\subsubsection{Combined Heat Balance and Thermal Radiation}

Figure 26 below shows the heat balance between the water-side and air-side heat transfer, and the percentage of radiative heat transfer throughout the test. Average value of the heat balance and radiative heat transfer during the test is about $3.3 \%$, and $2.54 \%$ respectively. The experimental uncertainty associated with the water-side and air-side heat transfer found as discussed in the later chapter of uncertainty analysis are $4.2 \%$ and $3.6 \%$ respectively. The radiation losses throughout the experimental study were less than 5\%, whereas the losses due to heat balance were less than $15 \%$.

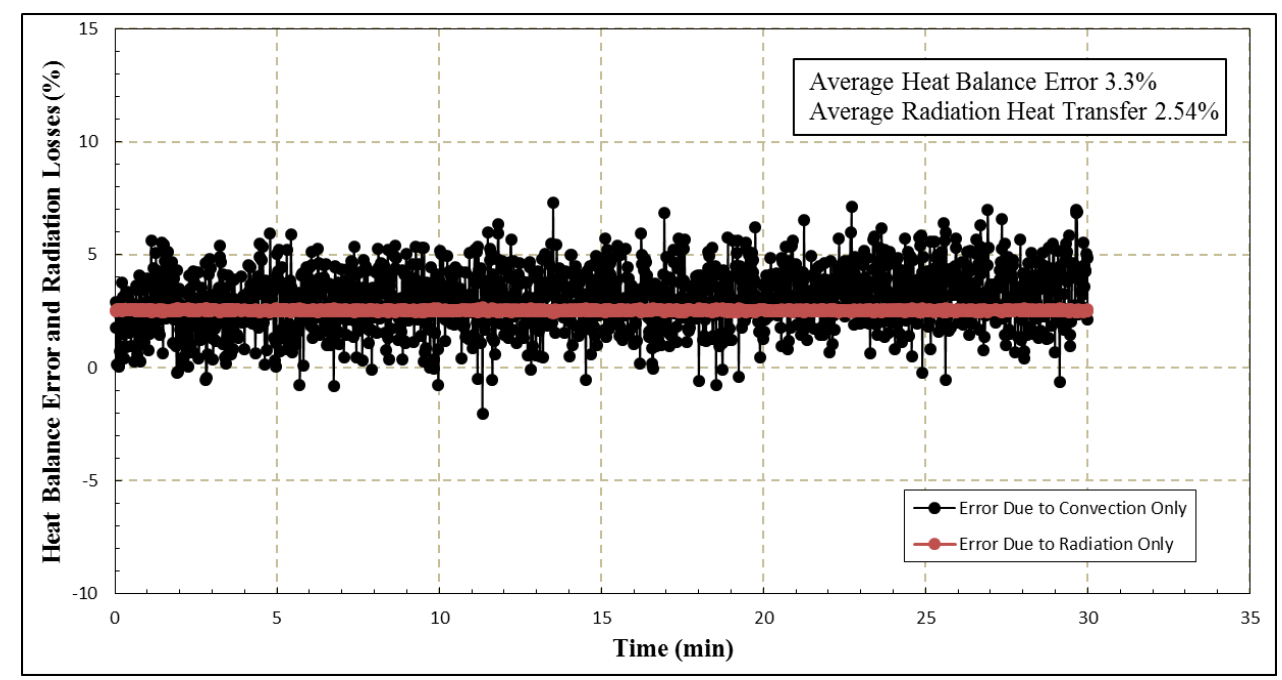

Figure 26. Heat Balance Errors and Radiation Losses 


\subsubsection{Repeatability Tests}

Repeatability tests have conducted at the beginning of experiments and after about every 6 months to verify the wind tunnel test facility's reliability. Figure 27 and Figure 28 show two typical repeatability tests for heat exchanger samples \#1 and \#13, respectively. In each repeatability test, at least 4 times of the same experiments are conducted. As can be seen from the two figures, the repeatability of the experiments has been satisfactory. This provides us confidence in the stability of the test facility and instruments during the course of the study period.

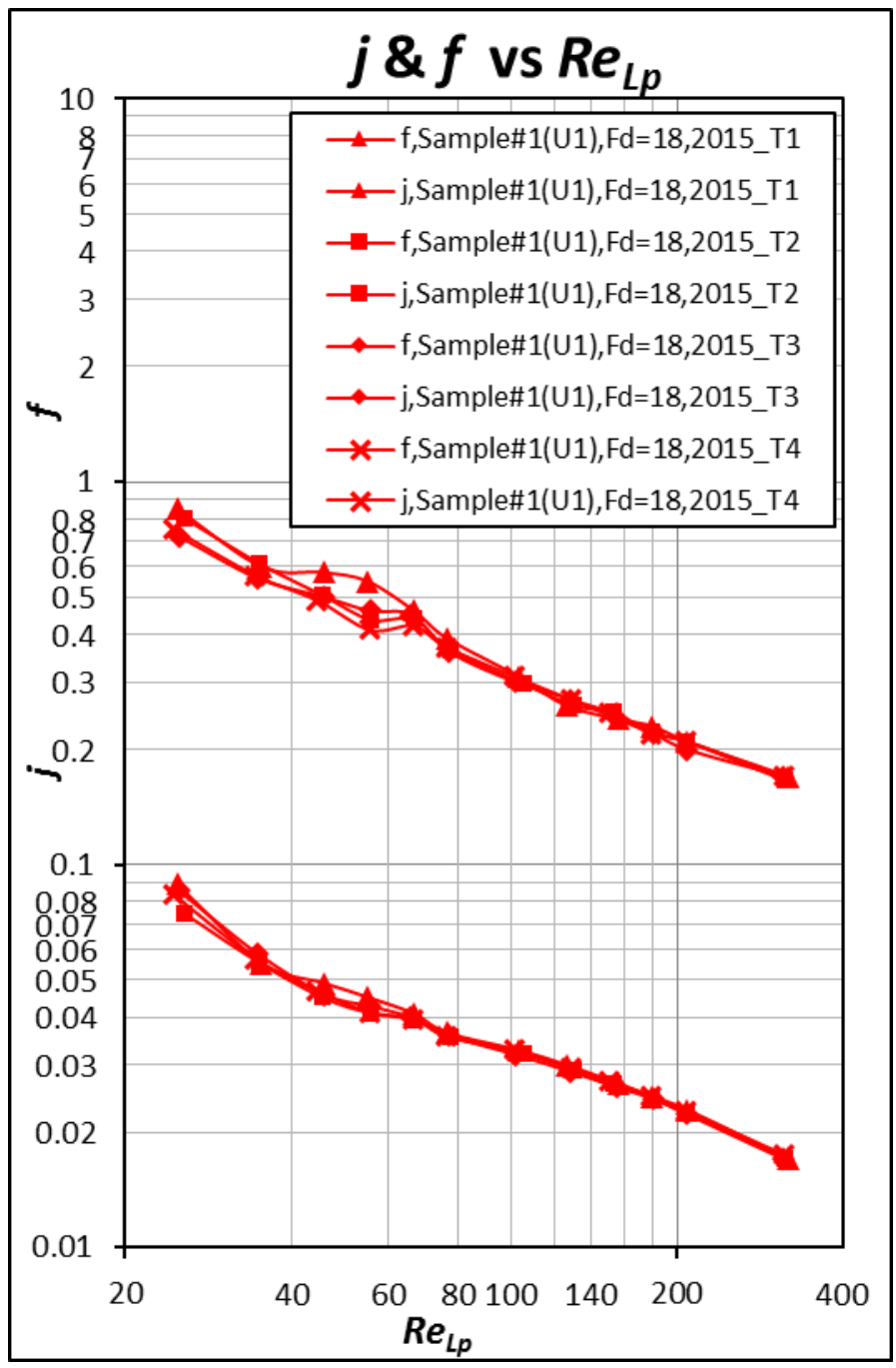

Figure 27. Repeatability Test for Sample \#1 


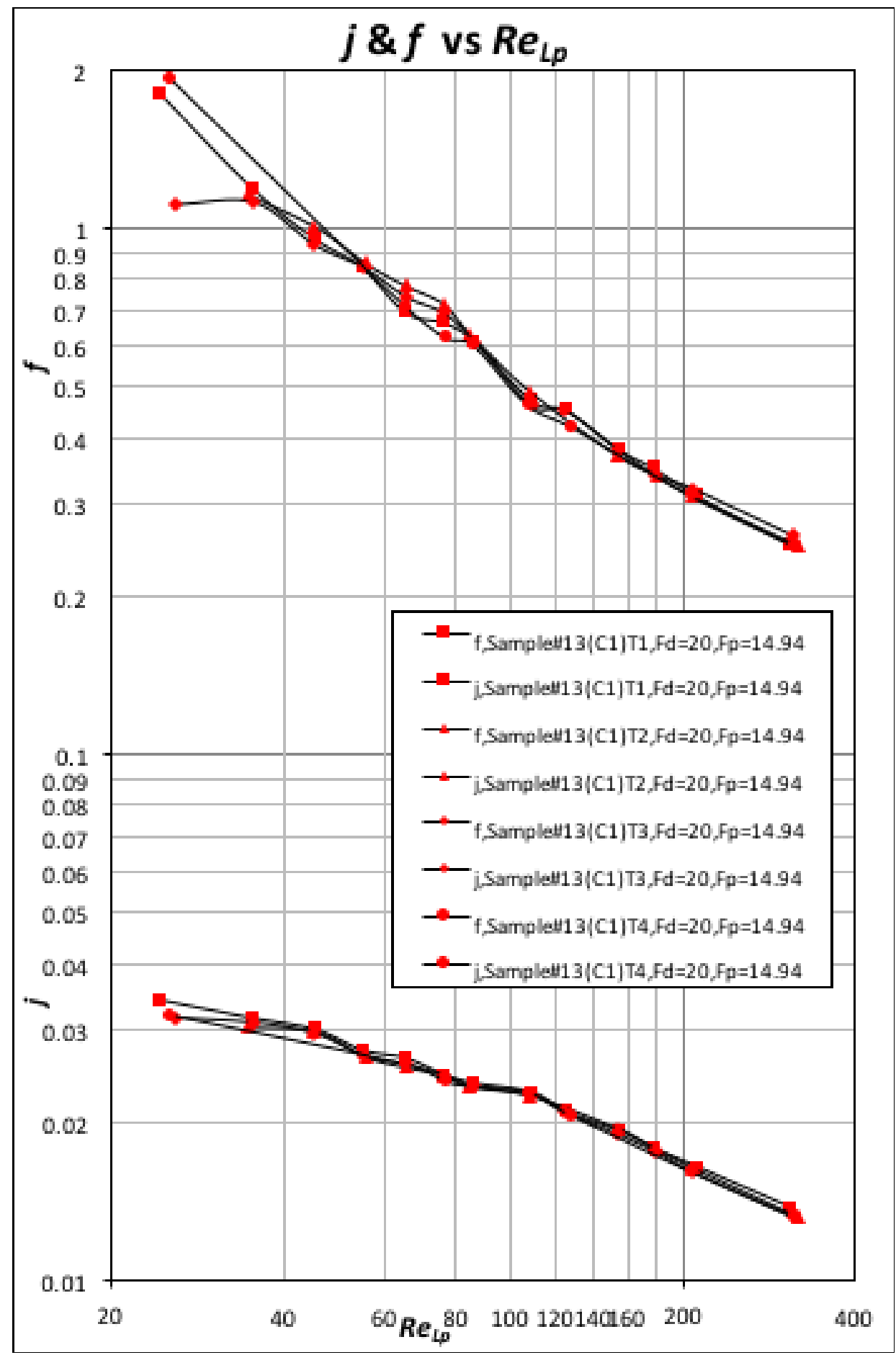

Figure 28. Repeatability test for sample \#13 


\section{CHAPTER 4 : EXPERIMENTAL UNCERTAINTIES}

This chapter describes some of the preliminary uncertainty analyses that were performed during the course of the study. The reported the uncertainty is based on the precision error as suggested in ASHRAE (2013). The report consists of the following principal components: methodology of uncertainty analysis that was used, detailed formulations for calculations, and selected results for a typical microchannel heat exchanger to be tested in the wind tunnel facility for this study. It was estimated that except for extremely low Reynolds numbers $\left(\operatorname{Re}_{\mathrm{Lp}}<45\right)$ or at the lowest end of the instrumental measurement range, most of the uncertainties of the f-factor and j-factor are less than $7.6 \%$ and $11.3 \%$, respectively, under ideal conditions, such as zero heat balance; most of the uncertainties of $\mathrm{f}$ and $\mathrm{j}$ factors are estimated at less than $13.6 \%$ and $16.7 \%$ respectively, when actual test data are used. Experimental uncertainties have been estimated. This chapter discusses the methodology and the results of the uncertainty estimates. Whereas, APPENDIX A provides the step by step formulations of uncertainties for $\mathrm{j}$ and $\mathrm{f}$ factors.

In summary, except for cases at extremely low Reynolds numbers or near the lowest end of the instrumental measurement range, reasonable uncertainties can be obtained for $\mathrm{j}$ and f factors. At ideal conditions, such as zero heat balance, most of the $\mathrm{j}$ and $\mathrm{f}$ factors have uncertainties less than $11.3 \%$ and $7.6 \%$, respectively. Using measurement data, most of the $\mathrm{j}$ and $\mathrm{f}$ factors have uncertainties estimated at less than $16.7 \%$ and $13.6 \%$, respectively.

\subsection{METHOD OF ANALYSIS}

In engineering analysis, the uncertainty is an estimated value for error. Total 
uncertainty could be the result of both the accuracy and the precision errors. According to the ASHRAE guideline (ASHRAE, 1996), the uncertainty is analyzed as a precision error only, since instrumental calibration can suffice the biased errors. Therefore, uncertainties are formulated as the precision errors only in this report, which summarizes some of our preliminary studies. The uncertainty analysis is based on the basic mathematics in Moffat (1988), which provides the following general uncertainty equation that is used widely by engineers and researchers.

For a calculated result $\mathrm{R}$, which is a function of variable $\mathrm{Xi}$,

$$
R=R\left(X_{1}, X_{2}, X_{3}, \ldots \ldots \ldots \ldots . . ., X_{N}\right)
$$

the uncertainty of R, WR, is determined by the following root-sum-square (RSS) method:

$$
W R=\sqrt{\left(\frac{\partial R}{\partial X_{1}} W X_{1}\right)^{2}+\left(\frac{\partial R}{\partial X_{2}} W X_{2}\right)^{2}+\cdots+\left(\frac{\partial R}{\partial X_{N}} W X_{N}\right)^{2}}
$$

If the $\mathrm{R}$ can be expressed in the following format,

$$
R=X_{1}^{a} X_{2}^{b} X_{3}^{c} \ldots \ldots \ldots \ldots X_{N^{n}}^{n}
$$

then the relative uncertainty can be found directly as

$$
\frac{W R}{R}=\sqrt{\left(a \frac{W X_{1}}{X_{1}}\right)^{2}+\left(b \frac{W X_{2}}{X_{2}}\right)^{2}+\cdots+\left(n \frac{W X_{N}}{X_{N}}\right)^{2}}
$$

Please refer to the APPENDIX A for the step by step uncertainty formulation for $\mathrm{j}$ and $\mathrm{f}$ factors from the measurement sources.

\subsection{UNCERTAINTES IN THE EXPERIMENTAL TESTING}

Using the geometrical parameters of a typical microchannel heat exchanger; tested in our wind tunnel facility; an uncertainty analysis was carried out. Table 5 above shows the 
precisions of the installed instruments, used in the uncertainty calculations. Uncertainty estimates also account the heat exchanger sample's manufacturing or geometrical errors.

Table 7 shows the uncertainties at different air-side Reynolds numbers (ReLp) within our experimental range, under the following ideal conditions: the heat is perfectly balanced, and only one flow meter, the venturi, is used. The uncertainty for the $\mathrm{j}$-factor is on order of 11\%. Except at extremely low Reynolds numbers (less than 45), the uncertainty in the ffactor is less than $7.6 \%$.

Table 8 shows the uncertainties for the experimental range when actual measured data recorded with both the orifice and venturi flowmeters. It was estimated that except for very low Reynolds numbers or at the lowest end of the instrumental measurement range, most of the uncertainties of the f-factor and $\mathrm{j}$-factor are less than $13.6 \%$ and $16.7 \%$ respectively.

To provide an overall perspective on the uncertainties associated with microchannel heat exchangers, a comparison with reported uncertainties in literature is given in Table 9.

Table 7. Uncertainties of ReLp, j-factor, and f-factor for a Typical Heat Exchanger ( $(\dot{\mathrm{mi}}=$ $3.4 \mathrm{gpm}, \mathrm{ti1}=60^{\circ} \mathrm{C}$, to $1=20^{\circ} \mathrm{C}$ )

\begin{tabular}{c|c|c|c}
\hline $\boldsymbol{R e}_{L p}$ & $W_{\boldsymbol{R} e_{L p} / \boldsymbol{R e}_{L p}(\%)}$ & $\boldsymbol{W} \mathbf{j} / \mathbf{j}(\%)$ & $\boldsymbol{W} \boldsymbol{f} / \boldsymbol{f}(\%)$ \\
\hline 25 & 11.45 & 11.48 & 20.02 \\
35 & 11.34 & 11.25 & 10.70 \\
45 & 11.30 & 11.16 & 7.57 \\
50 & 11.29 & 11.14 & 6.77 \\
76 & 11.26 & 11.08 & 5.32 \\
100 & 11.25 & 11.06 & 5.05 \\
125 & 11.24 & 11.05 & 4.97 \\
150 & 11.24 & 11.04 & 4.94 \\
161 & 11.24 & 11.04 & 4.94 \\
175 & 11.24 & 11.04 & 4.93 \\
184 & 11.24 & 11.04 & 4.93 \\
200 & 11.24 & 11.04 & 4.93 \\
\hline
\end{tabular}


Table 8. Uncertainties of ReLp, j-factor, and f-factor for a Typical Heat Exchanger (Based on Test Data for Sample \#1)

\begin{tabular}{c|c|c|c}
\hline $\boldsymbol{R e}_{L p}$ & $W \boldsymbol{R e}_{L p} / \boldsymbol{R e}_{L p}(\%)$ & $W \boldsymbol{j} / \boldsymbol{j}(\%)$ & $\boldsymbol{W} \boldsymbol{f} / \boldsymbol{f}(\%)$ \\
\hline 24.51 & 11.54 & 11.64 & 42.96 \\
34.39 & 11.31 & 11.19 & 21.85 \\
44.55 & 11.26 & 11.09 & 13.63 \\
55.51 & 11.24 & 11.05 & 9.52 \\
66.6 & 11.24 & 11.04 & 7.55 \\
76.37 & 11.24 & 11.03 & 6.53 \\
101.44 & 18.02 & 22.80 & 5.69 \\
128.55 & 14.30 & 16.70 & 5.26 \\
151.2 & 12.95 & 14.33 & 5.17 \\
179.43 & 11.76 & 12.82 & 5.11 \\
206.80 & 11.24 & 12.09 & 5.10 \\
\hline
\end{tabular}

Table 9. Comparis ons with Uncertainties in Selected Lite rature

\begin{tabular}{|c|c|c|c|c|c|c|}
\hline \multirow{2}{*}{ Author and Year } & \multicolumn{2}{|c|}{$\begin{array}{c}\text { Uncertainty in } \\
\text { j-factor }\end{array}$} & \multicolumn{2}{|c|}{$\begin{array}{c}\text { Uncertainty in } \\
\text { f-factor }\end{array}$} & \multirow{2}{*}{ Data } & \multirow{2}{*}{$\begin{array}{c}\text { Reynolds } \\
\text { Number } \\
\text { Range }\end{array}$} \\
\hline & $\begin{array}{c} \pm \text { Min } \\
(\%)\end{array}$ & $\begin{array}{c} \pm \operatorname{Max} \\
(\%)\end{array}$ & $\begin{array}{c} \pm \text { Min } \\
(\%)\end{array}$ & $\begin{array}{c} \pm \operatorname{Max} \\
(\%)\end{array}$ & & \\
\hline \multirow{2}{*}{ Our Estimate } & 11.03 & 11.48 & 4.92 & 20.02 & Ideal & \multirow{2}{*}{$\operatorname{Re}_{\mathrm{Lp}}: 50-200$} \\
\hline & 11.03 & 16.70 & 5.10 & 13.63 & Actual & \\
\hline $\begin{array}{l}\text { Chang et al. } \\
\text { (1994) }\end{array}$ & 5.3 & 9.2 & 6.6 & 12.2 & & $\operatorname{Re}_{L p}: 200-1600$ \\
\hline $\begin{array}{l}\text { Xiaokui Ma et al. } \\
\text { (2007) }\end{array}$ & 6.9 & 10.2 & 3.7 & 9.4 & & $\operatorname{Re}_{\mathrm{Dc}}: 400-4500$ \\
\hline Dong et al. (2007) & \multicolumn{2}{|c|}{9.6} & \multicolumn{2}{|c|}{8.4} & & $\operatorname{Re}_{\mathrm{Lp}}: 200-2500$ \\
\hline $\begin{array}{l}\text { Kim and Bullard } \\
\text { (2002) }\end{array}$ & \multicolumn{2}{|c|}{12.5} & \multicolumn{2}{|c|}{10} & & $\operatorname{Re}_{L p}: 80-300$ \\
\hline $\begin{array}{l}\text { Kim and Bullard } \\
(2002)\end{array}$ & \multicolumn{2}{|c|}{12} & \multicolumn{2}{|c|}{10} & & $\operatorname{Re}_{L p}: 100-600$ \\
\hline $\begin{array}{l}\text { Wei Li et al. } \\
\text { (2010) }\end{array}$ & \multicolumn{2}{|c|}{9.6} & \multicolumn{2}{|c|}{8.4} & & $\operatorname{Re}_{L p}: 400-1600$ \\
\hline
\end{tabular}

\subsection{UNCERTAITIES IN $R e_{L P}, j$-factor, AND $f$-factor}

Table 10 shows the required input in finding the uncertainty for Reynolds number of 25 along with the relative uncertainty in Reynolds number in percentage. Figure 29 
demonstrates the result of this sample calculation. In the case of finding total uncertainty in an individual variable such as temperature and pressure, precision in the measurement and instrumental accuracy added together by the root-sum-square method.

Table 10. Sample Uncertainty Calculation Data

\begin{tabular}{|c|c|c|c|c|c|c|c|c|}
\hline $\operatorname{Re}_{\mathrm{Lp}}$ & $\begin{array}{c}\mathrm{L}_{\mathrm{p}} \\
(\mathrm{m})\end{array}$ & $\begin{array}{c}\mathrm{W} \mathrm{L}_{\mathrm{p}} \\
(\mathrm{m})\end{array}$ & $\begin{array}{c}\mathrm{V}_{\mathrm{c}} \\
(\mathrm{m} / \mathrm{s})\end{array}$ & $\begin{array}{c}\mathrm{W} \mathrm{V}_{\mathrm{c}} \\
(\mathrm{m} / \mathrm{s})\end{array}$ & $\begin{array}{c}v_{\mathrm{o}} \\
(\mathrm{m} 2 / \mathrm{s})\end{array}$ & $\begin{array}{c}\mathrm{W} v_{\mathrm{o}} \\
(\mathrm{m} 2 / \mathrm{s})\end{array}$ & $W \operatorname{Re}_{\mathrm{Lp}}$ & $\begin{array}{c}\% \mathrm{~W} \operatorname{Re}_{\mathrm{Lp}} \\
\operatorname{Re}_{\mathrm{Lp}}\end{array}$ \\
\hline 25 & $1.14 \mathrm{E}-03$ & $1.27 \mathrm{E}-04$ & 0.35 & $9.69 \mathrm{E}-03$ & $1.59 \mathrm{E}-05$ & $1.84 \mathrm{E}-08$ & 2.87 & 11.5 \\
\hline
\end{tabular}

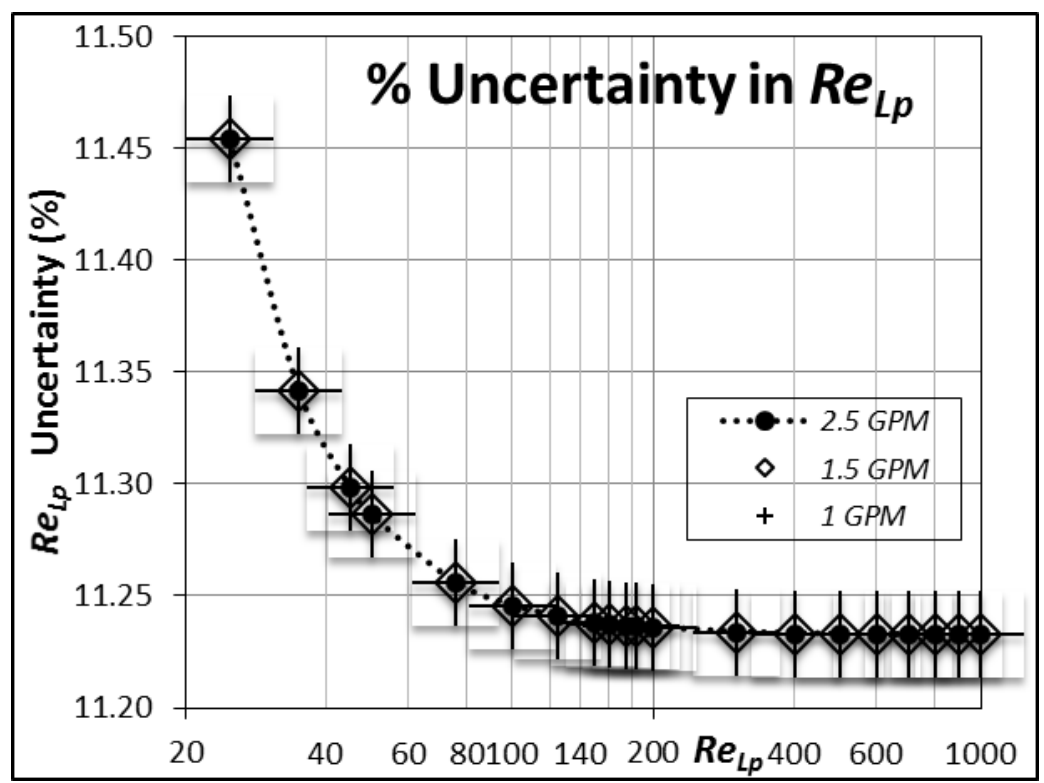

Figure 29. Uncertainty in Reynolds Number based on Louver pitch

Since, $\operatorname{Re}_{\mathrm{L}_{\mathrm{p}}}$ as shown by equation (16) is independent of the waterside flow conditions.

The variations in the airside flow conditions are same for every variation in the waterside flow condition. Therefore, the uncertainty variation in the Reynolds number with respect to the variation in the water flow rate is negligible. However, with the changes in the waterside flow conditions, changes the heat transfer to the airside, and the uncertainty in the temperature measurement, which in turn affects the variation in the uncertainty of the 
viscosity and consequently the in the Reynolds number. Since, air inlet temperature is the room temperature, the bulk mean temperature rise in the air temperature at the conditions tested, is not much. Its effect on the uncertainty is insignificant. Therefore, the uncertainty variation in the Reynolds number is less sensitive to the precision errors associated with the waterside measurements as can be seen from the Figure 29.

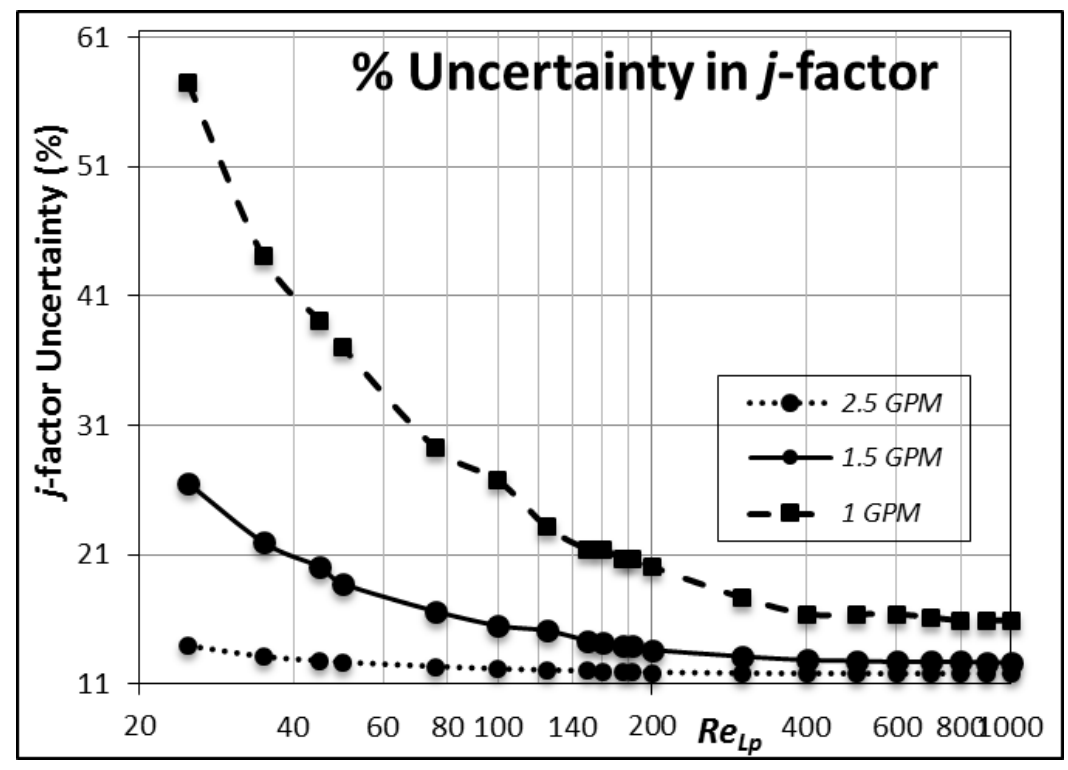

Figure 30. Uncertainty in $j$ factor

Figure 30 , shows the percentage variation of uncertainties in $j$-factor with three different water flow conditions, at 1, 1.5, and 2.5 GPM. As can be seen from the equation (45), $j$-factor is directly proportional to the airside heat transfer coefficient and its dependence on waterside heat transfer coefficient is indirect. One can see a gradual decrease in the percentage uncertainty for Reynolds number from 25 to 1000 . At lower $R e_{L p}$, the small change in water flow rate varies the precision uncertainty drastically, whereas, at higher $\operatorname{Re}_{L P}$, this variation is distinguishable and almost constant. After $\operatorname{Re}_{L P}$ more than 200, uncertainty propagation is comparatively very much constant, particularly 
at higher water flow rate. The uncertainty variation in $j$-factor at a flow rate of 2.5 GPM stays almost constant for the complete range. Therefore, uncertainty in $j$-factor is equally sensitive to the airside as well as waterside flow characteristics.

Since, as seen from Figure 30, at lower airflow rates, water flow rate shows a drastic impact on $\mathrm{j}$-factor uncertainty. It is suggested that to achieve higher accuracy in the experimental results at lower airflow rates; one must keep the higher waterside flow rate. One of the ways to tackle this situation is to decrease the heat exchange surface area for better experimental results at lower airflow conditions.

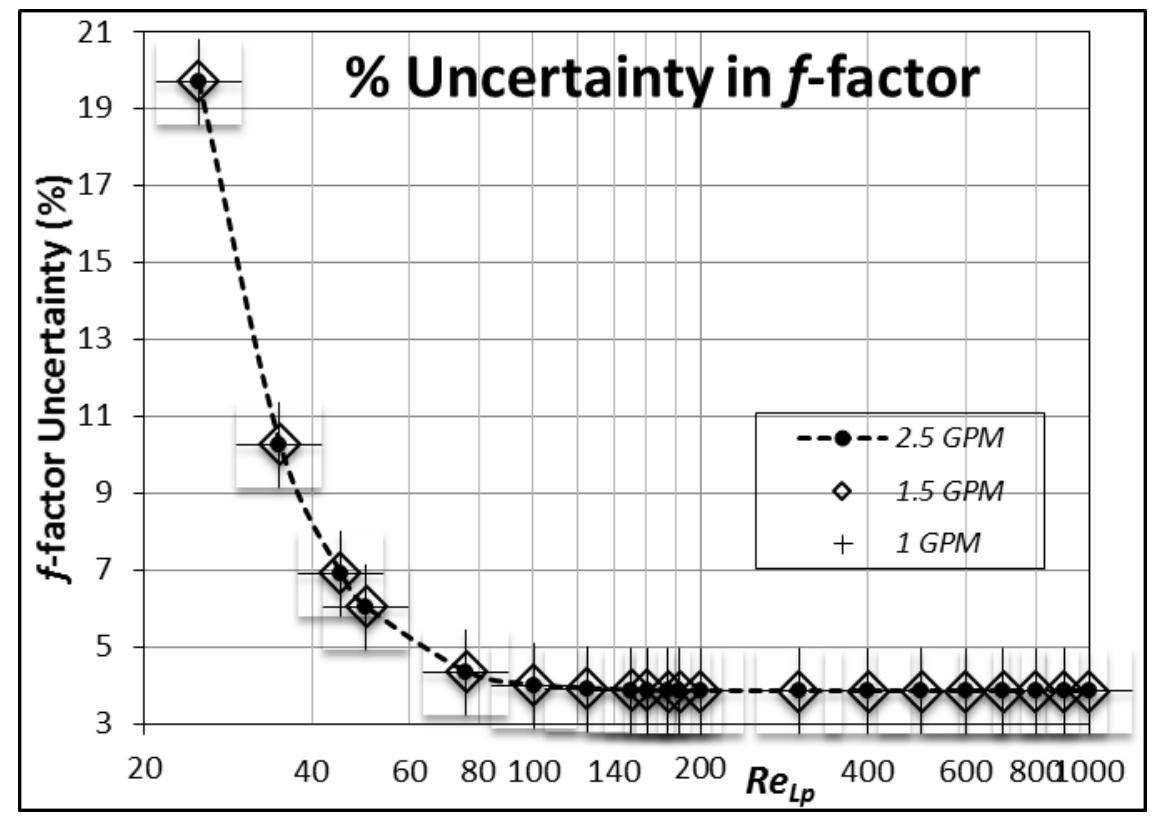

Figure 31. Uncertainty in $f$ factor

Equation (47) shows the $f$-factor dependence on the pressure drop across the test unit, air properties, and the area ratio. The Fanning friction factor is completely independent of the waterside flow parameters, in a similar manner with that of $\operatorname{Re}_{L P}$. With the similar reason as mentioned in the case of $\operatorname{Re}_{L P}$, the uncertainty propagation in $f$-factor due to the 
precision error in the measurements is highly sensitive to the airside flow characteristics, physical characteristics of the heat exchanger geometry, and is less susceptible to the waterside as shown in Figure 31.

From Figure 29 to 31 , it can be seen that the uncertainties in the performance parameters such as $\operatorname{Re}_{L P}, j$-factor, and $f$-factor of the heat exchanger unit are purely due to the precision errors in the air flow measurement. This seems reasonable too, as the airflow decreases, error in the flow measurement increases. This is highly influenced by the accuracy of the device of airflow measurement and its range of operation. For the present study, as listed in Table 5, two different types of flow meters measure the airflow, venturi meter and orifice meter to cover the range of measurement. Both the flow meters have some inaccuracies associated with them.

The differential pressure reader, Dwyer 477A Digital Manometer used has an accuracy of $0.1 \%$ of full-scale reading. Though the reader and the flow meters are highly accurate, the sensitivity of the reader is very low for $\operatorname{Re}_{L P}$ less than 200 . Since the existing experimental facility has 1HP motor drawing the air over the test heat exchanger core, orifice meter was able to measure the lower air flow of $\operatorname{Re}_{L P}$, less than 75 whereas the venturi meter measured for the airflow over $\operatorname{Re}_{L P}$ greater than 75 .

The manufacturer's calibration sheet gives the pressure drop of 4 in wc, for air flow of $\operatorname{Re}_{L P}=75$. The flow conditions in this region are highly sensitive to the pressure changes, a small change in pressure drop shows the substantial change in the airflow. On the contrary, highly accurate airflow meter with the measurement accuracy of $0.1 \%$ FS $(0.02$ in w.c., absolute) has a very low resolution of the measurement. This indeed is reflected in 
the precision uncertainties of $\operatorname{Re}_{L P}, j$-factor, and $f$-factor. It is suggested that to use the airflow reader with a low range of measurement and higher accuracy. Trade between the accuracy and resolution is advisable to gain the accurate experimental measurements.

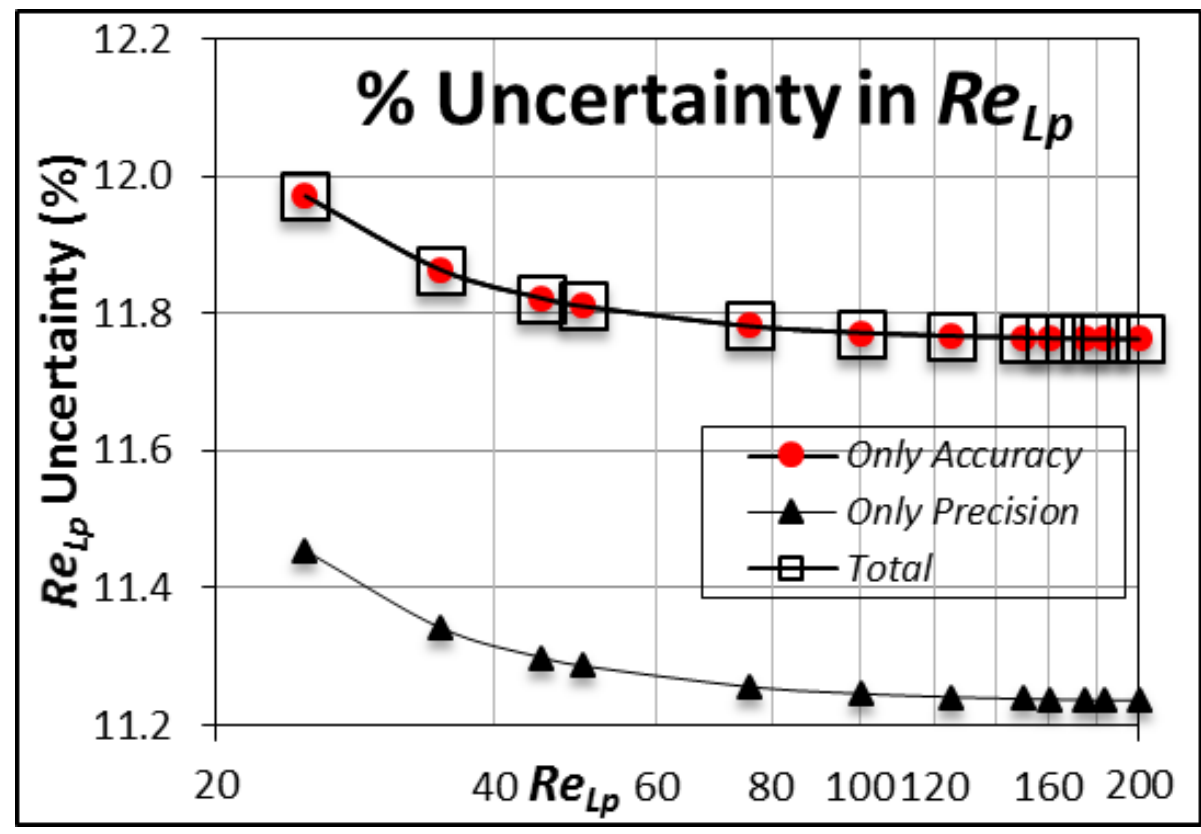

Figure 32. Accuracy, Precision and Combined Uncertainty in $\operatorname{Re}_{\mathrm{Lp}}$

Significant variations in the percentage uncertainties are found for $\operatorname{Re}_{L p}$ below 75. Therefore, further study kept limited for the discussion of the uncertainty propagation for the range of $\operatorname{Re}_{L p}$ from $25-200$. For the comparison purpose and better understanding of the effect of instrumental accuracy, on the uncertainty propagation, uncertainty calculations for $\operatorname{Re}_{L p}, j$-factor, and $f$-factor are repeated twice more. Once by only taking instrumental uncertainty into consideration and then secondly by taking both, precision error and accuracy of the instrument into account. Effect of precision error, accuracy, and total uncertainty is studied by comparison for the constant waterside flow rate of 3.4 GPM. It should be noted here that; higher water flow rate reduces the uncertainty propagation in the 
$j$-factor. It again decreased dramatically from 57.46 at 1 GPM to 12.15 at 3.4 GPM but does not affect the uncertainty propagation in $\operatorname{Re}_{L p}$ and $f$-factor. The plots of $\%$ uncertainty propagation are shown in Figure $32-34$.

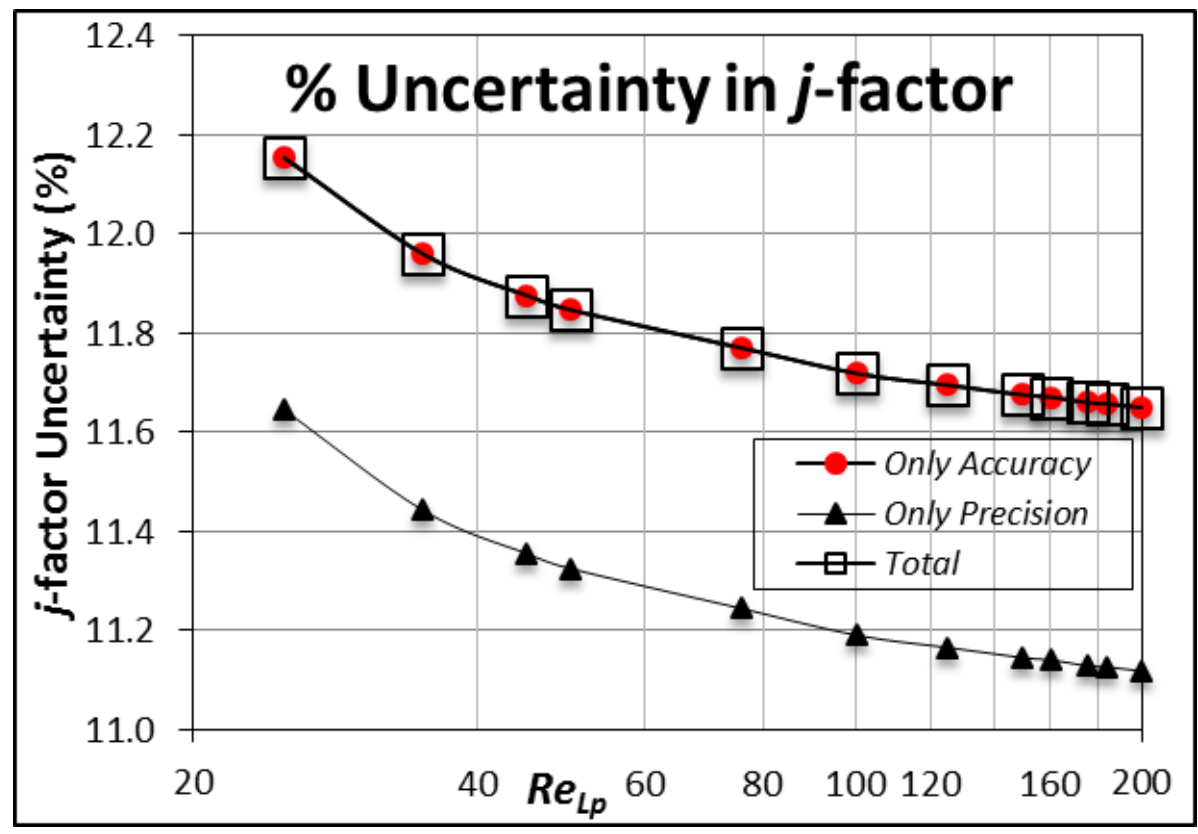

Figure 33. Accuracy, Precision and Combined Uncertainty in $\boldsymbol{j}$ factor

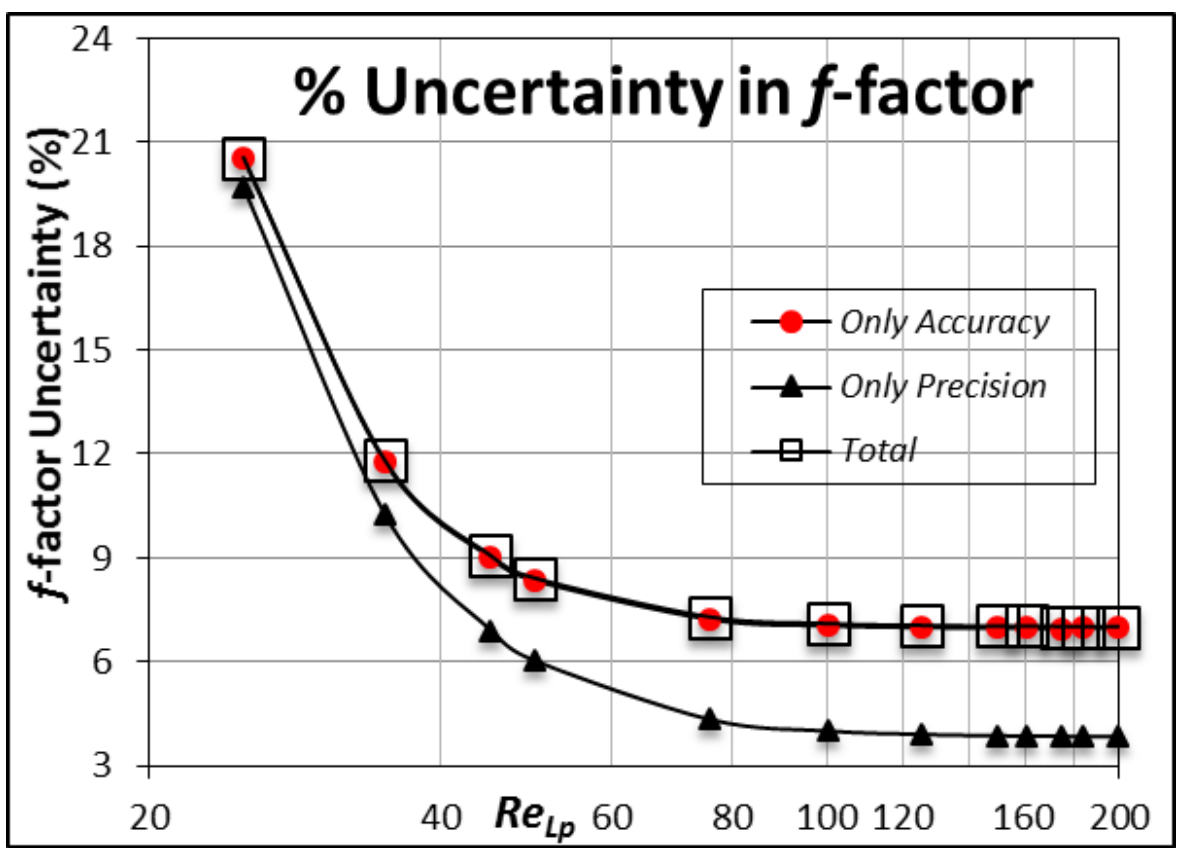

Figure 34. Accuracy, Precision and Combined Uncertainty in $f$ factor 
Glance over the plots shows good agreement in the trends of uncertainty propagation in all of the three performance parameters ( $\operatorname{Re}_{L p}, j$-factor, and $f$-factor). However, there are two notable trends in each of the case covering the complete range of $\operatorname{Re}_{L p}$, from 25 to 200 . The trends of these graphs show a distinctive shift between the percentage uncertainty propagation curve with only consideration of precision error and another with only consideration of accuracy.

General understanding shows the total uncertainty that is the root sum square of uncertainty due to precision and due to accuracy, should be higher. However; as can be seen from all of the three plots (Figure 32-34) that, the total uncertainty curve and the uncertainty due to accuracy only, overlap. At the same time, uncertainty due to precision error only can also be seen on the same graph distinctively.

This may seem confusing; the reason for overlap of uncertainty due to total error and due to accuracy only is that when accounting for an accuracy of the measurement equipment, the effect of the precision error of the same equipment is suppressed. This is also true, the precision error of the measurement instruments are very small compared with the instruments accuracy.

Since waterside flow characteristics kept constant and the effect of the accuracy and the precision error is studied, the uncertainty propagation in $\operatorname{Re}_{L p}$ and $j$-factor shows the same variation, whereas in the case of $f$-factor this shift is less at lower $\operatorname{Re}_{L p}$ and higher at higher $\operatorname{Re}_{L p}$, as expected.

Throughout the above discussion, heat exchanger physical characteristics were included in all the cases. Errors due to the heat exchanger geometry are inherited part of accuracy uncertainties. However, accuracy error in the measurement instrument is also an 
unavoidable part of an entire system to quantify the uncertainties in the performance parameters. The effect of geometrical parameters on the uncertainty analys is for different geometry types can also be studied. To accurately predict the heat exchanger performance or to properly size the heat exchanger system, one must take into account both accuracy as well as the precision error of the system. Depends on the flow regime of the experiment, choices of the devices is of vital importance. Greater accuracy devices with the lower range of measurements are always advisable for the highly accurate experimental practices. A good trade-off between the accuracy and the resolution is prudent.

As mentioned earlier, the uncertainty values are higher at lower experimental conditions, i.e. at lower flow conditions both on waterside as well as the airside uncertainties are at the maximum. This is exactly can be seen from the uncertainty plots.

In this chapter, the standard uncertainty analysis procedure for brazed aluminum microchannel heat exchanger with louver fin heat exchanger is discussed. Effect of accuracy and the precision error on uncertainty propagation is studied. Effect of waterside and airside flow characteristics on the uncertainty propagation is explained. For better experimentation, testing and design of the heat exchanger units, suggestions on the instrument selection are provided. The effects of accuracy, precision, and resolution of measurement instruments and the trade-off required between them in the design of heat exchanger performance prediction experiments are discussed. General overall understanding about the uncertainty propagation behavior and the actual uncertainty propagation is discussed. 


\section{CHAPTER 5 : RESULTS AND DISCUSSION}

In this chapter, the experimental data, in the form of heat transfer coefficient, pressure drop, dimensionless $\mathrm{j}$, and f factors are provided and discussed with the graphical figures. This chapter also discusses the effect of geometrical parameters.

\subsection{HEAT TRANSFER COEFFICIENT $h_{o}$ AND PRESSURE DROP $\Delta P$}

The air-side heat transfer coefficient and pressure drop are determined from the experimentally collected data for the range of Reynolds number from 25 to 200 . To investigate the geometrical effects on thermal hydraulic performance of the louver fin micro-channeled aluminum heat exchangers, seven main parameters are considered on the experimental evaluation in this paper. They are the fin density $\left(F_{p}\right)$, the fin depth $\left(F_{d}\right)$, fin height $(\mathrm{H})$, fin thickness $(\delta)$, louver angle $(\theta)$, louver pitch $\left(\mathrm{L}_{\mathrm{p}}\right)$, and tube height $\left(\mathrm{D}_{\mathrm{m}}\right)$. Figures $37-42$ presents the results of airside thermal hydraulic performance of louvered fin flat tube heat exchangers.

\subsubsection{Influence of fin density $\left(F_{p}\right)$}

Figure 35 depicts the variation of heat transfer coefficient and pressure drop with respect to the Reynolds number for geometry \#16 \& \#17. The heat transfer coefficient and pressure drop increase with the increase in Reynolds number, and the fin density, as expected. This is because of the fact that with the increase in Reynolds number, the air flow between the fin, and louver surfaces can be mixed better, whereas with the increase in fin 
density increases the surface area available for the heat exchange, and hence the resistance to the air flow.

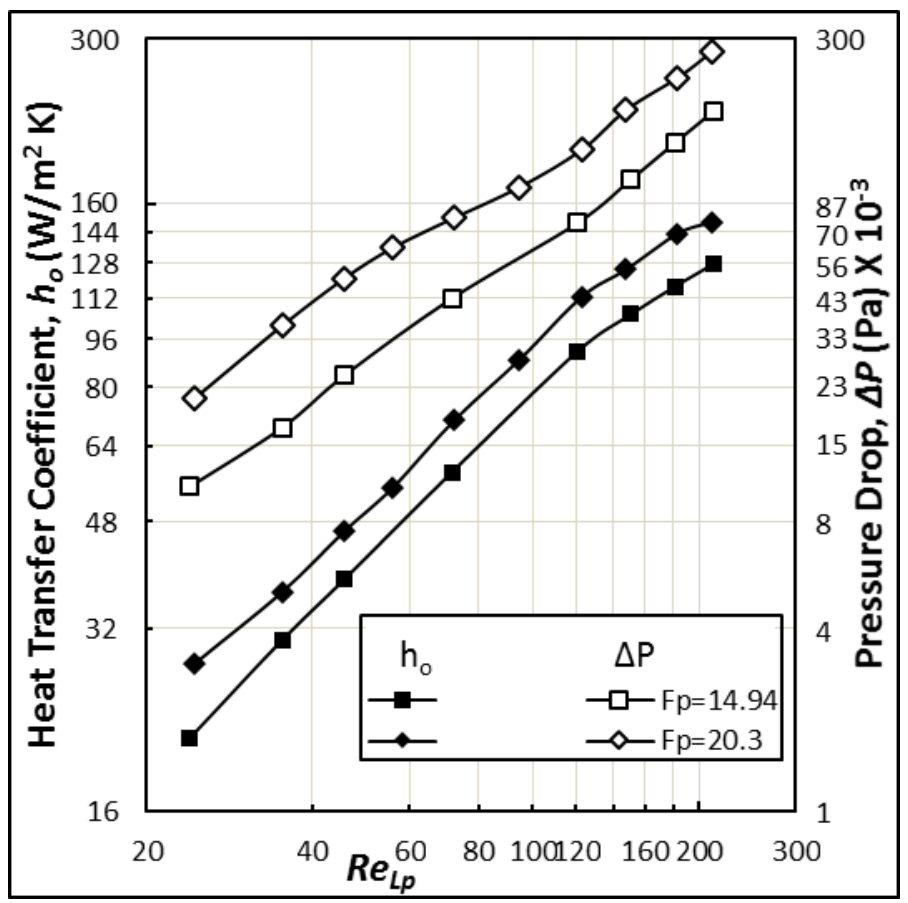

Figure 35. Variations of heat transfer coefficients and pressure drop with fin density and Reynolds number, Sample \#16, and \#17

About $26 \%$ decrease in fin density from \#17 to \#16, reduces the heat transfer coefficient, and the pressure drop by an average around $18 \%$, and $44 \%$ respectively. It can also be seen clearly that the slopes of the heat transfer coefficient curves of \#16 \& \#17 are nearly equal to 0.8 till the Reynolds number at louver pitch equal to 120 , and then suddenly decreases to 0.4 for the rest. In the case of pressure drop curves of \#16 \& \#17, the average slopes are found to be nearly equal to 0.7 , and 1.2 till the Reynolds number equal to 120 , and then suddenly increases to 1.1 , and 1.6 respectively. This signifies the fact that with the Reynolds number more than 120, air flow starts flowing over the louver region more efficiently, than for the Reynolds number less than 120. From the Figure 35, it can also be seen that the slope of the pressure drop curves changes from Reynolds number between 60 
and 120, representing the transitioning of the flow from the fin directed to the louver directed. Similar effects have seen in case of comparison between Samples \#20, \#21, and $\# 22$, \#23, \#24, and \#26, and \#4, \#5, and \#6 as listed in APPENDIX B. This suggests that for the studied range of Reynolds number, a small variation in fin density shows relatively low deviation in heat transfer coefficient but larger changes in the pressure drop.

\subsubsection{Influence of fin depth $\left(F_{d}\right)$}

The variation of heat transfer coefficient and pressure drop with respect to the Reynolds number for geometries \#12 \& \#15, and \#14 \& \#17 is shown in Figure 36 (a) \& (b). The heat transfer coefficient and pressure drop, increases with the increase in Reynolds number, as expected for the similar reasons of better flow mixing at higher Reynolds number.

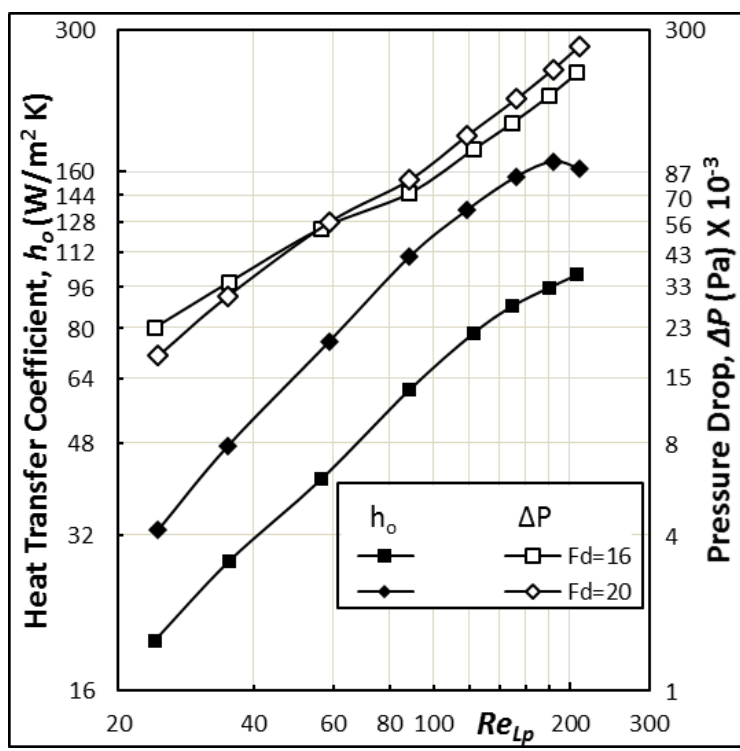

(a)

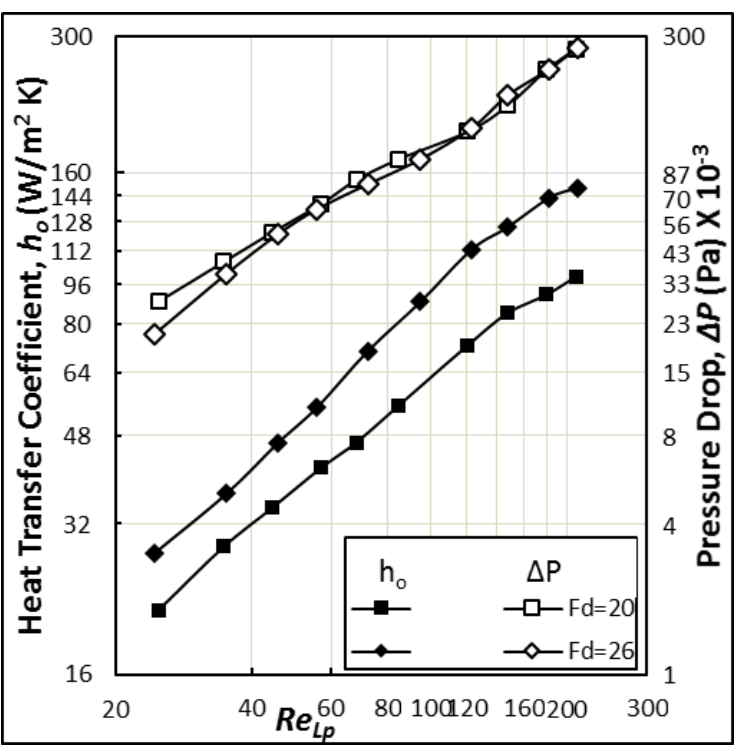

(b)

Figure 36. Variations of heat trans fer coefficient and pres sure drop with fin depth and Reynolds number; (a) Sample \#12 and \#15, (b) Sample \#14 and \#17

However, an increase in the heat transfer coefficient is found with the increase in flow depth throughout the range of experimental measurements, which is similar to the results 
listed in the recent work by Kim et al. (2002). The decrease in the pressure drop found with the increase in flow depth, for low Reynolds number, till the peak Reynolds number close to 60 , and then increased with respect to the flow depth. As shown in Figure 36 (a), 25\% increase in the fin depth, shows an average increase in the heat transfer coefficient of around $73 \%$, and pressure drop of about $9 \%$.

It can also be seen clearly that $84 \%$ increase in the slope of the heat transfer coeffic ie nt curves of \#15 with respect to that of \#12, from the value of 0.6 to 1.1 , found till the Reynolds number at louver pitch equal to 120 , and then suddenly decreases to 0.3 for the rest. Whereas in the case of pressure drop curves of \#12 \& \#15, the average increase in the slopes is found to be nearly about $22 \%$ from 0.9 , to 1.1 till the Reynolds number equal to 120 , and then increases to 1.2 , and 1.5 respectively for the rest of the curve.

At Reynolds number of 60, the pressure drop curve shows the reversal of flow behavior with the change of flow depth. Below Reynolds number of 60 complete opposite behaviors to that of above 60 is found. Whereas in the case of heat transfer coefficient, a significant change in the flow behavior is found at after Reynolds number of 120 . This clearly signifies the fact that with the Reynolds number more than 60, air flow starts flowing over the louver region more efficiently, than the flow for the Reynolds number less than 60 .

Similar flow behavior can be seen form the Fig. 36 (b), with $30 \%$ increase in the flow depth, resulted in an average of $43 \%$ increase in the heat transfer coefficient, and $4 \%$ decrease in the pressure drop between the sample \#14, and \#17. This signifies that for the studied range of low Reynolds number with the increase in the fin depth up to $20 \mathrm{~mm}$, increases the heat transfer coefficient rapidly, and reduces the pressure drop significantly. Further increase in the fin depth up to $26 \mathrm{~mm}$, reduces the intensity of increase in the heat 
transfer coefficient by about $48 \%$, and the intensity of decrease in the pressure drop by about $44 \%$. This clearly suggests the optimum range of fin depth can be between $25 \mathrm{~mm}$ to $27 \mathrm{~mm}$ for higher heat transfer without any increase in pressure drop for the studied range of Reynolds number.

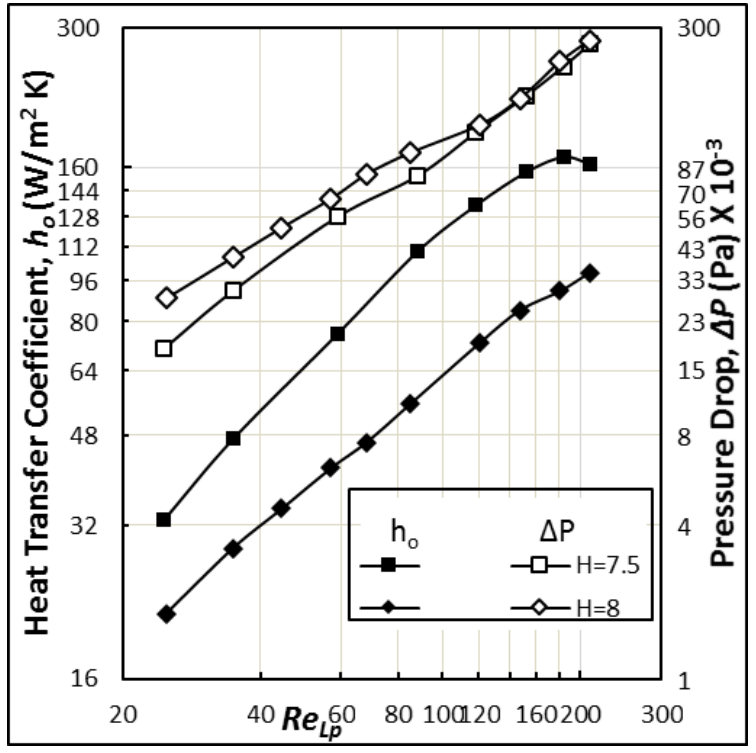

(a)

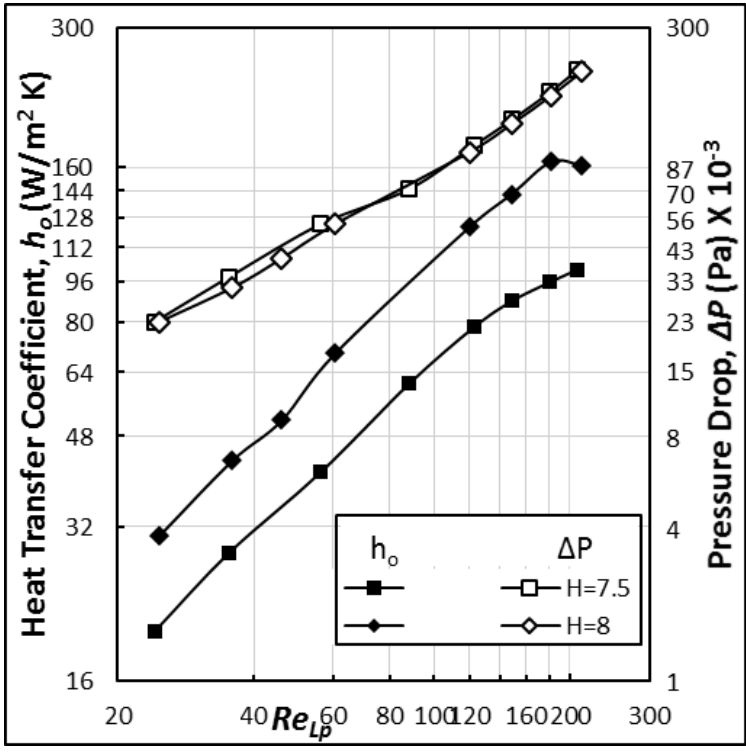

(b)

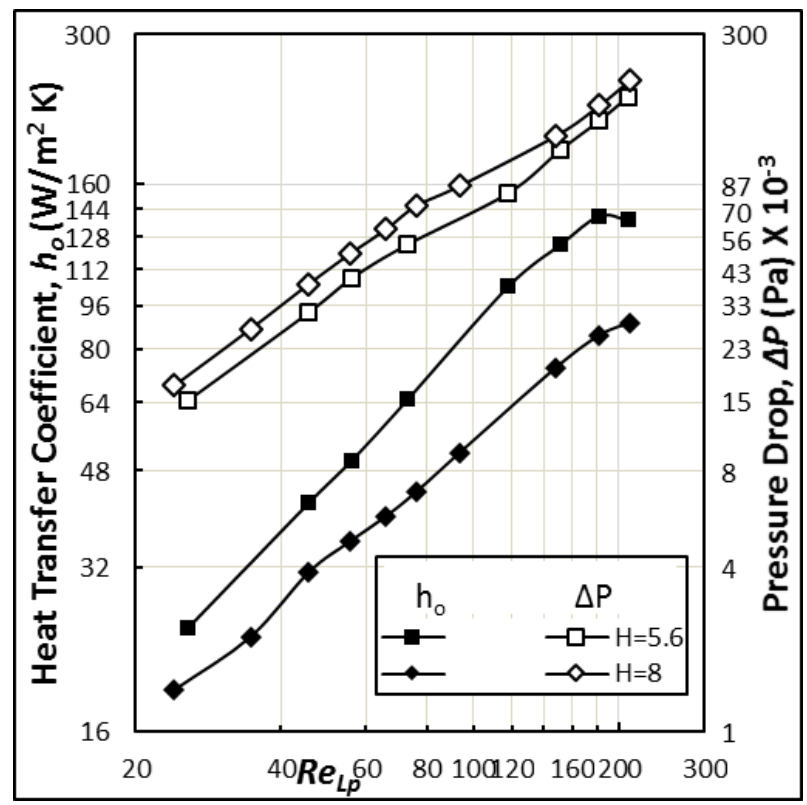

(c)

Figure 37. Variations of heat transfer coefficient and pressure drop with fin height and Reynolds number; (a) Sample \#14, and \#15, (b) Sample \#11, and \#12, and (c) Sample \#9 and \#18 


\subsubsection{Influence of fin height $(H)$ and tube height $\left(D_{m}\right)$}

Effect of fin height on the variation of heat transfer coefficient and pressure drop with respect to the Reynolds number for geometries \#14 and \#15, is shown in Fig. 37(a). above. An increase in fin height decreases the heat transfer coefficient, and increases the pressure drop, as expected. Average $43 \%$ of the decline in heat transfer coefficient, and $18 \%$ increase in pressure drop is found with $7 \%$ average increase in fin height.

This is because of the fact that with the increase in fin height, the spacing between the tubes increases, and therefore overall heat exchange surface area decreases, which in turn reduces the heat transfer to the airflow. Change in the slope of the heat transfer coeffic ient curves of geometry \#14 and \#15 can be seen for the Reynolds number more than 140 . Whereas in the case of pressure drop linear increase in the slope of the curves up to Reynolds number of around 75 , then slightly decrease till the Reynolds number equal to 120, where both the curves almost coincide each other, as can be seen in the Figure 37(a).

For Reynolds number more than 120 drastic linear increase in the slopes is seen for the rest of the range. This shows that for the Reynolds number below 75, thick boundary layer formed in the flow direction indicates distinctive pressure drop variations. With the increase in Reynolds number more than 75 and up to 120 , the reduction in boundary layer thickness shows re-alignment of the air flow in the louver direction which can be seen in the Figure as transitioning flow regime. Whereas for the Reynolds number more than 120, the air flow seems to be flowing through the louver gaps, reflecting in increased in heat transfer more in comparison to the pressure drop with the variation in fin height. Geometry \#14 and \#15 shows change in the louver length of the same order to that of fin height. 
Figure 37 (b) shows the variation in heat transfer coefficient and pressure drop due to the effect of fin height, and tube height with respect to the Reynolds number for geometry $\# 11$, and \#12. As similar to Figure 37 (a), the increase in fin height of geometry $\# 11$ is by about $7 \%$ of that of geometry \#12. This, about $6 \%$ decrease in fin height shows approximately $37 \%$ decrease in heat transfer coefficient and $4 \%$ increase in pressure drop.

The comparison between the Figure 37 (a), and Figure 37 (b) shows that almost 10\% decrease in tube height, further increases the heat transfer coefficient by an average $6 \%$, and reduces the pressure drop by roughly $14 \%$ on average as compared to the geometries in the Figure 37 (a). Similarly, Figure 37 (c) shows combine effect of fin height, and tube height on the variation of heat transfer coefficient and pressure drop with respect to the Reynolds number for geometries \#9 \& \#18. Average total $32 \%$ of the decrease in heat transfer coefficient, and $20 \%$ increase in pressure drop is found with $43 \%$ average increase in fin height, and tube height, individually.

A careful look towards the geometrical parameters shows that geometry \#9 has around $43 \%$ increase in the tube height which is exactly similar to the increase in the fin height, in addition to the constant louver length compared with the geometry \#18. Considering the effects of the tube height on the heat transfer and pressure drop; it can be estimated that the effects only due to $43 \%$ increase in fin height contribute to the $58 \%$ decrease in heat transfer coefficient, and $36 \%$ decrease in pressure drop.

Similarly, in the case of geometries \#14 and \#15, by considering the effect of fin height, $6 \%$ increase in louver length shows about $34 \%$ decrease in heat transfer coefficient, and $23 \%$ increase in pressure drop. This is because of the fact that increase in louver height adds the resistance to the airflow in the flow direction resulting in an increase in the 
pressure drop, extending the boundary layer formation, and hence reducing the air flow through the louver gap resulting in the reduction in heat transfer coefficient. Increase in fin height with an increase in louver length concurrently causes the decrease in pressure drop, which has been reported by several researchers in the literature (Dong et al. (2007), and Li et al. (2011)). However, no change in the louver length does not contribute to the heat transfer enhancement but the increase in pressure drop.

Besides, increase in tube height reduces the frontal cross sectional area in the air flow direction, on top of the change in the fin height. Therefore, this increase in tube height significantly adds the pressure drop to the air flow without contributing towards the heat transfer.

\subsubsection{Influence of louver angle $(\theta)$}

Louver angle effect on the variation of heat transfer coefficient and pressure drop with respect to the Reynolds number for geometries $\# 7 \& \# 11$, is shown in Figure 38 . The increase in louver angle and the Reynolds number, increases the heat transfer coefficient, and the pressure drop, as expected. About $40 \%$ increase in louver angle, increases average heat transfer coefficient by $61 \%$, and average pressure drop by $15 \%$. This is because, at low Reynolds number, the air flow is aligning with the fin direction instead of the louver direction, which is the case in the present study. Increasing the louver angle introduces the restrictions to the airflow by breaking the boundary layer formed in the fin direction, and forcing the flow to align with the louvers and pass through the louver gap. This, in turn, better uses the heat exchange surface area, resulting in higher heat transfer with less than $1 / 4^{\text {th }}$ of additional pressure drop to that of heat transfer. It can be clearly seen that average 
slopes of the heat transfer coefficient of \#7 \& \#11 are nearly equal to 0.5 and 0.8 , respectively. Whereas, in the case of pressure drop, the slopes of the curves are equal to 1 .

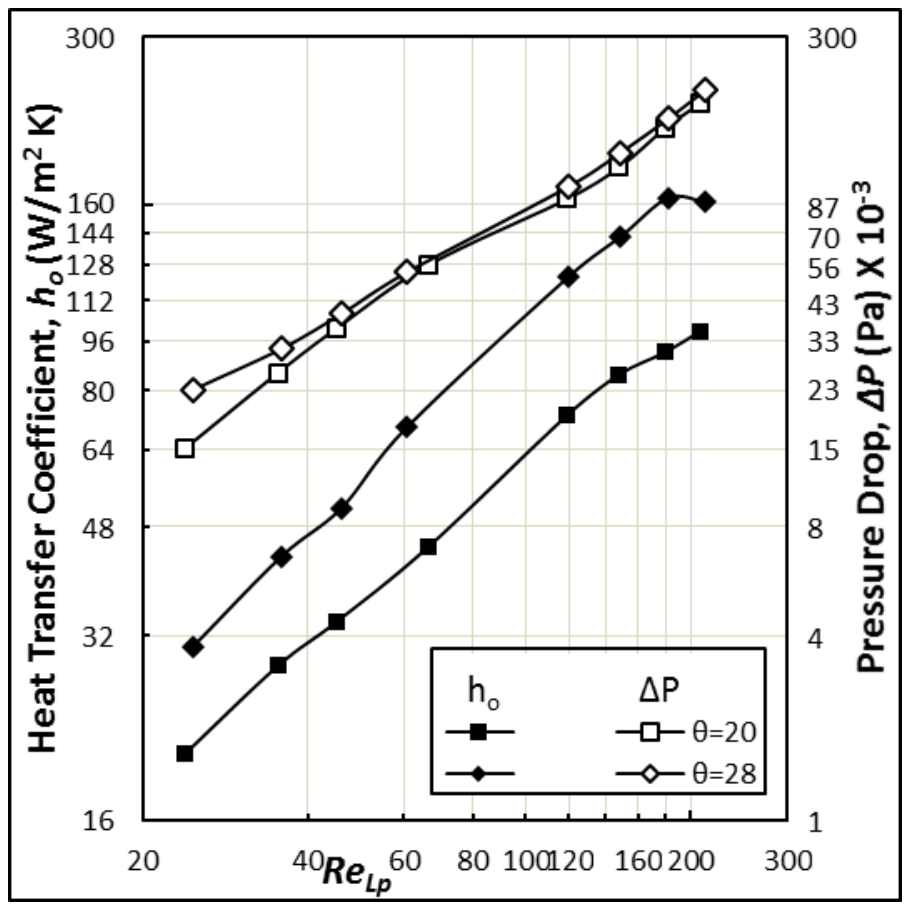

Figure 38. Variations of he at transfer coefficient and pressure drop with louver angle and Reynolds number; Sample \#7 and \#11

The heat transfer coefficient has shown a change in the slope for Reynolds number higher than 150 , and 180 for the louver angle of $20^{\circ}$, and $28^{\circ}$ respectively. Whereas, no such change has seen in the pressure drop variations. For the Sample \#7, the slope of the heat transfer coefficient is 0.5 until the Reynolds number is 150 , then it decreases by $60 \%$ gradually for the rest of $40 \%$ increase in the Reynolds number. In the case of sample \#11, the heat transfer coefficient increases with the slope of 1 until the Reynolds number of 180, then suddenly decreases by $109 \%$ for the rest of $18 \%$ increase in the Reynolds number. This signifies that the flow behavior is still in transition, from fin directed to louver directed flow. With small louver angle the transition is smooth, whereas with large louver angle the transition does show a sudden change in the flow alignment. 


\subsubsection{Influence of louver pitch $\left(L_{p}\right)$}

Figure 39 illustrates the louver pitch effect in combination with the effect of fin density on the variation of heat transfer coefficient and pressure drop with respect to the Reynolds number for geometries \#24\&\#25. There is about $2 \%$ increase in the louver pitch along with about $7 \%$ decrease in fin density. As discussed in section 5.1.1, the effect of $7 \%$ decrease in the fin density contributes to the reduction in heat transfer coefficient and pressure drop of about $5 \%$, and $12 \%$, respectively.

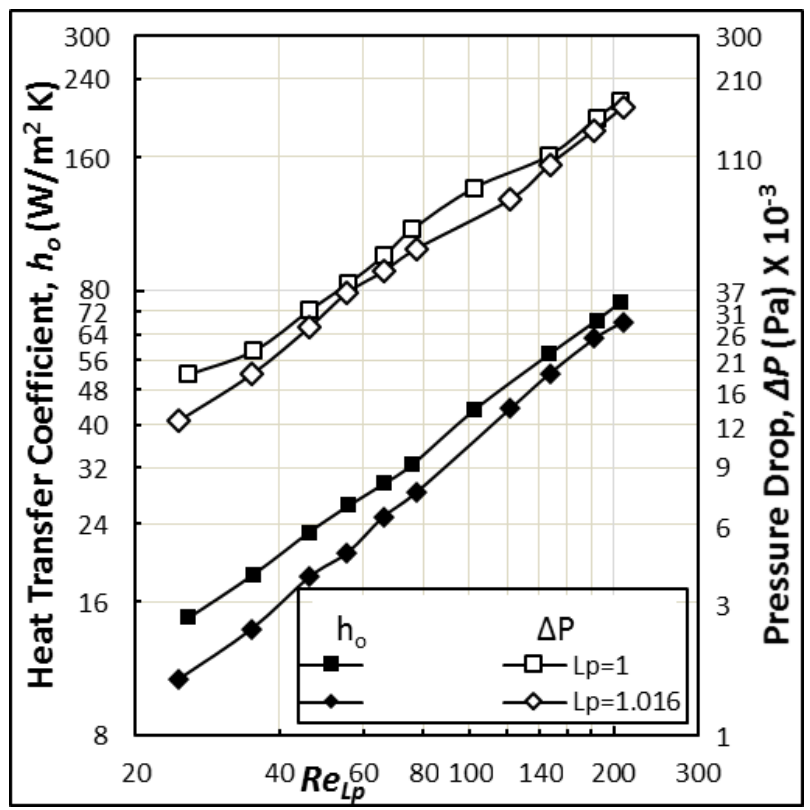

Figure 39. Variations of heat transfer coefficient and pressure drop with louver pitch and Reynolds number; Sample \#24 and \#25

The combined effect of louver pitch and fin density contributes to the decrease in heat transfer coefficient and pressure drop by about $17 \%$ and $13 \%$ respectively, of which 5\% decrease in heat transfer coefficient and $12 \%$ decrease in pressure drop is due to the effect of fin density only. Therefore, the effect of $2 \%$ increase in louver pitch contributes to decrease the average heat transfer coefficient by $12 \%$, and average pressure drop by $1 \%$. Increasing the louver pitch reduces the restrictions to the air flow, and the boundary layer 
formed in the fin direction. This in turn decreases the heat exchange surface area, resulting in lower heat transfer coefficient and pressure drop.

It can be clearly seen that average slopes of the heat transfer coefficient, and pressure drop of geometries \#24 \& \#25 are nearly equal to 0.33 , and 0.85 , respectively. The heat transfer coefficient has shown change in the slope for Reynolds number higher than 75 for both the geometries. The overall average decrease in the heat transfer coefficient is about $21 \%$ for the range of Reynolds number from 25 to 75 , with the maximum and minimum decrease of about $27 \%$ and $13 \%$ at lower and higher Reynolds number respectively. For the Reynolds number more than 80 , the average decrease in heat transfer coefficient is $9.5 \%$, with minimum and maximum decrease of $9.2 \%$, and $9.7 \%$ respectively.

Similar change was seen in the pressure drop variations. Clear transition of the pressure drop curves can be seen from Figure 39 between Reynolds number of 75 and 150. This signifies the fact that for the low Reynolds number, the boundary layer thickness is high enough to avoid the air flow to pass through the gap between the louvers leading to the higher and gradual variations in the heat transfer coefficient. For the Reynolds number between 75 and 150, increased air flow starts breaking the boundary layer thickness between the louvers, and the flow starts aligning with the louvers. For the higher Reynolds number, air flow shows developed profile in alignment with the louver exchanging the heat transfer efficiently, and steadily.

\subsubsection{Influence of fin thickness $(\delta)$}

The influence of fin thickness in combination with the effect of fin depth and tube height on the variation of heat transfer coefficient and pressure drop with respect to the 
Reynolds number for geometries \#4 \& \#8 is illustrated in Figure 40. There is about $25 \%$ increase in the fin thickness along with nearly $11 \%$ increase in tube height, and around $33 \%$ increase in fin depth.

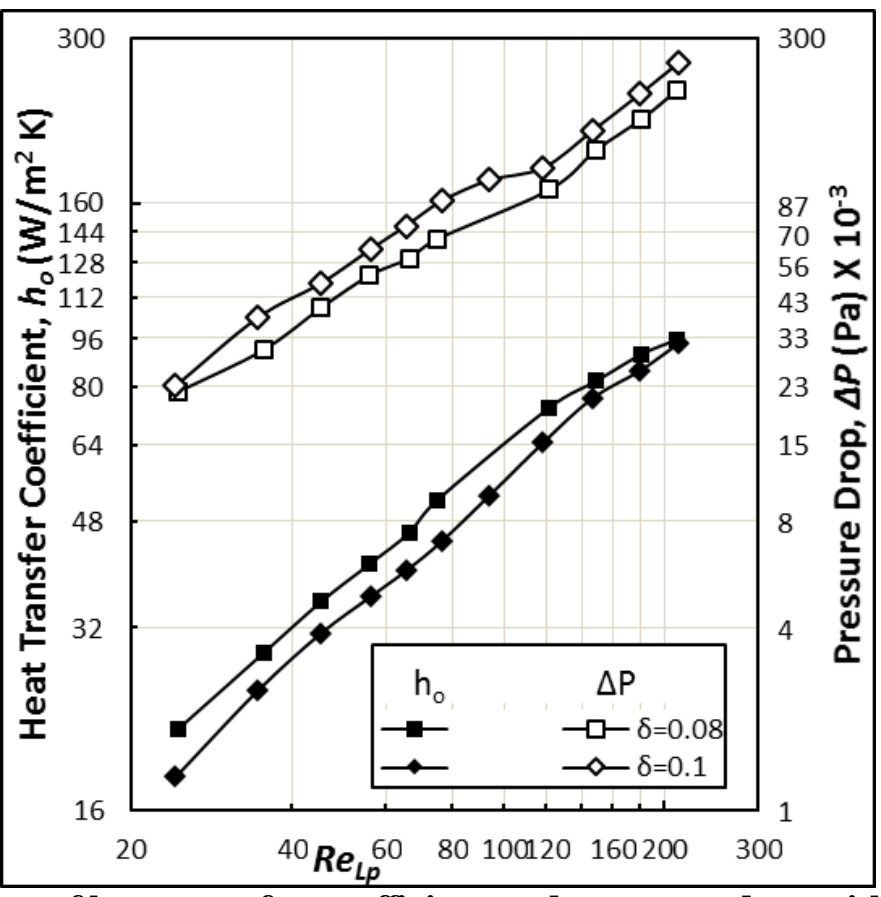

Figure 40. Variations of heat transfer coefficient and pressure drop with fin thickness and Reynolds number; Sample \#4 and \#8

As discussed in section 5.1.2, the effect of $33 \%$ increase in the fin depth contributes to the increase in heat transfer coefficient by about $42 \%$ and decrease in pressure drop by about $5 \%$. Similarly, as per the discussion in section 5.1 .3 , the effect of about $11 \%$ increase in tube height contributes to about $7 \%$ increase in heat transfer coefficient and nearly $14 \%$ increase in pressure drop.

The combined effect of fin thickness, fin depth, and tube height contributes to the decrease in heat transfer coefficient by approximately $11 \%$ and increase in pressure drop by roughly $21 \%$. Of which $60 \%$ decrease in heat transfer coefficient, and $12 \%$ increase in pressure drop is solely due to the effect of $25 \%$ increase in the fin thickness. Increasing the 
fin thickness instigates the formation of a thick boundary layer which in turn obstructing the air flow passage through the louver gap and therefore decreasing the air side convective heat transfer coefficient.

From the Figure 40 it can be seen that average slopes of the heat transfer coeffic ient and pressure drop of geometries \#4 \& \#8 are nearly equal to 0.5 , and 1 , resp. Slightly decrease in the slope of heat transfer coefficient has seen for Reynolds number higher than 120 for both the geometries. In the case of pressure drop curves, two distinctive regions in addition to the transition region in between can be seen from the Figure 40. The transition region can be seen between Reynolds number 75 and 120, for the similar reasons of airflow transitional behavior from fin directed to louver directed as discussed in section 5.1.5.

\section{$5.2 f-$ AND $j$ - FACTOR DATA}

\subsubsection{General Observations about the $j$ and $f$ Factors}

Figure 41 through Figure 55 provides the $\mathrm{f}$ and $\mathrm{j}$ factors obtained from the present experimental measurements. In these figures, the experimental data are grouped loosely in a way to try to show the effects of the key parameter (s) on the $\mathrm{j}$ and f factors whenever possible. However, cautions must be paid by the readers in interpreting the effects of the parameter, as most of the samples compared in the same figure have more than one variable that is different in value. In other words, for most of the figures, the differences of $f$ or $j$ factors for different samples are the combined results of multiple parameters. This is due to the fact that the test matrix was formed based on available heat exchangers in the market.

Only a few heat exchangers were custom-made by the manufacturers due to the cost and other restrictions. 
The effects of fin pitch, $F_{p}$, on the $f$ and $j$ factors are illustrated in Figure 41 (samples \# 20, 21, 22), Figure 42 (samples \# 23 and 24), and Figure 43 (samples \# 5 and 6). The values of $\mathrm{Fp}_{\mathrm{p}}$ are marked in the figures. These figures cover a fin pitch range of $7-20.3$ FPI. In each of these figures, it is clearly shown that with the increase of fin pitch (increase in density in FPI or decrease in pitch in $\mathrm{mm}$ ), the magnitudes of both $\mathrm{f}$ and $\mathrm{j}$ factors increase at fixed Reynolds numbers. This is consistent with previous research work in the literature (Chang and Wang (1997); Kim et al. (2002)).

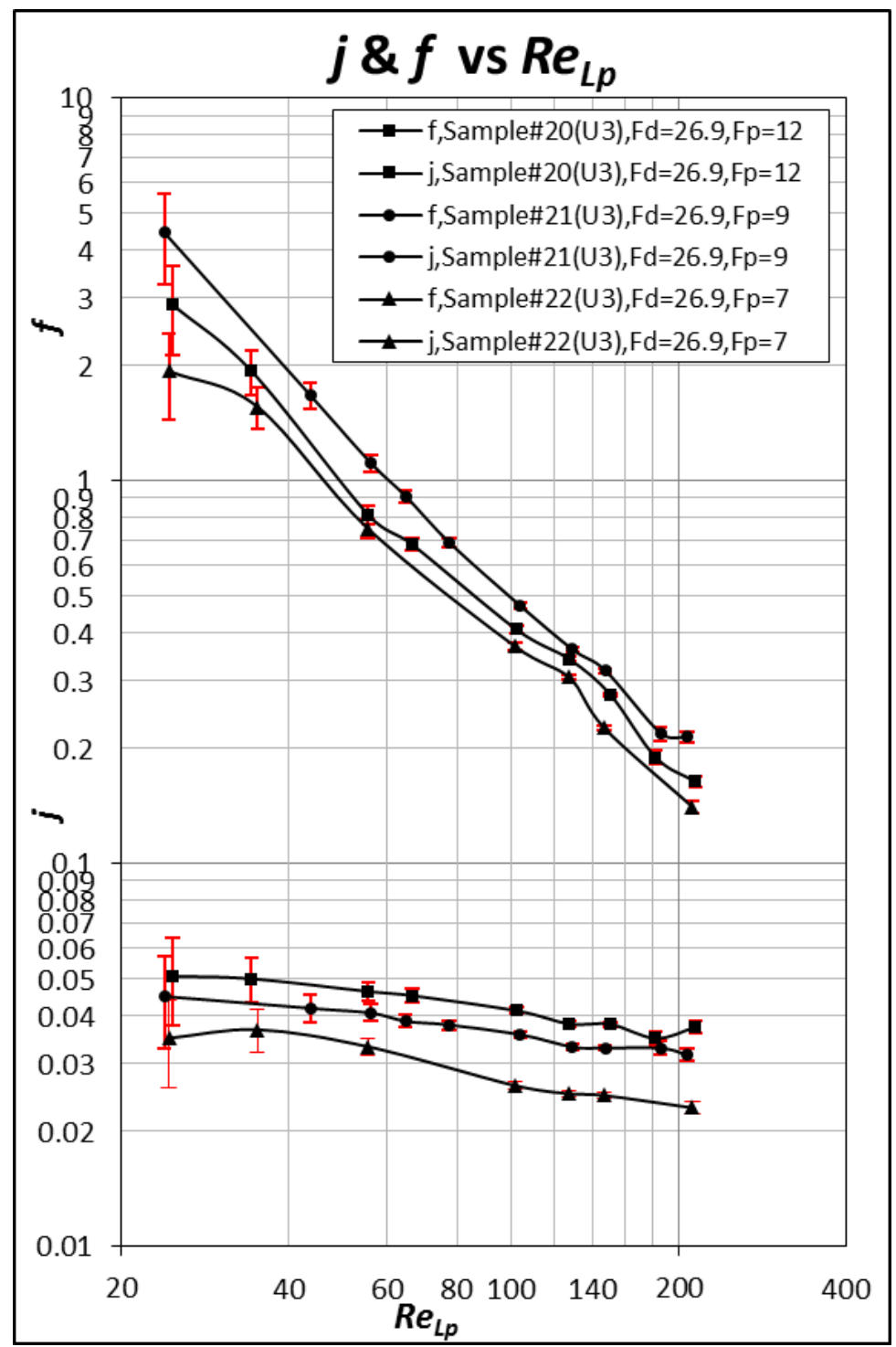

Figure 41. f \& j Factors Vs $\operatorname{Re}_{\mathrm{Lp}}$ for samples \#20, \#21, \& \#22 


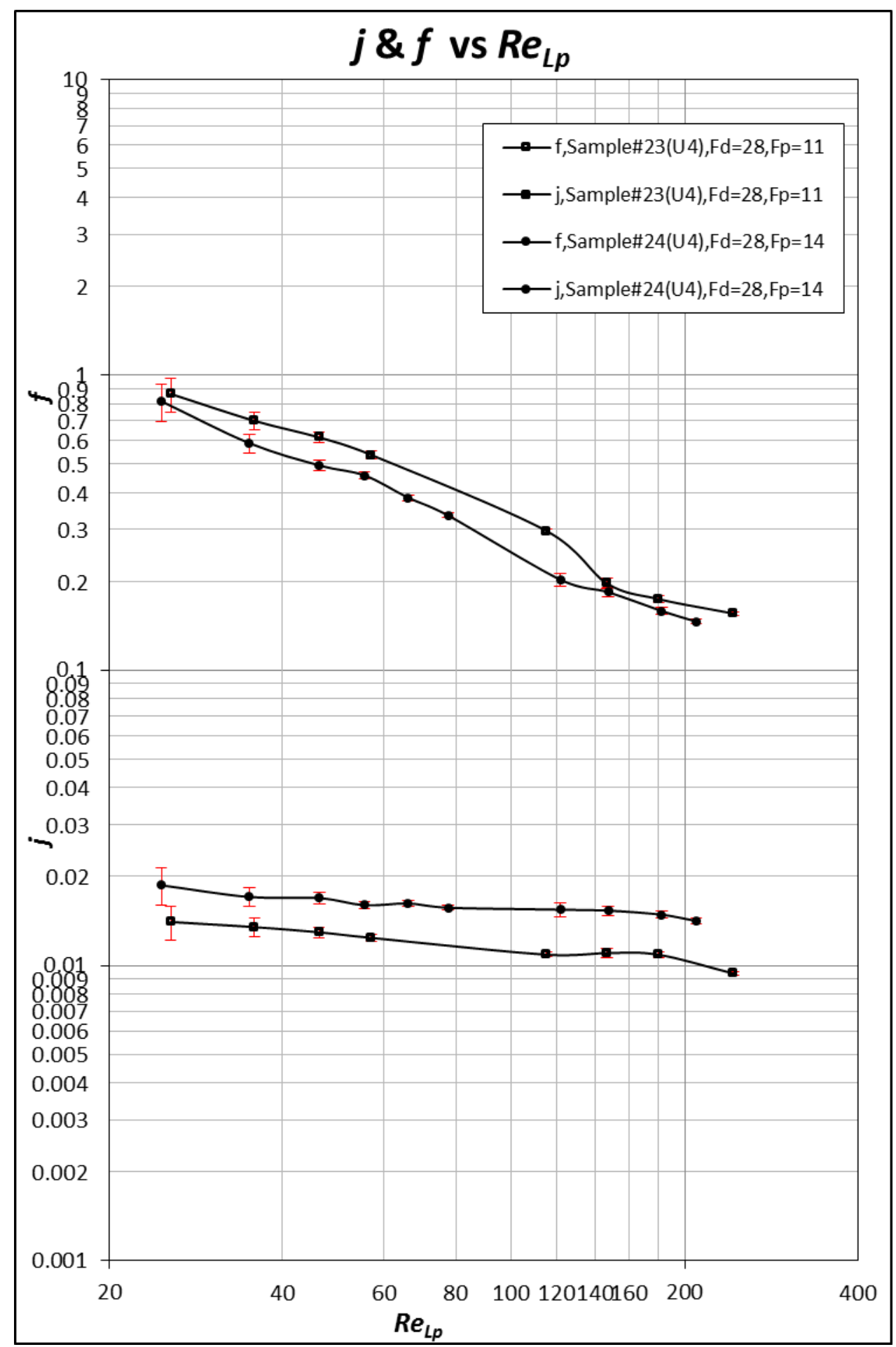

Figure 42. f \& j factors $V s \operatorname{Re}_{L p}$ for samples \#23 \& \#24 


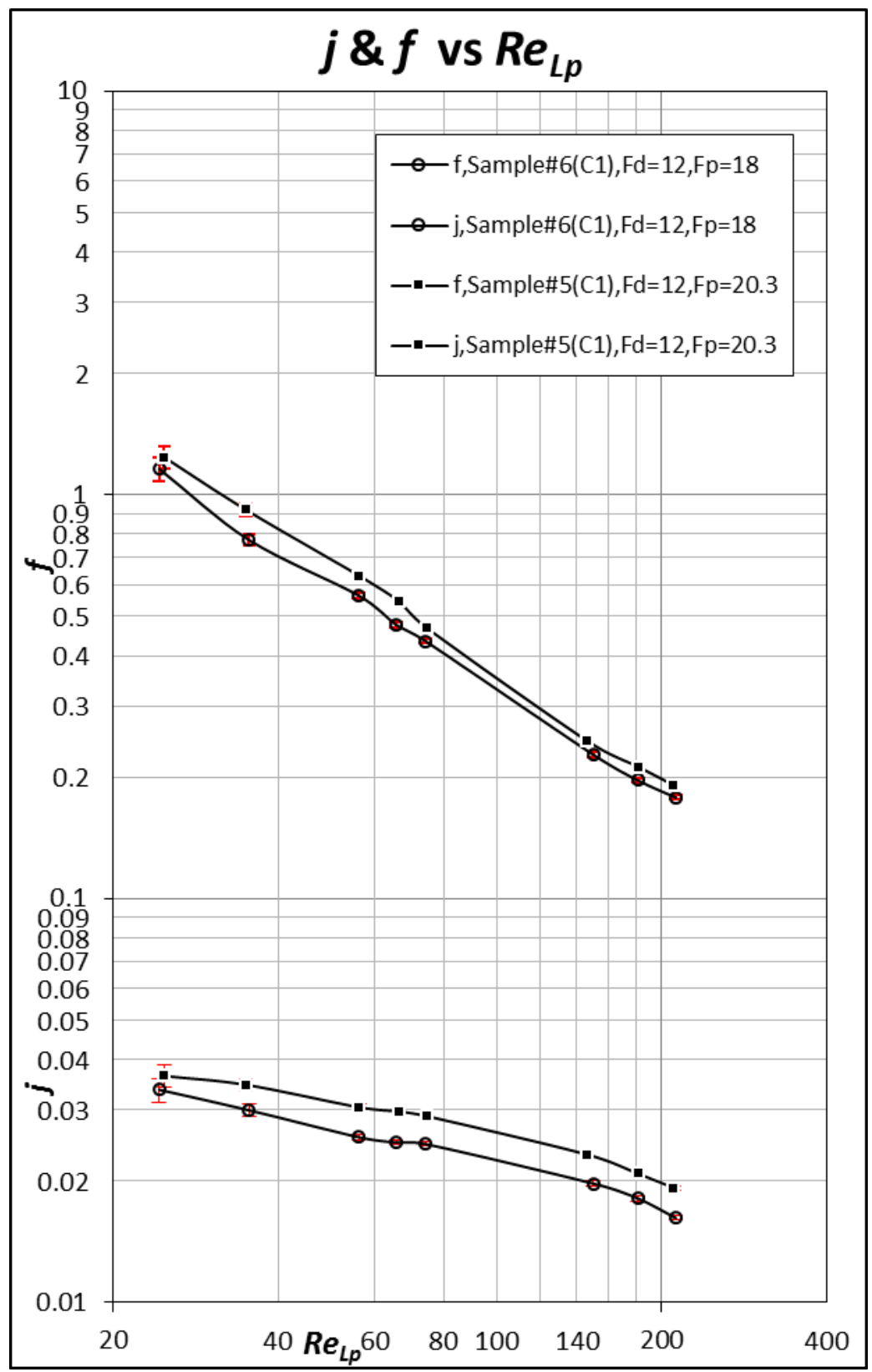

Figure 43. f \& j Factors Vs $\operatorname{Re}_{L p}$ for samples \#5, \& \#6

The effects of tube depth, $\mathrm{T}_{\mathrm{d}}$, on the $\mathrm{f}$ and $\mathrm{j}$ factors are illustrated in Figure 44 and Figure 45. In Figure 44, the $\mathrm{T}_{\mathrm{d}}$, values for samples \# 14 and 17 are $20 \mathrm{~mm}$ and $26 \mathrm{~mm}$, respectively; while in Figure 45, the $\mathrm{T}_{\mathrm{d}}$ values for samples \# 12 and 15 are 16mm and $20 \mathrm{~mm}$, respectively. These figures show that with an increase in tube depth, the $\mathrm{j}$ factor 
increases while $\mathrm{f}$ factor decreases. This seems consistent with some of the previous work in the literature (Chang and Wang, 1997; Chang et al. 2000) if not all.

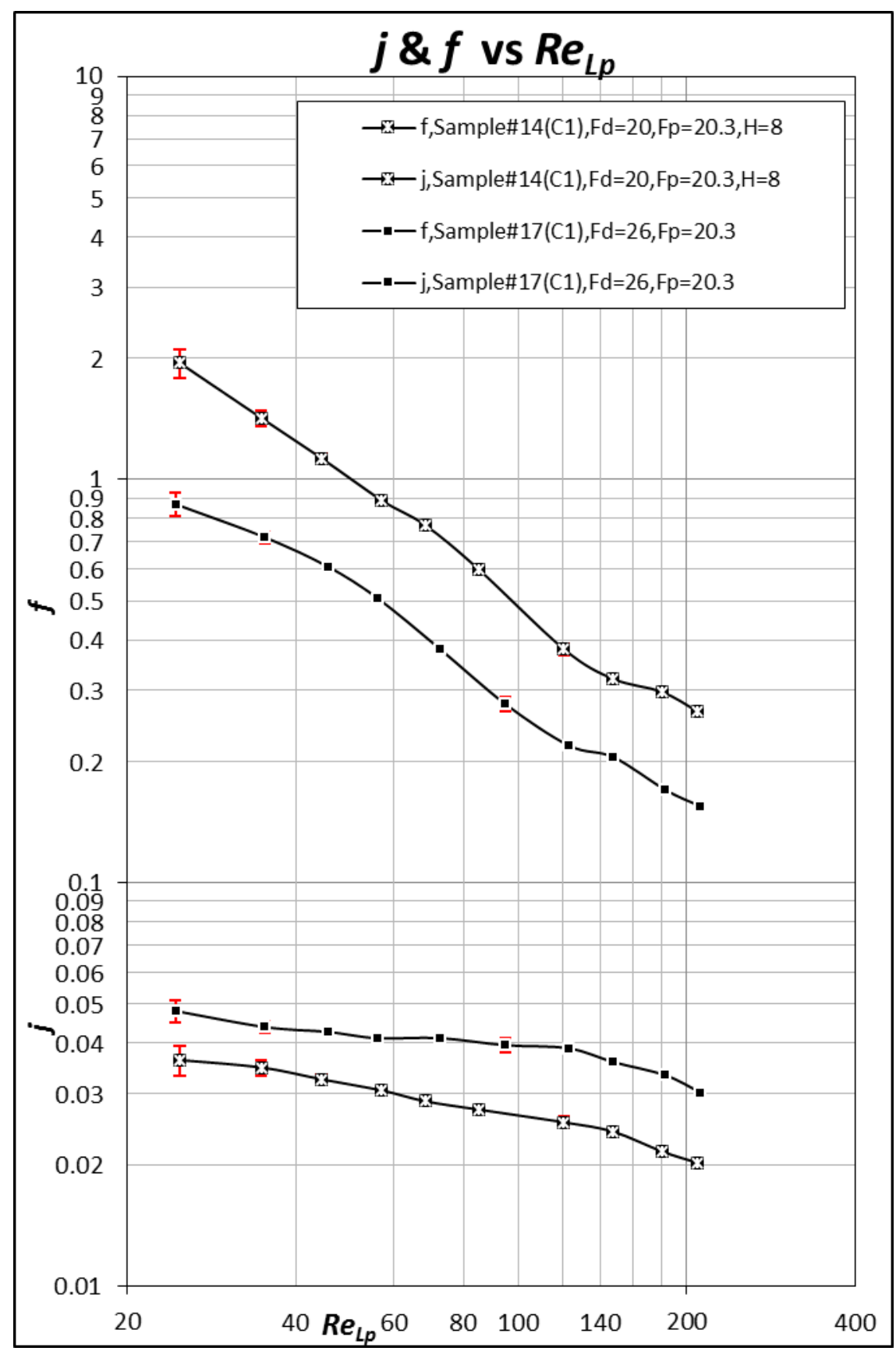

Figure 44. $f \&$ jactors $V s \operatorname{Re}_{L p}$ for samples $\# 14\left(T_{d}=20 \mathrm{~mm}\right)$ and \#17 $\left(T_{d}=26 \mathrm{~mm}\right)$ 


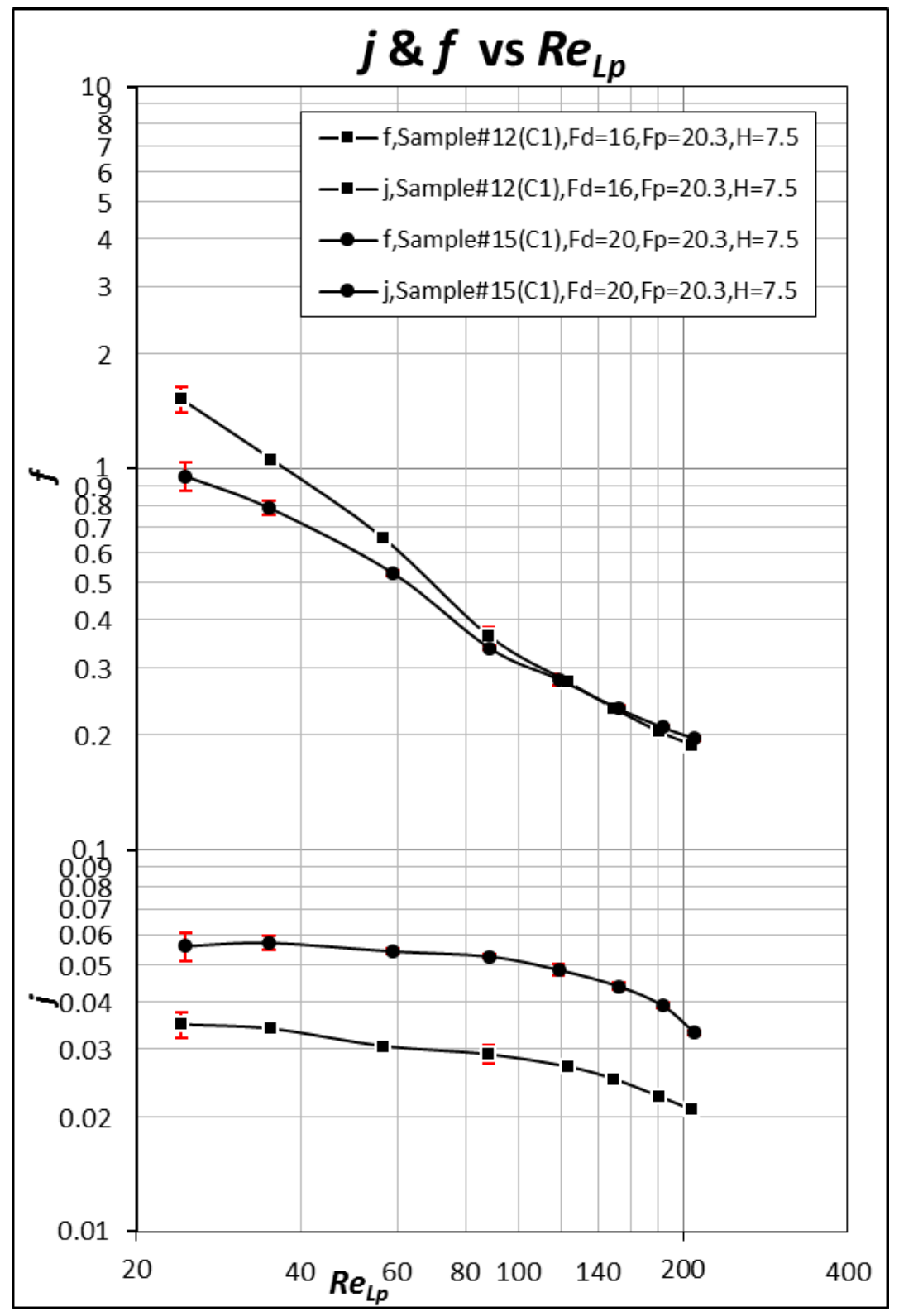

Figure 45. f \& j Factors Vs $\operatorname{Re}_{\mathrm{Lp}}$ for samples \#12 $\left(\mathrm{T}_{\mathrm{d}}=16 \mathrm{~mm}\right)$ and \#15 $\left(\mathrm{T}_{\mathrm{d}}=20 \mathrm{~mm}\right)$

Figure 46 shows the $\mathrm{j}$ and f factors for samples \# 10 and 16, where both their tube depth $\left(\mathrm{T}_{\mathrm{d}}\right)$ and fin pitch $\left(\mathrm{F}_{\mathrm{p}}\right)$ are different. The tube depth for samples \# 10 and 16 are $16 \mathrm{~mm}$ and $26 \mathrm{~mm}$, respectively; while the fin depth for samples \# 10 and 16 are 19.24 FPI and 14.94 FPI, respectively. The combined effect is that sample \#10, as compared to sample \#16, has higher f and lower j. 


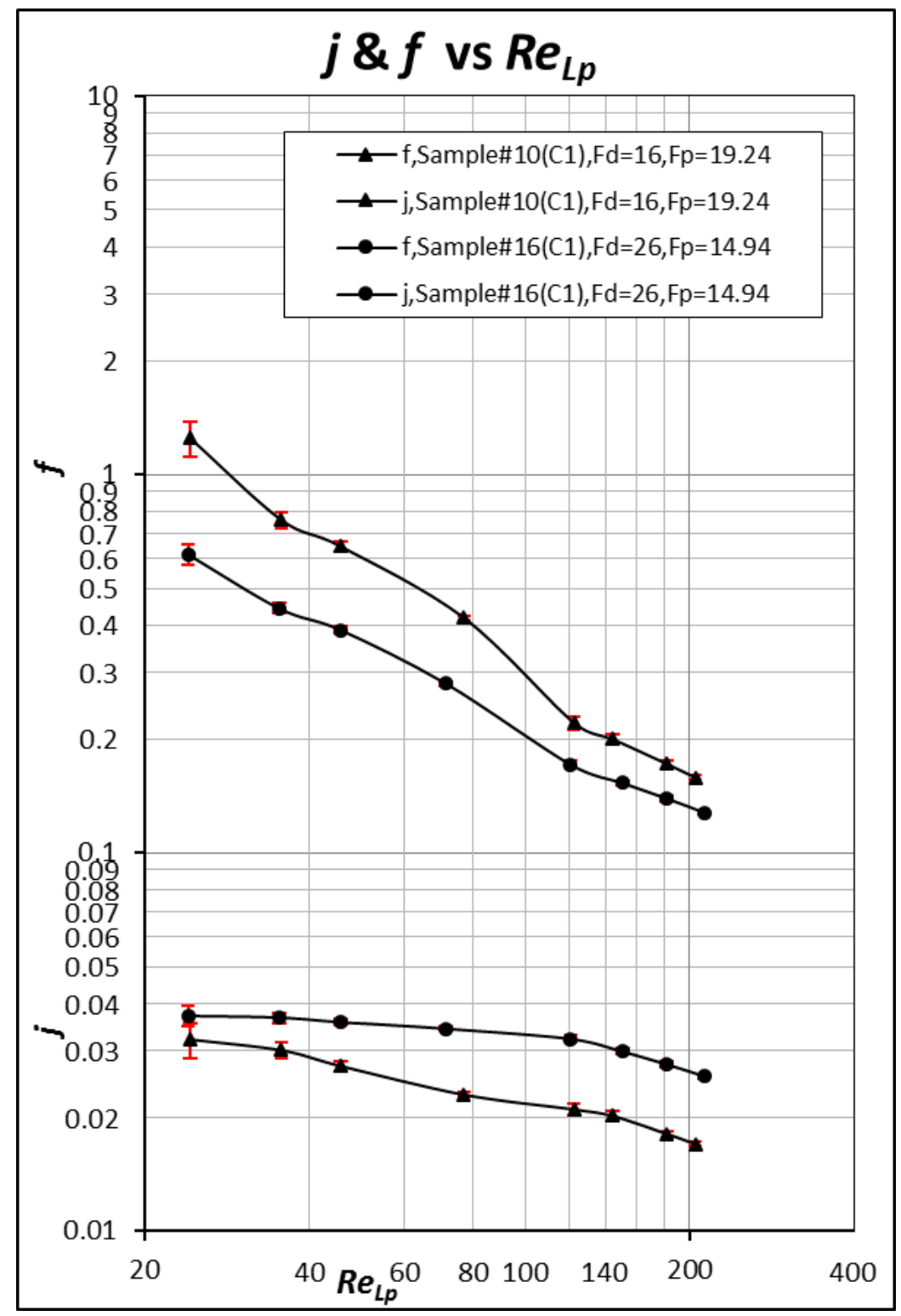

Figure 46. $f \&$ j factors $V s \operatorname{Re}_{L p}$ for samples \#10 $\left(F_{p}=19.24\right.$ FPI, $\left.T_{d}=16 \mathrm{~mm}\right)$ and $\# 16\left(F_{p}=14.94 \mathrm{FPI}, T_{d}=26 \mathrm{~mm}\right)$

Figure 47 shows the $\mathrm{j}$ and $\mathrm{f}$ factors for samples \# 7 and 11, where both their louver angle $(\theta)$ and tube height $(\mathrm{Dm})$ are different. The louver angles for samples \# 7 and 11 are 20o and $28^{\circ}$, respectively; while the tube height for samples \# 7 and 11 are $2 \mathrm{~mm}$ and 1.8 mm, respectively. The combined effect is that sample \#7, as compared to sample \#11, has lower $\mathrm{f}$ and $\mathrm{j}$ factors. 


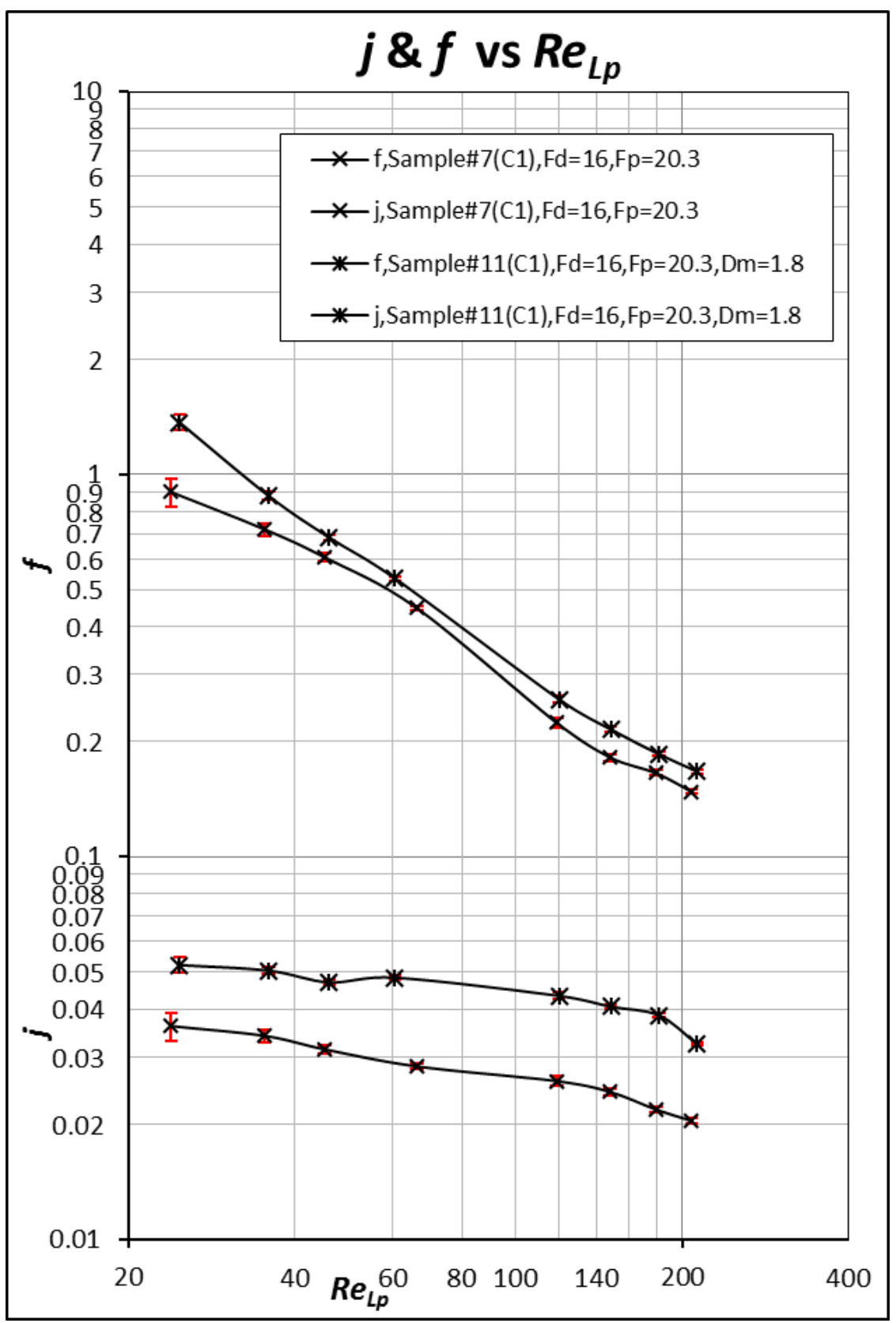

Figure 47. $\&$ \& $j$ Factors Vs $\operatorname{Re}_{L p}$ for samples $\# 7\left(\theta=20^{\circ}, D_{m}=2 \mathrm{~mm}\right)$ and $\# 11\left(\theta=28^{\circ}, D_{m}=\right.$ $1.8 \mathrm{~mm}$ )

Figure 48 through Figure 52 provide the $\mathrm{f}$ and $\mathrm{j}$ plots for other test samples. As there are more than one geometrical parameters that are varying, the differences in the $\mathrm{f}$ and $\mathrm{j}$ factors in each one of these figures reflected the combined effects of the varying parameters, which are listed in the Test Matrix (Table 3). 


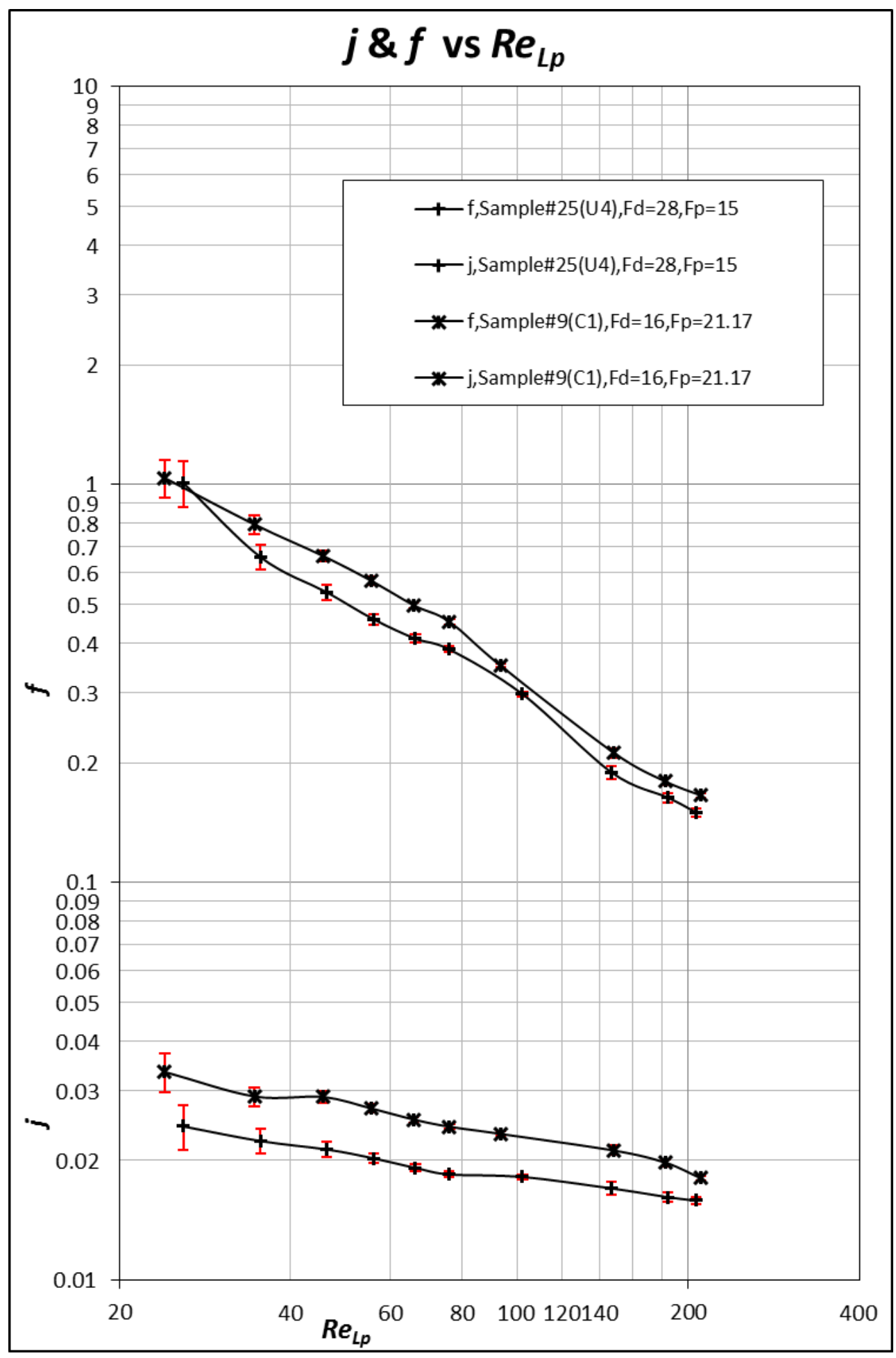

Figure 48. $\mathrm{f} \&$ j factors $V s \operatorname{Re}_{\mathrm{Lp}}$ for samples \#9 and \#25 


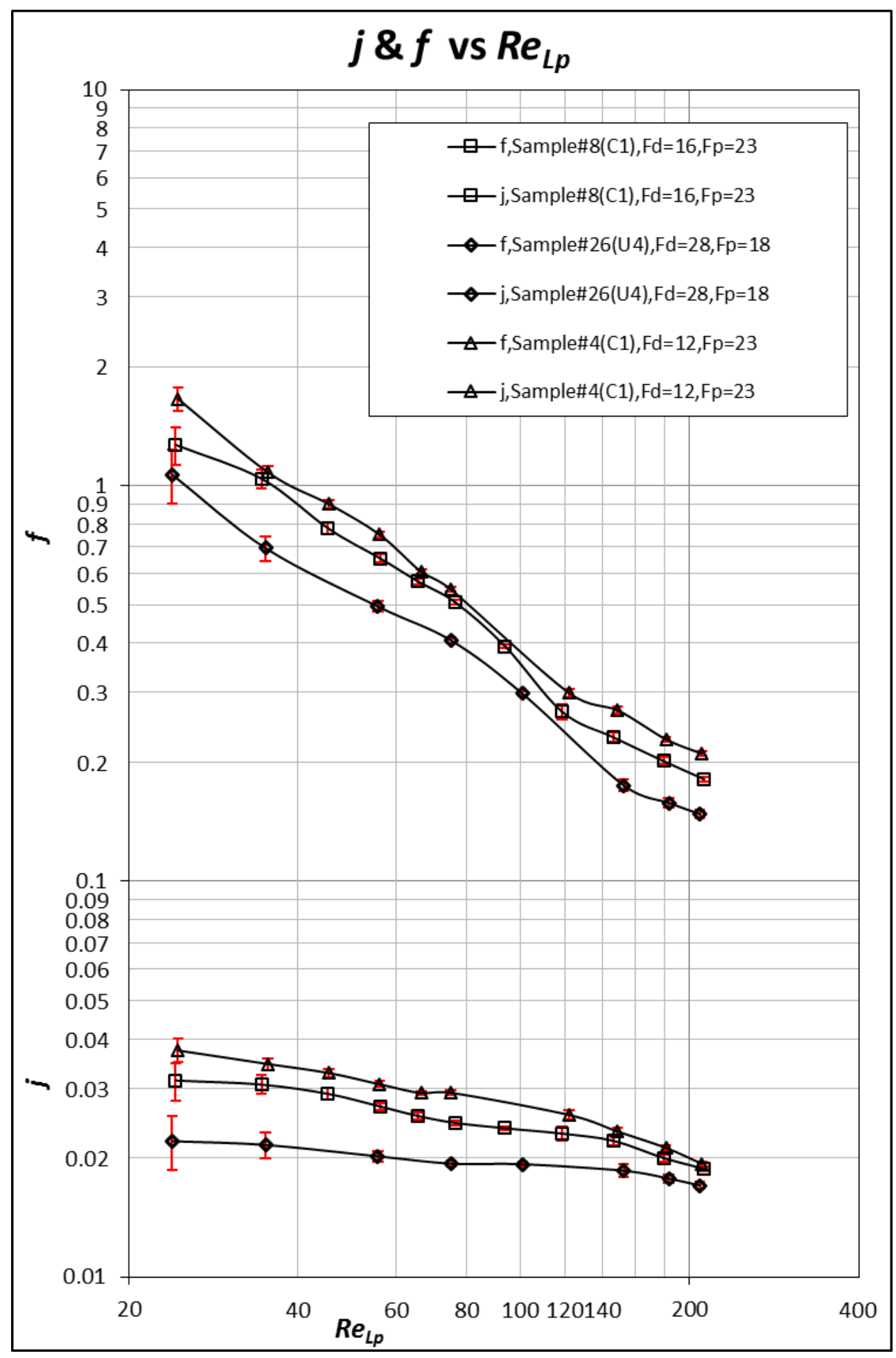

Figure 49. $f$ \& $\mathrm{j}$ Factors $V s \operatorname{Re}_{\mathrm{Lp}}$ for samples \#4, \#8, and \#26 


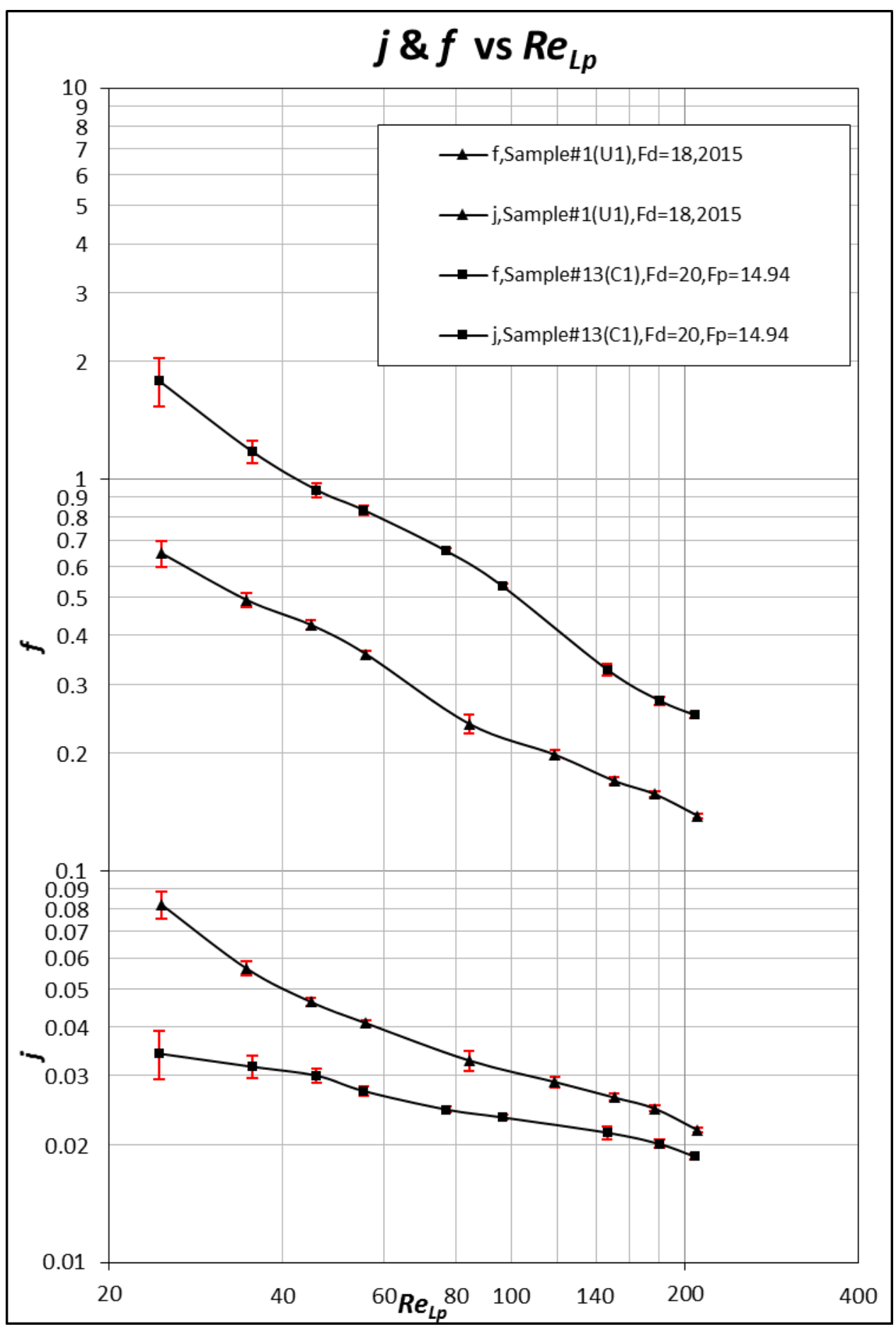

Figure 50. $f \&$ j factors $V s \operatorname{Re}_{\mathrm{Lp}}$ for samples \#1 and \#13 


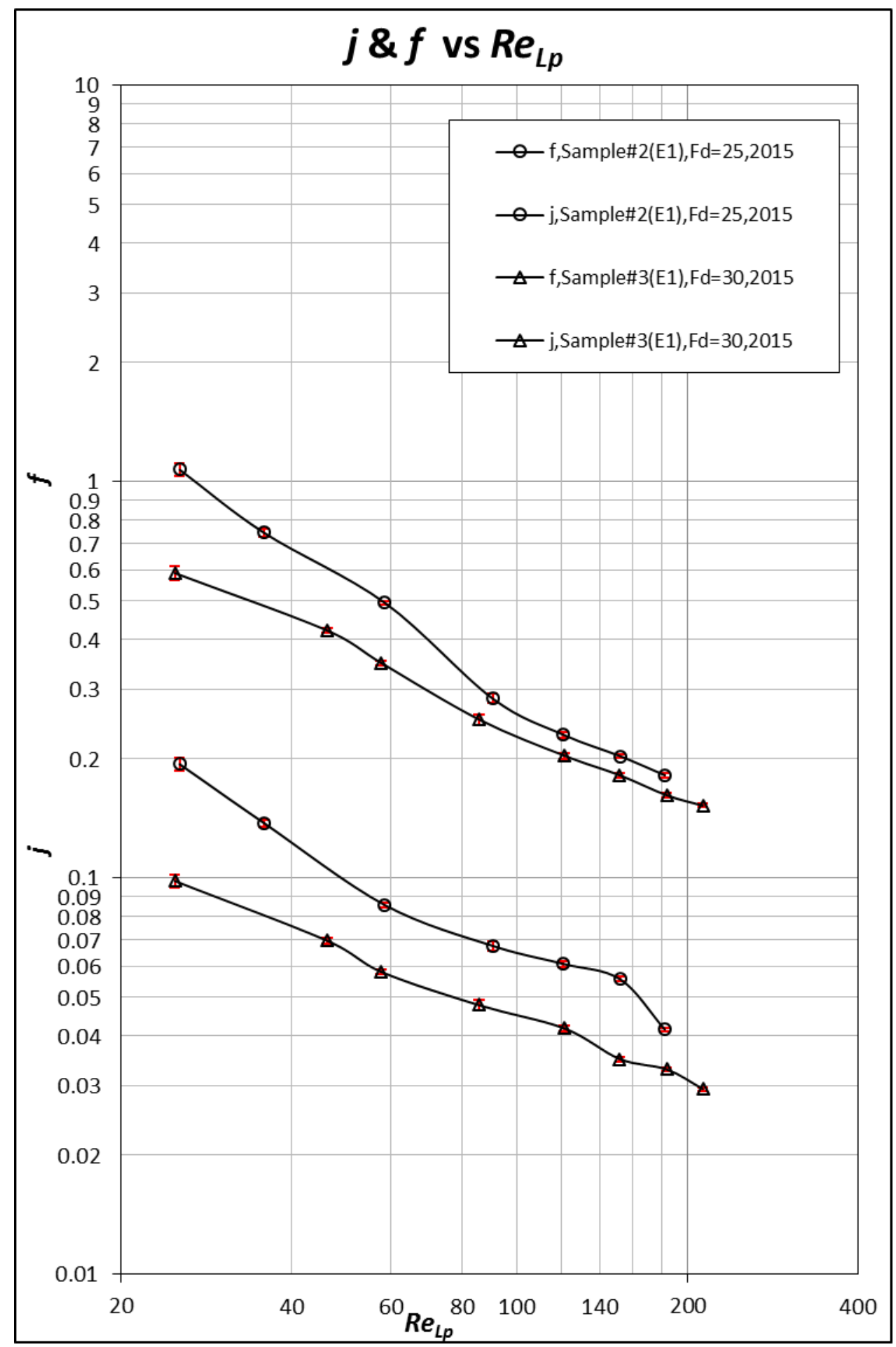

Figure 51. f \& j Factors Vs $\operatorname{Re}_{\mathrm{Lp}}$ for samples \#2, and \#3 


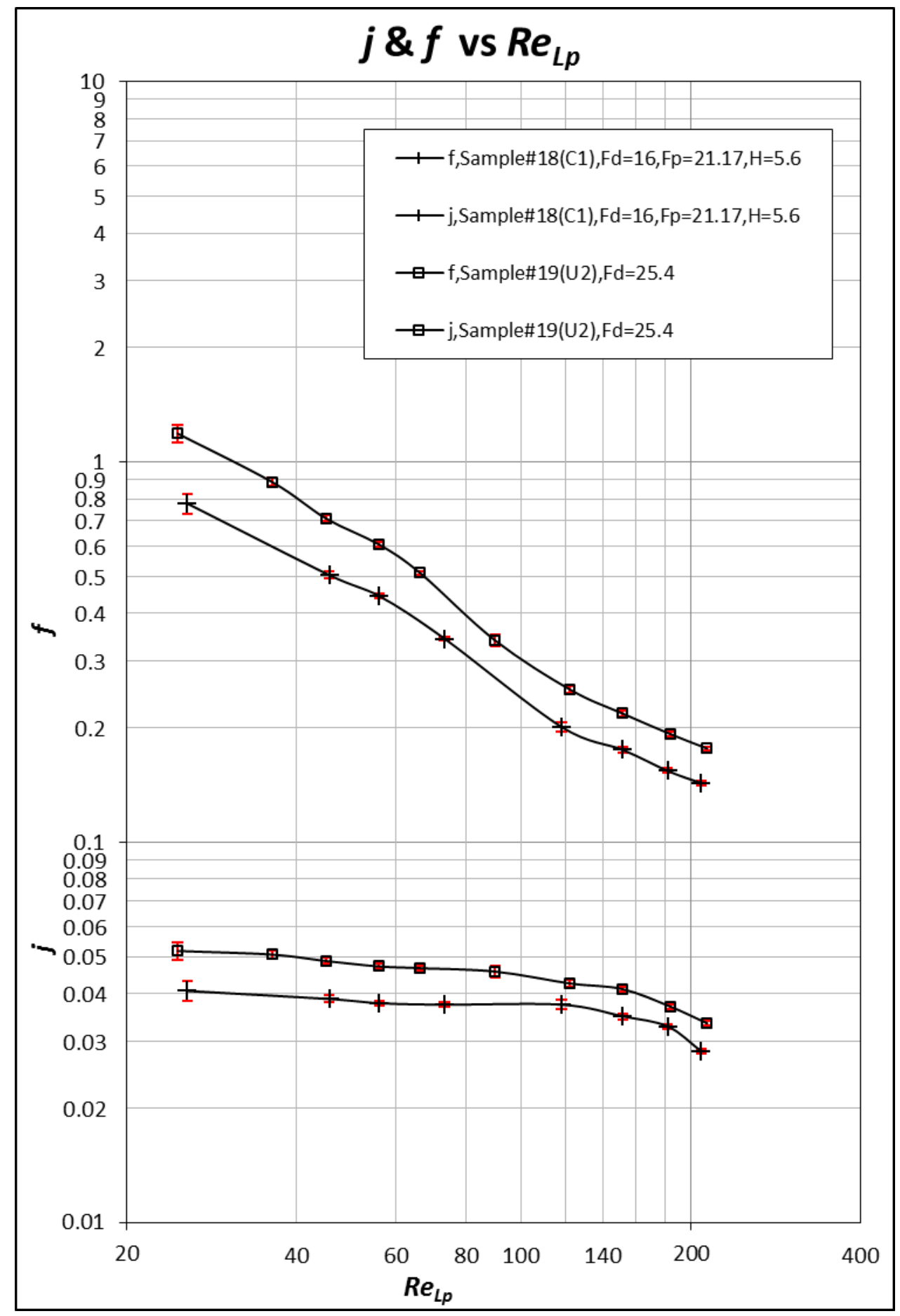

Figure $52 . \mathrm{f} \& \mathrm{j}$ factors $V s \operatorname{Re}_{L p}$ for samples \#18 and \#19

All the experimental data are provided in Figure 53, which gives an overview of the data ranges for $\mathrm{j}$ and $\mathrm{f}$ factors within the investigated parameter ranges for this study. 


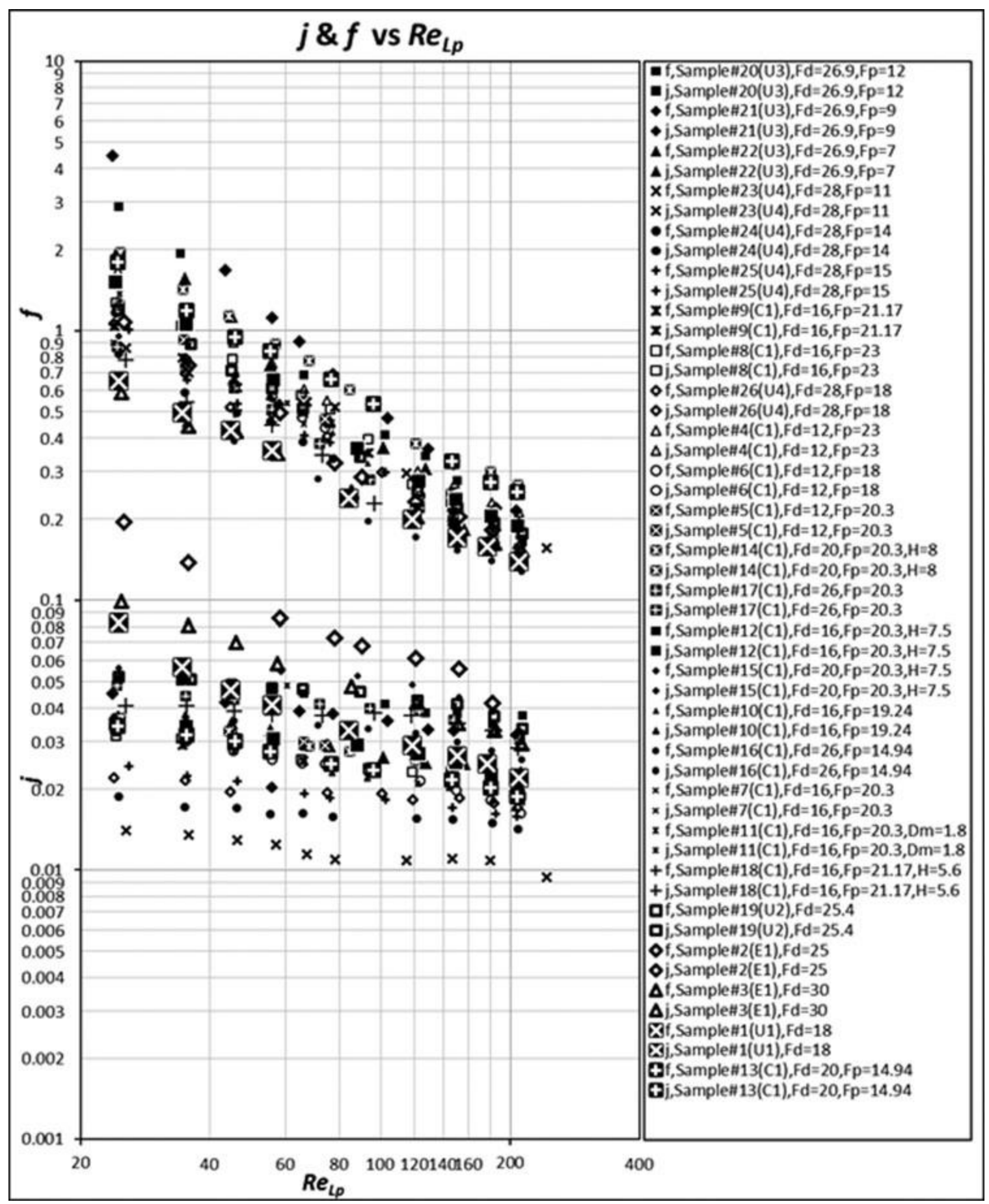

Figure 53. $f \&$ j factors $V s \operatorname{Re}_{L p}$ for all the samples

\subsubsection{Discussions about the Two Flow Regime Phenomena}

This section comments briefly on the general characteristics of present experimental 
data as compared to the previously reported research. In the work by Achaichia and Cowell (1988), the heat transfer data, in terms of Stanton number (St, which is proportional to the $\mathrm{j}$ factor), have noticeable "wavy" behavior when the Reynolds number is in very low range (loosely in the order of about $\operatorname{Re}_{\mathrm{Lp}}<100$ as it depends on samples). In other words, with the increase of $\mathrm{Re}_{\mathrm{Lp}}$, the heat transfer data first drops and then increases within this region in logarithmic scale. The extent of the wavy behavior seems significantly affected by the geometrical parameters, such as fin pitches. This is the region that was sometimes claimed as the transition from louver-direct to fin directed flows. However, such "wavy" behavior was not clearly identified as the dominated characteristics in the heat transfer data obtained from the present study.

As will be shown in the next section, only a couple of samples, such as Sample \#11 in Figure 47, have shown weak wavy behavior in the present study. In overall, most of the heat transfer test data seem to behave "monotonically" with the change of Reynolds number - with the increase of Reynolds number, the $\mathrm{j}$-factor decreases. It seems the present heat transfer data behave in a way closer to a linear relationship with $\mathrm{Re}_{\mathrm{Lp}}$ in the logarithmic scale, except that the slopes of the data lines are different from each other in two flow regions $\left(\operatorname{Re}_{\mathrm{Lp}} \leq 80\right.$ and $\left.\operatorname{Re}_{\mathrm{Lp}}>80\right)$.

It is also important to point out the differences between the types of heat exchangers used in the present study and those in Achaichia and Cowell (1988), although they all called microchannel or compact heat exchangers with louvered fins. Per the classification by Chang and Yang (1997), the test samples in the present study is Type A Corrugated Louver with Triangular Channel, while those used in the literature is Type B Plate and Tube Louver Fin Geometry. The main differences between Type A and Type B louver fin heat 
exchangers are:

1) Fins of Type A forms triangular channel while fins of Type B form parallel plate channel for the air flows;

2) There is usually single flat tube in Type A while there are two or multiple flat tubes in Type B within the fin depth.

These differences between the Type A and Type B louver fin heat exchangers could be the main reason that present heat transfer data look somewhat different from previous research in the literature.

Never the less, almost all of the test samples in the present study have shown certain levels of "flattening" phenomena in the $\mathrm{j}$ factors with the decrease of the Reynolds numbers. While some of the test samples have very weak flattening behavior, some other samples, such as those of sample \#17 in Figure 47, samples \# 12 and 15 in Figure 48, and samples \# 18 and 19 in Figure 52, to name a few, do demonstrate the flattening phenomena that is noticeable in the graphs. This could serve as a confirmation of the existence of unusual or unique characteristics in heat transfer for compact heat exchangers at very low Reynolds numbers. In other words, the two regime concept still can be applied to the present research to explain the heat transfer behaviors in low Reynolds number range.

In summary, from the study, it is clear to the understanding that, the two flow regimes do exist, where fluid flow and heat transfer behave differently: when $\operatorname{Re}_{\mathrm{Lp}}$ is very low, air flow through the louver is minimized due to thick, viscous boundary layers, forming fin directed flow; when $\operatorname{Re}_{\mathrm{Lp}}$ is higher, air flow through the louver is augmented due to thinner boundary layers, forming louver direct flow. However, the specific heat transfer curve vs Re $_{\mathrm{Lp}}$ is dictated by the detailed configurations of the louver fins and flat tubes in the heat 
exchangers, which might look different from existing work. These observations provide some guides in developing the power-law correlations for $\mathrm{j}$ and $\mathrm{f}$ factors, to be detailed in the next chapter Correlations. 


\section{CHAPTER $6: j$ AND $f$ FACTOR CORRELATIONS}

The collected test data for low Reynolds numbers were analyzed to develop correlations for both the $\mathrm{j}$ and f factors using all of the key parameters in the text matrix, except the tube depth $\left(T_{d}\right)$. This is because, for most of the test samples used in this study, the fin depth $\left(F_{d}\right)$ is identical to the tube depth $\left(T_{d}\right)$. Inclusions of either $T_{d}$ or $F_{d}$ resulted in nearly the same correlations and coefficients. Therefore, only $F_{d}$, rather than both $T_{d}$ and $F_{d}$ was used in the development of correlations for the $\mathrm{j}$ and $\mathrm{f}$ factors.

In developing the correlations, the percentage of the correlated test data dictates the root-mean-square (rms) errors. In the literature for high Reynolds numbers, the percentage used by researchers varied considerably. For example, $83.14 \%$ of the test data of f-factor are correlated within $\pm 15 \%$ by Chang et al. (2000); $89.3 \%$ of the test data of $\mathrm{j}$-factor are correlated within $\pm 15 \%$ by Chang and Wang (1997); $94.5 \%$ of test data of f-factor are correlated within $\pm 12 \%$, and $91.1 \%$ of the test data of f-factor within $\pm 20 \%$ by Li and Wang (2010). As will be shown in the following discussion, roughly $85 \%$ of test data of the present study are correlated for the correlations.

As mentioned earlier, most of the present test data supports the existence of two powerlaw curves of different slopes within two sub-ranges: the lower range $\left(\operatorname{Re}_{\mathrm{Lp}}=20-80\right)$ and the higher range $\left(\operatorname{Re}_{\mathrm{Lp}}=80-200\right)$. Efforts of correlating all of the experimental data using a single correlation equation for either $\mathrm{j}$ or $\mathrm{f}$ factors have resulted un-satisfactory results. In the followings, we will present the correlations using the two $\operatorname{Re}_{\mathrm{Lp}}$ sub-ranges with 93.6 $-99.6 \%$ confidence levels. The rms error is indicated right under each correlation equation. 


\section{1 j FACTOR CORRELATIONS}

Equation 58 below represents $\mathrm{j}$ factor correlation for $20<\operatorname{Re}_{\mathrm{Lp}} \leq 200$, which predicts $85.46 \%$ of experimental data within $\pm 23.94 \%$. The plot of correlated data against the experimental data is shown in Figure 54 below.

$$
j=R e_{L p}^{-0.277}\left(\frac{F_{p}}{L_{p}}\right)^{-0.002}\left(\frac{H}{L_{p}}\right)^{-2.246}\left(\frac{\delta}{L_{p}}\right)^{-0.001}\left(\frac{\theta}{90}\right)^{1.337}\left(\frac{L_{l}}{L_{p}}\right)^{1.598}\left(\frac{D_{m}}{L_{p}}\right)^{1.739}\left(\frac{F_{d}}{L_{p}}\right)^{-0.091}
$$

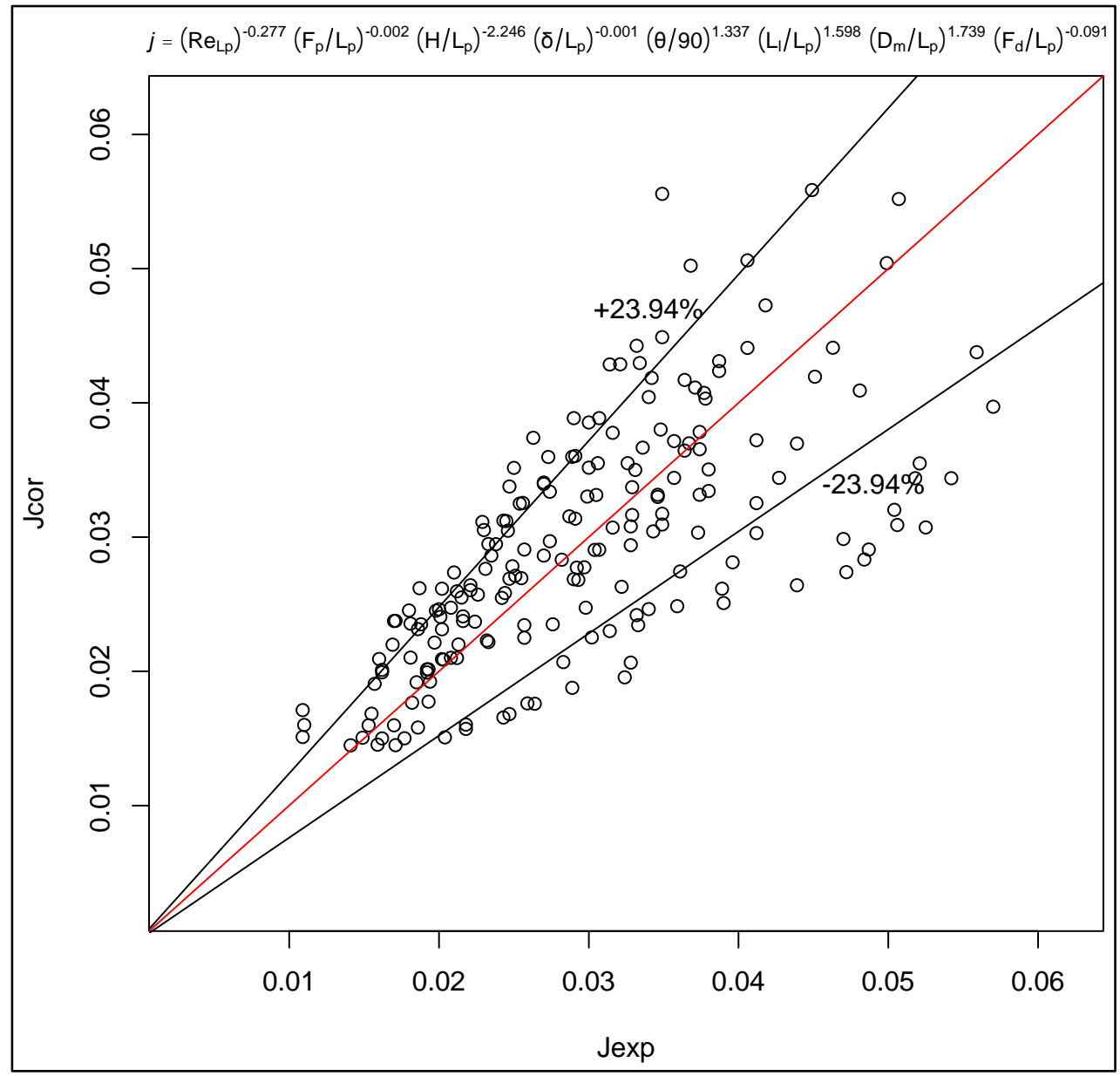

Figure 54. Comparison of Experimental Data and Correlation for $\mathrm{j}$ Factor $\left(20<\operatorname{Re}_{\mathrm{Lp}} \leq \mathbf{2 0 0}\right)$

When $20<\operatorname{Re}_{\mathrm{Lp}} \leq 80$, the $\mathrm{j}$ factor can be correlated by the following equation (59): 


$$
j=R e_{L p}-0.324\left(\frac{F_{p}}{L_{p}}\right)^{-0.2}\left(\frac{H}{L_{p}}\right)^{-2.3}\left(\frac{\delta}{L_{p}}\right)^{-0.001}\left(\frac{\theta}{90}\right)^{1.1}\left(\frac{L_{l}}{L_{p}}\right)^{1.72}\left(\frac{D_{m}}{L_{p}}\right)^{1.88}\left(\frac{F_{d}}{L_{p}}\right)^{-0.195}
$$

The above correlation (59) is developed with at least $84.48 \%$ of the test data being correlated.

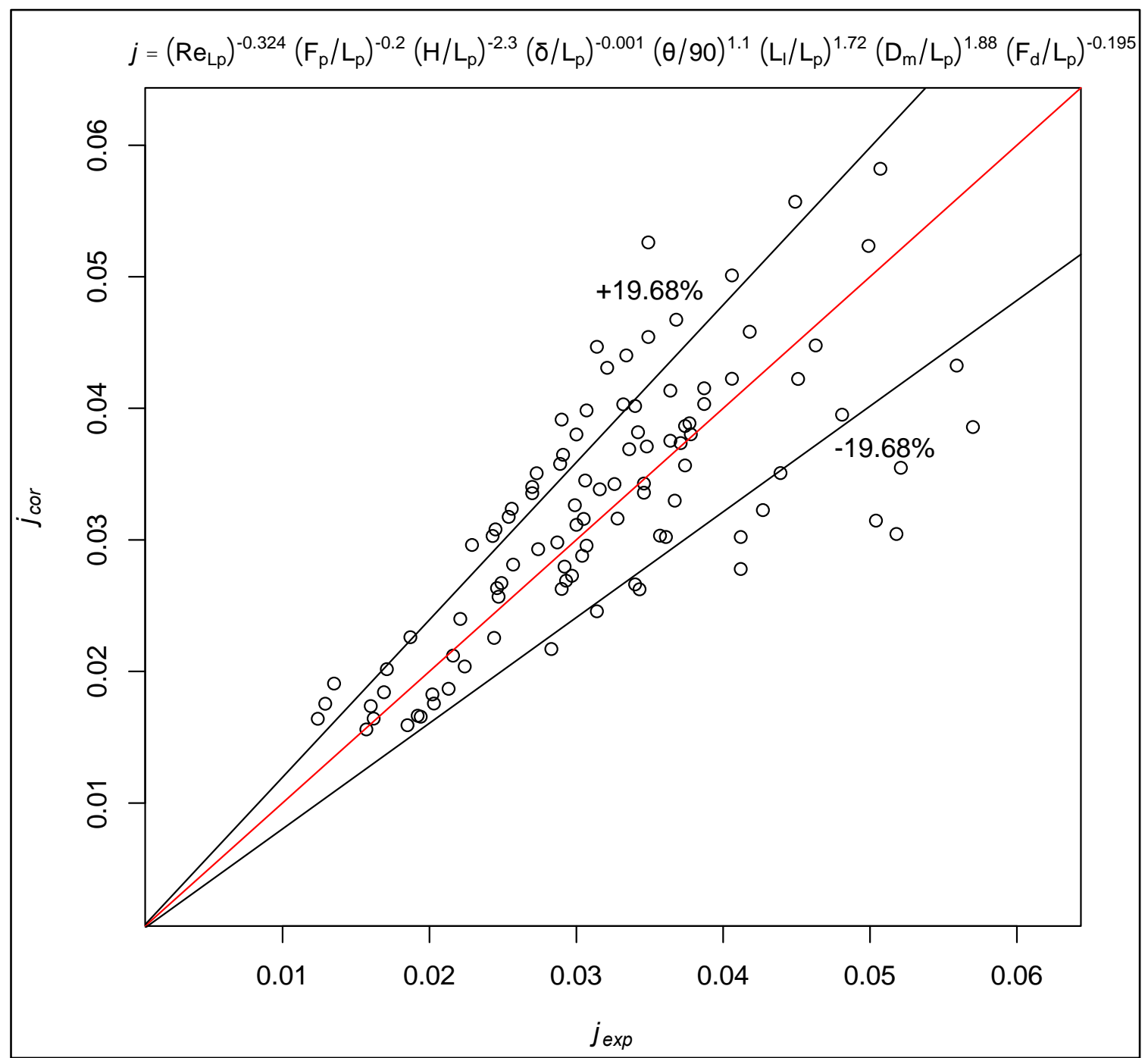

Figure 55. Comparison of Experimental Data and Corre lation for j Factor $\left(20<\operatorname{Re}_{\mathrm{Lp}} \leq 80\right)$

Figure 55 shows the comparison of experimental data and the correlation for the $\mathrm{j}$ factors. The present correlation predicts the test data within an rms error of $\pm 19.68 \%$. 
When $80<\operatorname{Re}_{\mathrm{Lp}} \leq 200$, the $\mathrm{j}$ factor can be expressed by the following equation (60):

$$
j=R e_{L p}^{-0.4}\left(\frac{F_{p}}{L_{p}}\right)^{-0.07}\left(\frac{H}{L_{p}}\right)^{-2.48}\left(\frac{\delta}{L_{p}}\right)^{-0.006}\left(\frac{\theta}{90}\right)^{0.9}\left(\frac{L_{l}}{L_{p}}\right)^{1.83}\left(\frac{D_{m}}{L_{p}}\right)^{1.65}\left(\frac{F_{d}}{L_{p}}\right)^{-0.012}
$$

The above correlation (60) correlates at least $84.8 \%$ of the test data.

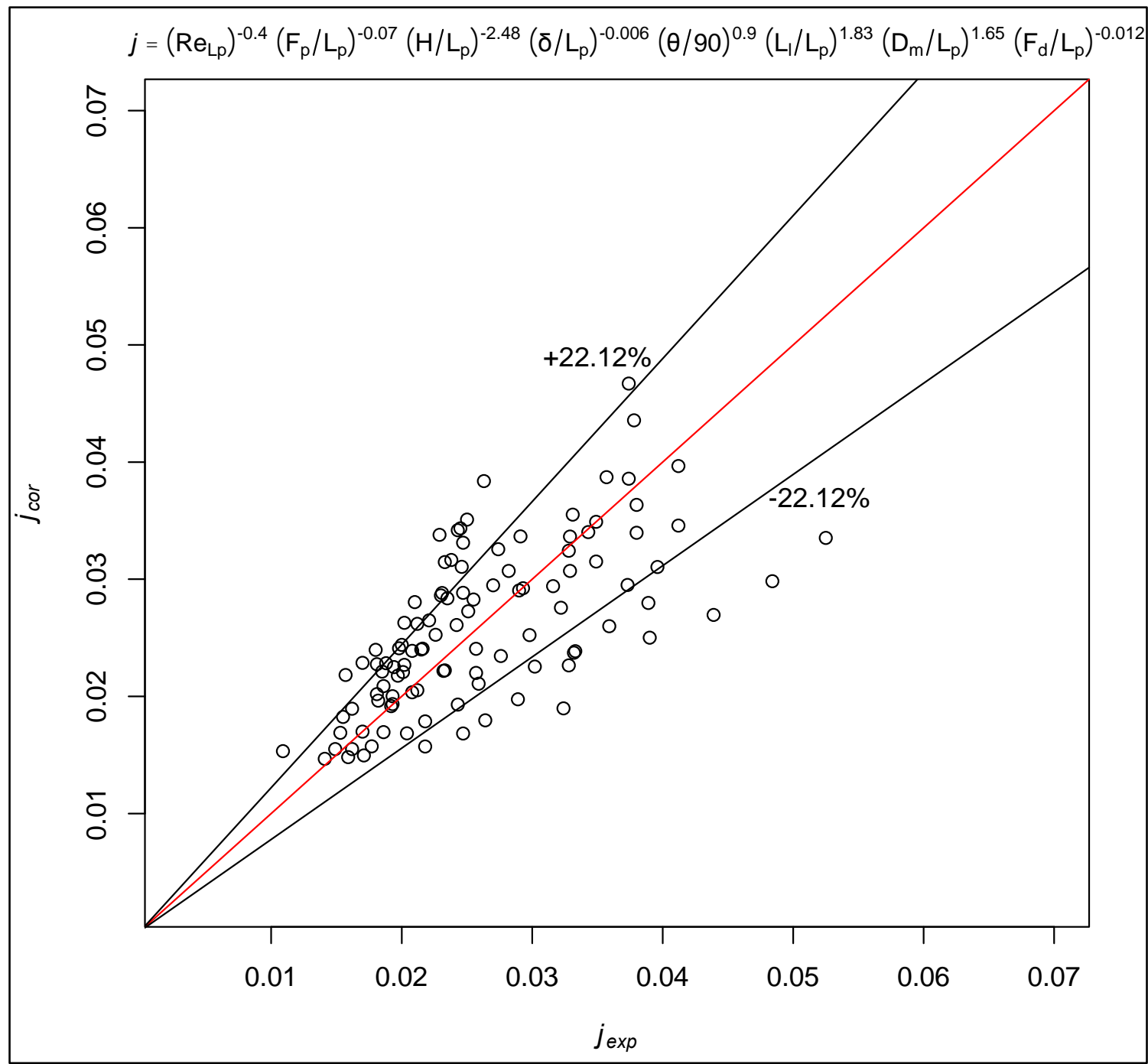

Figure 56. Comparison of Experimental Data and Corre lation for $\mathrm{j}$ Factor $\left(80<\operatorname{Re}_{\mathrm{Lp}} \leq 200\right)$

Figure 56 shows the comparison of the experimental data and predicted results using the above correlation for the $\mathrm{j}$ factor in the range of $80<\mathrm{Re}_{\mathrm{Lp}} \leq 200$, within an $\mathrm{rms}$ error of $\pm 22.12 \%$. 


\section{2 f FACTOR CORRELATIONS}

Equation 61 below represents $\mathrm{f}$ factor correlation for $20<\operatorname{Re}_{\mathrm{Lp}} \leq 200$, which predicts $86.78 \%$ of experimental data within $\pm 13.87 \%$. The plot of correlated data against the experimental data is shown in Figure 57 below.

$$
f=R e_{L p}{ }^{-0.908}\left(\frac{F_{p}}{L_{p}}\right)^{-0.004}\left(\frac{H}{L_{p}}\right)^{-0.007}\left(\frac{\delta}{L_{p}}\right)^{-1.259}\left(\frac{\theta}{90}\right)^{0.715}\left(\frac{L_{l}}{L_{p}}\right)^{0.253}\left(\frac{D_{m}}{L_{p}}\right)^{0.653}\left(\frac{F_{d}}{L_{p}}\right)^{0.033}
$$

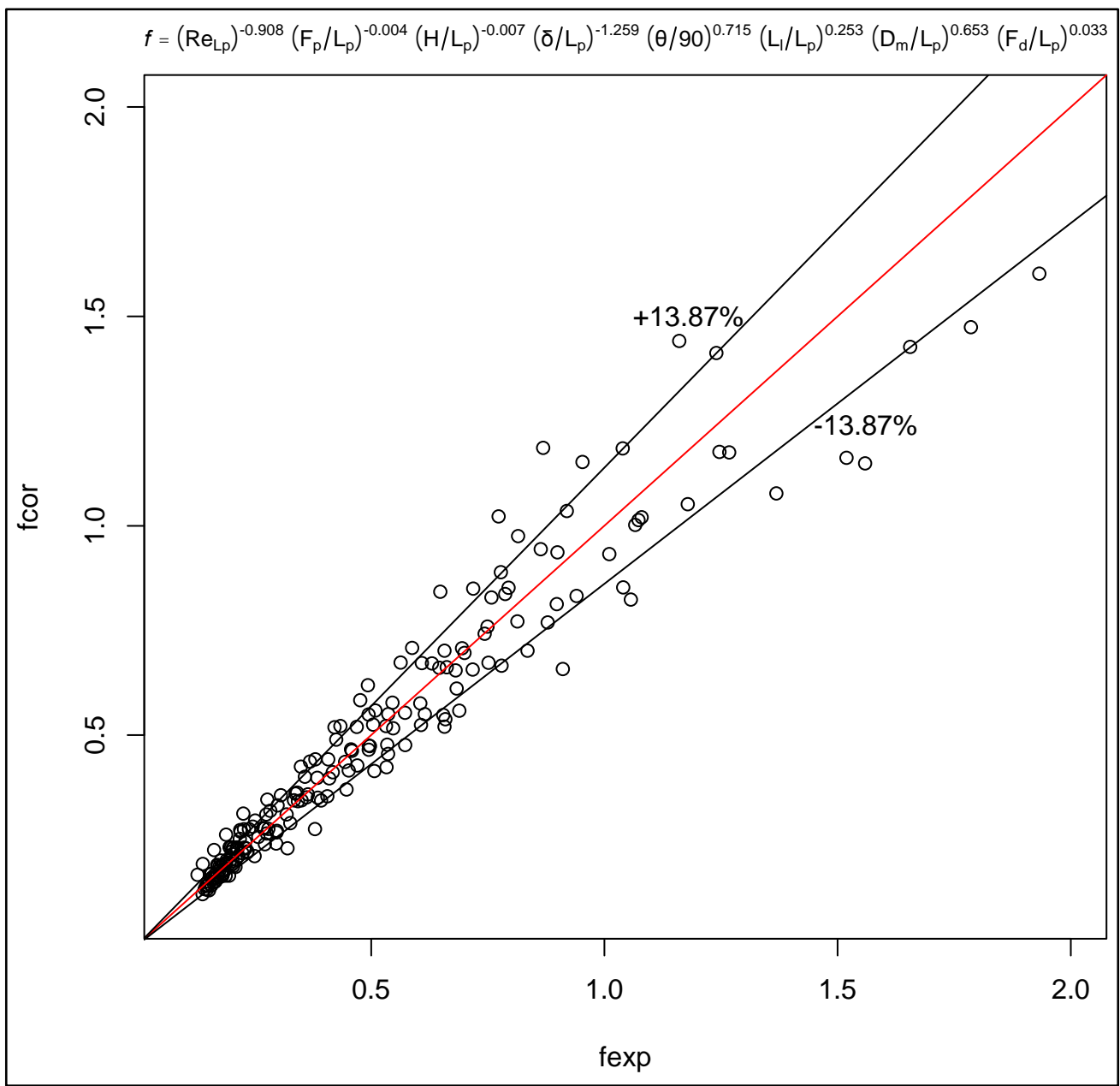

Figure 57. Comparis on of Experimental Data and Corre lation for $f$ Factor $\left(20<\operatorname{Re}_{\mathrm{Lp}} \leq \mathbf{8 0}\right)$

When $20<\operatorname{Re}_{L_{p}} \leq 80$, the f factor can be expressed by the following equation (62) with at least $85.34 \%$ test data correlated. 
$f=\operatorname{Re}_{L p}{ }^{-0.87}\left(\frac{F_{p}}{L_{p}}\right)^{-0.06}\left(\frac{H}{L_{p}}\right)^{-0.014}\left(\frac{\delta}{L_{p}}\right)^{-1.35}\left(\frac{\theta}{90}\right)^{0.67}\left(\frac{L_{l}}{L_{p}}\right)^{0.007}\left(\frac{D_{m}}{L_{p}}\right)^{0.83}\left(\frac{F_{d}}{L_{p}}\right)^{0.019}$

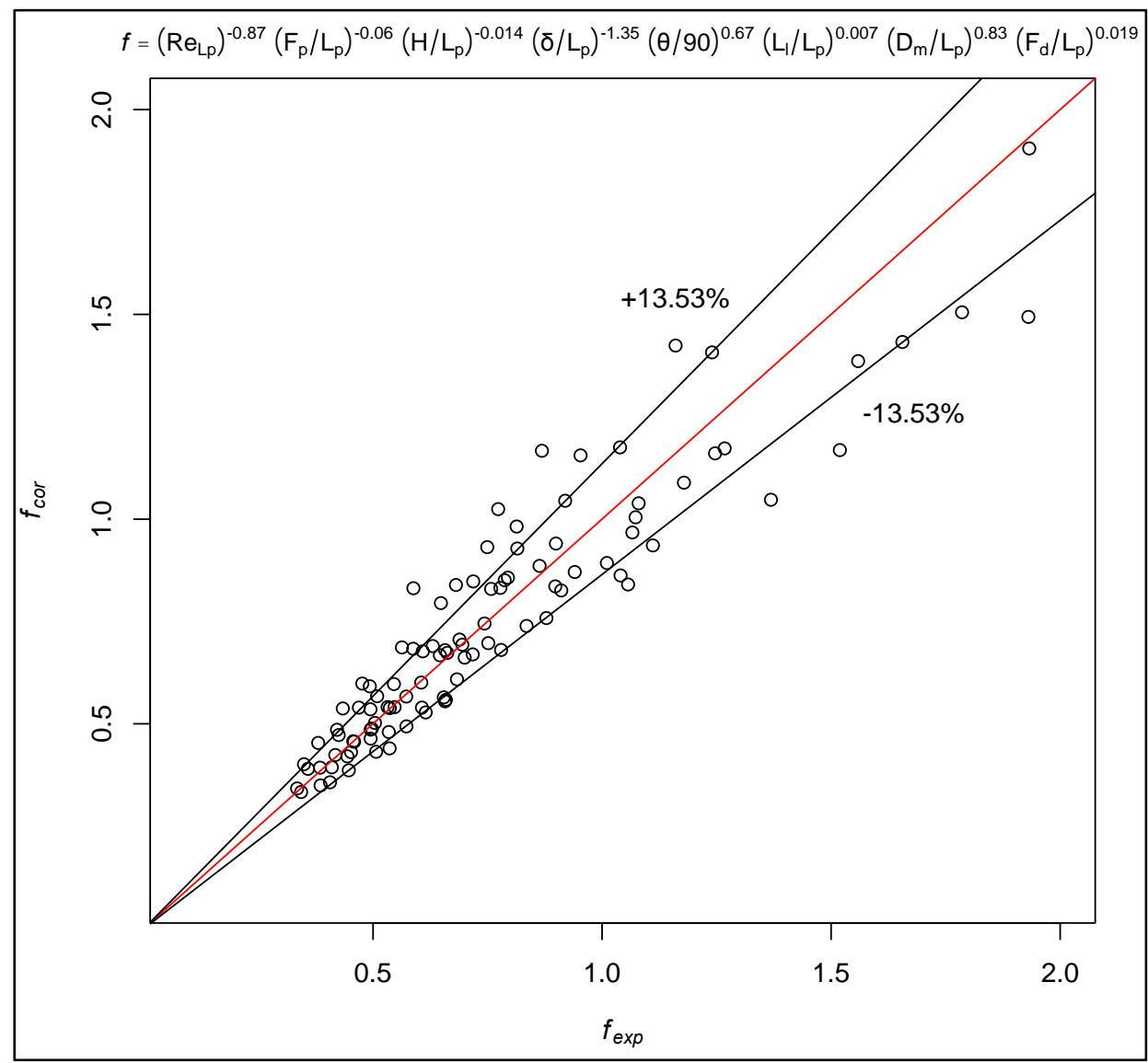

Figure 58. Comparis on of Experimental Data and Corre lation for $f$ Factor $\left(20<\operatorname{Re}_{\mathrm{Lp}} \leq \mathbf{8 0}\right)$

Figure 58 shows the comparison of experimental data and the correlation for the $\mathrm{f}$ factors in the range of $20<\operatorname{Re}_{\mathrm{Lp}} \leq 80$. The above correlation (62) predicts the test data within an rms error of $\pm 13.53 \%$.

When $80<\operatorname{Re}_{\mathrm{Lp}} \leq 200$, the f factor can be expressed by the following equation (63) with at least $85.6 \%$ test data correlated.

$$
f=R e_{L p}{ }^{-0.856}\left(\frac{F_{p}}{L_{p}}\right)^{-0.016}\left(\frac{H}{L_{p}}\right)^{-0.01}\left(\frac{\delta}{L_{p}}\right)^{-1.21}\left(\frac{\theta}{90}\right)^{0.74}\left(\frac{L_{l}}{L_{p}}\right)^{0.31}\left(\frac{D_{m}}{L_{p}}\right)^{0.52}\left(\frac{F_{d}}{L_{p}}\right)^{-0.054}
$$




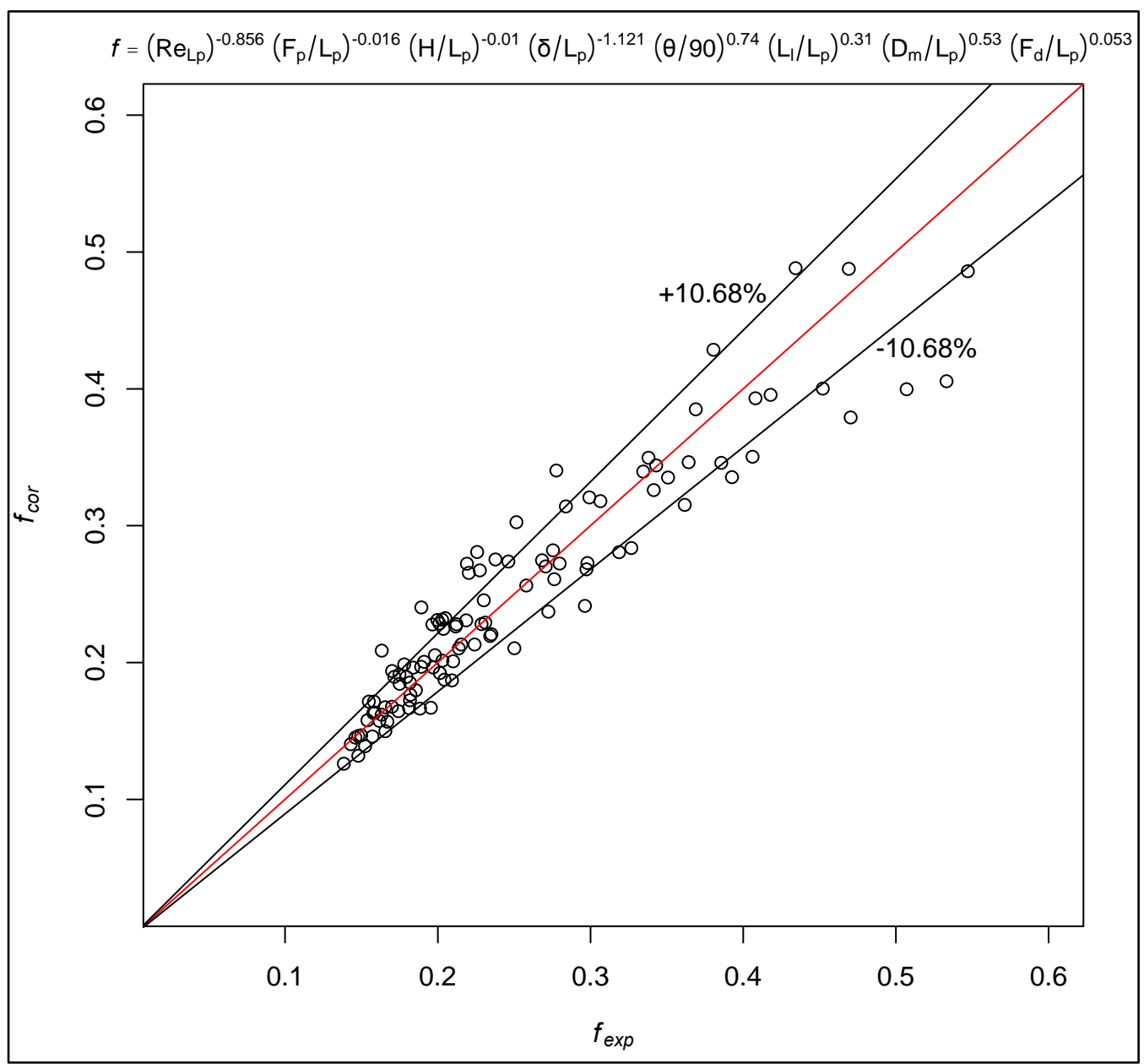

Figure 59. Comparison of Experimental Data and Correlation for $f$ Factor $\left(80<\operatorname{Re}_{\mathrm{Lp}} \leq 200\right)$

Figure 59 shows the comparison of the experimental data and predicted results using the above correlation for the f factor in the range of $80<\mathrm{Re}_{\mathrm{Lp}} \leq 200$. The above correlation (63) predicts the test data with an rms error of $\pm 10.68 \%$.

\subsection{SIMPLIFIED CORRELATIONS}

The correlation equations mentioned in the section 7.1.3 constitutes eight variables. In this section a simplified version of the equations for the two regimes are proposed by combining the variables. 


\subsubsection{Importance of Variables Test}

Prior to combining the variables, it is important to investigate the effect of each variable on the thermal hydraulic performance of the louver fin heat exchangers. Figures 60 to 62 show the analysis of principal components within the respective datasets.

Figure 60 depicts the variances of the components that can better represent the data for the range of Reynolds number from 20 to 80 . As can be seen from the figure the variances of the first three components are more than 5\%, and therefore, these three are the principal components that can better represent the data. From the variance analysis it is found that 91.5\% of experimental data can be represented using three principal components, in this case.

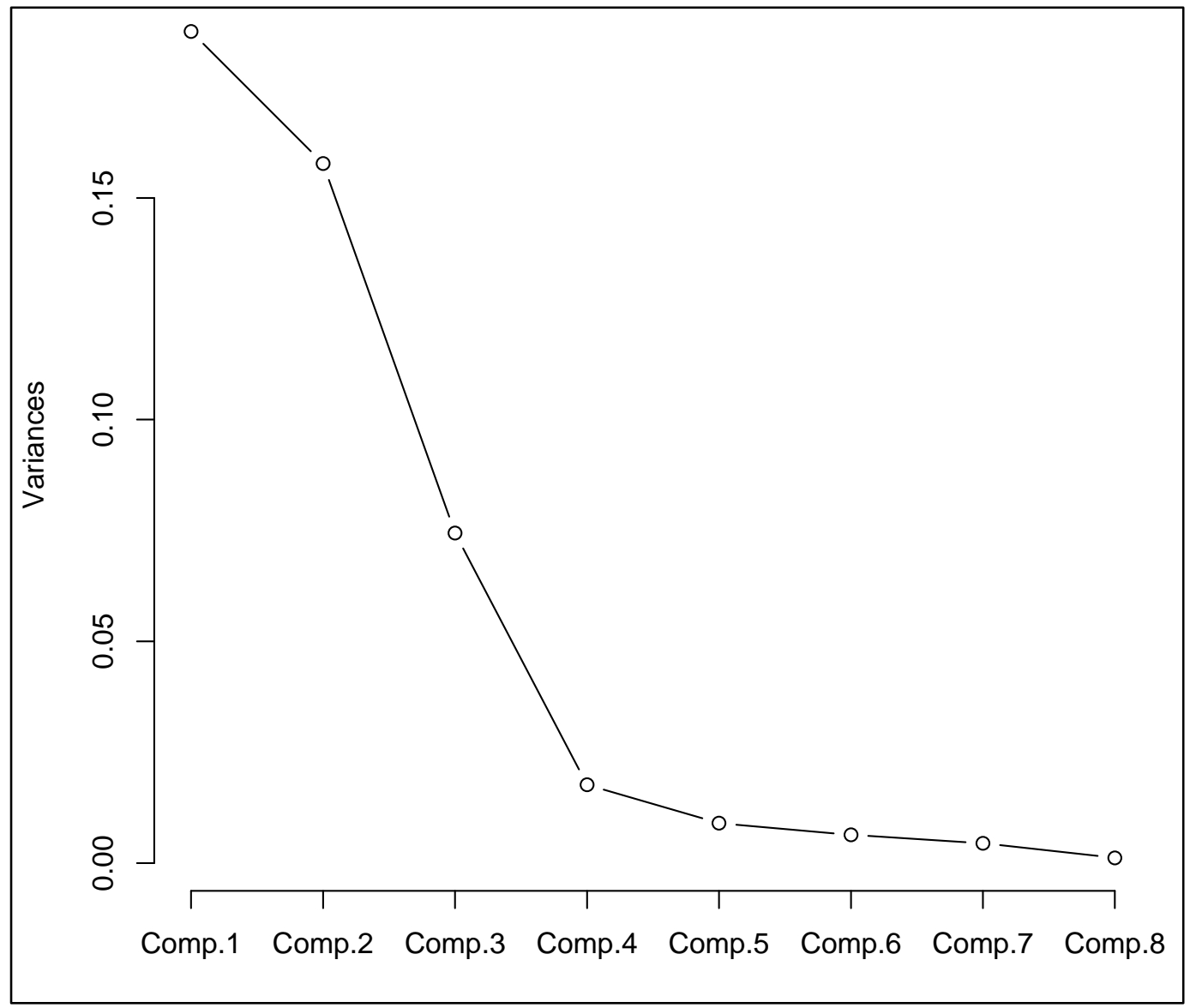

Figure 60. Analysis of principal components in j-factor for $20<\operatorname{Re}_{\mathrm{Lp}} \leq 80$ 
Figure 61 shows the covariance plot of the two principal components representing the experimental data. It can be seen from the figure that most of the variables in the consideration are aligning towards one direction except the Reynolds number and the louver angle, which are in completely opposite direction. This directs the unique independence of the Reynolds number and the louver angle, whereas the rest of the variables show their interdependence. Figure 62 reveals the correlation obtained by combining the variables together in the $\mathrm{j}$-factor equation for the Reynolds number from 20 to 80. Similar analysis has conducted for the simplified correlation development of $\mathrm{j}$ and $\mathrm{f}$ factor in two flow regimes. The plots of the analysis are listed in the APPENDIX B.

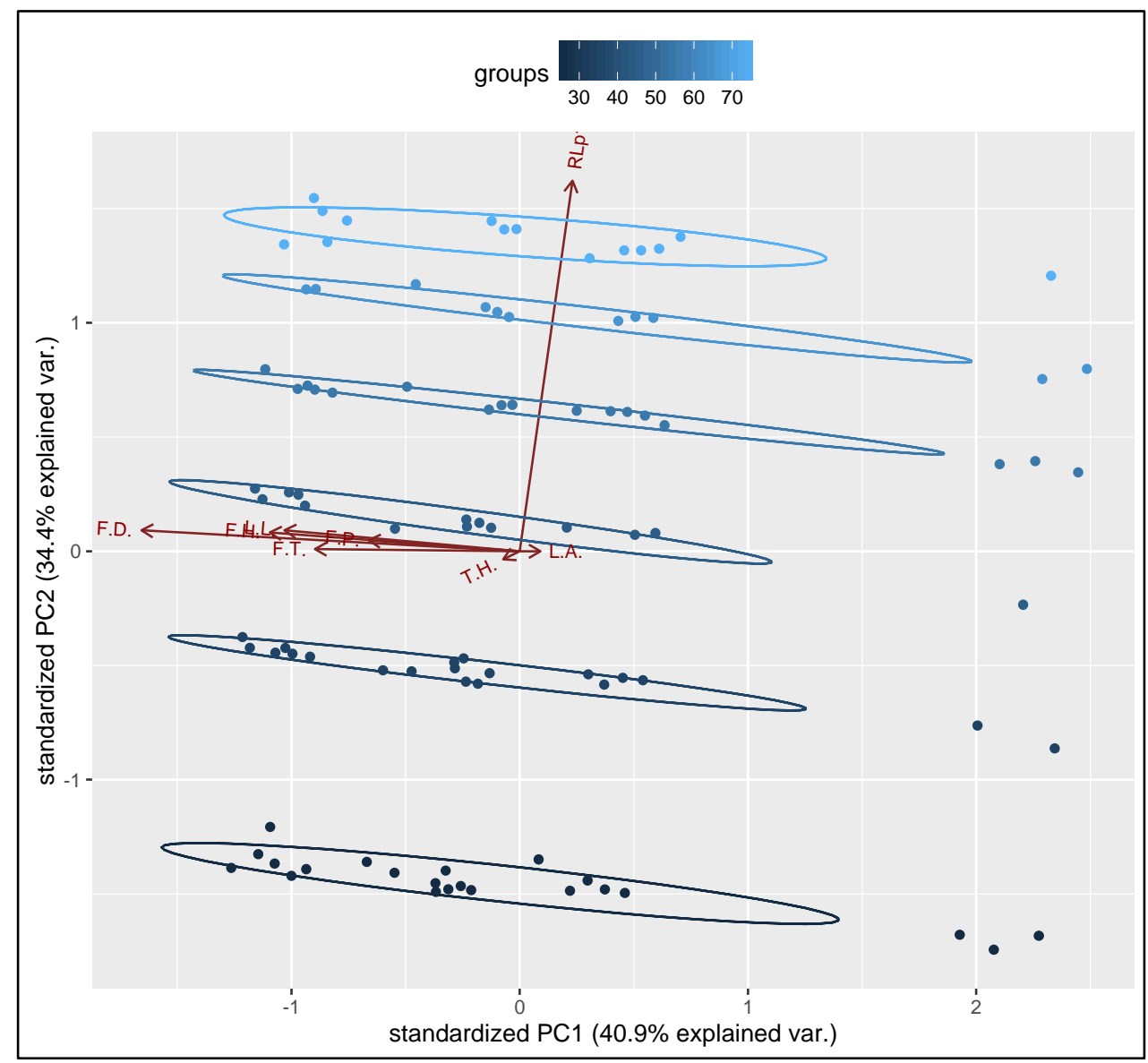

*Dataset groups in the Figure are based on the Reynolds number from 25 to 75.

Figure 61. Covariance of the two principal components representing the dataset 


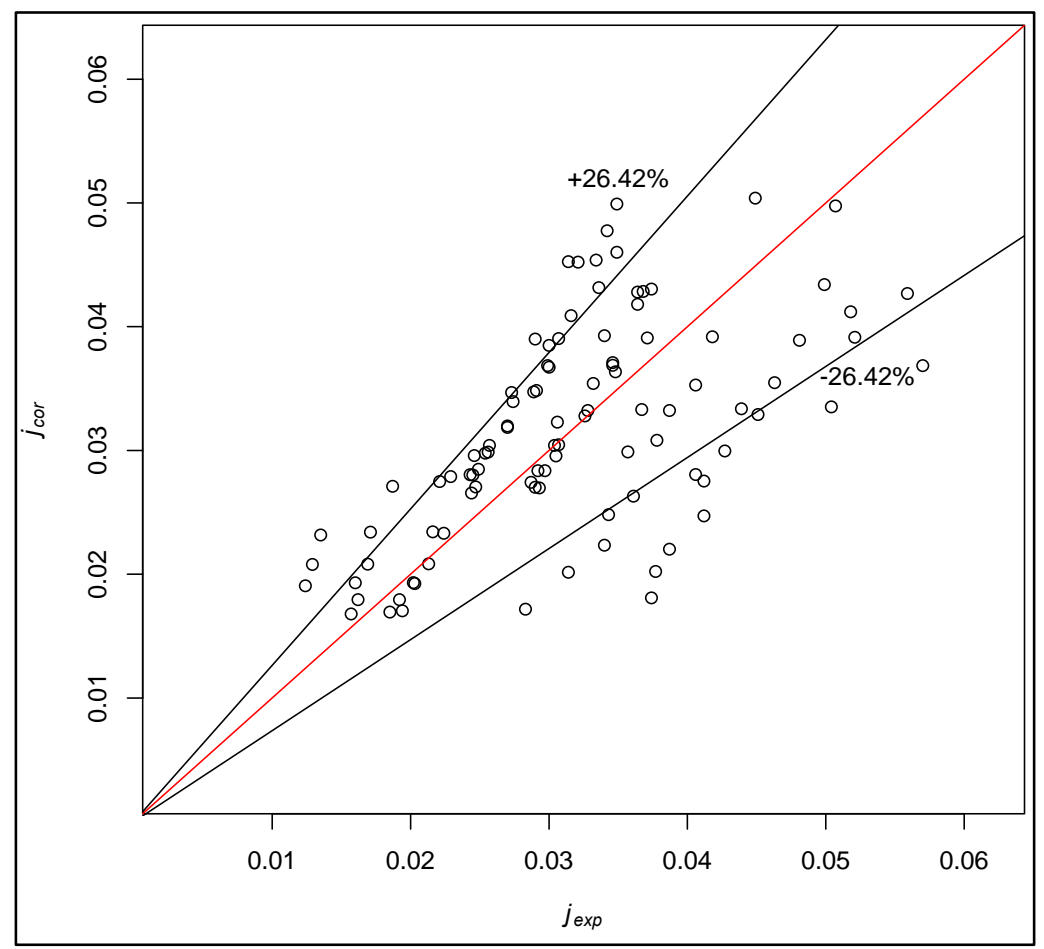

Figure 62. Corre lated Simplified j Factor vs. Experimental j Factor $\left(20<\operatorname{Re}_{L p} \leq 80\right)$

\subsubsection{Simplified Correlations of $\mathbf{j}$ and f Factors for Two Flow Regime}

Equations from 64 to 79 below shows the simplified correlations obtained by combination of variables for the two flow regimes of $\mathrm{j}$ and f factors by combining the variables together. Equation 64 depicts the simplified $\mathrm{j}$-factor correlation for $20<\operatorname{Re}_{\mathrm{Lp}} \leq$ 80 representing the experimental data within $\pm 26.42 \%$.

$$
j=R e_{L p}{ }^{-0.417}\left(\frac{\theta}{90}\right)^{1.629}\left(j_{1}\right)^{-0.035}\left(j_{2}\right)^{-0.155}\left(j_{3}\right)^{0.11}
$$

where,

$$
j_{1}=\left(\frac{H}{L_{p}}\right)^{0.937}\left(\frac{\delta}{L_{p}}\right)^{0.711}\left(\frac{L_{l}}{L_{p}}\right)^{0.988}
$$




$$
\begin{aligned}
& j_{2}=\left(\frac{F_{p}}{L_{p}}\right)^{0.697}\left(\frac{\delta}{L_{p}}\right)^{0.527}\left(\frac{F_{d}}{L_{p}}\right)^{0.955} \\
& j_{3}=\left(\frac{D_{m}}{L_{p}}\right)^{0.867}
\end{aligned}
$$

Equation 68 depicts the simplified j-factor correlation for $80<\operatorname{Re}_{\mathrm{Lp}} \leq 200$ representing the experimental data within $\pm 28.66 \%$.

$$
j=R e_{L p}{ }^{-0.464}\left(\frac{\theta}{90}\right)^{1.187}\left(j_{1}\right)^{-0.074}\left(j_{2}\right)^{-0.069}\left(j_{3}\right)^{0.077}
$$

where,

$$
\begin{aligned}
& j_{1}=\left(\frac{H}{L_{p}}\right)^{0.889}\left(\frac{\delta}{L_{p}}\right)^{0.776}\left(\frac{L_{l}}{L_{p}}\right)^{0.969} \\
& j_{2}=\left(\frac{F_{p}}{L_{p}}\right)^{0.624}\left(\frac{F_{d}}{L_{p}}\right)^{0.9} \\
& j_{3}=\left(\frac{D_{m}}{L_{p}}\right)^{0.961}
\end{aligned}
$$

Equation 72 depicts the simplified f-factor correlation for $20<\mathrm{Re}_{\mathrm{Lp}} \leq 80$ representing the experimental data within $\pm 20.4 \%$.

$$
f=R e_{L p}^{-0.52}\left(\frac{\theta}{90}\right)^{-1.339}\left(f_{1}\right)^{-0.176}\left(f_{2}\right)^{-0.155}\left(f_{3}\right)^{0.005}
$$

where,

$$
\begin{aligned}
& f_{1}=\left(\frac{H}{L_{p}}\right)^{0.904}\left(\frac{\delta}{L_{p}}\right)^{0.739}\left(\frac{L_{l}}{L_{p}}\right)^{0.99} \\
& f_{2}=\left(\frac{F_{p}}{L_{p}}\right)^{0.596}\left(\frac{F_{d}}{L_{p}}\right)^{0.956}
\end{aligned}
$$




$$
f_{3}=\left(\frac{D_{m}}{L_{p}}\right)^{0.88}
$$

Whereas, equation 76 depicts the simplified f-factor correlation for $80<\operatorname{Re}_{\mathrm{Lp}} \leq 200$ representing the experimental data within $\pm 22.23 \%$.

$$
f=R e_{L p}^{-0.489}\left(\frac{\theta}{90}\right)^{-0.804}\left(f_{1}\right)^{-0.084}\left(f_{2}\right)^{-0.087}\left(f_{3}\right)^{0.036}
$$

where,

$$
\begin{aligned}
& f_{1}=\left(\frac{H}{L_{p}}\right)^{0.886}\left(\frac{\delta}{L_{p}}\right)^{0.767}\left(\frac{L_{l}}{L_{p}}\right)^{0.976} \\
& f_{2}=\left(\frac{F_{p}}{L_{p}}\right)^{0.938} \\
& f_{3}=\left(\frac{D_{m}}{L_{p}}\right)^{0.979}
\end{aligned}
$$

\subsection{CORRELATIONS OVERVIEW}

\subsubsection{Comparison of Experimental Data with Available Correlations}

In this section, the $\mathrm{j}$ - and f-factor experimental data are compared to the well-known correlations by Chang, Y. J., and Wang (1997), Chang et al. (2000), and Kim \& Bullard (2002). A summary of the differences between the current data and the correlations by these authors are provided in Table 11 below.

As can be seen from the previously discussed four correlations, all the correlations by Chang and co-works and Kim and Bullard can only correlate less than 67\% (as low as $36.56 \%$ ) of the current experimental data with a deviation of $\pm 25 \%$. In contrast, as noted earlier, the proposed correlations equations are able to correlate about $85 \%$ of the data 
within errors of less than $\pm 25 \%$ (less than $\pm 22.12 \%$ for $\mathrm{j}$ and less than $\pm 13.53 \%$ for $\mathrm{f}$ ). This confirms that within the investigated parameter ranges, the proposed correlations work better than the existing ones for predicting the test data obtained from this project. This is not surprising as the existing correlations are developed primarily for high Reynolds number applications and the heat exchanger geometries are different from those used in this project. The existing correlations, as reported in the related references, work very well with their own data set, but not for the test data from this project.

Table 11: Percentage of the Total Data Falling Within the Specified Deviation

\begin{tabular}{|c|c|c|c|c|c|c|c|c|}
\hline & \multicolumn{8}{|c|}{ Deviation of prediction from data } \\
\hline $\begin{array}{l}\text { Source of } \\
\text { prediction }\end{array}$ & $\begin{array}{l}\text { Within } \\
\pm 5 \%\end{array}$ & $\begin{array}{l}\text { Within } \\
\pm 10 \%\end{array}$ & $\begin{array}{l}\text { Within } \\
\pm 15 \%\end{array}$ & $\begin{array}{l}\text { Within } \\
\pm 20 \%\end{array}$ & $\begin{array}{l}\text { Within } \\
\pm 25 \%\end{array}$ & $\begin{array}{l}\text { Within } \\
\pm 40 \%\end{array}$ & $\begin{array}{l}\text { Within } \\
\pm 45 \%\end{array}$ & $\begin{array}{l}\text { Within } \\
\pm 50 \%\end{array}$ \\
\hline $\begin{array}{l}j \text { (Chang and } \\
\text { Wang 1997) }\end{array}$ & $7.49 \%$ & $15.42 \%$ & $22.03 \%$ & $28.63 \%$ & $36.56 \%$ & $61.67 \%$ & $69.6 \%$ & $78.85 \%$ \\
\hline $\begin{array}{l}f(\text { Chang et al. } \\
2000)\end{array}$ & $20.26 \%$ & $33.92 \%$ & $47.58 \%$ & $55.95 \%$ & $66.96 \%$ & $92.51 \%$ & $97.36 \%$ & $100 \%$ \\
\hline $\begin{array}{l}\text { (Kim and } \\
\text { Bullard 2002) }\end{array}$ & $4.41 \%$ & $12.78 \%$ & $21.59 \%$ & $33.48 \%$ & $44.1 \%$ & $74.89 \%$ & $84.14 \%$ & $92.1 \%$ \\
\hline $\begin{array}{l}f(\text { Kim and } \\
\text { Bullard 2002) }\end{array}$ & $15.86 \%$ & $28.63 \%$ & $38.33 \%$ & $46.7 \%$ & $55.07 \%$ & $82.38 \%$ & $88.55 \%$ & $92.95 \%$ \\
\hline
\end{tabular}

\subsubsection{Additional Comments on the $\mathrm{j}$ - and f-Factor Correlations}

First, the fact that the test data can be correlated within two Reynolds number ranges supports the concept of flow regime transition from louver-directed flow to duct-directed flow, to some extent. The existence of the two flow regimes is believed to be the main reason that causes the differences in the correlations in two different Reynolds number ranges, although they are in the same power-law formats.

Secondly, the signs of the coefficients for every parameter in the power-law correlations are consistent with those reported in most of the literature, representing the physics of the flow behavior over the studied geometries. 
Simplified correlations reduces number of variables in the correlation equation at the same time representing $100 \%$ of the experimental data within each range. The factored correlations for $\mathrm{j}$ and $\mathrm{f}$ factors for both the range of flow regime follows the sign conventions as the unified correlations proposed, representing the flow physics quantitatively. However, there is a slight disadvantage seen as all of the simplified correlation equations show significantly higher rms errors. This is also reasonable, since the simplified equations are developed on $100 \%$ of the experimental data for the respective ranges, accounting the wide spread of the data, in addition to the higher errors in the measurement at this low Reynolds number flow, as mentioned earlier.

Table 12 below provides the comparison between three different types of correlations proposed inclusive of their attributes. The use of these correlations is left to ones needs and choices as per the application. 
Table 12: Comparison of Proposed Correlations

\begin{tabular}{|c|c|c|c|c|}
\hline $\mathbf{R e}_{\mathbf{L p}}$ & Proposed Correlations & $\begin{array}{c}\text { Data } \\
\text { Correlated } \\
(\%)\end{array}$ & $\begin{array}{c}\text { RMS } \\
\text { Error } \\
(\%) \\
\end{array}$ & Attributes \\
\hline \multirow{2}{*}{$20-200$} & $j=R e_{L p}^{-0.277}\left(\frac{F_{p}}{L_{p}}\right)^{-0.002}\left(\frac{H}{L_{p}}\right)^{-2.246}\left(\frac{\delta}{L_{p}}\right)^{-0.001}\left(\frac{\theta}{90}\right)^{1.337}\left(\frac{L_{l}}{L_{p}}\right)^{1.598}\left(\frac{D_{m}}{L_{p}}\right)^{1.739}\left(\frac{F_{d}}{L_{p}}\right)^{-0.091}$ & 85.46 & \pm 23.94 & \multirow{2}{*}{$\begin{array}{l}\text { Unified } \\
\text { Correlations }\end{array}$} \\
\hline & $f=R e_{L p}-0.908\left(\frac{F_{p}}{L_{p}}\right)^{-0.004}\left(\frac{H}{L_{p}}\right)^{-0.007}\left(\frac{\delta}{L_{p}}\right)^{-1.259}\left(\frac{\theta}{90}\right)^{0.715}\left(\frac{L_{l}}{L_{p}}\right)^{0.253}\left(\frac{D_{m}}{L_{p}}\right)^{0.653}\left(\frac{F_{d}}{L_{p}}\right)^{0.033}$ & 86.78 & \pm 13.87 & \\
\hline \multirow{2}{*}{$20-80$} & $j=R e_{L p}^{-0.324}\left(\frac{F_{p}}{L_{p}}\right)^{-0.2}\left(\frac{H}{L_{p}}\right)^{-2.3}\left(\frac{\delta}{L_{p}}\right)^{-0.001}\left(\frac{\theta}{90}\right)^{1.1}\left(\frac{L_{l}}{L_{p}}\right)^{1.72}\left(\frac{D_{m}}{L_{p}}\right)^{1.88}\left(\frac{F_{d}}{L_{p}}\right)^{-0.195}$ & 84.48 & \pm 19.68 & \multirow{4}{*}{$\begin{array}{l}\text { Two Flow } \\
\text { Regime } \\
\text { Correlations }\end{array}$} \\
\hline & $f=R e_{L p}^{-0.87}\left(\frac{F_{p}}{L_{p}}\right)^{-0.06}\left(\frac{H}{L_{p}}\right)^{-0.014}\left(\frac{\delta}{L_{p}}\right)^{-1.35}\left(\frac{\theta}{90}\right)^{0.67}\left(\frac{L_{l}}{L_{p}}\right)^{0.007}\left(\frac{D_{m}}{L_{p}}\right)^{0.83}\left(\frac{F_{d}}{L_{p}}\right)^{0.019}$ & 85.34 & \pm 13.53 & \\
\hline \multirow{2}{*}{$80-200$} & $j=R e_{L p}{ }^{-0.4}\left(\frac{F_{p}}{L_{p}}\right)^{-0.07}\left(\frac{H}{L_{p}}\right)^{-2.48}\left(\frac{\delta}{L_{p}}\right)^{-0.006}\left(\frac{\theta}{90}\right)^{0.9}\left(\frac{L_{l}}{L_{p}}\right)^{1.83}\left(\frac{D_{m}}{L_{p}}\right)^{1.65}\left(\frac{F_{d}}{L_{p}}\right)^{-0.012}$ & 84.8 & \pm 22.12 & \\
\hline & $f=R e_{L p}{ }^{-0.856}\left(\frac{F_{p}}{L_{p}}\right)^{-0.016}\left(\frac{H}{L_{p}}\right)^{-0.01}\left(\frac{\delta}{L_{p}}\right)^{-1.21}\left(\frac{\theta}{90}\right)^{0.74}\left(\frac{L_{l}}{L_{p}}\right)^{0.31}\left(\frac{D_{m}}{L_{p}}\right)^{0.52}\left(\frac{F_{d}}{L_{p}}\right)^{-0.054}$ & 85.6 & \pm 10.68 & \\
\hline $20-80$ & $\begin{array}{l}j=R e_{L p}{ }^{-0.417}\left(\frac{\theta}{90}\right)^{1.629}\left(j_{1}\right)^{-0.035}\left(j_{2}\right)^{-0.155}\left(j_{3}\right)^{0.11} \\
j_{1}=\left(\frac{H}{L_{p}}\right)^{0.937}\left(\frac{\delta}{L_{p}}\right)^{0.711}\left(\frac{L_{l}}{L_{p}}\right)^{0.988} \\
j_{2}=\left(\frac{F_{p}}{L_{p}}\right)^{0.697}\left(\frac{\delta}{L_{p}}\right)^{0.527}\left(\frac{F_{d}}{L_{p}}\right)^{0.955} \\
j_{3}=\left(\frac{D_{m}}{L_{p}}\right)^{0.867}\end{array}$ & 100 & \pm 26.42 & \\
\hline
\end{tabular}




\begin{tabular}{|c|c|c|c|c|}
\hline & $\begin{array}{l}f=R e_{L p}{ }^{-0.52}\left(\frac{\theta}{90}\right)^{-1.339}\left(f_{1}\right)^{-0.176}\left(f_{2}\right)^{-0.155}\left(f_{3}\right)^{0.005} \\
f_{1}=\left(\frac{H}{L_{p}}\right)^{0.904}\left(\frac{\delta}{L_{p}}\right)^{0.739}\left(\frac{L_{l}}{L_{p}}\right)^{0.99} \\
f_{1}=\left(\frac{H}{L_{p}}\right)^{0.904}\left(\frac{\delta}{L_{p}}\right)^{0.739}\left(\frac{L_{l}}{L_{p}}\right)^{0.99} \\
f_{3}=\left(\frac{D_{m}}{L_{p}}\right)^{0.88}\end{array}$ & 100 & \pm 20.4 & $\begin{array}{c}\text { Simplified } \\
\text { Two Flow } \\
\text { Regime } \\
\text { Correlations }\end{array}$ \\
\hline \multirow[t]{2}{*}{$80-200$} & $\begin{array}{l}j=R e_{L p}{ }^{-0.464}\left(\frac{\theta}{90}\right)^{1.187}\left(j_{1}\right)^{-0.074}\left(j_{2}\right)^{-0.069}\left(j_{3}\right)^{0.077} \\
j_{1}=\left(\frac{H}{L_{p}}\right)^{0.889}\left(\frac{\delta}{L_{p}}\right)^{0.776}\left(\frac{L_{l}}{L_{p}}\right)^{0.969} \\
j_{2}=\left(\frac{F_{p}}{L_{p}}\right)^{0.624}\left(\frac{F_{d}}{L_{p}}\right)^{0.9} \\
j_{3}=\left(\frac{D_{m}}{L_{p}}\right)^{0.961}\end{array}$ & 100 & \pm 28.66 & \\
\hline & $\begin{array}{l}f=R e_{L p}{ }^{-0.489}\left(\frac{\theta}{90}\right)^{-0.804}\left(f_{1}\right)^{-0.084}\left(f_{2}\right)^{-0.087}\left(f_{3}\right)^{0.036} \\
f_{2}=\left(\frac{F_{p}}{L_{p}}\right)^{0.596}\left(\frac{F_{d}}{L_{p}}\right)^{0.956} \\
f_{3}=\left(\frac{D_{m}}{L_{p}}\right)^{0.979}\end{array}$ & 100 & \pm 22.23 & \\
\hline
\end{tabular}


PART II - NUMERICAL INVESTIGATION 


\section{CHAPTER 7 : NUMERICAL METHODOLOGIES}

As a part of the present study, this chapter provides the foundation for the numerical investigation of the heat transfer and pressure drop characteristics of three-dimensional flow over louvered fins in aluminum heat exchangers for the range of Reynolds number from 25 to 200. The temperature distribution over the louver surface is simulated for ten different fin geometries with varied geometrical parameters. The geometries selected for the computations are the actual geometries tested in the Sustainable Energy and Thermal Transport Systems (SETTS) lab at Florida International University. In the selection of the geometries for the computational purpose, more emphasis has given towards the geometries with varied louver angle. The computational results are validated with the experimental data by Kim and Bullard (2002). Whereas, the comparison of the computational results with the present experimental data is conducted \& discussed further.

\subsection{MATHEMATICAL FORMULATION}

In the present study, simulations are performed for Reynolds number of 25 to 200 , based on the louver pitch. For this range of Reynolds number, the flow remains in the laminar region. Therefore, a viscous laminar model is applied throughout the simulation study and the turbulence effect of the flow field are neglected. However, k- $\varepsilon$ and $k-\omega$ turbulence models were applied for the verification, the details of which are given in the subsection "Numerical Validation". For the three-dimensional steady state model, conjugate heat transfer is taken into account. The governing equations representing the conservation of mass, momentum and energy are as follows: 


\section{$\underline{\text { Mass conservation }}$}

$\frac{\partial}{\partial x_{i}}\left(\rho u_{i}\right)=0$

Momentum conservation

$$
\frac{\partial}{\partial x_{i}}\left(\rho u_{i} u_{k}\right)=\frac{\partial}{\partial x_{i}}\left(\mu \frac{\partial u_{k}}{\partial x_{i}}\right)-\frac{\partial p}{\partial x_{i}}
$$

\section{Energy conservation}

$$
\frac{\partial}{\partial x_{i}}\left(\rho u_{i} T\right)=\frac{\partial}{\partial x_{i}}\left(\frac{k}{c_{p}} \frac{\partial T}{\partial x_{i}}\right)
$$

The change in the air temperature over the fin length is small. Therefore, all air properties are assumed to be constant and evaluated at the mean temperature. All thermophysical properties of the tubes, fins surfaces are assumed to be constant.

\subsection{GEOMETRICAL DETAILS}

Ten different heat exchanger geometries obtained for the experimental investigation purposes investigated numerically. To examine the flow behavior for the studied range of Reynolds number, all possible variations in louver angle are given primary importance in selecting the geometries. All of the heat exchanger geometries have singled row microchanneled tubes with tube depth equal to the fin depth. The parametric study was conducted on ten different louver fin geometries with different fin pitch, fin height, fin thickness, louver pitch, louver angle, louver length and fin depth as listed in Table 13.

In order to save the computational time and to reduce the mesh size, one half of the fin height is used for the generation of computational domain, as shown in Figure 63. The geometry is simplified as compared to the actual louver fin geometry to avoid the solution convergence issues. 


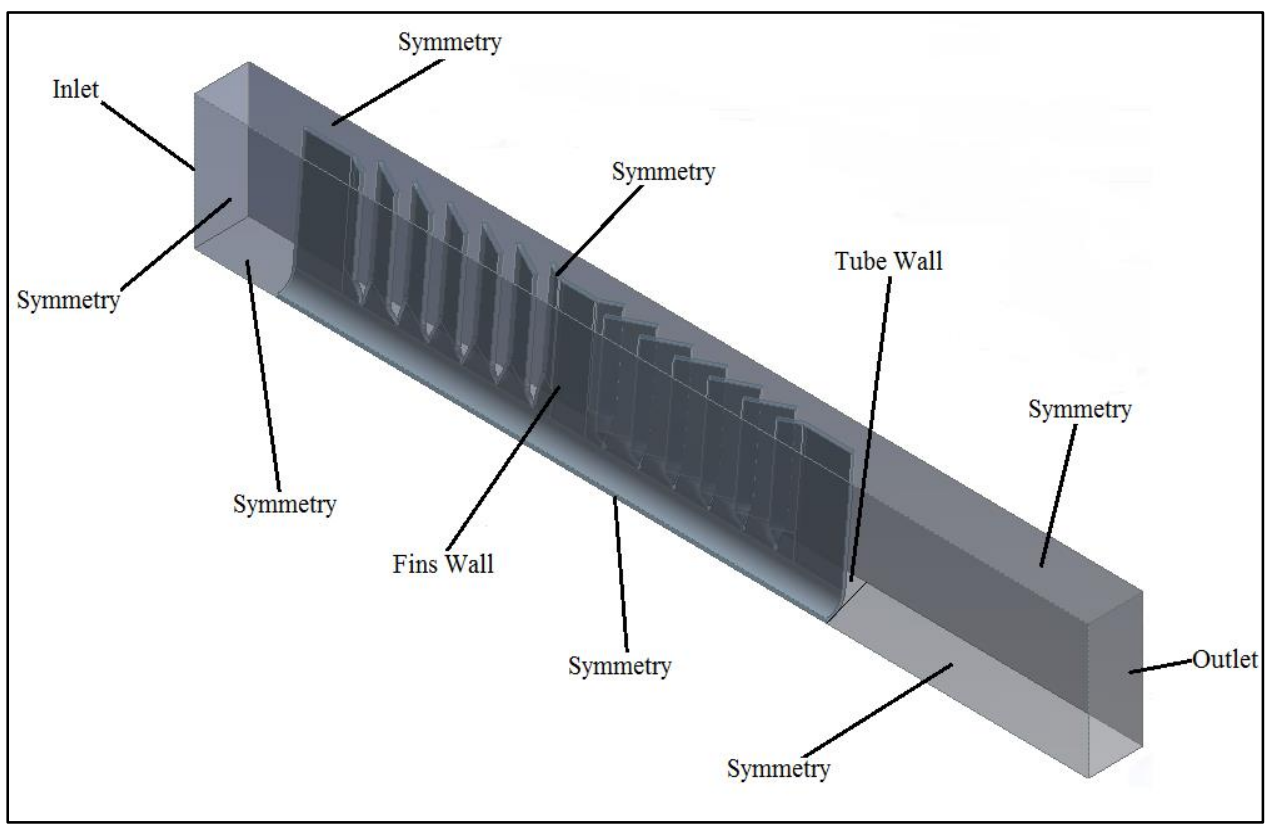

Figure 63. Computational Domain

Table 13. Dimensional details of the louvered fins studied

\begin{tabular}{c|c|c|c|c|c|c|c|c}
\hline $\begin{array}{c}\text { Geometry } \\
\text { No. }\end{array}$ & $\begin{array}{c}\boldsymbol{F}_{\boldsymbol{p}} \\
(\boldsymbol{F P I})\end{array}$ & $\begin{array}{c}\boldsymbol{H}_{\boldsymbol{f}} \\
(\mathbf{m m})\end{array}$ & $\begin{array}{c}\boldsymbol{\delta} \\
(\mathbf{m m})\end{array}$ & $\begin{array}{c}\boldsymbol{L}_{\boldsymbol{p}} \\
(\mathbf{m m})\end{array}$ & $\begin{array}{c}\boldsymbol{L}_{\boldsymbol{l}} \\
(\mathbf{m m})\end{array}$ & $\begin{array}{c}\boldsymbol{D}_{\boldsymbol{m}} \\
(\mathbf{m m})\end{array}$ & $\begin{array}{c}\boldsymbol{F}_{\boldsymbol{d}} \\
(\mathbf{m m})\end{array}$ & $\begin{array}{c}\boldsymbol{\theta} \\
\left({ }^{\circ}\right)\end{array}$ \\
\hline 1 & 14 & 8.58 & 0.13 & 1.14 & 7.11 & 1.83 & 18 & 27 \\
2 & 20.3 & 10 & 0.1 & 1.14 & 6.75 & 1.75 & 25 & 25 \\
5 & 20.3 & 8 & 0.08 & 1 & 6.6 & 1.8 & 12 & 28 \\
7 & 20.3 & 8 & 0.1 & 1 & 6.6 & 2 & 16 & 20 \\
11 & 20.3 & 8 & 0.1 & 1 & 6.6 & 1.8 & 16 & 28 \\
15 & 20.3 & 7.5 & 0.1 & 1 & 6.2 & 2 & 20 & 28 \\
19 & 14 & 8 & 0.17 & 1.14 & 5.97 & 2.03 & 25.4 & 30 \\
24 & 14 & 7.4 & 0.1 & 1.02 & 5.97 & 1.6 & 28 & 27 \\
25 & 15 & 7.4 & 0.1 & 1 & 6.0 & 1.6 & 28 & 27 \\
26 & 18 & 7.4 & 0.1 & 1.02 & 5.97 & 1.6 & 28 & 27 \\
\hline
\end{tabular}

This model simplification has some impact on the fin temperature distribution but the effect on overall heat transfer rate is minimal. The computational domain further resolved into 15 computational blocks as shown in Figure 64 below where the boundaries of the fluid domain are subdivided to access the velocity field at each louver region. Figure 64(b) 
shows these regions as numbered from 1 to 10 , and labelled as louver start, louver end, mid louver, air entrance and air exit. The air-exit region extends more than 2 times the geometrical louver height.

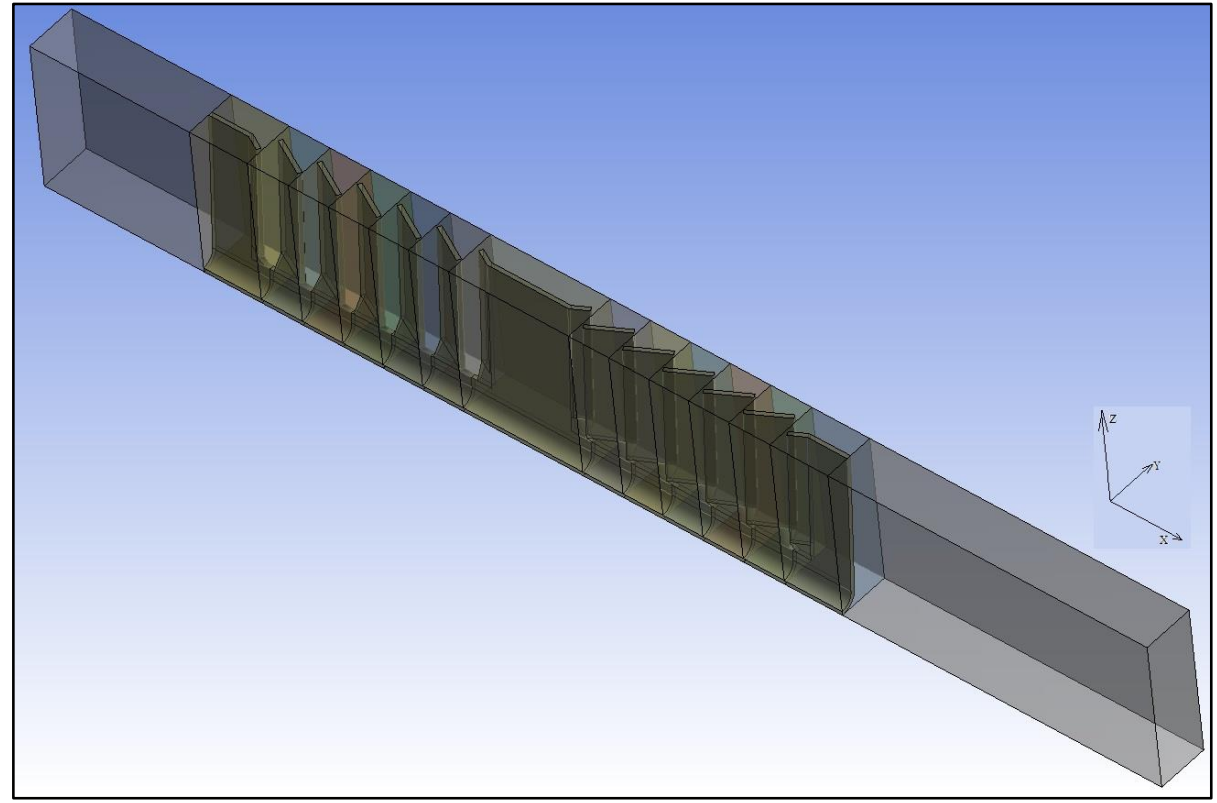

(a)

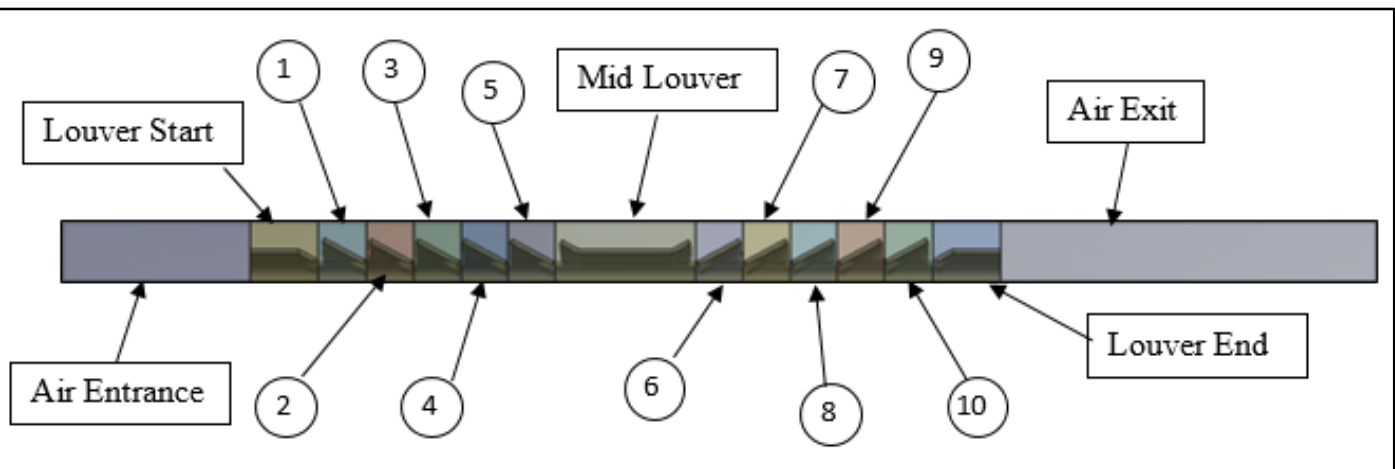

(b)

Figure 64. Air-side Subdivided Computational Domain: (a) 3-D View (b) Top View

\subsection{COMPUTATIONAL DETAILS}

An academic license version of ANSYS, Fluent 16 package is used for the numerical simulation. The governing equations are discretized by using the control volume method. 
Fluent's segregated steady-state solver is used for the numerical simulations. The SIMPLE algorithm is used to couple pressure and velocity. A second-order upwind scheme is used for the space discretization of the momentum, and energy equations in the simulations. The under-relaxation factors for the update of computed variables at each iteration are for pressure $=0.3$, momentum $=0.1$, energy $=1$, and body forces $=1$. The residuals of the continuity and components of velocities are below $10^{-5}$, while, for the energy, it is below $10^{-7}$ for converged solution.

The HEX Dominant/QUAD mesh is generated using the ANSYS meshing tool packaged software. The grid independence is checked using three different mesh sizes, and the variation between them is found to be within $5 \%$. The detail grid independence study is discussed in the validation section. The fine mesh with an average skewness of 0.2 whereas the average orthogonality of 0.8 is used for all of the numerical simulation cases studied. Due to symmetry of the flow domain, calculations are performed for half fin height and symmetry conditions are imposed on the sides, top and bottom of the domain. At the inlet, velocity boundary is imposed, in which uniform velocity magnitude and temperature of air are defined. The pressure-outlet boundary is used at outlet plane, where static gauge pressure and temperature are given. Tube walls are defined as constant wall temperature. On the fin and tube surfaces, no slip boundary condition is assumed to exist.

\subsection{NUMERICAL DATA REDUCTION}

\subsubsection{Colburn j-factor and Friction f-factor}

The heat transfer and pressure drop performance of aluminum louvered fin can be characterized by Colburn $j$ factor and friction $f$ factor, respectively. Heat exchanger 
performance depends on the flow as well as the geometrical conditions. The inertial and viscous effect of the flow conditions is characterized by Reynolds number. Geometrical conditions can be characterized by defining the geometrical parameters in dimensionless form such as fin to louver pitch ratio $\left(F_{p} / L_{p}\right)$ and louver angle $(\theta)$. The Reynolds number based on louver pitch can be defined as:

$$
R e_{L_{p}}=\frac{\rho V_{c} L_{p}}{\mu}
$$

To provide the heat transfer characteristics, the logarithmic mean temperature difference $L M T D$ method is used. $L M T D$ is defined as:

$$
L M T D=\frac{\Delta T_{o}-\Delta T_{i}}{\ln \left(\Delta T_{o} / \Delta T_{i}\right)}
$$

Where $\Delta T_{o}$ and $\Delta T_{i}$ are the difference of the temperature between the fin and air at outlet and inlet respectively. That is,

$$
\Delta T_{o}=\left(T_{f, o}-T_{a, o}\right)
$$

and

$$
\Delta T_{i}=\left(T_{f, i}-T_{a, i}\right)
$$

The rate of heat transfer is given by:

$$
\dot{Q}=\rho V_{c} A_{c} c_{p}\left(T_{a, o}-T_{a, i}\right)
$$

The heat transfer coefficient $h_{o}$ is defined in terms of LMTD and heat transfer rate as:

$$
h_{o}=\frac{\dot{Q}}{A_{o} \times L M T D}
$$

Therefore,

$$
h_{o}=\rho V_{c} c_{p} \frac{A_{c}}{A_{o}} \frac{\left(T_{a, o}-T_{a, i}\right)}{L M T D}
$$


The Colburn $j$ factor and friction $f$ factor are defined in terms of the mean velocity $u$ through the minimum flow area $A_{c}$ and the total heat transfer area $A$, can be calculated as follows:

$$
j=\frac{h_{o}}{G_{c} c_{p}} \operatorname{Pr}^{2 / 3}
$$

and

$$
f=\frac{\Delta p}{\frac{\rho u^{2}}{2} \frac{A_{o}}{A_{c}}}
$$

\subsubsection{Flow Angle and Flow Efficiency}

Availability of the velocity field data from the numerical simulation can be used to calculate the flow angle for the flow over each louver, using the equation 92 below.

$$
\alpha=\tan ^{-1}\left(\frac{v_{\text {avg }}}{u_{\text {avg }}}\right)
$$

The numerator is the average flow field in the y-direction, whereas the denominator is the average flow field in the $\mathrm{x}$-direction for the 3-D computational block of each independent louver. The flow direction has substantial effects on the heat transfer coefficient of louver fin geometry, and can be categorized as duct directed or louver directed flow. This categorization of the flow regime can be conducted by calculating the flow efficiency from the equation 93 below.

$$
\eta_{\text {flow }}=\frac{\tan \alpha}{\tan \theta} \cong \frac{\alpha}{\theta}
$$

The expression $\eta_{\text {flow }}=\tan \alpha / \tan \theta$ is preferred to define the characteristics of the mean flow. Whereas, the approximation $\eta \cong \alpha / \theta$ is valid within $2 \%$ for $0<\eta_{\text {flow }}<0.2$. 


\subsection{NUMERICAL VALIDATION OF THE SIMULATION MODELS}

\subsubsection{Grid Independence Study}

Grid dependency study was performed for Sample\#1 at high Reynolds number to check the accuracy of the computer program and the resolution used in louver fin simulations. Three different cell sizes for the mesh generation were chosen to study the grid independence of the simulation results.

For the coarse mesh, Case 1, the cell size equal to half times more the fin thickness was used. For fine mesh, Case 2, and 3 the respective cell sizes equal to 1 , and 0.9 times the fin thickness were used. Table 14 below shows the results of the grid independence study.

Table 14. Grid Inde pe ndence

\begin{tabular}{l|c|c|c}
\hline Case & 1 & 2 & 3 \\
\hline Grid Cell Size (mm) & 0.15 & 0.1 & 0.09 \\
No. of Nodes & 104018 & 229947 & 296300 \\
No. of Elements & 567701 & 1253959 & 1619666 \\
\% Increase in No. of Nodes w.r.t. Case 1 & - & 121.1 & 184.85 \\
\% Increase in No. of Elements w.r.t. Case 1 & - & 120.88 & 185.30 \\
j-factor & 0.0158 & 0.0152 & 0.0154 \\
f-factor & 0.121 & 0.118 & 0.117 \\
\% Change in j-factor w.r.t. Case 1 & - & 3.797 & 2.532 \\
\% Change in f-factor w.r.t. Case 1 & - & 2.479 & 3.306 \\
\hline
\end{tabular}

For the case 2 , in which the cell size equal to the fin thickness shows around less than $4 \%$ and $3 \%$ reductions in $\mathrm{j}$-factor, and f-factor respectively, with around $121 \%$ (more than double) increase in the number of elements. Further increase in the number of elements by about $185 \%$ shows less than $3 \%$ and $4 \%$ decrease in $\mathrm{j}$ and $\mathrm{f}$ factors respectively, in case 3. However, it can be seen from the Table that, further increase in the mesh size from case 2 to case 3 , has shown the variations in the $\mathrm{j}$ and $\mathrm{f}$ factor, less than $1.5 \%$. It is found that by 
varying the grid resolution in both directions, the average variations in $\mathrm{j}$ and $\mathrm{f}$ factor are found to be within $2-4 \%$. Therefore, to compensate for the computational time, and the solution accuracies, the cell size of the meshing was kept $0.09 \mathrm{~mm}$ for all of the numerical simulations performed. Figure below shows the effect of cell size variation on $\mathrm{j}$ and $\mathrm{f}$ factor parameters graphically.

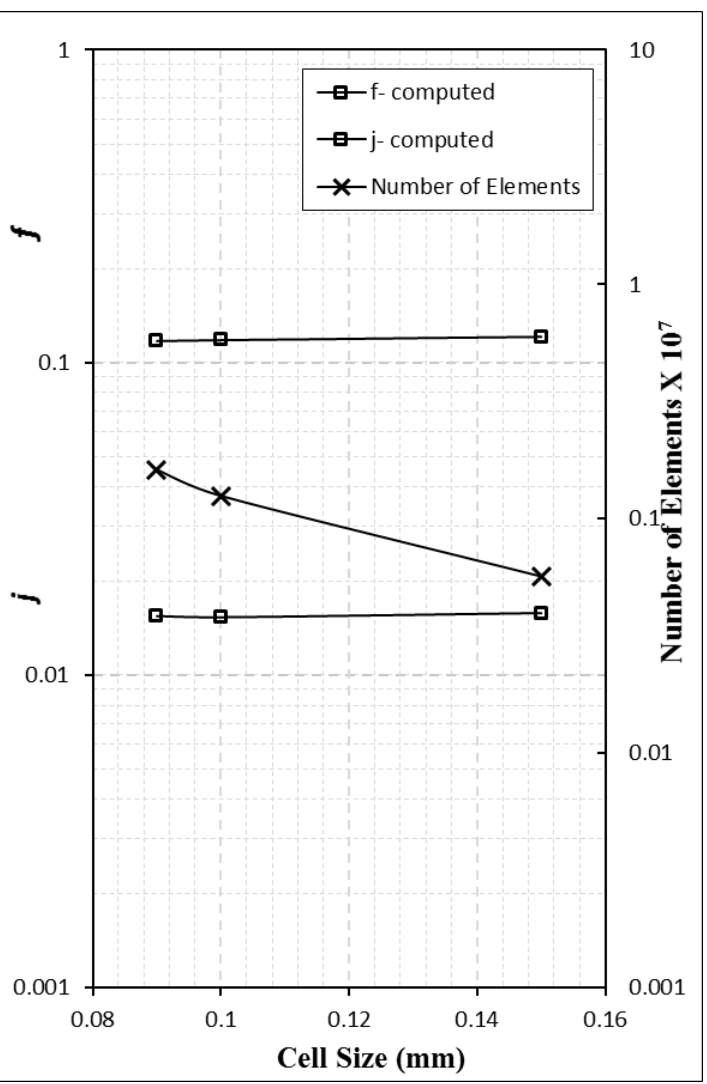

Figure 65. Effect of Cell Size on Heat Exchanger Performance Parameters

\subsubsection{Model Validation}

Present study involves categorization of the flow pattern for low Reynolds number based on louver pitch, less than 200, where the flow is laminar. However, several researchers have noticed the changes in the flow behavior due to the geometrical conditions at low Reynolds number condition. In the present experimental study such changes are also 
observed. For the numerical study of flow investigation, it is vital to validate the computational model before using for the study. Therefore, six different alternative models were applied and the heat exchanger performance and flow behavior studied for the test sample\#1 for the range of Reynolds number from 20 to 200. Since, the variations in the flow behavior increases with the decrease in the Reynolds number, therefore the validations were performed at the lower range of Reynolds number. To save the computational time, the model validations were performed for the four Reynolds number at 25, 35, 45, and 55 . The five different models considered for the validation study in addition to the laminar model are, turbulent $\mathrm{k}-\varepsilon$ standard model $(\mathrm{k}-\varepsilon), \mathrm{k}-\varepsilon$ standard model with enhanced wall treatment model (k- $\varepsilon \mathrm{WT}), \mathrm{k}-\varepsilon$ standard model with full buoyancy effects (k-cbouyancy), k- $\omega$ standard model (k- $\omega)$, \& k- $\omega$ standard model with low Reynolds correction (k- $\omega$ LRC).

Numerically attained results then compared against the experimental values extracted from the work by Kim and Bullard (2002). Figure 66 shows the plots of $\mathrm{j}$ and $\mathrm{f}$ factors obtained numerically for the six different models against the Kim and Bullard's experimental values. It can be seen from the Figure that the computational results of the jfactor from Laminar and standard $\mathrm{k}-\varepsilon$ models are in better agreement with the Kim and Bullard's model. Rest of the models under predict the $\mathrm{j}$-factor. In case of f-factor, Laminar and standard k- $\varepsilon$ model with enhanced wall treatment shows better agreement, whereas the rest of the models over predicts the f-factor. It is to be noted that experimental values extracted from the Kim and Bullard's work is applicable for the range of Reynolds number from 80 to 300 , based on louver pitch. The experimental uncertainties in $\mathrm{j}$ and $\mathrm{f}$ factors estimated by them have been reported to be $16.9 \%$ and $13.6 \%$, respectively. In the present numerical studies, the validations are performed for the Reynolds number below 55 . 


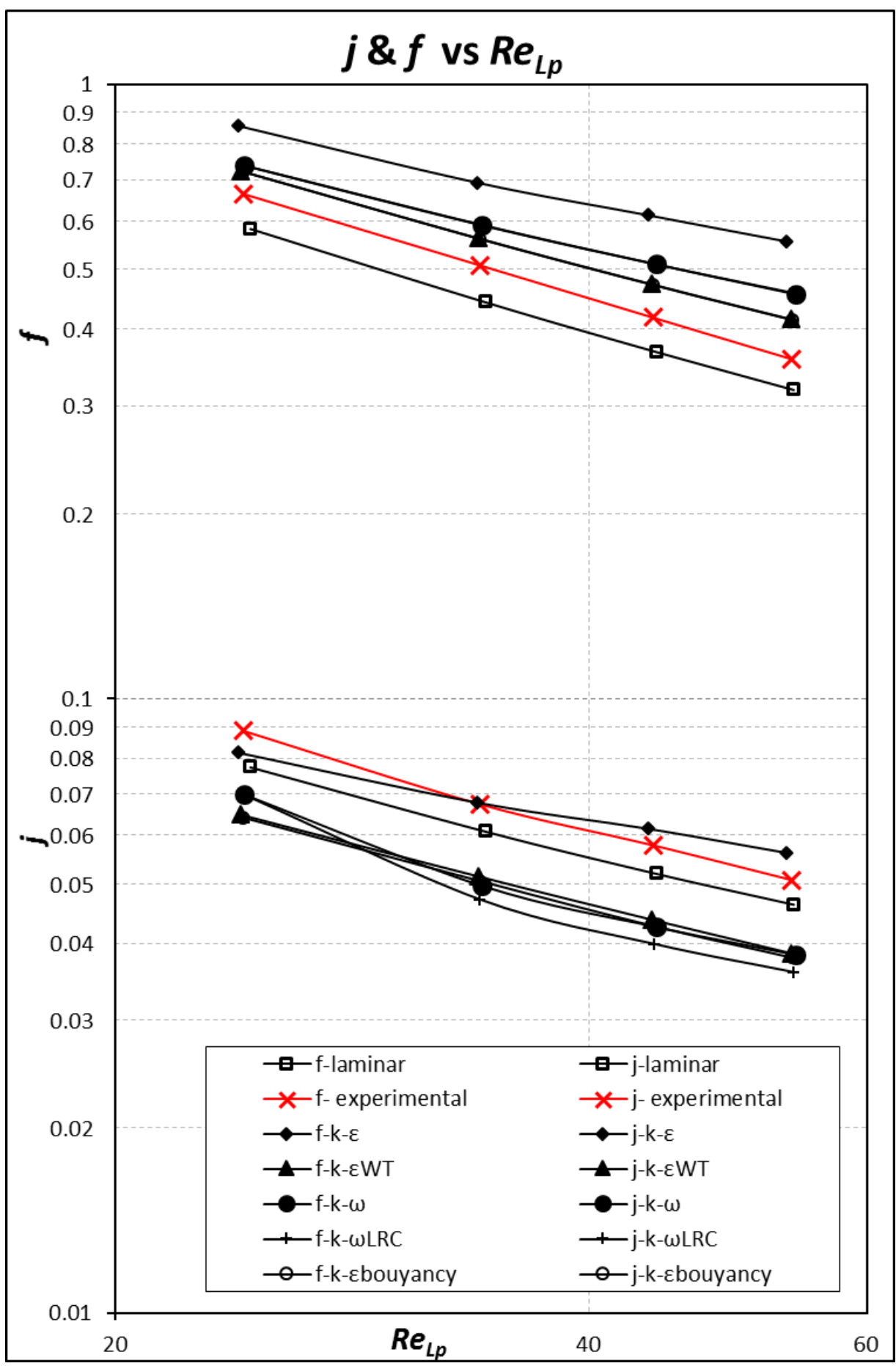

Figure 66. Performance Parameters for Laminar and Turbulent Models

In the present study air temperature is raised at low flow rates. This leads the possibility of the existence of buoyant flow in addition to the laminar flow. Therefore, it is important 
to verify the presence of buoyancy effect in the flow behavior. The importance of buoyancy forces in the mixed convection flow can be measured by the ratio of the Grashof and Reynolds number as shown in the equation 94 below.

$$
\frac{G r}{R e_{L p}^{2}}=\frac{g \beta \Delta T H_{f}}{v_{c}^{2}}
$$

The strong buoyancy contribution to the flow exists for the above ratio equal to or greater than unity. For smaller values of the above ration the buoyancy forces can be ignored in the simulations. In the present study, the maximum value of the ratio of Grashof to the Reynolds number is 0.027 , which is very less against the unity. Therefore, the presence of buoyancy forces in the simulation is neglected from the current simulations.

In overall Laminar model better predicts the $\mathrm{j}$ and $\mathrm{f}$ factors both with maximum deviation of $12.8 \%$ and $13 \%$, respectively as shown in the Table 15 . Therefore, througho ut the numerical studies Laminar model is applied for all of the studied geometries.

Table 15. Comparison of computed and refe renced experimental $j$ and $f$ factor

\begin{tabular}{ccccc}
\hline \multirow{2}{*}{$\boldsymbol{R}_{\boldsymbol{L} \boldsymbol{p}}$} & \multicolumn{4}{c}{ Sample\#1 } \\
\cline { 2 - 5 } & $\boldsymbol{j}_{\boldsymbol{c}}$ & $\boldsymbol{j}_{\boldsymbol{k} \boldsymbol{b}}$ & $\boldsymbol{f}_{\boldsymbol{c}}$ & $\boldsymbol{f}_{\boldsymbol{k} \boldsymbol{b}}$ \\
\hline 25 & 0.0773 & 0.089 & 0.582 & 0.664 \\
35 & 0.0608 & 0.067 & 0.442 & 0.508 \\
45 & 0.0518 & 0.058 & 0.367 & 0.417 \\
55 & 0.0462 & 0.051 & 0.318 & 0.357 \\
\hline
\end{tabular}

\subsubsection{Flow Angle Measurement Validation}

The numerically measured flow angle for Sample\#15 was validated against the data experimental work of Webb and Trauger (1991) and Achaichia \& Cowell (1988). It is to be noted that their studied range of Reynolds number was from 400 to 4000 , and 120 to 
8000 , respectively, based on louver pitch, whereas the present work focuses on the range of Reynolds number from 25 to 200 .

Figure 67(a) below shows the comparison of the computed flow efficiency with that of the predicted by Webb and Trauger (1991) based on experimental results, and by Achaichia \& Cowell (1988) based on numerical results. Distinctive nature of the plots can be seen from the Figure for the Reynolds number below 200. It is important to note that the Webb and Trauger (1991) have studied the geometries that are different than the present study with very high louver pitch of $15 \mathrm{~mm}$ with the scaled up model of 10:1. In the case of Achaichia \& Cowell (1988), the authors conducted the numerical studies for the experimentally studied geometries. Their tube fin geometry differs significantly from the present geometries in terms of tube fin arrangement. In addition to that in the numerical model the effect of louver thickness was also neglected. Figure 67(b) shows the experimental flow efficiencies obtained by Webb and Trauger (1991).

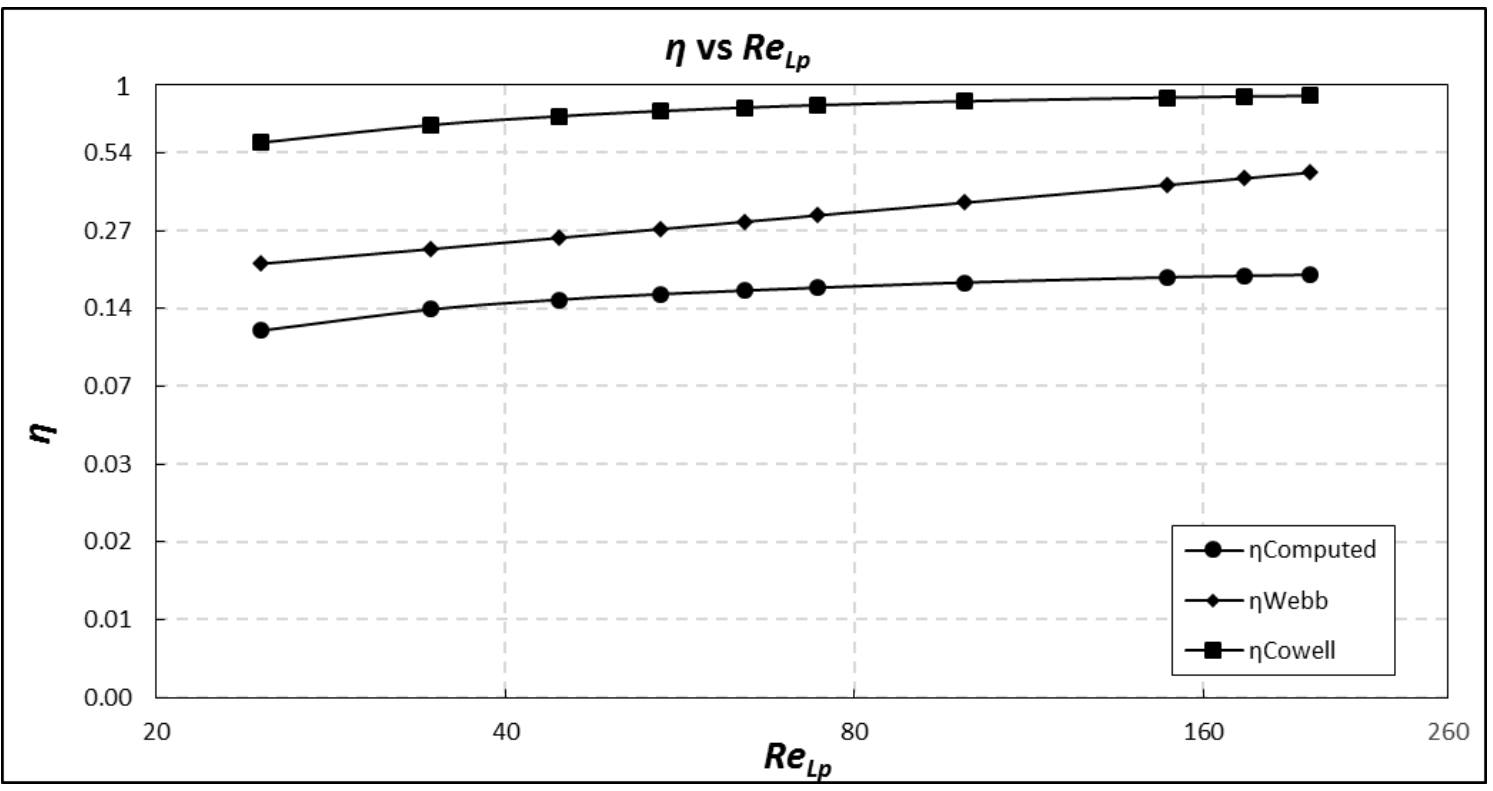

(a) 


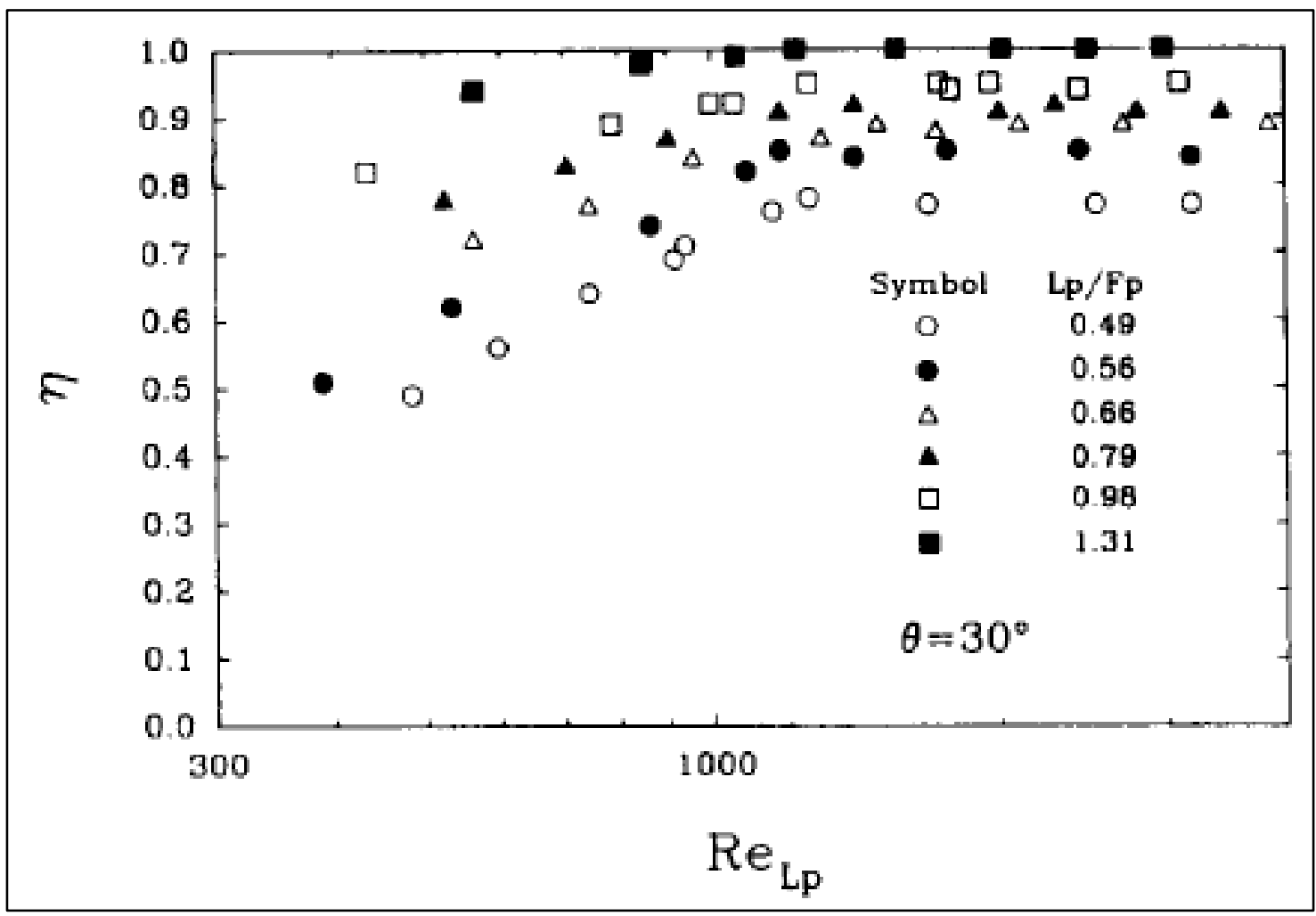

(b)

Figure 67. (a) Computed Flow Efficiency for $\theta=28^{\circ}$ Vs. predicted by Webb and Trauger (1991) and Achaichia \& Cowell (1988).(b) Flow Efficiency Vs. Reynolds Number for $\theta=30^{\circ}$ Webb and Trauger (1991). 


\section{CHAPTER 8 : RESULTS AND DISCUSSION}

Numerical simulations were conducted for the described geometries of flat tube and louvered fins. The fin height, fin thickness, louver pitch, louver angle, louver length and fin depth were varied for Reynolds number based on louver pitch from 25 to 200 . Temperatures of the tube surface and inlet air were maintained at $333.15 \mathrm{~K}$ and $293.15 \mathrm{~K}$, respectively. The results are presented in the form of velocity and temperature contours, Colburn $j$ factor and friction $f$ factor plots against Reynolds number.

\subsection{HEAT TRANSFER COEFFICIENT $h_{o}$ AND PRESSURE DROP $\Delta P$}

Figure 68 and Figure 69 below, shows the computed velocity and temperature contours for three different Reynolds numbers, 25, 100 and 200. As it can be observed from Figure 69 that at all the three cases, most of the air flows through the gap between the fins rather than through the louvers. Air at low Reynolds number flows with low kinetic energy. Most of the air passes through the path of least resistance. Louver surface of the fin provides higher flow resistance in the flow path, this leads air to flow through the fin gaps rather than the louver gaps. Very thick boundary layer formation can be observed at very low Reynolds number with gradual decrease till Reynolds number of 200 . At $\operatorname{Re}_{L p}=25$, the air temperature reaches the fin temperature in the first half of the louvered array itself, and as a result the heat transfer performance of the fin is poor. Whereas at $\operatorname{Re}_{L p}=200$, air temperature reaches the fin temperature in the second half of the louvered array. The second half of the louver arrays account for increase in pressure drop without significant heat transfer. 


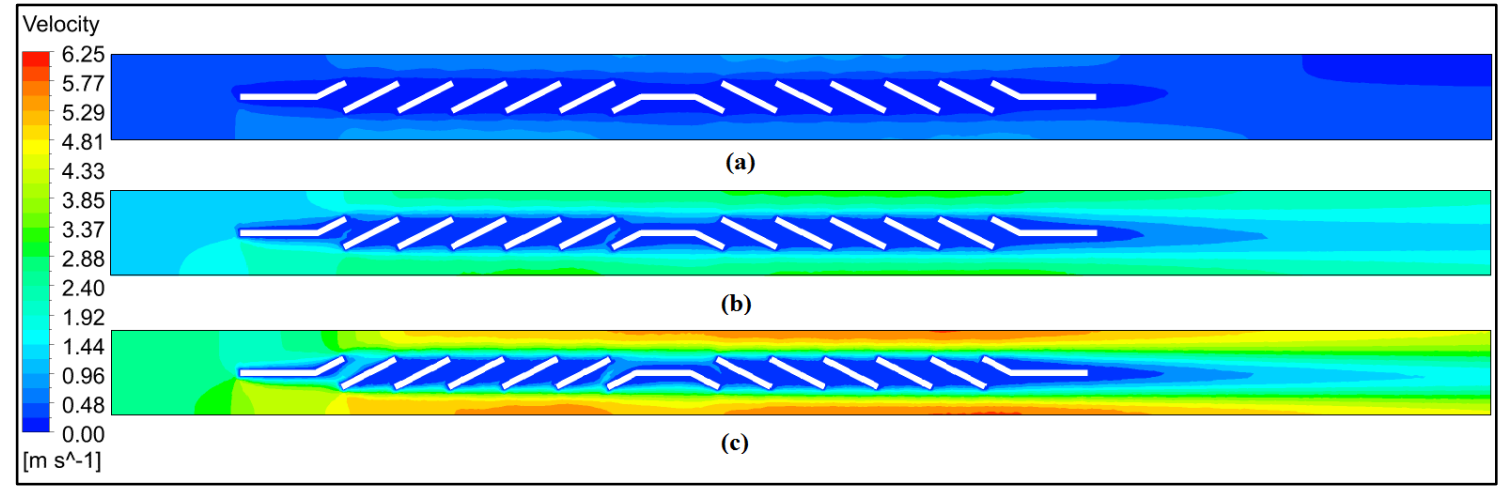

Figure 68. Velocity (m/s) contours for (a) $R e_{L p}=25$, (b) $R e_{L p}=100$, (c) $R e_{L p}=200$ for Sample\#1

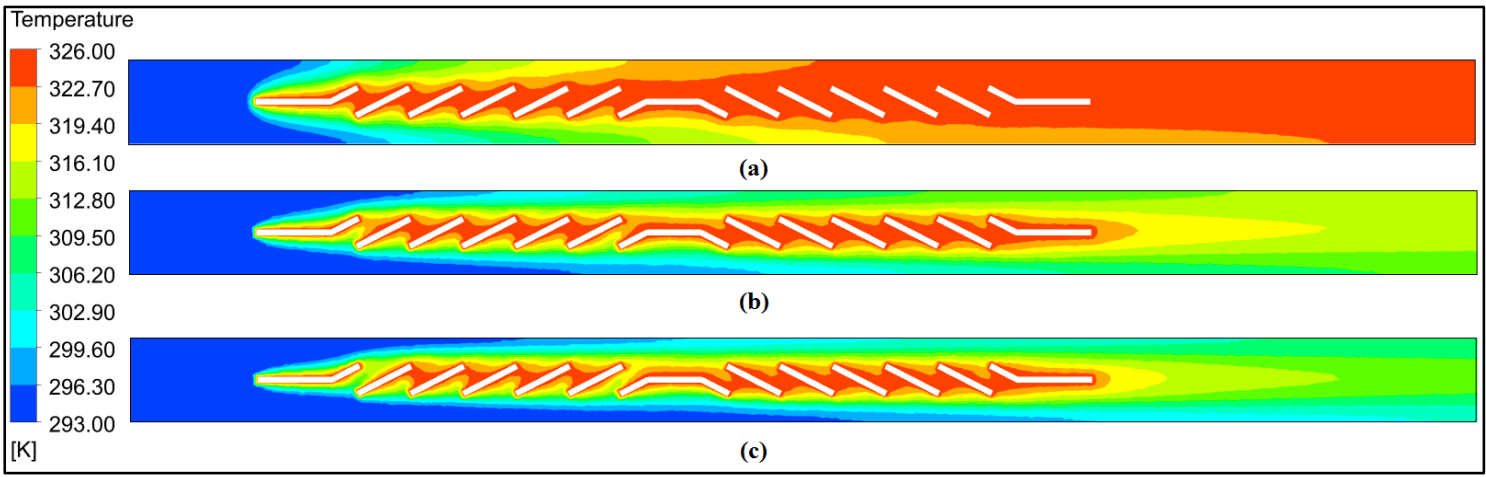

Figure 69. Tempe rature (K) contours for (a) $R e_{L p}=25$, (b) $R e_{L p}=100$, (c) $R e_{L p}=200$ for Sample\#1

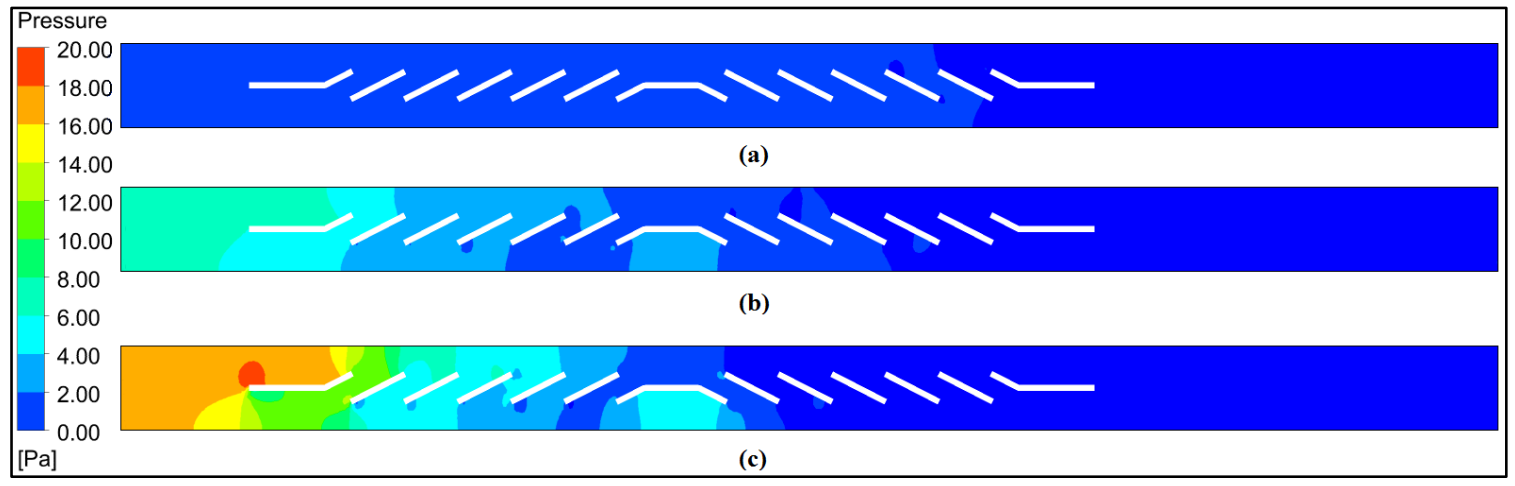

Figure 70. Pressure (Pa) contours for (a) $\operatorname{Re} L p=25$, (b) $\operatorname{Re} L p=100$, (c) $\operatorname{Re} L p=200$ for Sample\#1

Figure 70 shows the pressure contours for three different Reynolds numbers, 25, 100 and 200 for Sample\#1. In case of Reynolds number of 25, as the air passes through a path of least resistance, through the fin gap, the pressure drop across the louver is almost 
negligible. The louver geometry does not contribute to the pressure drop in this case other than the loss due to the entrance region.

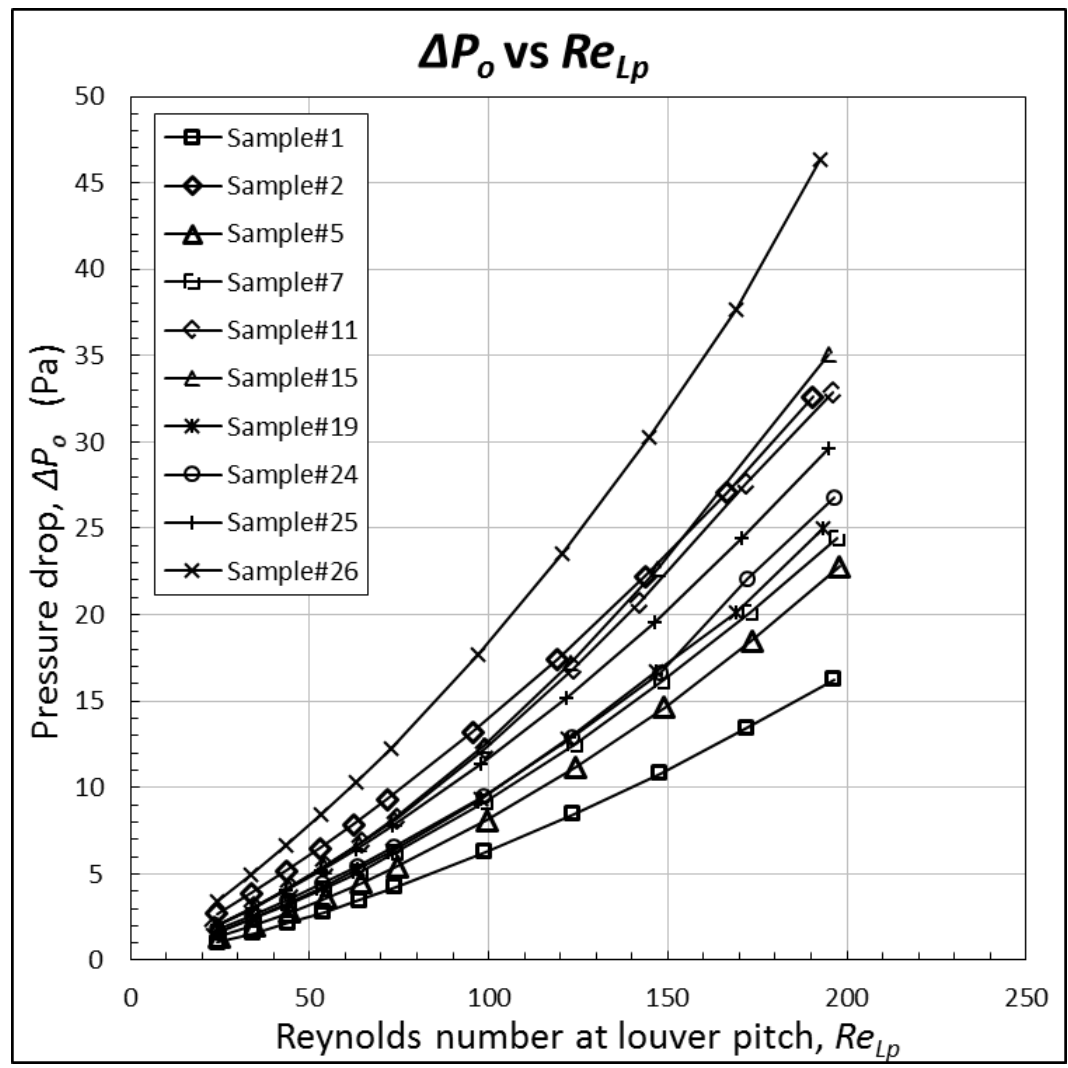

Figure 71. Pressure drop (Pa) across the louvered fin

With the increase of Reynolds number, air starts flowing through the louver gap and the pressure drop across the fin increases. In case of Reynolds number 100 and 200, it can be seen that low pressure zone is formed near the louvers due to the boundary layer. The air which flows through the louver strikes on the flat plate and is turned. This flow diversion causes high pressure zone in the middle portion of the fin, as observed in Figure 70. The pressure drop across the louver fin for all of the 10 fin configurations with respect to the Reynolds number is shown in Figure 71. Similar profiles of the velocity, temperature, and 
pressure drop for the Reynolds number of 25, 100 and 200 for some of the configurations are plotted in APPENDIX C.

The performance of the louver fin heat exchanger depends upon the geometrical parameters such as fin pitch, fin height, fin thickness, louver pitch, louver angle, louver length and flow depth. However, at low Reynolds number, as explained earlier in the present study that, the air flows through the fin gap instead of louver gap, this leads to minimal to almost negligible influence of louver geometrical parameters on the air flow. Therefore, the pressure drop across the louver is almost negligible, and due to the effect of entrance region at the studied range of Reynolds number. Also, it is observed from the developed correlations that the flow behavior is highly influenced by the Reynolds number and the louver angle. Therefore, in this section, the effect of geometrical parameters on the pressure drop performance are studied for the fin pitch and louver angle only. Whereas, all the geometrical parameters are evaluated for the numerical investigation of heat transfer performance.

\subsubsection{Influence of fin density $\left(F_{p}\right)$}

The Sample\#24 and Sample\#25 has identical geometrical parameters with the variation in fin density only. The effect of the variation of the fin density on the heat transfer and pressure drop are shown in Figure 72, below. It is observed from the figure that with the increase in fin density from 14 fins per inch to 15 fins per inch, heat transfer rate increases. Whereas, the decrease in pressure drop is seen with increase in din density. This is because of the fact that with the increase in fin density the restriction to the air flow at the entrance 
region increases, lessening the interaction between the louver and the air flow due to the boundary layer formation.

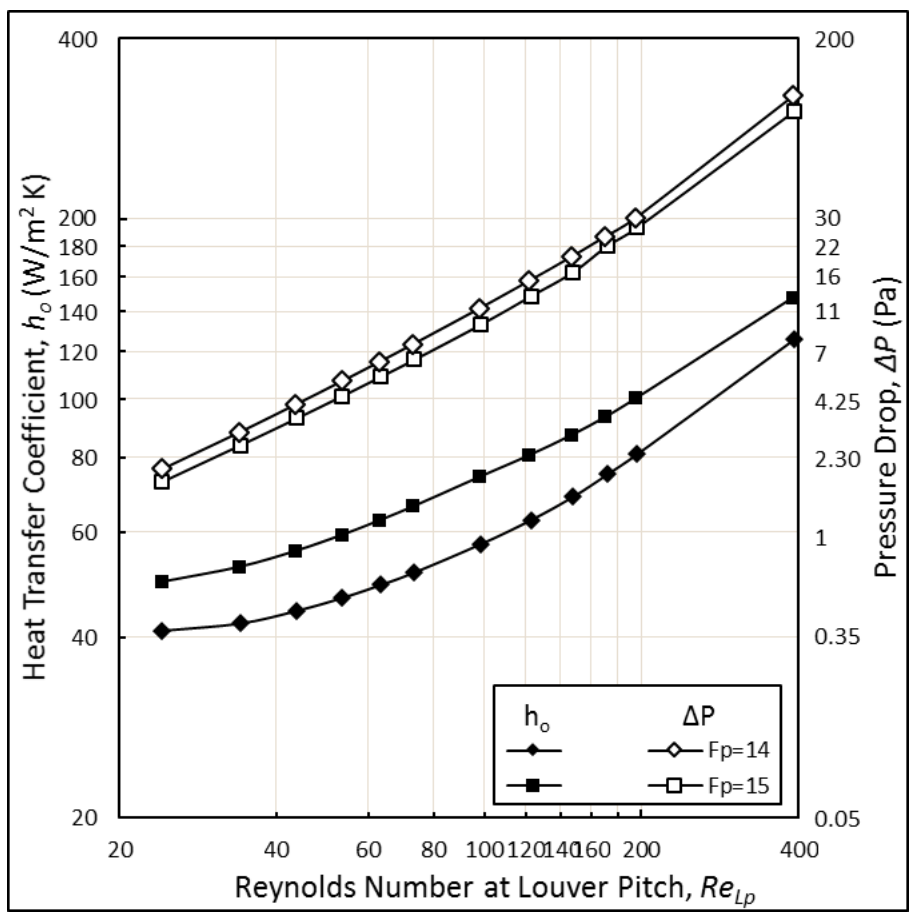

Figure 72. Effect of fin density $\left(F_{p}\right)$ on heat transfer coefficient $\left(h_{o}\right)$

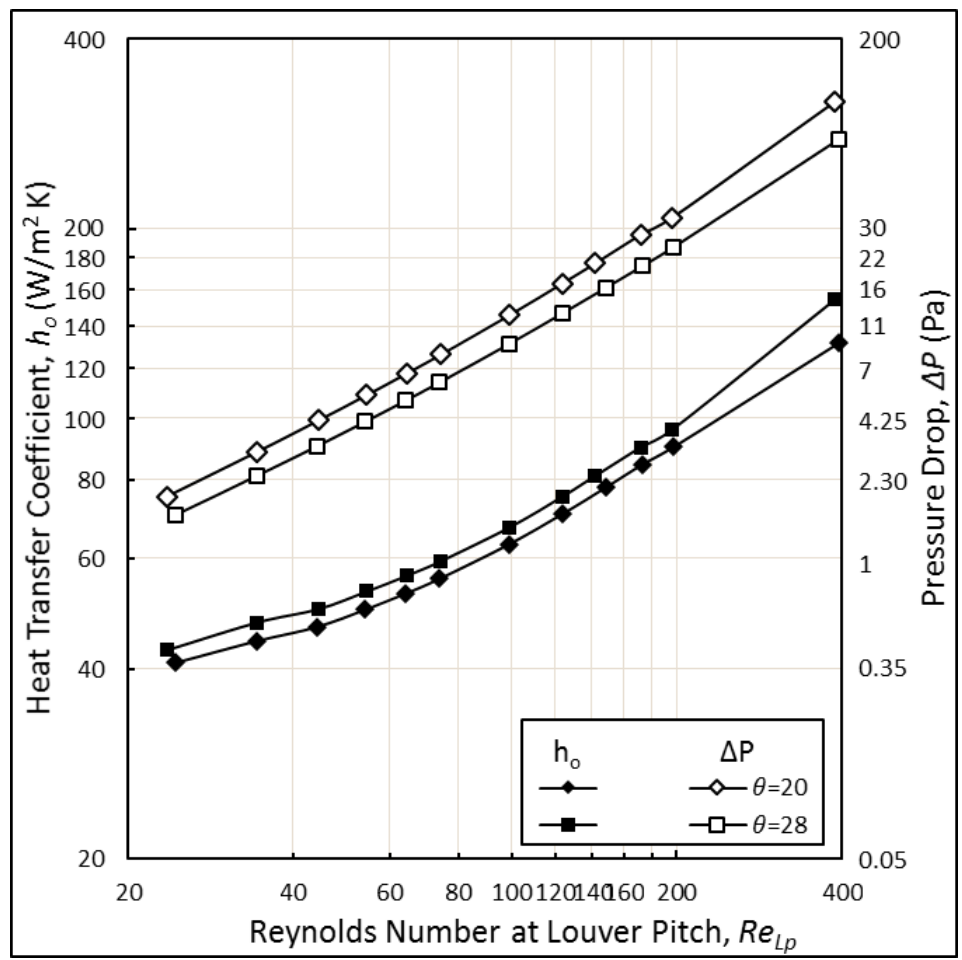

Figure 73. Effect of louver angle $(\theta)$ on heat transfer coefficient $\left(h_{o}\right)$ 


\subsubsection{Influence of louver angle $(\theta)$}

The Sample\#7 and Sample\#11 has identical geometrical parameters with the variation in louver angle only. The effect of the variation of the louver angle on the heat transfer and pressure drop are shown in Figure 73, below.

It is observed from the figure that with the increase in louver angle from $20^{\circ}$ to $28^{\circ}$, heat transfer rate increases, whereas, the pressure drop decreases. This is because of the fact that with the increase in louver angle the restriction to the air flow in the louver region decreases, and better flow alignment with the louver occurs in turn better mixing of the airflow resulting in increased heat transfer and lesser pressure drop. Similar effects are observed with the increase in the Reynolds number.

\subsubsection{Influence of fin depth $\left(F_{d}\right)$}

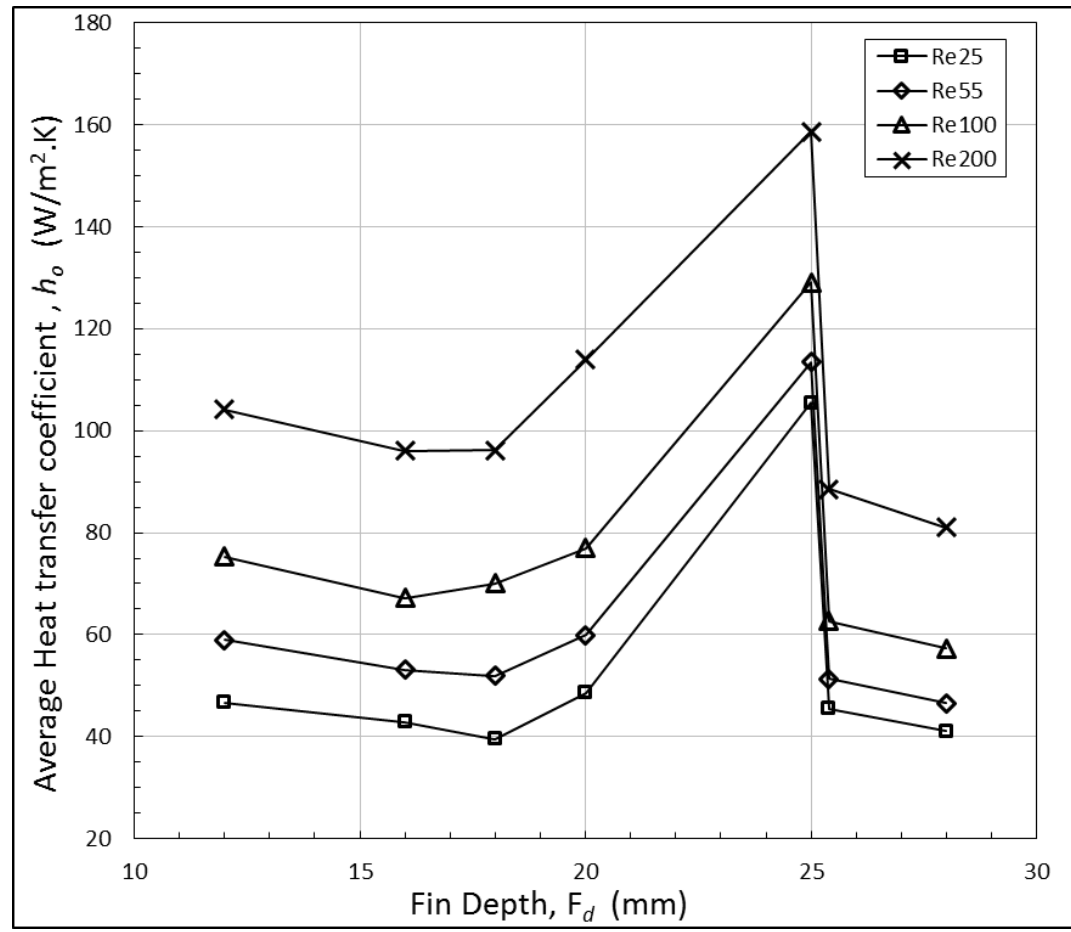

Figure 74. Effect of fin depth $\left(F_{d}\right)$ on heat transfer coefficient $\left(h_{o}\right)$ 
Figure 74, shows the effect of the fin depth on the heat transfer coefficient for the Reynolds number from 25 to 200 . It can be observed that with the increase in fin depth heat transfer coefficient decreases till fin depth reaches to $18 \mathrm{~mm}$ and then increases sharply with the further increase in the fin depth to the maximum heat transfer at $25 \mathrm{~mm}$. After the fin depth of $25 \mathrm{~mm}$, the heat transfer coefficient decreases drastically. The increase in fin depth causes increase in the heat transfer surface area and hence the better heat transfers to the air flow over the fin surface contributing to reaching the air temperature as that of the fin temperature. Further increase in the fin depth adds the pressure drop in the system without much increase in heat transfer.

\subsubsection{Influence of fin height $(H)$}

Figure 75 shows the effect of fin height on the heat transfer coefficient for the fin height ranging from $7.4 \mathrm{~mm}$ to $10 \mathrm{~mm}$.

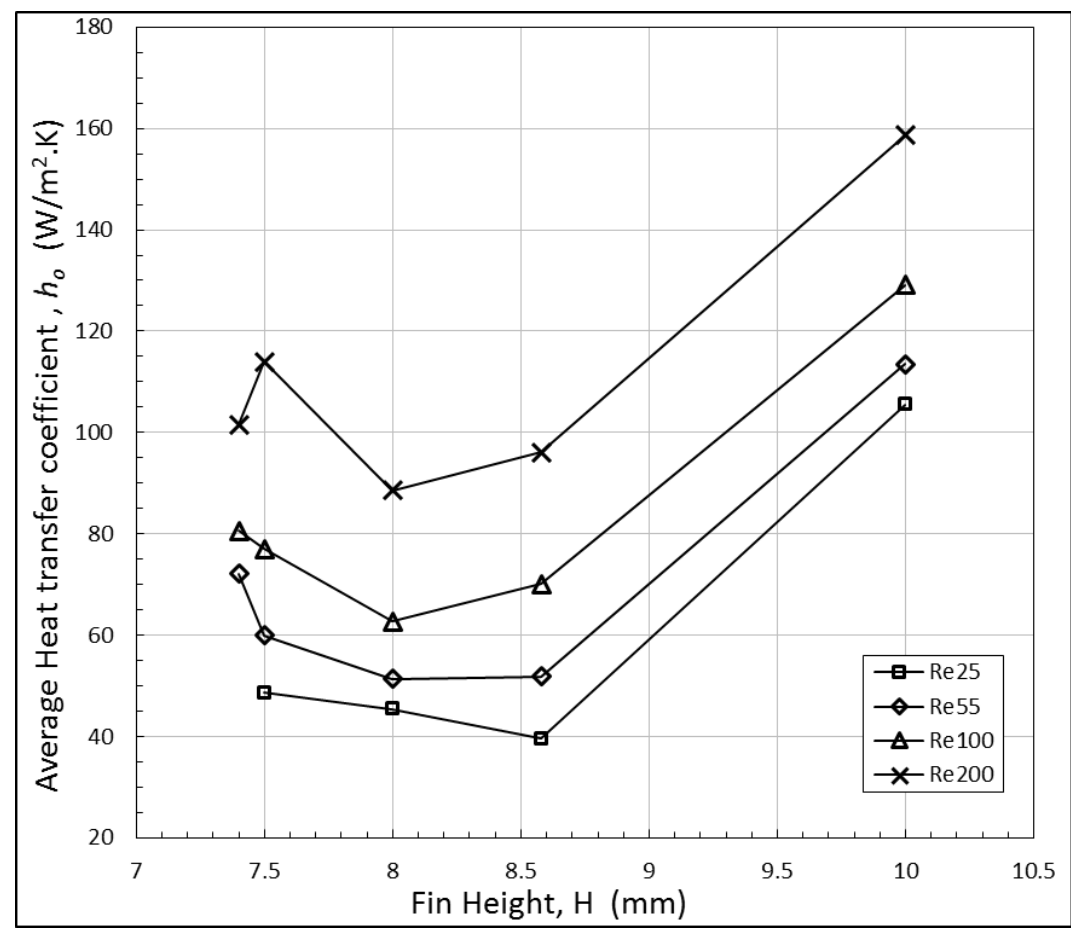

Figure 75. Effect of fin height $\left(H_{f}\right)$ on heat trans fer coefficient $\left(h_{o}\right)$ 
The heat transfer coefficient is observed to be decreasing with the increase in fin height from $7.4 \mathrm{~mm}$ to $8.6 \mathrm{~mm}$, and then rises dramatically with the increase of fin height. This is because, till the fin height of $8.6 \mathrm{~mm}$ the airflow is still trying to overcome the boundary layer restrictions. Further increase of fin height, contributes to the decrease in the flow resistance allowing more air to pass through the fin gap and increase in convective heat transfer surface area. Similar trend has seen throughout the Range of Reynolds number.

\subsubsection{Influence of louver pitch $\left(L_{p}\right)$}

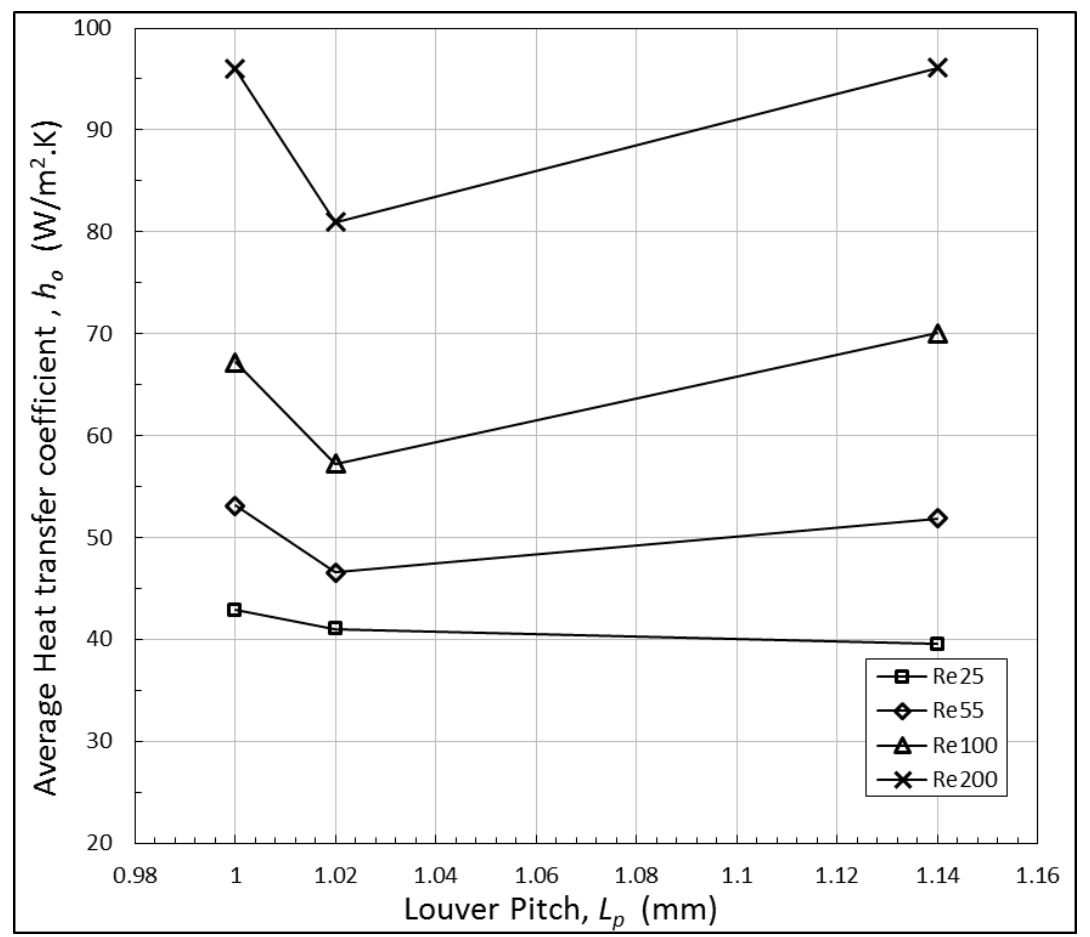

Figure 76. Effect of louver pitch $\left(L_{p}\right)$ on heat transfer coefficient $\left(h_{o}\right)$

Figure 76 above, shows the effect of louver pitch on the heat transfer coefficient for the varied Reynolds number from 25 to 200 . The decrease in the heat transfer is observed for louver pitch from $1 \mathrm{~mm}$ to $1.02 \mathrm{~mm}$ and followed by the increase for the louver pitch of $1.14 \mathrm{~mm}$. However, the geometries in the comparison have several variation in the 
parameters. It appears that the variation in this case is mostly due to the variations in the fin pitch and the fin height, instead of the purely due to the louver pitch. It is also to be noted that the overall variaiton in the heat transfer resulting from the louver pitch is minimal, due to the boundary layer resistance formed in the louver region by the low airflow.

\subsubsection{Influence of fin thickness $(\delta)$}

Figure 77 below, shows the effect of fin thickness on heat transfer coefficient at varied Reynolds numbers. It can be observed that with the increase in fin thickness heat transfer coefficient decreases. This is because, the increase in fin thickness causes the formation of a thick boundary layer which in turn blocking the air flow passage through louver gap and therefore decreasing the air side convective heat transfer coefficient.

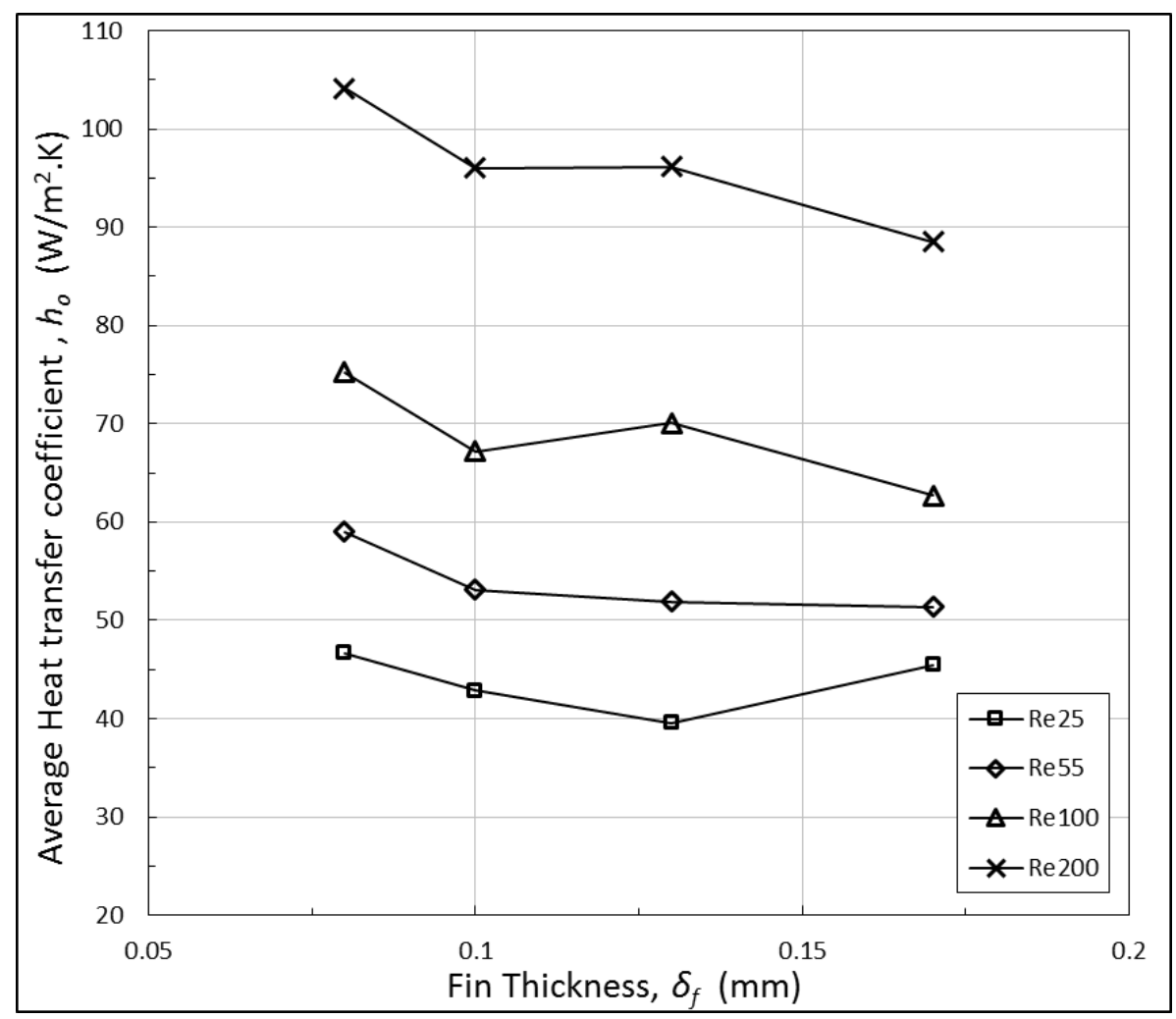

Figure 77. Effect of fin thickness $(\delta)$ on heat transfer coefficient $\left(h_{o}\right)$ 


\subsection{FLOW EFFICIENCY $(\eta)$}

The louver directed flow signifies the flow efficiency equal to 1 as per the definition of flow efficiency, whereas the fin directed flow signifies the flow efficiency equal to 0 . Therefore, the ratio of louver pitch to fin pitch plays vital role in the definition of the flow efficiency. It is observed from the current experimental study and also from the literature that the geometrical parameters such as fin pitch, fin thickness, louver pitch, and louver angle and the flow speed are most likely to influence the flow behavior.

As a part of the present study, this section provides the foundation for the numerical investigation of the flow behaviour of three-dimensional flow over louvered fins in aluminum heat exchangers for the range of Reynolds number from 25 to 200 . Five different louver angles $\left(20^{\circ}, 25^{\circ}, 27^{\circ}, 28^{\circ}\right.$, and $\left.30^{\circ}\right)$ are studied with the variation in the ratio of louver pitch to fin pitch from 0.56 to 0.91 , and the variation in the ratio of fin thickness to louver pitch from 0.08 to 0.15 . Following sub-sections discusses the effect of Reynolds number, louver angle, $L_{p} / F_{p}$ and $\delta / L_{p}$ on the flow efficiency and in the later sub-section the flow efficiency correlation is developed for the range of Reynolds number from 25 to 200 .

Figure 78 provides the flow efficiency $(\eta)$ obtained from the present numerical results. In these figures, the numerical data are grouped loosely in a way to try to show the effects of the key parameter (s) on the flow efficiency whenever possible. However, cautions must be paid by the readers in interpreting the effects of the parameter, as for most of the figures, the differences of flow efficiencies for different samples are the combined results of multiple parameters. Of course, this is due to the fact that the original test matrix was formed based on available heat exchangers in the market in addition to the geometrical and flow domain simplifications made to the computational model. 


\subsubsection{Effect of Reynolds Number $\left(\operatorname{Re}_{L p}\right)$}

Figure 78 below show $\eta$ vs. $\operatorname{Re}_{L p}$ for the range of louver angles from $20^{\circ}$ to $30^{\circ}$. It can be observed from the figure that the flow efficiency increases with Reynolds number up to a particular Reynolds number, which is defined as the transitional Reynolds number $\operatorname{Re}_{L p}{ }^{t}$.

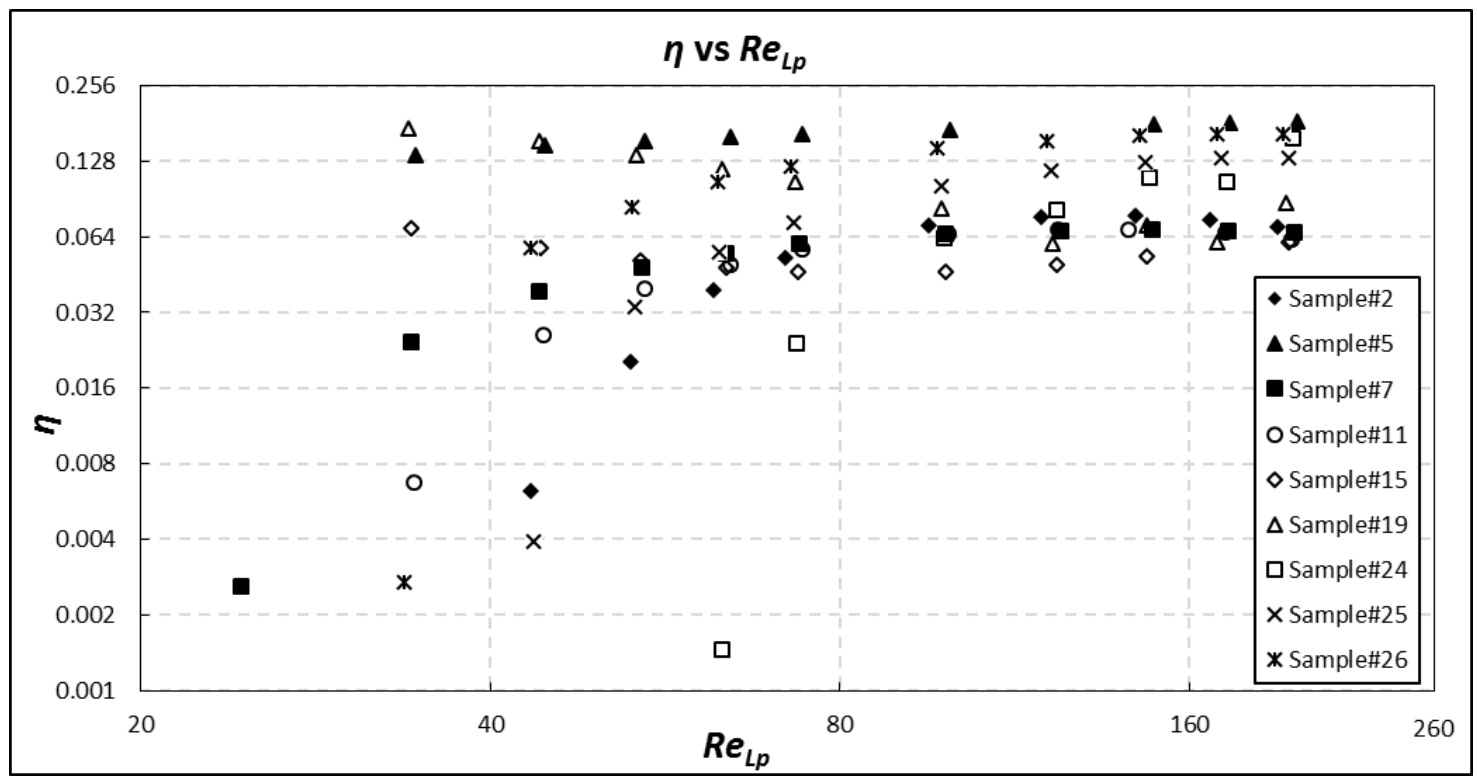

(a)

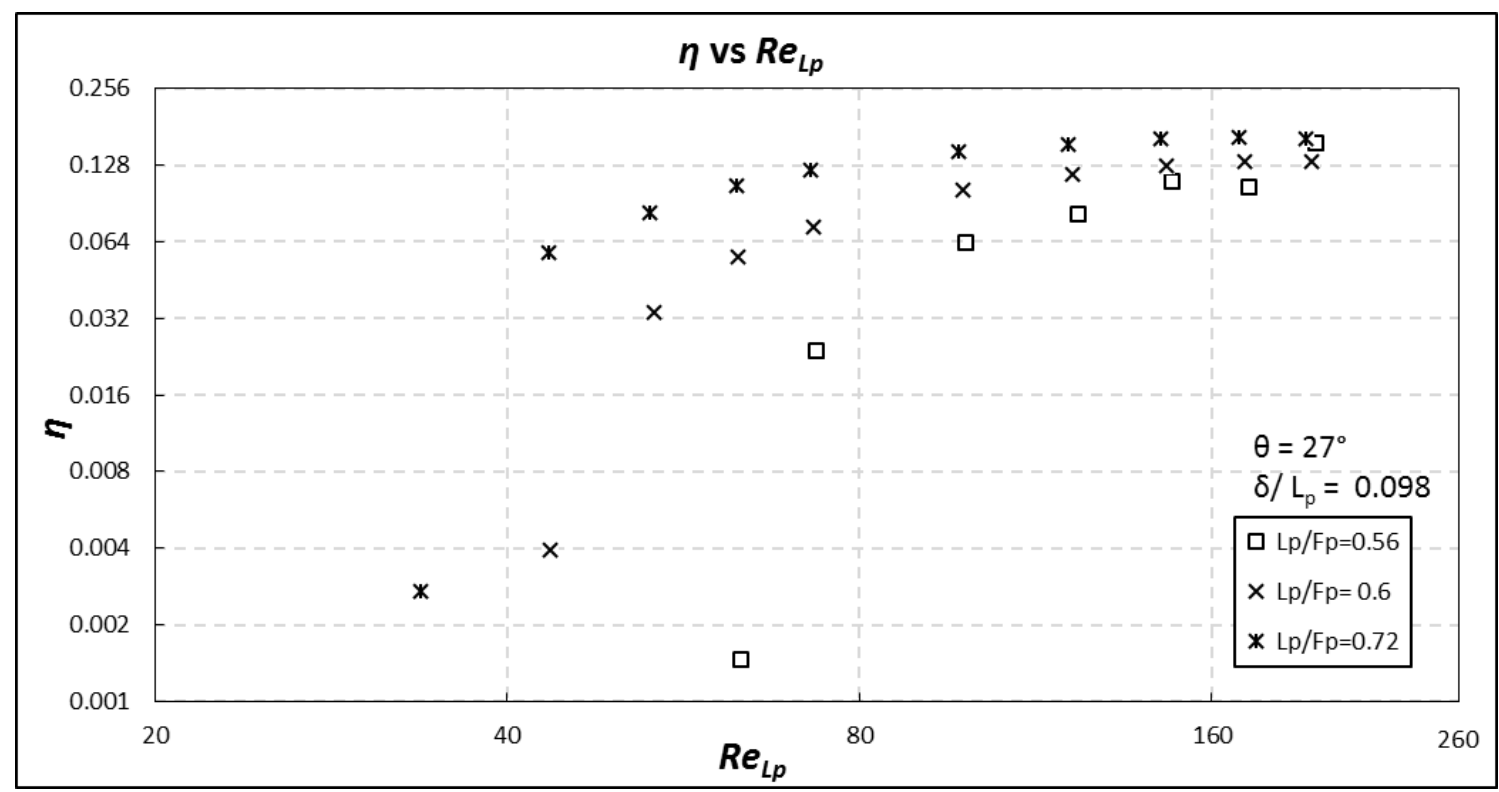

(b) 


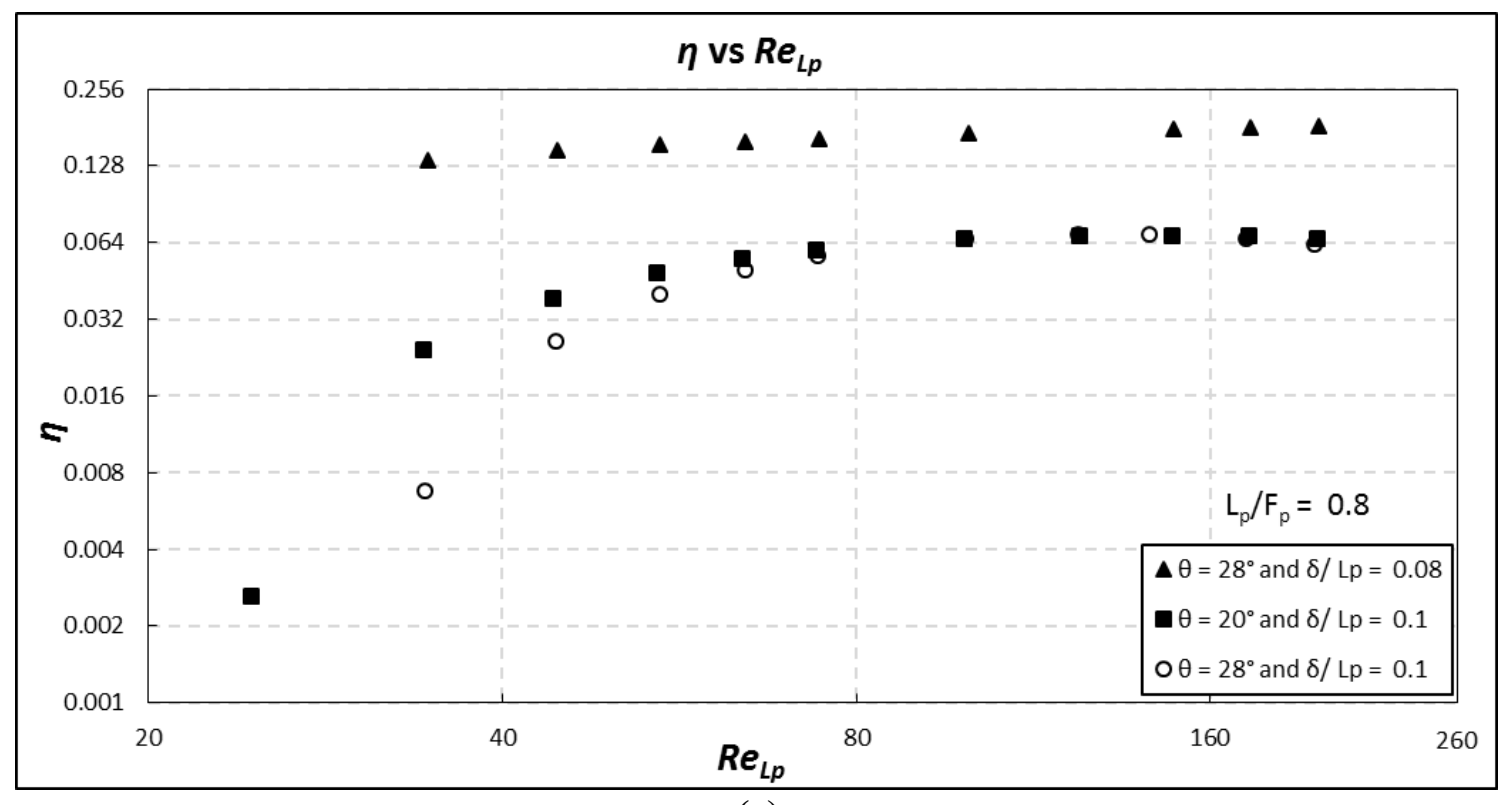

(c)

Figure 78. $\eta$ vs. $R e_{L p}$ (a) All Numerically Tested Samples (b) Effect of $L_{p} / F_{p}$ (c) Combined Effect of $\theta$ and $\delta / L_{p}$

Above $\operatorname{Re}_{L p}{ }^{t}$, the flow efficiency becomes independent of Reynolds number for the fixed ratio of $L_{p} / F_{p}$ and $\delta / L_{p}$. From the Figure 78 it is seen that the transitional Reynolds number is independent of $L_{p} / F_{p}$ and $\delta / L_{p}$ for a fixed louver angle. The transitional $R e_{L p}$ appears to be at approximately equal to 80 from the simulation results.

It can be seen from the Figure 78, that the maximum flow efficiency at high $\operatorname{Re}_{L p}$ of 200 is less than 0.256 in all the studied cases. This clearly signifies the fact that for the complete range of Reynolds number from 20 to 200, based on louver pitch, the flow is not fully aligned with the louver direction. The transition of the flow from fin directed to the louver directed is not complete. From the Figure 78, it can be also seen that the average flow efficiency for the Reynolds number of 80 , is less than $10 \%$. With the increase of Reynolds number from 20 to 200, the flow pattern will transition from the fin directed flow to the louver directed flow. 


\subsubsection{Combined Effect of Louver Angle $(\theta)$ and Thickness to Louver Pitch Ratio $\left(\delta / L_{p}\right)$}

As can be seen from the Figure 78a and Figure 78c that increasing the louver angle from $20^{\circ}$ to $30^{\circ}$, decreases the flow efficiency for the constant $L_{p} / F_{p}$ and $\delta / L_{p}$ up to the transitional Reynolds number. Then after the flow efficiency remains constant for the rest of the studied cases of Reynolds number. For the constant $L_{p} / F_{p}$ and decreasing $\delta / L_{p}$ shows the increase in the flow efficiency with the increase in louver angle for the Reynolds number below the transition number. The variation in the flow efficiency may be up to $300 \%$ for the $50 \%$ increase in the louver angle from $20^{\circ}$ to $30^{\circ}$ and $20 \%$ decrease in $\delta / L_{p}$. This will add up the turning losses in the flow as the louver angle is increased. For the Reynolds number above the transitional number, the effect of louver angle is not seen.

\subsubsection{Effect of Louver to Fin Pitch Ratio $\left(L_{p} / F_{p}\right)$}

From the observations of Figure $78 \mathrm{a}$ and $78 \mathrm{~b}$, it is evident that flow efficiency increases with increasing louver to fin pitch ration $\left(L_{p} / F_{p}\right)$. This is similar to the observation made by previous researchers (Webb and Cowell). About 200\% variation in the flow efficie ncy is seen with $29 \%$ variation in the $L_{p} / F_{p}$ for the studied range from 0.56 to 0.72 below the transitional Reynolds number. Whereas, about $45 \%$ variation is observed above the transitional Reynolds number.

\subsubsection{Prediction of Flow Efficiency}

Observations from the Figures 78a, 78b, and 78c shows two distinct Reynolds number regions, which is also analogous to the present experimental studies. Therefore, for these 
two flow regimes, separate flow efficiency correlations are developed. One for $20<\operatorname{Re}_{L p}$ $\leq 80$, and another for $80<\operatorname{Re}_{L p} \leq 200$. These correlations are given below.

\subsubsection{For $\operatorname{Re}_{L p} \leq 80$}

For the Reynolds number below 80 flow efficiency is a function of louver angle $\theta$, louver to fin pitch ratio $L_{p} / F_{p}$, fin thickness to louver pitch ratio $\delta / L_{p}$, and $R e_{L p}$. A multiple linear regression was performed to provide the best fit of the numerical data for this region. Equation 94 below predicts the flow efficiency $\eta$ for $20<\operatorname{Re}_{\mathrm{Lp}} \leq 80$, within $\pm 10.3 \%$.

$$
\eta=\left(R e_{L p}\right)^{1.533}(\theta / 90)^{3.034}\left(L_{p} / F_{p}\right)^{3.026}\left(\delta / L_{p}\right)^{2.001}
$$

\subsubsection{For $\operatorname{Re}_{L p}>80$}

For the Reynolds number more than 80 flow efficiency is a function of louver to fin pitch ratio $L_{p} / F_{p}$ and fin thickness to louver pitch ratio $\delta / L_{p}$. Equation 95 below predicts the $\eta$ for $80<\operatorname{Re} \operatorname{Lp} \leq 200$ within $\pm 14.2 \%$.

$$
\eta=0.445\left(L_{p} / F_{p}\right)^{-1.432}\left(\delta / L_{p}\right)^{-1.569}
$$

\subsection{COMPARISON BETWEEN EXPERIMENTAL AND NUMERICAL DATA}

Figure 79 through Figure 88 provides the $\mathrm{j}$ and $\mathrm{f}$ factors obtained from the numerical simulations plotted against the present experimental results from the similar geometry. It is important to remember that only 10 heat exchanger geometries are tested numerically due to the consideration of the variation in the louver angle only. Therefore, only these 10 numerical results are compared with the same 10 experimental results. 
The numerical results for the $\mathrm{j}$ and $\mathrm{f}$ factors for the Sample\#1 are illustrated in Figure 79. The computational results are in excellent agreement with the experimental results. However, the wavy behavior of the experimental data is not captured in the numerical results. This is because the standard laminar model utilized in the simulations does not account for the combined effect of the flow and heat transfer phenomena as it is observed experimentally. Similar agreement between the experimental and numerical results of $j$ and $\mathrm{f}$ factors data is found for the Sample\#2, within the acceptable limits, as seen from the Figure 80 .

Figure 81 to Figure 88 shows, divergence between the numerical and experimental results. For the Reynolds numbers less than around 80, the computational and experimental results for $\mathrm{j}$-factors are oblique to each other with an angle more than $30^{\circ}$ on average. Whereas, for the Reynolds number more than 80 , the $\mathrm{j}$-factor plots show parallel variation with better agreement, as can be seen in the figures. Similar observations are seen from the comparison between numerical and experimental results for f-factors. In all the cases, for the Reynolds number more than 80 , most of the numerical results are in good agreement with the experimental results, whereas, for the Reynolds number below 80, greater disagreement has observed. Especially, the two flow regime behavior observed in the experimental studies is not seen in the numerical results.

This is again for the obvious reasons that current no such computational laminar models exists to the date to account for the experimentally observed flow behavior. For accurate numerical prediction, new model for the laminar region accounting the variation in flow behavior needs to be developed. It is also to remember that the numerical simulations are conducted with simplified geometrical parameters, and reduced complexity for the 
reduction of simulation time and meshing problems. In addition, the tube side effects on the flow behavior are neglected. These could also be the potential reasons for the variations seen between the experimental and the numerical data.

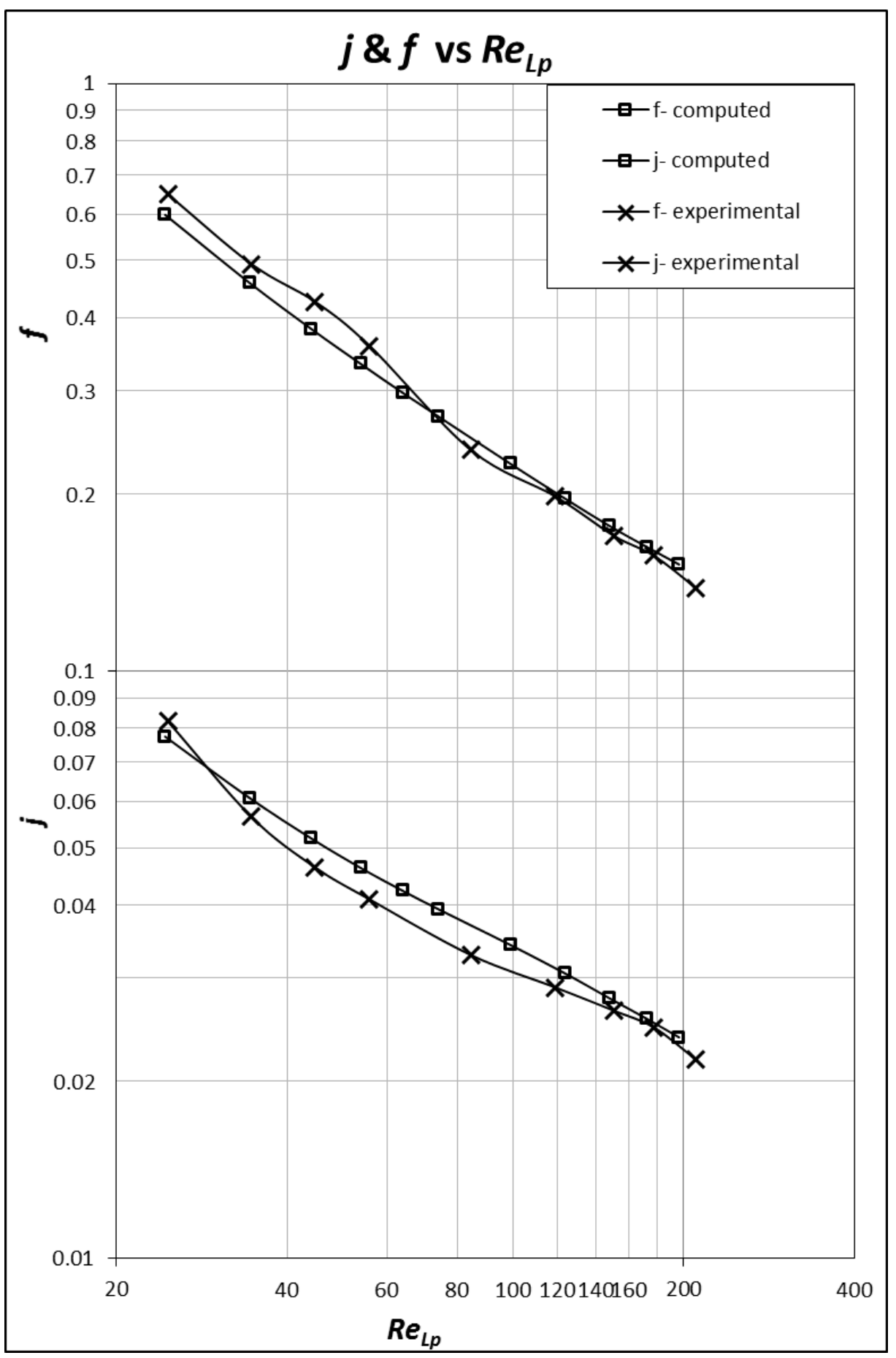

Figure 79. Numerical vs Experimental $j$ and $f$ Factors For Sample\# 1 


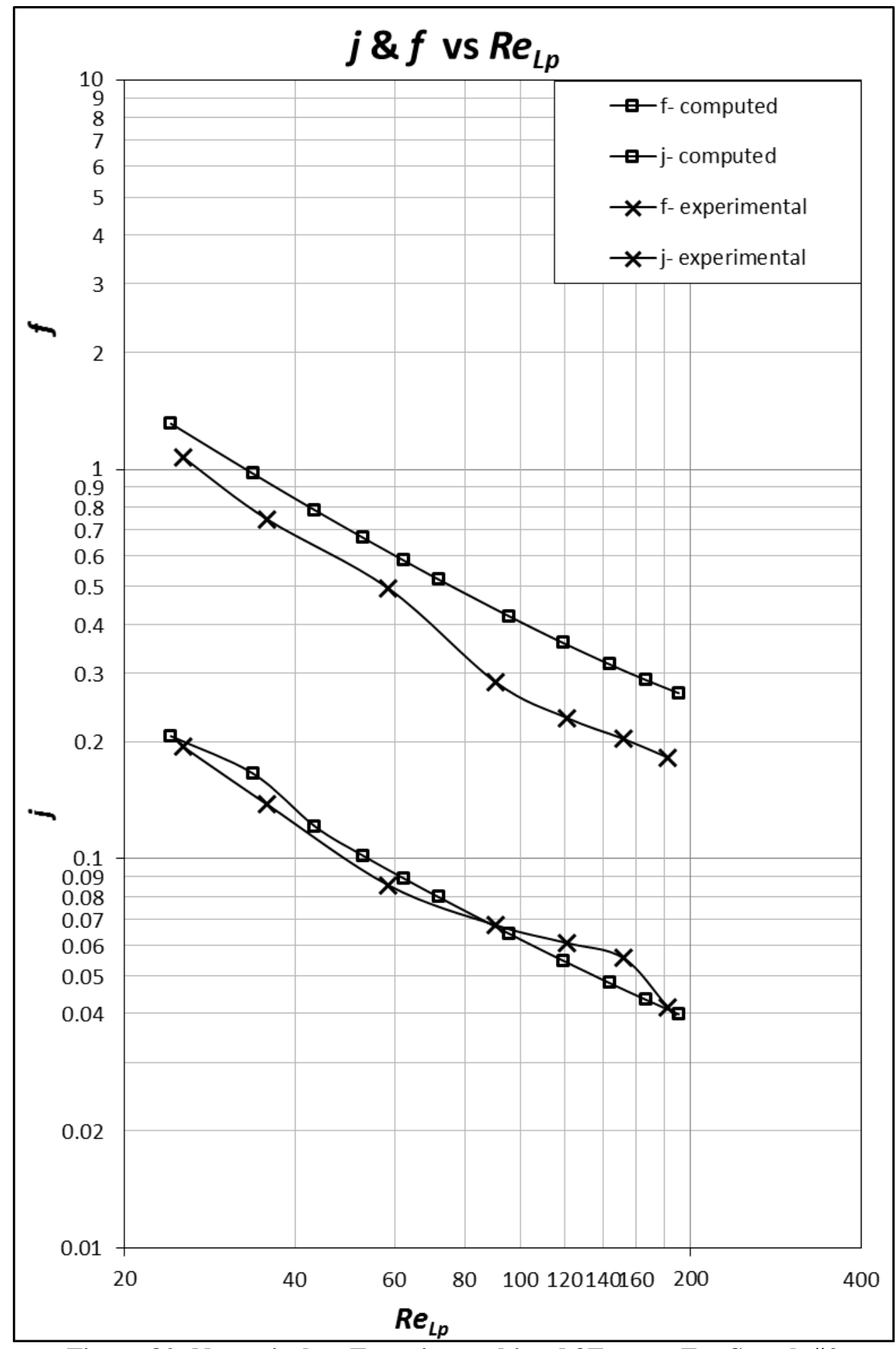

Figure 80. Numerical vs Experimental j and f Factors For Sample\#2 


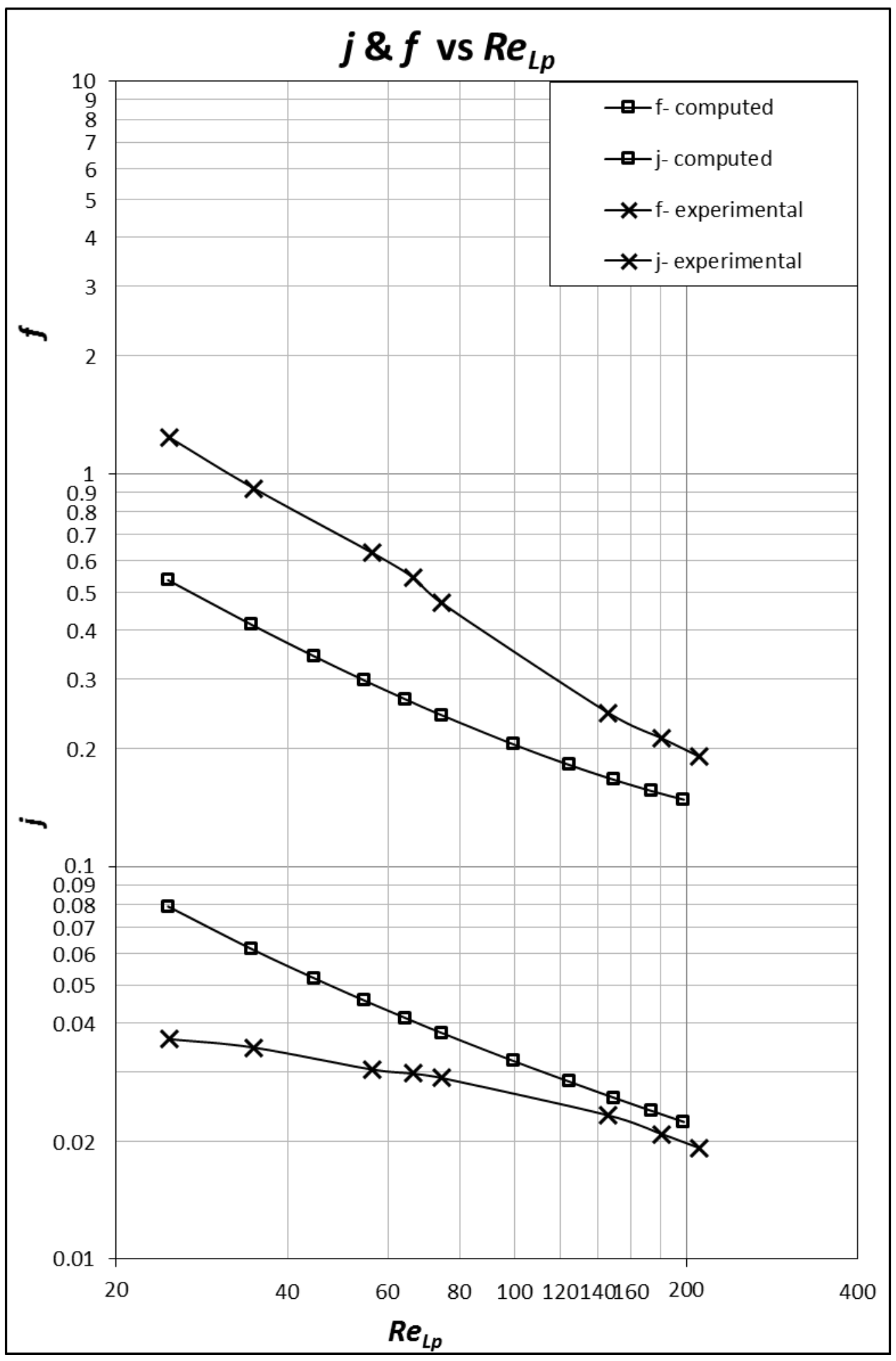

Figure 81. Numerical vs Experimental j and f Factors For Sample\#5 


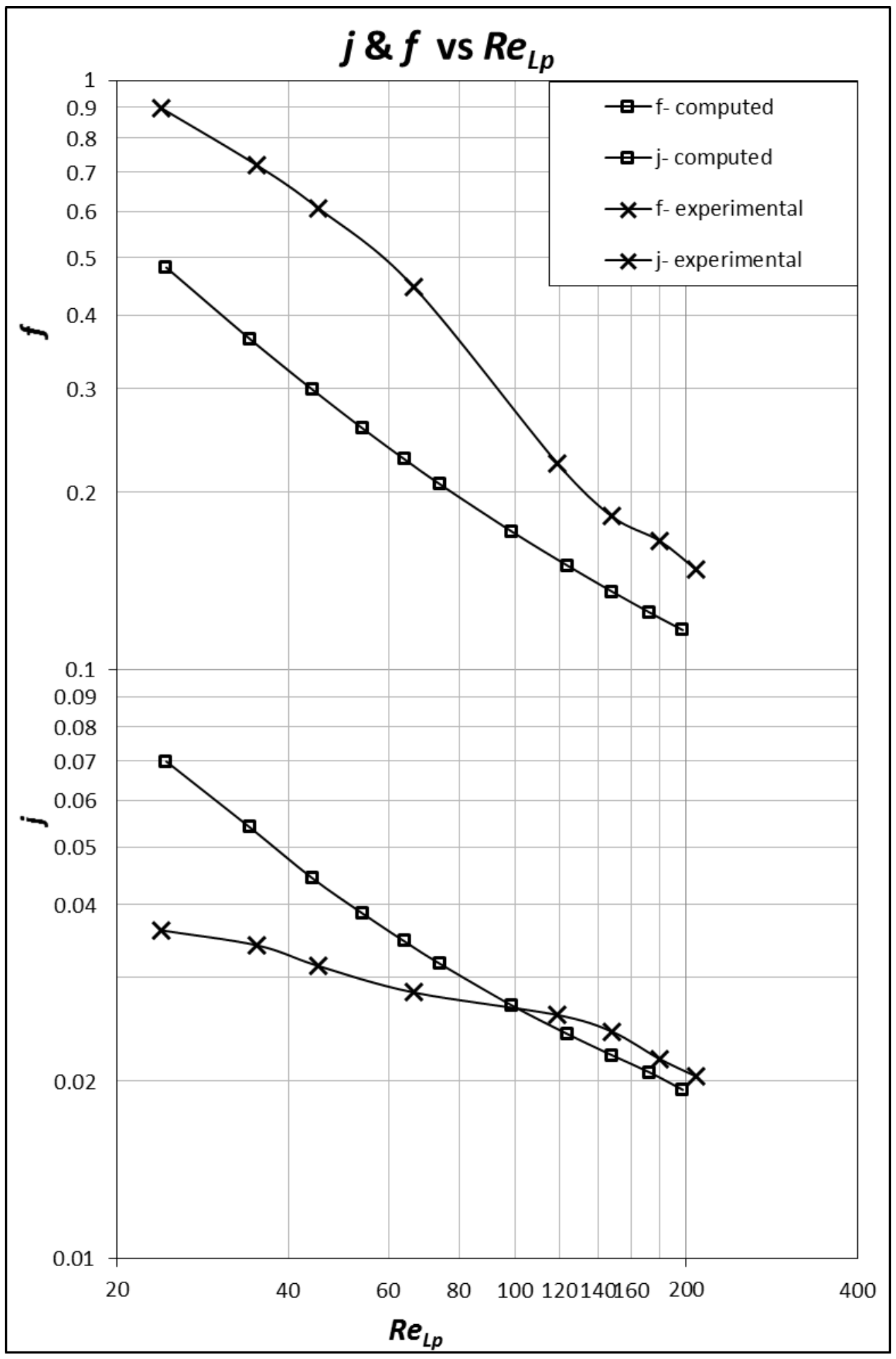

Figure 82. Numerical vs Experimental j and f Factors For Sample\#7 


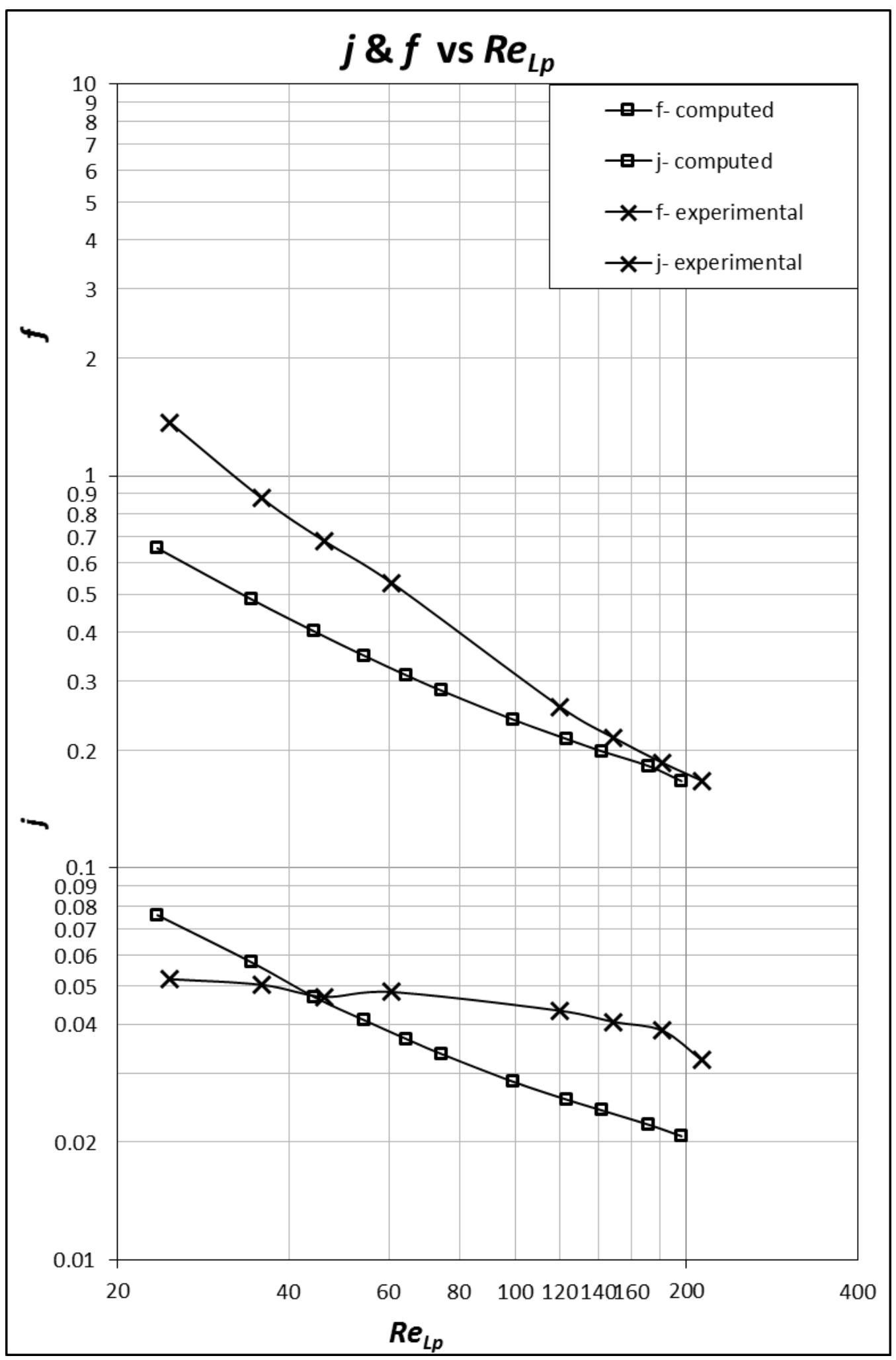

Figure 83. Numerical vs Experimental j and f Factors For Sample\#11 


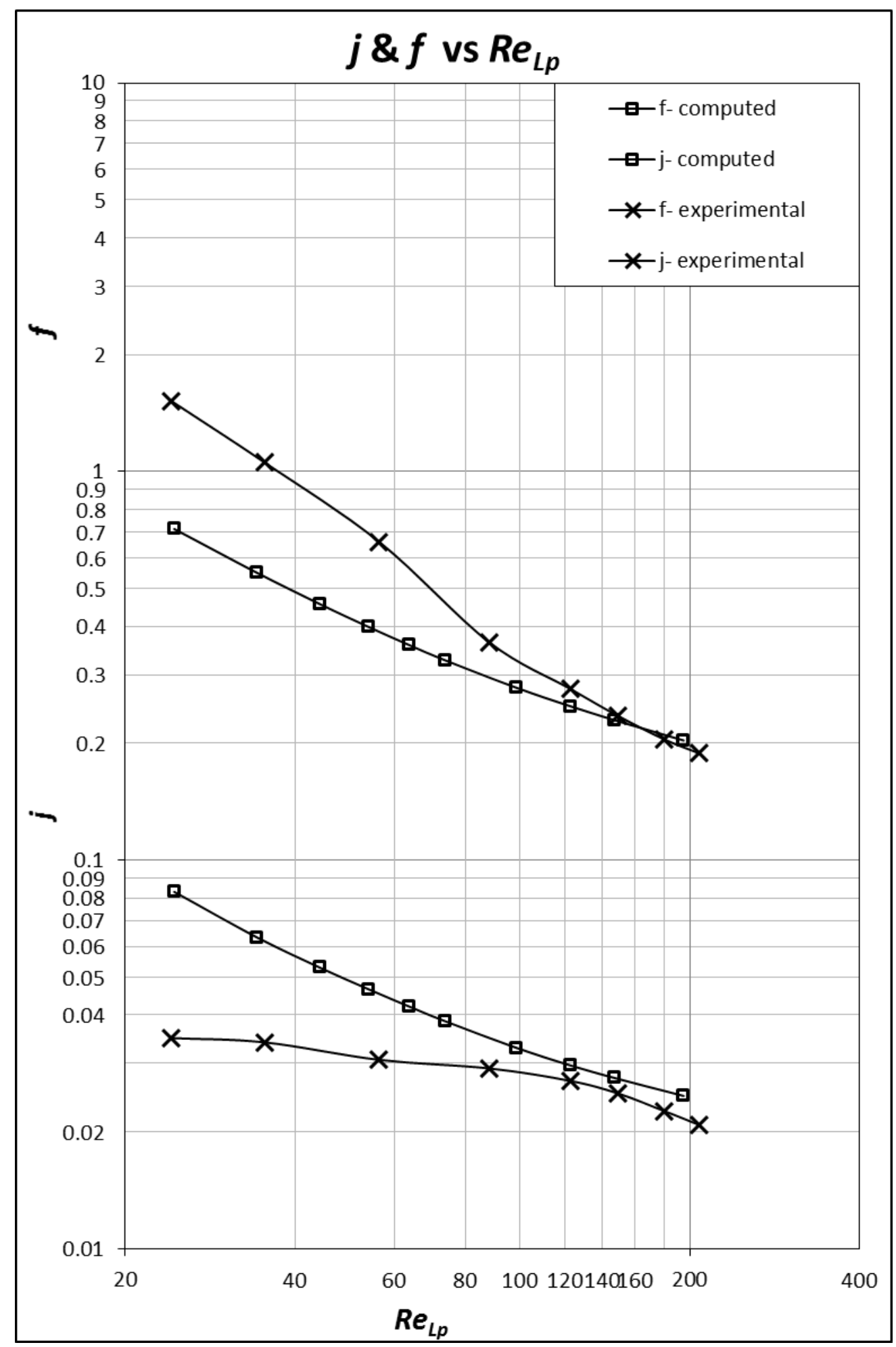

Figure 84. Numerical vs Experimental j and f Factors For Sample\#15 


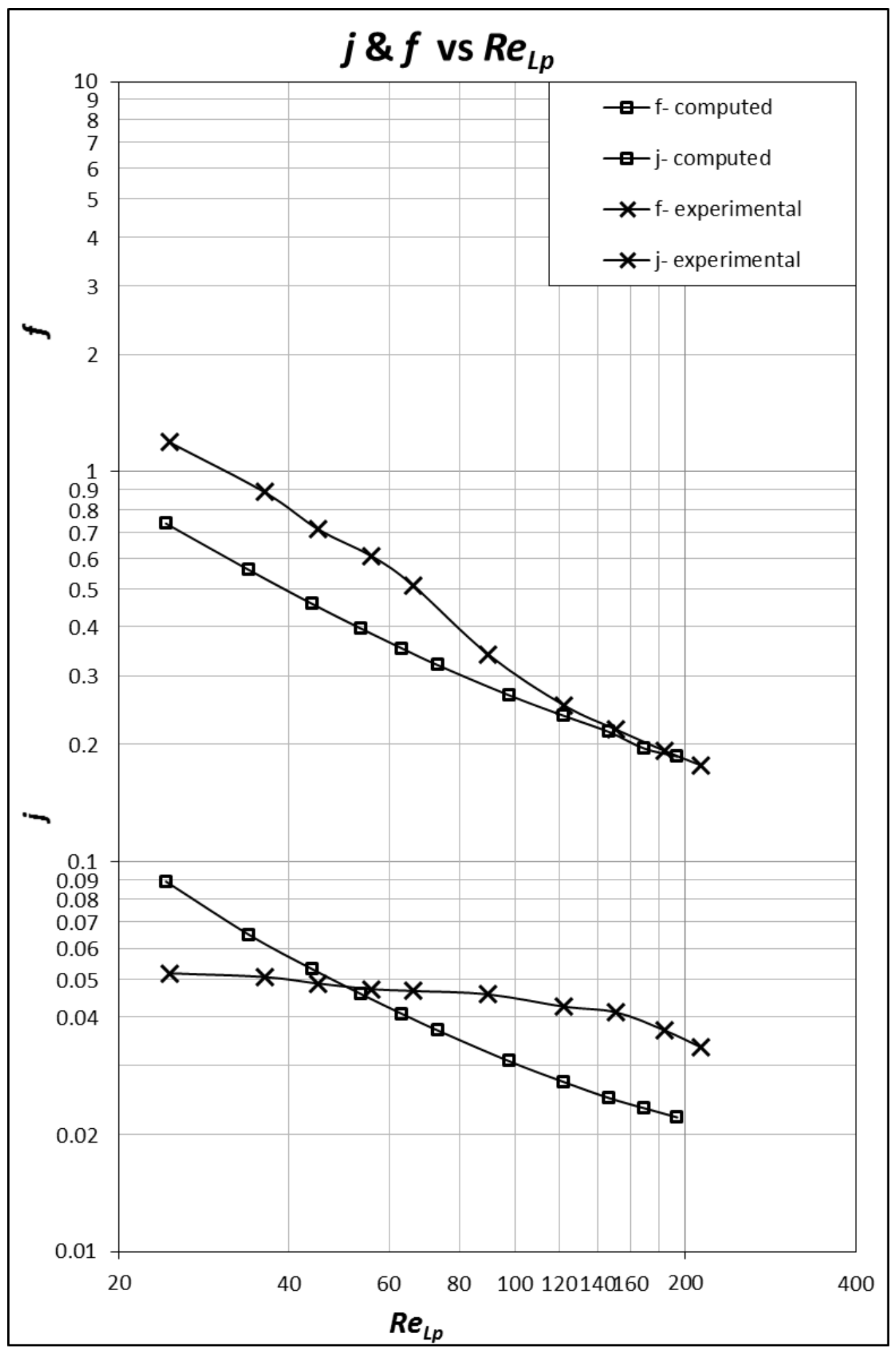

Figure 85. Numerical vs Experimental j and f Factors For Sample\#19 


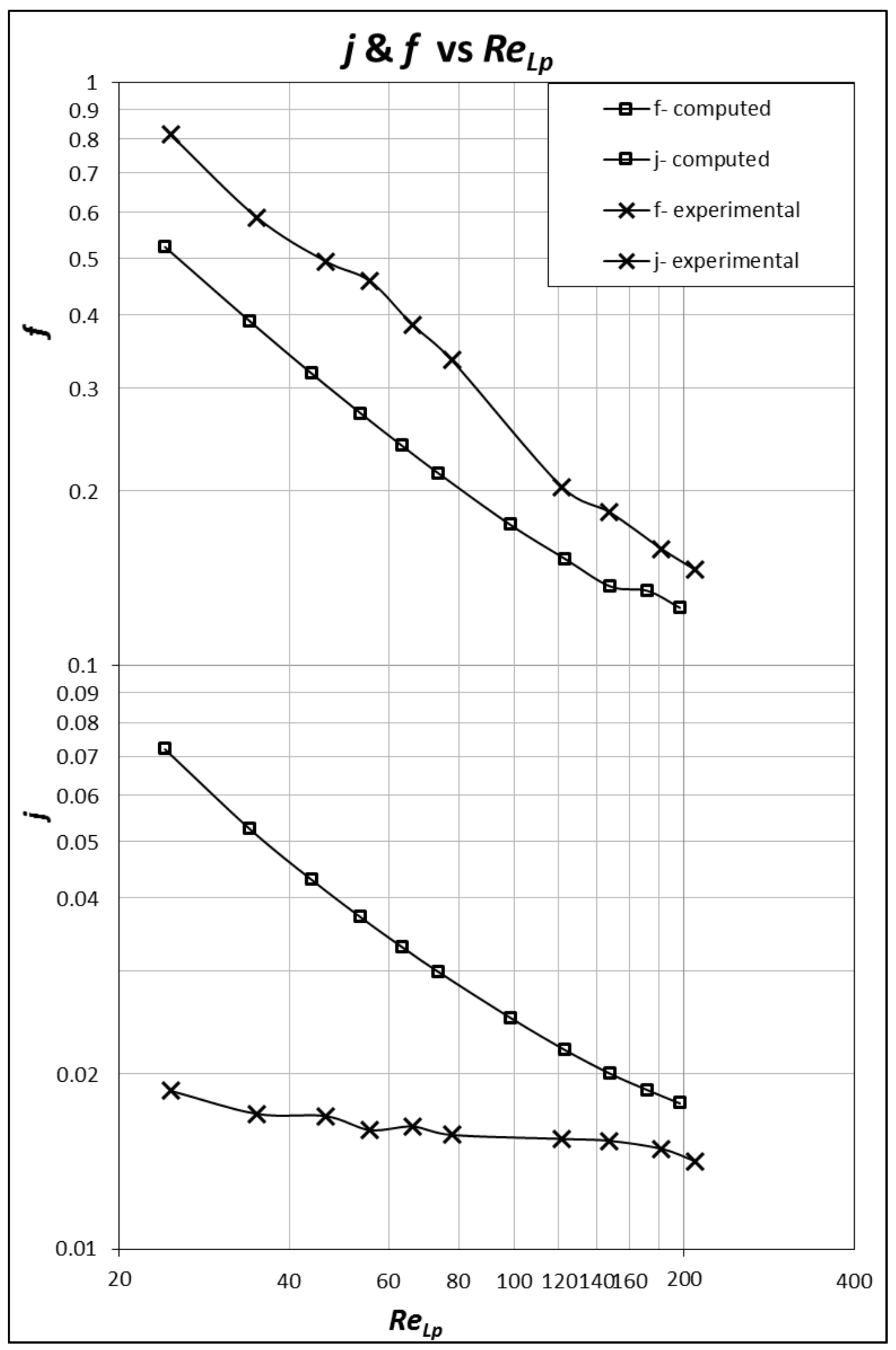

Figure 86. Numerical vs Experimental j and f Factors For Sample\#24 


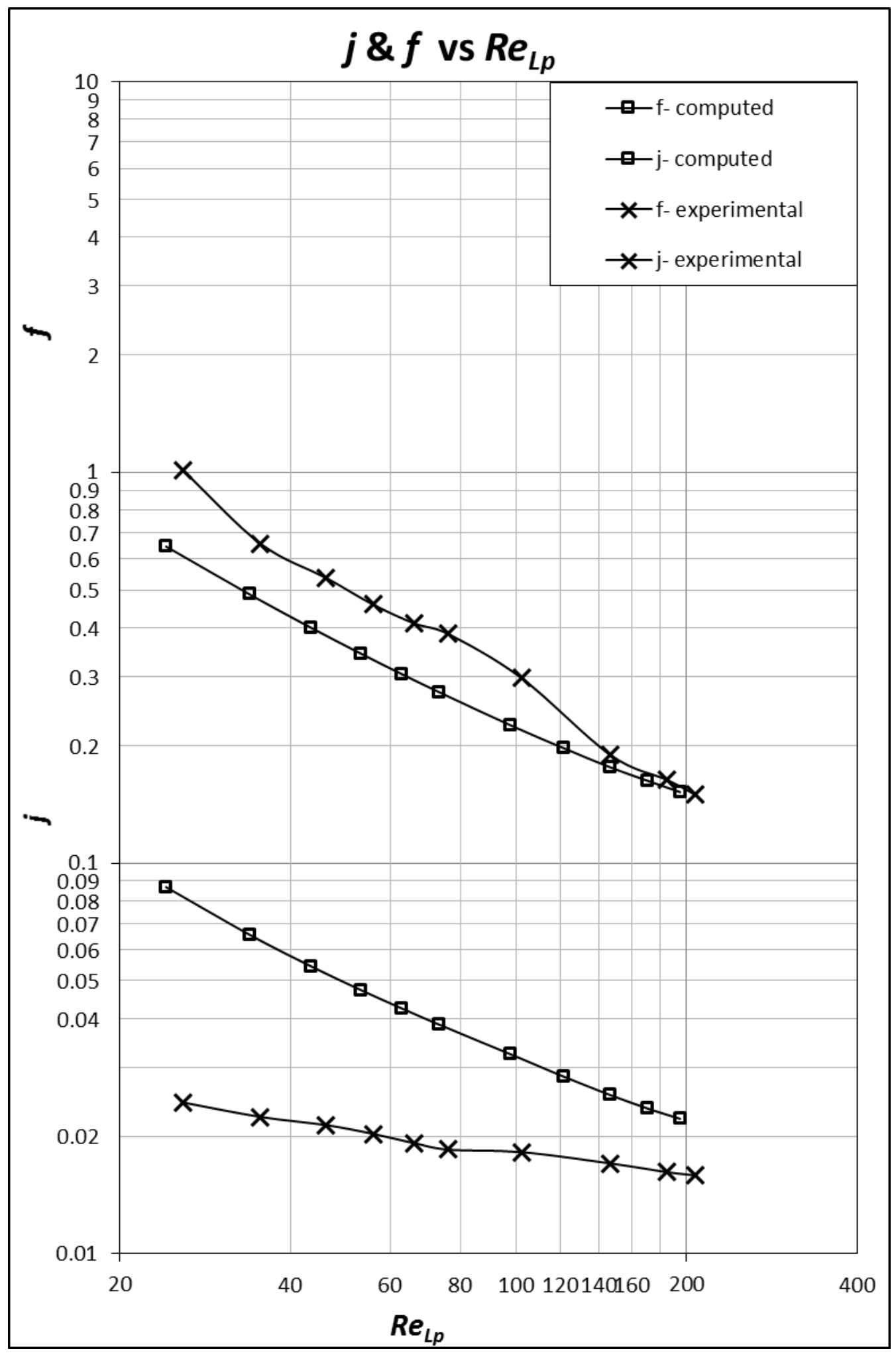

Figure 87. Numerical vs Experimental j and f Factors For Sample\#25 


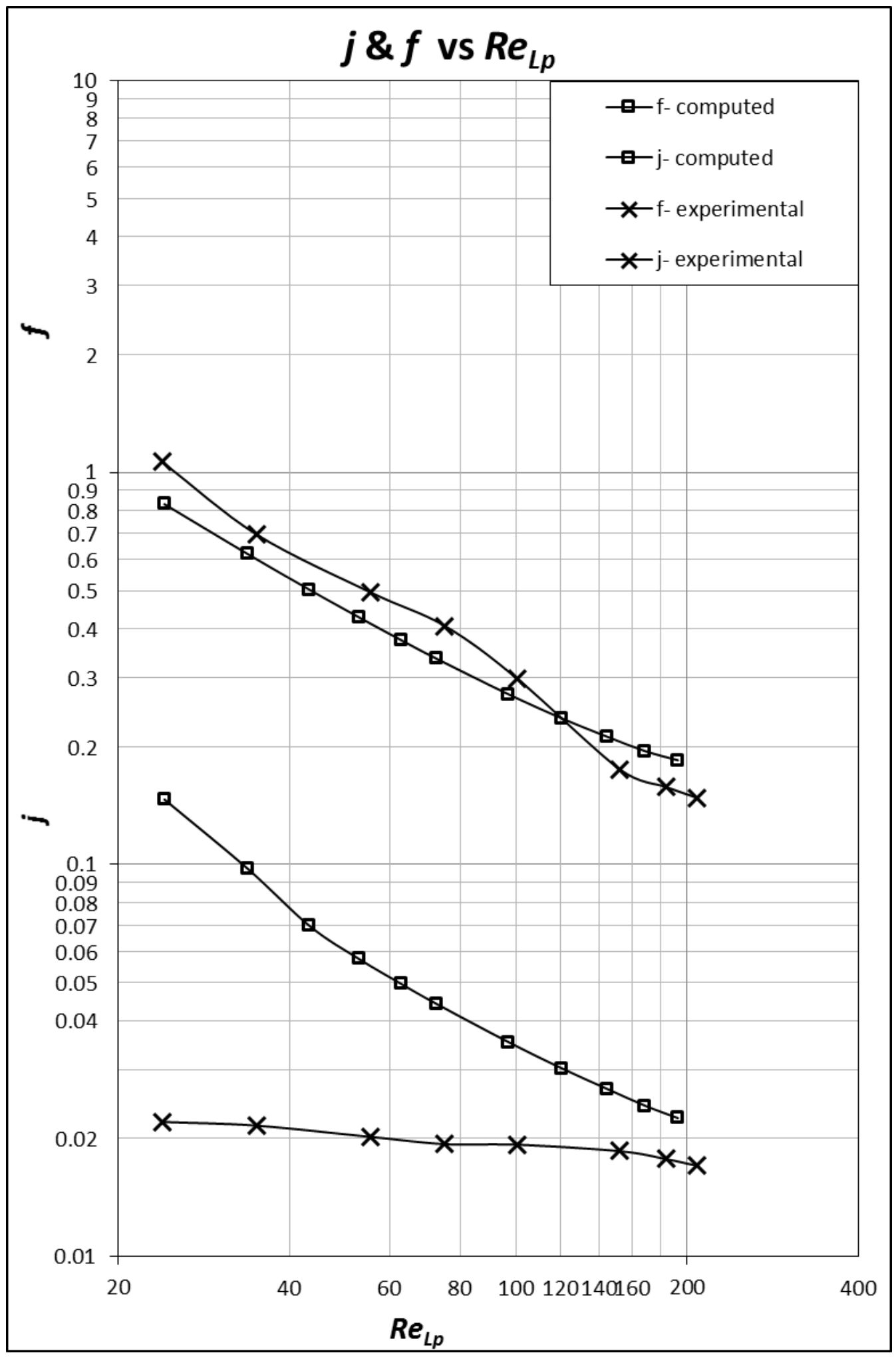

Figure 88. Numerical vs Experimental j and f Factors For Sample\#26 


\section{CHAPTER 9 : CONCLUSIONS}

In this study, the heat transfer and pressure drop data for microchannel heat exchangers are measured on a wind tunnel facility, which was instrumented specifically for low air-side Reynolds number testing in the range of $20<\operatorname{Re}_{L p}<225$. Experiments were carried out with 26 brazed aluminum heat exchanger samples with different designs. The text matrix covered fairly wide geometrical parameter ranges for fin pitch, fin height, fin thickness, louver pitch, louver angle, louver length, tube height and tube depth.

Within the investigated parameter ranges, it was found that heat transfer relationship, in term of $\mathrm{j}$-factor vs. $R e_{L p}$, in low Reynolds number range, could be differe nt from that in the high Reynolds number range. However, the characteristics of the $\mathrm{j}$ factors vs. Reynolds numbers are not the same as reported in the past, which is characterized by a non-power law behavior. The present heat transfer data are better characterized as a flattening behavior.

Based on the test data, it is possible that the f-factor and j-factor behave as if there are two flow regimes based on the magnitude of $R e_{L p}$. Two sets of corrections have been developed for both f-factor and j-factor in the range of $20<\operatorname{Re}_{L p} \leq 80$ and $80<\operatorname{Re}_{L p} \leq 200$. The correlations developed using eight key parameters considered in the format of powerlaw. All parameters used in the correlations are non-dimensionalized based the louver pitch. Although power-law formats are used for both $\mathrm{f}$ and $\mathrm{j}$ correlations, the coefficients in each flow regimes are different, reflecting the difference in flow and heat transfer characteristics between the relatively lower and relatively higher Reynolds number ranges. 
For the range $20<\operatorname{Re}_{L p} \leq 80,85.3 \%$ experimental $\mathrm{j}$-factor data correlated within $\pm 19.68 \%$, whereas, $84.8 \%$ of $\mathrm{j}$-factor data for the range $80<\operatorname{Re}_{L p} \leq 200$ correlated within $\pm 22.12 \%$. In the case of f-factor, $85.3 \%$ of the experimental data correlated within $\pm 13.53 \%$, and $85.6 \%$ of the data correlated within $\pm 10.68 \%$, for the lower and higher range of Reynolds number range respectively.

The numerical investigation was conducted for further understanding of the flow behavior at the range of experimentally tested Reynolds number. Ten different heat exchanger geometries with varied geometrical parameters obtained for the experimental studies were considered for the numerical investigation. The variations in the louver angle were the basis of the selection. The heat transfer and pressure drop performance were numerically investigated, and the effect of the geometrical parameters was evaluated. It is found that the flow is fin directed instead of louver directed throughout the studied range of Reynolds number. Therefore, the heat exchanger shows poor performance.

Numerical results were compared against the experimental results. From the comparison, it is found that the current laminar numerical models do not reflect experimentally observed transitional two regime flow behavior on the thermal hydraulic performance of the heat exchangers from the fin directed flow to the louver directed flow at very low Reynolds number. The numerical results are in good agreement with the experimental results for the Reynolds number more than 80, whereas, for the Reynolds number below 80 , greater disagreement has observed.

The flow distribution through the fin and the louver region was quantified in terms of flow efficiency. The flow regime change was observed at very low Reynolds number similar to the experimental observations. However, the effect of two regime flow change 
does not reflect on the thermal hydraulic performance of numerical models. Two sets of correlations for the flow efficiency $\eta$ have developed for the range of $20<R e_{L p} \leq 80$ and $80<R_{L p} \leq 200$ in terms of power law format of non-dimensional parameters within $\pm 10.3 \%$ and $\pm 14.2 \%$, respectively.

For the range of $20<\operatorname{Re}_{L p} \leq 80$, the correlations for $\eta$ is a function of louver angle $\theta$, louver to fin pitch ratio $L_{p} / F_{p}$, fin thickness to louver pitch ratio $\delta / L_{p}$, and $R e_{L p}$. Whereas, for the range of $80<\operatorname{Re}_{L p} \leq 200$, the correlations for $\eta$ is a function of louver to fin pitch ratio $L_{p} / F_{p}$ and fin thickness to louver pitch ratio $\delta / L_{p}$.

Completion of the present study serves as a good start to fill the knowledge gap in the flow behavior and the heat transfer and pressure drop data within low air-side Reynolds number range for design and application of microchannel heat exchangers using louver fins with flat tubes. However, one should be careful when using the obtained results, as they are based on (and therefore, more suitable for) the microchannel heat exchangers of Type A corrugated louver with triangular channels. Other types of louver fins might result in different conclusions that need to be investigate 


\section{REFERENCES}

Achaichia, A. \& Cowell, T.A., 1988. Heat transfer and pressure drop characteristics of flat tube and louvered plate fin surfaces. Experimental Thermal and Fluid Science, 1(2), pp.147-157.

Achaichia, A. \& Cowell, T.A., 1988. A Finite Difference Analysis of Fully Developed Periodic Laminar Flow in Inclined Louver Arrays. Proc. $2^{\text {nd }} U K$ National Heat Transfer Conference, Glasgow, 2, pp.883-888.

ANSYS® Academic Research, Release 16.2

Aoki, H., Shinagawa, T. \& Suga, K.K., 1989. No Title. Experimental Thermal and Fluid Science, 2(3), pp.293-300.

Asako, Y. \& Faghri, M., 1987. Finite-volume solutions for laminar flow and heat transfer in a corrugated duct. J. Heat Transfer, 109(3), pp.627-634.

ASHRAE, 2013. ASHRAE Handbook—Fundamentals 2013th ed., Atlanta: ASHRAE.

Atkinson, K.N.. b et al., 1998. Two- and three-dimensional numerical models of flow and heat transfer over louvred fin arrays in compact heat exchangers. International Journal of Heat and Mass Transfer, 41(24), pp.4063-4080.

Čarija, Z. \& Franković, B., 2008. Heat transfer analysis of flat and louvered fin-and-tube heat exchangers using CFD. HEFAT.

Chang, Y. J., Wang, C.C., 1997. A Generalized Heat Transfer Correlation for Louver Fin Geometry. International Journal of Heat and Mass Transfer, 40(3), pp.533-544.

Chang, Y.-J. et al., 2000. A generalized friction correlation for louver fin geometry. International Journal of Heat and Mass Transfer, 43(12), pp.2237-2243.

Chang, Y.-J. \& Wang, C.-C., 1997. A generalized heat transfer correlation for Iouver fin geometry. International Journal of Heat and Mass Transfer, 40(3), pp.533-544.

Chang, Y.J., 1994. Heat Transfer and Flow Characteristics of Automotive Brazed Aluminum Heat Exchangers. ASHRAE Transactions, 100(2), pp.643-652.

Cheng, Z.D., He, Y.L. \& Cui, F.Q., 2012. International Journal of Heat and Mass Transfer Numerical study of heat transfer enhancement by unilateral longitudinal vortex generators inside parabolic trough solar receivers. , 55, pp.5631-5641. 
Coker, A.K., 2007. Ludwig's Applied Process Design for Chemical \& Petrochemical Plants 4th ed., Jordan Hill, Oxford, UK: Elsevier Science \& Technology.

Cui, J. \& Tafti, D.K., 2002. Computations of flow and heat transfer in a three-dimensional multilouvered fin geometry. International Journal of Heat and Mass Transfer, 45(25), pp.5007-5023.

Davenport, C.J., 1983. Correlation for heat transfer and flow friction characteristics of louvered fin. AIChE Symp, Ser. 79, pp.19-27.

Davenport, C.J., 1980. Heat Transfer and Fluid Flow in Louvered Triangular Ducts. Lanchester Polytechnic.

Dong, J. et al., 2007. Heat transfer and pressure drop correlations for the multi-louvered fin compact heat exchangers. Energy Conversion and Management, 48(5), pp.15061515.

Ebeling, P. \& Thole, K.A., 2004. Measurements and predictions of the heat transfer at the tube-fin junction for louvered fin heat exchangers. Int. J. Compact Heat Exchang., 5, pp.265-286.

EPRI TR-107397, 1998. Service Water Heat Exchanger Testing, Palo Alto, CA: Electric Power Research Institute.

Hiramatsu, M., Ishimaru, T. \& Matsuzaki, K., 1990. Research on fins for air conditio ning heat exchangers (first report, numerical analysis of heat transfer on louvered fins). JSME International Journal, Series II, 33(4), p.Paper No. 88-1254 A.

Hsieh, C.T. \& Jang, J.Y., 2006. 3-D thermal-hydraulic analysis for louver fin heat exchangers with variable louver angle. Applied Thermal Engineering, 26(14-15), pp.1629-1639.

Huihua, Z. \& Xuesheng, L., 1989. The experimental investigation of oblique angles and interrupted plate lengths for louvered fins in compact heat exchangers. Experimental Thermal and Fluid Science, 2(1), pp.100-106.

Incroprea, F.P. \& DeWitt, D.P., 2000. Fundamentals of Heat and Mass Transfer 4th ed., New York, NY: John Wiley and Sons.

Jacobi, M., Park, Y., Zhong, Y., Michna, G. and Xia, Y., 2005. High performance heat exchangers for air-conditioning and refrigeration applications (non-circular tubes). Air- Conditioning and Refrigeration Technology Institute (ARTI), ARTI-21CR(60520021-1). 
Jang, J.-Y., Wu, M.-C. \& Chang, W.-J., 1996. Numerical and experimental studies of threedimensional plate-fin and tube heat exchangers. International Journal of Heat and Mass Transfer, 39(14), pp.3057-3066.

Jang, J.Y. \& C., C.C., 2013. Optimization of the louver angle and louver pitch for a louver finned and tube heat exchanger. Int. J. Phys. Sci., 8(43), pp.2011-2022.

Jang, J.Y. \& Chen, C.C., 2015. Optimization of louvered-fin heat exchanger with variable louver angles. Applied Thermal Engineering, 91, pp.138-150.

Jang, J.Y. \& Tsai, Y.C., 2011. Optimum louver angle design for a louvered fin heat exchanger. Int. J. Phys. Sci, 6, pp.6422-6438.

Jeon, C.D. \& Lee, J., 2001. Local heat transfer characteristics of louvered plate fin surfaces. ASHRAE Transactions, 1, p.107.

Kajino, M., Hiramatsu, M., 1987. Research and development of automotive heat exchangers W. . Wang \& Y. Mori, eds., Washington DC: Hemisphere.

Kays, W.M. \& London, A.L., 1984. CompactHeat Exchangers 3rd ed., Malabar, FL: Krieger.

Kim, M.H., Lee, S.Y., Mehendale, S.S. and Webb, R.L., 2003. Microchannel Heat Exchanger Design for Evaporator and Condenser Applications. Advances in Heat Transfer, 37, pp.297-429.

Kim, M. \& Bullard, C.W., 2002. Air-side performance of brazed aluminum heat exchangers under dehumidifying conditions ' air des e' changeurs de chaleur en aluminium Performance co ' te ' $\mathrm{s}$ sous des conditions de de 'shumidification brase. , 25, pp.924-934.

Kim, M.H. \& Bullard, C.W., 2002. Air-side performance of brazed aluminum heat exchangers under dehumidifying conditions. International Journal of Refrigeration, 25(7), pp.924-934.

Kim, M.H., Kim, M. \& Bullard, C.W., 2000. Air-Side Thermal Performance of MicroChannel Heat Exchangers Under Dehumidifying Conditions. International Refrigeration and Air Conditioning Conference, pp.119-126.

Kim, M.H., Song, S. \& Bullard, C.W., 2002. Effect of inlet humidity condition on the airside performance of an inclined brazed aluminium evaporator. International Journal of Refrigeration, 25(5), pp.611-620. 
Leu, J.S. et al., 2001. A numerical investigation of louvered fin-and-tube heat exchangers having circular and oval tube configurations. International Journal of Heat and Mass Transfer, 44(22), pp.4235-4243.

Li, J., Wang, S. \& Zhang, W., 2011. Air-side thermal hydraulic performance of an integrated fin and micro-channel heat exchanger. Energy Conversion and Management, 52(2), pp.983-989.

Li, W. \& Wang, X., 2010. Heat transfer and pressure drop correlations for compact heat exchangers with multi-region louver fins. International Journal of Heat and Mass Transfer, 53(15-16), pp.2955-2962.

Lyman, A.C. et al., 2002. Scaling of heat transfer coefficients along louvered fins. Experimental Thermal and Fluid Science, 26(5), pp.547-563.

Malapure, V.P., Mitra, S.K. \& Bhattacharya, A., 2007. Numerical investigation of fluid flow and heat transfer over louvered fins in compact heat exchanger. International Journal of Thermal Sciences, 46(2), pp.199-211.

McNab, C.A. et al., 1998. Numerical modelling of heat transfer and fluid flow over herringbone corrugated fins. Heat Transfer, 6, pp.119-124.

McQuiston, F.C., Parker, J.D. \& Spitler, J.D., 2005. Extended Surface Heat Exchangers. In Heating, ventilating, and air conditioning analysis and design. Hoboken, NJ: John Wiley \& Sons, Inc., pp. 482-513.

Moran, M.J. \& Shapiro, H.N., 2004. Fundamentals of Engineering Thermodynamics 5th ed., Hoboken, NJ: John Wiley \& Sons, Inc.

Panse, S., 2005. A Numerical Investigation of Thermal and Hydraulic Characteristics in 3D Plate and Wavy Fin-Tube Heat Exchangers for Laminar and Transitional Flow Regimes. Montana State University.

Patel, V., Chon, J.T. \& Yoon, J., 1991. Laminar flow over wavy walls. J. Fluids Eng., 113(4), pp.574-578.

Qi, Z., Chen, J. \& Chen, Z., 2007. Parametric study on the performance of a heat exchanger with corrugated louvered fins. Applied Thermal Engineering, 27(2), pp.539-544.

Rugh, J.P., Pearson, J.T. \& Ramadhyani, S., 1992. A study of a very compact heat exchanger used for passenger compartment heating in automobiles. In ASME Symposium Series HTD. pp. 15-24.

Ryu, K., Yook, S.-J. \& Lee, K.-S., 2014. Optimal design of a corrugated louvered fin. Applied Thermal Engineering, 68(1), pp.76-79. 
Sahnoun, A. \& Webb, R.L., 1992. Prediction of heat transfer and friction for the louver fin geometry. International Journal of Heat and Mass Transfer, 114, pp.893-900.

Sanders, P.A. \& Sanders, P.A., 2005. Effects of Louver Length and Vortex Generators to Augment Tube Wall Heat Transfer in Louvered Fin Heat Exchangers. , pp.1-128.

Sanders, P.A. \& Thole, K.A., 2006. Effects of winglets to augment tube wall heat transfer in louvered fin heat exchangers. International Journal of Heat and Mass Transfer, 49(21-22), pp.4058-4069.

Shah, R.K. \& Webb, R.L., 1983. Compact and Enhanced Heat Exchangers. In J. Taborek, G. F. Hewitt, \& N. Afghan, eds. Heat exchangers: theory and practice. New York, NY: McGraw-Hill, pp. 425-468.

Shinde, P. \& Lin, C.-X., 2016. A heat transfer and friction factor correlation for low airside Reynolds number applications of compact heat exchangers (1535-RP). Science and Technology for the Built Environment, 0, pp.1-19.

Springer, M.E. \& Thole, K.A., 1999. Entry region of louvered fin heat exchangers. Experimental Thermal and Fluid Science, 19(4), pp.223-232.

Sunden, B. \& Svantesson, J., 1992. Correlation of $\mathrm{j}$ - and $\mathrm{f}$ factors for multi louvered heat transfer surfaces. In Proceedings of the 3rd UK National Conference on Heat Transfer. pp. 805-811.

Tafti, D.K., Wang, G. \& Lin, W., 2000. Flow transition in a multilouvered fin array. International Journal of Heat and Mass Transfer, 43(6), pp.901-919.

Tafti, D.K., Zhang, X. \& Guo, D., 2004. Study of Multilouvered Heat Exchangers at Low Reynolds numbers. , 61801(217).

Tang, L.H., Zeng, M. \& Wang, Q.W., 2009. Experimental and numerical investigation on air-side performance of fin-and-tube heat exchangers with various fin patterns. Experimental Thermal and Fluid Science, 33(5), pp.818-827.

Tannehill, J.C., Anderson, D.A. \& Pletcher, R.H., 1997. Computational fluid mechanics and heat transfer. , pp.1-803.

Tiwari, S. et al., 2003. Heat transfer enhancement in cross-flow heat exchangers using oval tubes and multiple delta winglets. International Journal of Heat and Mass Transfer, 46(15), pp.2841-2856.

Tsai, S.F., Sheu, T.W.H. \& Lee, S.M., 1999. Heat transfer in a conjugate heat exchanger with a wavy fin surface. International Journal of Heat and Mass Transfer, 42(10), pp.1735-1745. 
Wang, C.-C., Chi, K.-Y. \& Chang, C.-J., 2000. Heat transfer and friction characteristics of plain fin-and-tube heat exchangers, part II: Correlation. International Journal of Heat and Mass Transfer, 43(15), pp.2693-2700.

Webb, R. L., Jung, S.H., 1992. Air-side Performance of Enhanced Brazed Aluminum Heat Exchangers. ASHRAE Transactions, 98(2), pp.391-401.

Webb, R.L. \& Trauger, P., 1991. How structure in the louvered fin heat exchanger geometry. Experimental Thermal and Fluid Science, 4(2), pp.205-217.

White, F.M., 2011. Fluid Mechanics 7th ed., New York, NY: McGraw-Hill.

Yang, L. et al., 1997. Numerical prediction of transitional characteristics of flow and heat transfer in a corrugated duct. J. Heat Transfer, 119(1), pp.62-69. 
APPENDICES 


\section{APPENDIX A. UNCERTAINTY FORMULATIONS}

\section{Thermophysical Properties}

Air properties depend on the temperature at which they are evaluated. In this analysis, the air is considered as an ideal gas, and its properties are obtained based on the following bulk mean temperature:

$$
\begin{aligned}
& T_{o b m}=\frac{T_{o 1}+T_{o 2}}{2} \\
& W T_{o b m}=\sqrt{\left(\frac{1}{2} W T_{o 1}\right)^{2}+\left(\frac{1}{2} W T_{o 2}\right)^{2}}
\end{aligned}
$$

In calculating the values and uncertainties of the air properties, the property correlations provided in references (White (2011), Moran and Shapiro (2004), Tannehill et al. (1997)) are used for viscosity, specific heat, and thermal conductivity, respectively. For example, Sutherland's formula is used to calculate air's thermal conductivity at different temperatures.

$$
\begin{aligned}
& \rho_{o b m}=\rho_{o}=\frac{P}{R T_{o b m}} \\
& \frac{W \rho_{o b m}}{\rho_{o b m}}=\frac{W \rho_{o}}{\rho_{o}}=\sqrt{\left(-\frac{W T_{o b m}}{T_{o b m}}\right)^{2}} \\
& \frac{W \rho_{o 1}}{\rho_{o 1}}=\sqrt{\left(-\frac{W T_{o 1}}{T_{o 1}}\right)^{2}} \\
& \frac{W \rho_{o 2}}{\rho_{o 2}}=\sqrt{\left(-\frac{W T_{o 2}}{T_{o 2}}\right)^{2}}
\end{aligned}
$$




$$
\begin{aligned}
& \mu_{o}=1.71 \times 10^{-5}\left(\frac{T_{o b m} K}{273 K}\right)^{0.7} \\
& \frac{W \mu_{o}}{\mu_{o}}=\sqrt{\left(0.7 \frac{W T_{o b m}}{T_{o b m}}\right)^{2}} \\
& C_{p_{o}}=\frac{8.314}{28.97}\left(3.653-1.337 \times 10^{-3} T_{o b m}+3.294 \times 10^{-6} T_{o b m}{ }^{2}\right. \\
& \left.-1.913 \times 10^{-9} T_{o b m}{ }^{3}+0.2763 \times 10^{-12} T_{o b m}{ }^{4}\right)
\end{aligned}
$$

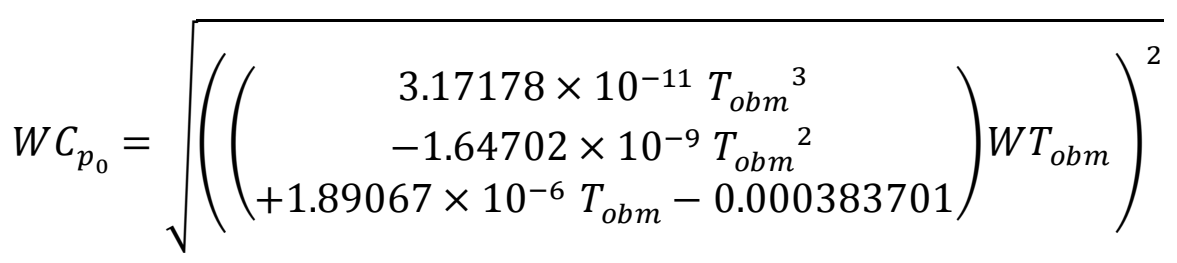

$$
\begin{aligned}
& k_{o}=\frac{2.495 \times 10^{-3} T_{o b m}{ }^{3 / 2}}{194 K+T_{o b m}} \\
& W k_{o}=\sqrt{\left(\left(\frac{\left(0.0012475 T_{o b m}+0.726045\right) \sqrt{T_{o b m}}}{\left(T_{o b m}+194\right)^{2}}\right) W T_{o b m}\right)^{2}}
\end{aligned}
$$

Likewise, water properties are temperature-dependent. Its properties are also determined based on the bulk mean temperature:

$$
\begin{aligned}
& T_{i b m}=\frac{T_{i 1}+T_{i 2}}{2} \\
& W T_{i b m}=\sqrt{\left(\frac{1}{2} W T_{i 1}\right)^{2}+\left(\frac{1}{2} W T_{i 2}\right)^{2}}
\end{aligned}
$$

In calculating the values and uncertainties of the water properties, the property correlations provided in references (White (2011)) are used for density and viscosity, while those in references (Coker (2007)) are used for specific heat and thermal conductivity. 


$$
\begin{aligned}
& \rho_{i}=1000-0.0178\left|T_{i b m}\left({ }^{\circ} \mathrm{C}\right)-4\left({ }^{\circ} \mathrm{C}\right)\right|^{1.7} \\
& W \rho_{i}=\sqrt{\left(\left(-0.03026\left(T_{i b m}-4\right)^{0.7}\right) W T_{i b m}\right)^{2}} \\
& \mu_{i}=0.001788 e^{\left(-1.704-5.306\left(\frac{273 K}{T_{i b m} K}\right)+7.003\left(\frac{273 K}{T_{i b m} K}\right)^{2}\right)} \\
& W \mu_{i}=\sqrt{\left(\frac{0.471259\left(T_{i b m}-720.625\right) e^{\left(\frac{521927-1448.54 T_{i b m}}{T_{i b m}{ }^{2}}\right)}}{T_{i b m}{ }^{3}} W T_{i b m}\right)^{2}} \\
& C_{p_{i}}=(1000 / 18.02)\left(92.053-0.039953 T_{i b m}-.00021103 T_{i b m}{ }^{2}\right. \\
& \left.+5.3469 \times 10^{-7} T_{i b m}{ }^{3}\right)
\end{aligned}
$$

\section{Uncertainty in Reynolds Number}

The air side Reynolds number is defined as:

$$
R e_{L_{P}}=\frac{\rho \bar{V}_{c} L_{P}}{\mu}
$$

The uncertainty associated with the air side Reynolds number is affected by air density, minimum free flow velocity, louver pitch, and viscosity. The uncertainty in the Reynolds number is estimated by 
$\frac{W R e_{L_{p}}}{R e_{L_{p}}}=\sqrt{\left(\frac{W \rho_{o}}{\rho_{o}}\right)^{2}+\left(\frac{W \bar{V}_{c}}{\bar{V}_{c}}\right)^{2}+\left(-\frac{W \mu_{o}}{\mu_{o}}\right)^{2}+\left(\frac{W L_{p}}{L_{p}}\right)^{2}}$

The minimum free flow velocity is calculated by

$$
\bar{V}_{c}=\frac{\dot{Q}_{o}}{A_{c}}
$$

The uncertainty associated with the minimum free flow velocity is estimated by

$$
\frac{W \bar{V}_{c}}{\bar{V}_{c}}=\sqrt{\left(\frac{W \dot{Q}_{o}}{\dot{Q}_{o}}\right)^{2}+\left(-\frac{W A_{C}}{A_{C}}\right)^{2}}
$$

The volumetric air flow rate is determined by the measurement of the pressure drops across the orifice or the venture meter:

$$
\dot{Q}_{o}=\dot{Q}_{r e f} \sqrt{\frac{\Delta P_{f m}}{\Delta P_{r e f}}}
$$

\section{Uncertainty in j-factor}

The $\mathrm{j}$-factor is defined by the following equation (McQuiston et al., 2005):

$$
j=\frac{h_{0}}{G_{c} C_{p_{0}}} P r_{0}^{2 / 3}
$$

The uncertainty associated with the $\mathrm{j}$-factor is estimated by

$$
\frac{W j}{j}=\sqrt{\left(\frac{W h_{0}}{h_{0}}\right)^{2}+\left(-\frac{W G_{c}}{G_{c}}\right)^{2}+\left(-\frac{W C_{p_{0}}}{C_{p_{0}}}\right)^{2}+\left(\frac{2}{3} \frac{W P r_{0}}{P r_{0}}\right)^{2}}
$$

where,

$$
\operatorname{Pr}_{o}=\frac{\mu_{o} C_{p_{0}}}{k_{o}}
$$




$$
\begin{aligned}
& \frac{W P r_{0}}{P r_{0}}=\sqrt{\left(\frac{W \mu_{o}}{\mu_{o}}\right)^{2}+\left(\frac{W C_{p_{0}}}{C_{p_{0}}}\right)^{2}+\left(-\frac{W k_{o}}{k_{o}}\right)^{2}} \\
& G_{c}=\rho_{0} \bar{V}_{c} \\
& \frac{W G_{c}}{G_{c}}=\sqrt{\left(\frac{W \rho_{o}}{\rho_{o}}\right)^{2}+\left(\frac{W \bar{V}_{c}}{\bar{V}_{c}}\right)^{2}}
\end{aligned}
$$

The uncertainty associated with the air side convective heat transfer coefficient, $h_{o}$, is estimated by the following equation (McQuiston et al., 2005):

$$
h_{o}=\frac{1}{\varepsilon_{s} A_{o}\left(\frac{1}{U A}-\frac{1}{h_{i} A_{i}}-\frac{\delta_{w}}{k_{w} A_{w}}\right)}
$$

To facilitate programming, the above equation and its uncertainty are expressed in the following formats:

$$
\begin{aligned}
& h_{o}=\frac{1}{\varepsilon_{s} A_{o} \beta} \\
& \frac{W h_{o}}{h_{o}}=\sqrt{\left(-\frac{W \varepsilon_{s}}{\varepsilon_{s}}\right)^{2}+\left(-\frac{W A_{o}}{A_{o}}\right)^{2}+\left(-\frac{W \beta}{\beta}\right)^{2}} \\
& \beta=\left(\frac{1}{U A}-\frac{1}{h_{i} A_{i}}-\frac{\delta_{w}}{k_{w} A_{w}}\right) \\
& \beta=\beta_{1}-\beta_{2}-\beta_{3} \\
& W \beta=\sqrt{\left(W \beta_{1}\right)^{2}+\left(-W \beta_{2}\right)^{2}+\left(-W \beta_{3}\right)^{2}} \\
& \beta_{1}=\frac{1}{U A} \\
& \frac{W \beta_{1}}{\beta_{1}}=\sqrt{\left(-\frac{W U A}{U A}\right)^{2}}
\end{aligned}
$$




$$
\begin{aligned}
& \beta_{2}=\frac{1}{h_{i} A_{i}} \\
& \frac{W \beta_{2}}{\beta_{2}}=\sqrt{\left(-\frac{W h_{i}}{h_{i}}\right)^{2}+\left(-\frac{W A_{i}}{A_{i}}\right)^{2}} \\
& \beta_{3}=\frac{\delta_{w}}{k_{w} A_{w}} \\
& \frac{W \beta_{3}}{\beta_{3}}=\sqrt{\left(\frac{W \delta_{w}}{\delta_{w}}\right)^{2}+\left(-\frac{W k_{w}}{k_{w}}\right)^{2}+\left(-\frac{W A_{w}}{A_{w}}\right)^{2}} \\
& A_{b}=A_{s}-A_{f b c s} \\
& W A_{b}=\sqrt{\left(W A_{s}\right)^{2}+\left(-W A_{f b c s}\right)^{2}} \\
& A_{s}=2 T_{d} L t_{n}+2 D_{m} L t_{n} \\
& A_{s}=A_{s 1}+A_{s 2} \\
& W A_{s}=\sqrt{\left(W A_{s 1}\right)^{2}+\left(W A_{s 2}\right)^{2}} \\
& A_{s 1}=2 T_{d} L t_{n} \\
& \frac{W A_{s 1}}{A_{s 1}}=\sqrt{\left(\frac{W T_{d}}{T_{d}}\right)^{2}+\left(\frac{W L}{L}\right)^{2}}=\sqrt{\left(\frac{W D_{m}}{D_{m}}\right)^{2}+\left(\frac{W L}{L}\right)^{2}} \\
& A_{s 2}=2 D_{m} L t_{n} \\
& A_{f b c s}+\left(\frac{W \delta_{f}}{\delta_{f}}\right)^{2} \\
& \delta_{f} T_{d} f_{n} t_{n} \\
& \frac{\left(T_{n}\right.}{2}
\end{aligned}
$$




$$
\begin{aligned}
& A_{f}=f_{A / f} f_{n}\left(t_{n}+1\right) \\
& \frac{W A_{f}}{A_{f}}=\sqrt{\left(\frac{W f_{A / f}}{f_{A / f}}\right)^{2}} \\
& f_{A / f}=4 f_{A / s}+A_{f c s}+A_{l c s} \\
& W f_{A / f}=\sqrt{\left(4 W f_{A / s}\right)^{2}+\left(W A_{f c s}\right)^{2}+\left(W A_{l c S}\right)^{2}}
\end{aligned}
$$

$$
\begin{aligned}
& A_{f c s}=4\left(\frac{H^{\prime} \delta_{f}}{2}\right) \\
& \frac{W A_{f c s}}{A_{f c s}}=\sqrt{\left(\frac{W H^{\prime}}{H^{\prime}}\right)^{2}+\left(\frac{W \delta_{f}}{\delta_{f}}\right)^{2}} \\
& H^{\prime}=\sqrt{H^{2}+f_{p}^{2}}
\end{aligned}
$$$$
W H^{\prime}=\sqrt{\left(\frac{H W H}{\sqrt{H^{2}+f_{p}^{2}}}\right)^{2}}
$$$$
A_{l c s}=2\left(\frac{l_{n} l_{l} \delta_{f}}{2}\right)
$$$$
\frac{W A_{l c s}}{A_{l c s}}=\sqrt{\left(\frac{W \delta_{f}}{\delta_{f}}\right)^{2}+\left(\frac{W l_{l}}{l_{l}}\right)^{2}}
$$$$
f_{A / s}=\left[2\left(\frac{s_{1} l_{l}}{2}\right)+\left(\frac{s_{2} l_{l}}{2}\right)+\left(\frac{A_{l}}{2}\right)+\left(\left(\frac{H^{\prime}-l_{l}}{2}\right)-\delta_{f}\right) f_{d}\right]
$$$$
f_{A / s}=f_{A / s 1}+f_{A / s 2}+f_{A / s 3}+f_{A / s 4}
$$ 


$$
\begin{aligned}
& W f_{A / s}=\sqrt{\left(W f_{A / s 1}\right)^{2}+\left(W f_{A / s 2}\right)^{2}+\left(W f_{A / s 3}\right)^{2}+\left(W f_{A / s 4}\right)^{2}} \\
& f_{A / s 1}=2\left(\frac{s_{1} l_{l}}{2}\right) \\
& \frac{W f_{A / s 1}}{f_{A / s 1}}=\sqrt{\left(\frac{W s_{1}}{s_{1}}\right)^{2}+\left(\frac{W l_{l}}{l_{l}}\right)^{2}} \\
& f_{A / s 2}=\left(\frac{s_{2} l_{l}}{2}\right) \\
& \frac{W f_{A / s 2}}{f_{A / s 2}}=\sqrt{\left(\frac{W s_{2}}{s_{2}}\right)^{2}+\left(\frac{W l_{l}}{l_{l}}\right)^{2}} \\
& f_{A / s 3}=\left(\frac{A_{l}}{2}\right) \\
& \frac{W f_{A / s 3}}{f_{A / s 3}}=\sqrt{\left(\frac{W A_{l}}{A_{l}}\right)^{2}} \\
& A_{l}=l_{w 1} l_{l} l_{n}+2 l_{w 2} l_{l}+2 l_{w 3} l_{l} \\
& A_{l}=A_{l 1}+A_{l 2}+A_{l 3} \\
& W A_{l}=\sqrt{\left(W A_{l 1}\right)^{2}+\left(W A_{l 2}\right)^{2}+\left(W A_{l 3}\right)^{2}} \\
& A_{l 1}=l_{w 1} l_{l} l_{n} \\
& \frac{W A_{l 1}}{A_{l 1}}=\sqrt{\left(\frac{W l_{w 1}}{l_{w 1}}\right)^{2}+\left(\frac{W l_{l}}{l_{l}}\right)^{2}} \\
& A_{l 2}=2 l_{w 2} l_{l} \\
& \frac{W A_{l 2}}{A_{l 2}}=\sqrt{\left(\frac{W l_{w 2}}{l_{w 2}}\right)^{2}+\left(\frac{W l_{l}}{l_{l}}\right)^{2}} \\
& A_{l 3}=2 l_{w 3} l_{l}
\end{aligned}
$$




$$
\begin{aligned}
& \frac{W A_{l 3}}{A_{l 3}}=\sqrt{\left(\frac{W l_{w 3}}{l_{w 3}}\right)^{2}+\left(\frac{W l_{l}}{l_{l}}\right)^{2}} \\
& f_{A / s 4}=\frac{H^{\prime} f_{d}-l_{l} f_{d}-2 \delta_{f} f_{d}}{2} \\
& W f_{A / s 4}=\sqrt{\frac{\left(\frac{f_{d}}{2} W H^{\prime}\right)^{2}+\left(-\frac{f_{d}}{2} W l_{l}\right)^{2}+\left(-f_{d} W \delta_{f}\right)^{2}+}{\left(\left(\frac{H^{\prime}-l_{l}-2 \delta_{f}}{2}\right) W f_{d}\right)^{2}}} \\
& A_{i}=2 L_{m c} L M_{n} t_{n}+2 H_{m c} L M_{n} t_{n} \\
& A_{i}=A_{i 1}+A_{i 2} \\
& W A_{i}=\sqrt{\left(W A_{i 1}\right)^{2}+\left(W A_{i 2}\right)^{2}} \\
& A_{i 1}=2 L_{m c} L M_{n} t_{n} \\
& \frac{W A_{i 1}}{A_{i 1}}=\sqrt{\left(\frac{W L_{m c}}{L_{m c}}\right)^{2}+\left(\frac{W L}{L}\right)^{2}} \\
& A_{i 2}=2 H_{m c} L M_{n} t_{n} \\
& \frac{W A_{i 2}}{A_{i 2}}=\sqrt{\left(\frac{W H_{m c}}{H_{m c}}\right)^{2}+\left(\frac{W L}{L}\right)^{2}} \\
& U A=N T U * \dot{m}_{o} * C_{p_{0}}
\end{aligned}
$$

where, the variable $N T U$ is considered as a constant. The uncertainty associated with the overall heat transfer coefficient is estimated by

$$
\begin{aligned}
& \frac{W U A}{U A}=\sqrt{\left(\frac{W m_{o}}{m_{o}}\right)^{2}+\left(\frac{W C_{p_{0}}}{C_{p_{0}}}\right)^{2}} \\
& \dot{m_{o}}=\dot{Q}_{o} * \rho_{0}
\end{aligned}
$$




$$
\begin{aligned}
& \frac{W \dot{m}_{o}}{m_{o}}=\sqrt{\left(\frac{W \dot{Q}_{o}}{\dot{Q}_{o}}\right)^{2}+\left(\frac{W \rho_{o}}{\rho_{o}}\right)^{2}} \\
& \operatorname{Pr}_{i}=\frac{\mu_{i} C_{p_{i}}}{k_{i}} \\
& \frac{W \operatorname{Pr}_{i}}{\operatorname{Pr}_{i}}=\sqrt{\left(\frac{W \mu_{i}}{\mu_{i}}\right)^{2}+\left(\frac{W C_{p_{i}}}{C_{p_{i}}}\right)^{2}+\left(-\frac{W k_{i}}{k_{i}}\right)^{2}}
\end{aligned}
$$

Following previous researcher's practice, the water side convective heat transfer coefficient, hi, is determined by the following correlation (McQuiston et al. (2005)):

$$
h_{i}=\left(\frac{k_{i}}{D_{h_{i}}}\right) 0.023\left(\operatorname{Re}_{D_{h}, i}\right)^{0.8}\left(P r_{i}\right)^{n}
$$

Uncertainty associated with the waterside heat transfer coefficient is based on the thermal conductivity of water, Reynolds's number at hydraulic diameter, and Prandtl number. Hydraulic diameter of water is kept constant.

$$
\frac{W h_{i}}{h_{i}}=\sqrt{\left(\frac{W k_{i}}{k_{i}}\right)^{2}+\left(-\frac{W D_{h_{i}}}{D_{h_{i}}}\right)^{2}+\left(0.8 \frac{W R e_{D_{h}, i}}{R e_{D_{h}, i}}\right)^{2}+\left(n \frac{W P r_{i}}{P r_{i}}\right)^{2}}
$$

where,

$$
\begin{aligned}
& D_{h_{i}}=\frac{4 A_{c s i}}{P_{w e, i}} \\
& \frac{W D_{h_{i}}}{D_{h_{i}}}=\sqrt{\left(\frac{W A_{c s i}}{A_{c s i}}\right)^{2}+\left(-\frac{W P_{w e, i}}{P_{w e, i}}\right)^{2}} \\
& A_{c s i}=H_{m c} L_{m c} M_{n} \\
& \frac{W A_{c s i}}{A_{c s i}}=\sqrt{\left(\frac{W H_{m c}}{H_{m c}}\right)^{2}+\left(\frac{W L_{m c}}{L_{m c}}\right)^{2}} \\
& P_{w e, i}=2\left(H_{m c}+L_{m c}\right) M_{n}
\end{aligned}
$$




$$
\begin{aligned}
& W P_{w e, i}=\sqrt{\left(2 M_{n} W H_{m c}\right)^{2}+\left(2 M_{n} W L_{m c}\right)^{2}} \\
& R e_{D_{h}, i}=\frac{\rho_{i} V_{i} D_{h_{i}}}{\mu_{i}}
\end{aligned}
$$

Uncertainty associated with the Waterside Reynolds number is based on water density at average temperature, average water velocity at hydraulic diameter, hydraulic diameter, and dynamic viscosity. Hydraulic diameter will be treated, as a constant and remaining variables will be analyzed.

$$
\begin{aligned}
& \frac{W R e_{D_{h}, i}}{R e_{D_{h}, i}}=\sqrt{\left(\frac{W \rho_{i}}{\rho_{i}}\right)^{2}+\left(\frac{W V_{i}}{V_{i}}\right)^{2}+\left(\frac{W D_{h_{i}}}{D_{h_{i}}}\right)^{2}+\left(-\frac{W \mu_{i}}{\mu_{i}}\right)^{2}} \\
& V_{i}=\frac{\dot{Q}_{i}}{A_{c s i}}
\end{aligned}
$$

Uncertainty associated with the waterside velocity is based on volume flow of water and flow area of tube cross section. Flow area of tube cross section will be treated, as a constant and only uncertainty in the volume flow of water will be analyzed.

$$
\begin{aligned}
& \frac{W V_{i}}{V_{i}}=\sqrt{\left(\frac{W \dot{Q}_{i}}{\dot{Q}_{i}}\right)^{2}+\left(-\frac{W A_{c s i}}{A_{c s i}}\right)^{2}} \\
& \frac{W V_{i}}{V_{i}}=\sqrt{\left(\frac{W \dot{Q}_{i}}{\dot{Q}_{i}}\right)^{2}+\left(-\frac{W A_{c s i}}{A_{c s i}}\right)^{2}}
\end{aligned}
$$

Waterside flow is measured using turbine flow meter; therefore, uncertainty in the flow measurement is based on the precision of the measurement gauge only.

$$
\frac{W \dot{Q}_{i}}{\dot{Q}_{i}}=\sqrt{\left(\frac{W \dot{Q}_{\text {igauge }}}{\dot{Q}_{\text {igauge }}}\right)^{2}}
$$




$$
\begin{aligned}
& \operatorname{Pr}_{i}=\frac{\mu_{i} C_{p_{i}}}{k_{i}} \\
& \frac{W P r_{i}}{P r_{i}}=\sqrt{\left(\frac{W \mu_{i}}{\mu_{i}}\right)^{2}+\left(\frac{W C_{p_{i}}}{C_{p_{i}}}\right)^{2}+\left(-\frac{W k_{i}}{k_{i}}\right)^{2}} \\
& \beta_{3}=\frac{\delta_{w}}{k_{w} A_{w}} \\
& \frac{W \beta_{3}}{\beta_{3}}=\sqrt{\left(\frac{W \delta_{w}}{\delta_{w}}\right)^{2}+\left(-\frac{W k_{w}}{k_{w}}\right)^{2}+\left(-\frac{W A_{w}}{A_{w}}\right)^{2}} \\
& T_{w b m}=\frac{T_{o b m}+T_{i b m}}{2}
\end{aligned}
$$$$
W T_{w b m}=\sqrt{\left(\frac{1}{2} W T_{o b m}\right)^{2}+\left(\frac{1}{2} W T_{i b m}\right)^{2}}
$$$$
k_{w}=\left(228.2103+0.0578 T_{w b m}-8.6806 \times 10^{-5} T_{w b m}{ }^{2}\right)
$$$$
W k_{w}=\sqrt{\left(\left(0.0578-.000173612 T_{w b m}\right) W T_{w b m}\right)^{2}}
$$$$
A_{w}=2 T_{d} L t_{n}-2 \delta_{w} L t_{n}+2 D_{m} L t_{n}-2 \delta_{w} L t_{n}
$$$$
A_{w}=A_{w 1}-A_{w 2}+A_{w 3}-A_{w 4}
$$

$$
W A_{w}=\sqrt{\left(W A_{w 1}\right)^{2}+\left(-W A_{w 2}\right)^{2}+\left(W A_{w 3}\right)^{2}+\left(-W A_{w 4}\right)^{2}}
$$

$A_{w 1}=2 T_{d} L t_{n}$

$\frac{W A_{w 1}}{A_{w 1}}=\sqrt{\left(\frac{W T_{d}}{T_{d}}\right)^{2}+\left(\frac{W L}{L}\right)^{2}}$

$$
A_{w 2}=2 \delta_{w} L t_{n}
$$

$\frac{W A_{w 2}}{A_{w 2}}=\sqrt{\left(\frac{W \delta_{w}}{\delta_{w}}\right)^{2}+\left(\frac{W L}{L}\right)^{2}}$ 


$$
\begin{aligned}
& A_{w 3}=2 D_{m} L t_{n} \\
& \frac{W A_{w 3}}{A_{w 3}}=\sqrt{\left(\frac{W D_{m}}{D_{m}}\right)^{2}+\left(\frac{W L}{L}\right)^{2}} \\
& A_{w 4}=2 \delta_{w} L t_{n} \\
& \frac{W A_{w 4}}{A_{w 4}}=\sqrt{\left(\frac{W \delta_{w}}{\delta_{w}}\right)^{2}+\left(\frac{W L}{L}\right)^{2}}
\end{aligned}
$$

\section{Uncertainty in f-factor}

The f-factor is determined by the following relationship (McQuiston et al., 2005):

$$
\begin{aligned}
f=\frac{A_{c}}{A_{o}} \frac{\rho_{o b m}}{\rho_{o 1}} & {\left[\frac{2 \rho_{o 1} \Delta P_{t}}{G_{c}{ }^{2}}-\left(K_{c}+1-\sigma^{2}\right)-2\left(\frac{\rho_{o 1}}{\rho_{o 2}}-1\right)\right.} \\
& \left.+\left(1-\sigma^{2}-K_{e}\right) \frac{\rho_{o 1}}{\rho_{o 2}}\right]
\end{aligned}
$$

Uncertainty associated with the f-factor is based on air density at the inlet, outlet and mean temperature, mass velocity through minimum free flow area, and the pressure difference across the test section. All remaining variables kept constant. The above equation is rewritten in the following format:

$$
f=\frac{A_{c}}{A_{o}} \frac{\rho_{o b m}}{\rho_{o 1}} \Gamma
$$

where,

$$
\Gamma=\left[\frac{2 \rho_{o 1} \Delta P_{t}}{G_{c}{ }^{2}}-\left(K_{c}+1-\sigma^{2}\right)-2\left(\frac{\rho_{o 1}}{\rho_{o 2}}-1\right)+\left(1-\sigma^{2}-K_{e}\right) \frac{\rho_{o 1}}{\rho_{o 2}}\right]
$$

The uncertainty associated with the f-factor is estimated using the following equations: 
$\frac{W f}{f}=\sqrt{\left(\frac{W \rho_{0 b m}}{\rho_{o b m}}\right)^{2}+\left(-\frac{W \rho_{01}}{\rho_{o 1}}\right)^{2}+\left(\frac{W \Gamma}{\Gamma}\right)^{2}+\left(\frac{W A_{c}}{A_{c}}\right)^{2}+\left(-\frac{W A_{o}}{A_{o}}\right)^{2}}$

The above equation no. (2.106) is treated as summation of four terms:

$$
\begin{aligned}
& \Gamma=\Gamma_{1}-\Gamma_{2}-\Gamma_{3}+\Gamma_{4} \\
& W \Gamma=\sqrt{\left(W \Gamma_{1}\right)^{2}+\left(-W \Gamma_{2}\right)^{2}+\left(-W \Gamma_{3}\right)^{2}+\left(W \Gamma_{4}\right)^{2}} \\
& \Gamma_{1}=\frac{2 \rho_{o 1} \Delta P_{t}}{G_{c}{ }^{2}} \\
& \frac{W \Gamma_{1}}{\Gamma_{1}}=\sqrt{\left(\frac{W \rho_{01}}{\rho_{o 1}}\right)^{2}+\left(-\frac{W \Delta P_{t}}{\Delta P_{t}}\right)^{2}+\left(-2 \frac{W G_{c}}{G_{c}}\right)^{2}} \\
& \Gamma_{2}=\left(K_{c}+1-\sigma^{2}\right) \\
& W \Gamma_{2}=\sqrt{(-2 \sigma W \sigma)^{2}} \\
& \sigma=\frac{A_{c}}{A_{f r}} \\
& \frac{W \sigma}{\sigma}=\sqrt{\left(\frac{W A_{c}}{A_{c}}\right)^{2}+\left(-\frac{W A_{f r}}{A_{f r}}\right)^{2}} \\
& A_{f r}=L H_{c}
\end{aligned}
$$

$$
\frac{W A_{f r}}{A_{f r}}=\sqrt{\left(\frac{W L}{L}\right)^{2}+\left(\frac{W H_{c}}{H_{c}}\right)^{2}}
$$

Since the variables in $\Gamma_{2}$ are treated constant, the uncertainty in $\Gamma_{2}$ is zero.

$$
\Gamma_{3}=2\left(\frac{\rho_{o 1}}{\rho_{o 2}}-1\right)
$$




$$
\begin{aligned}
& \frac{W \Gamma_{3}}{\Gamma_{3}}=\sqrt{\left(\frac{W \rho_{01}}{\rho_{o 1}}\right)^{2}+\left(-\frac{W \rho_{02}}{\rho_{o 2}}\right)^{2}} \\
& \Gamma_{4}=\left(1-\sigma^{2}-K_{e}\right) \frac{\rho_{o 1}}{\rho_{o 2}} \\
& \Gamma_{4}=\Gamma_{5} \frac{\rho_{o 1}}{\rho_{o 2}} \\
& \frac{W \Gamma_{4}}{\Gamma_{4}}=\sqrt{\left(\frac{W \Gamma_{5}}{\Gamma_{5}}\right)^{2}+\left(\frac{W \rho_{01}}{\rho_{o 1}}\right)^{2}+\left(-\frac{W \rho_{02}}{\rho_{o 2}}\right)^{2}} \\
& \Gamma_{5}=\left(1-\sigma^{2}-K_{e}\right) \\
& W \Gamma_{5}=\sqrt{(-2 \sigma W \sigma)^{2}} \\
& A_{c}=L H\left(t_{n}+1\right)-f_{n} H^{\prime} \delta_{f}\left(t_{n}+1\right) \\
& A_{c}=A_{c 1}-A_{c 2} \\
& W A_{c}=\sqrt{\left(W A_{c 1}\right)^{2}+\left(-W A_{c 2}\right)^{2}} \\
& \frac{W A_{c 2}}{A_{c 2}}=L \sqrt{\left(\frac{W H^{\prime}}{H^{\prime}}\right)^{2}+\left(\frac{W \delta_{f}}{\delta_{f}}\right)^{2}} \\
& \frac{W A_{c 1}}{A_{c 1}}=\sqrt{\left(\frac{W L}{L}\right)^{2}+\left(\frac{W H}{H}\right)^{2}} \\
& A_{c 2}=f_{n} H^{\prime} \delta_{f}\left(t_{n}+1\right) \\
& \left.t_{n}\right)
\end{aligned}
$$




\section{APPENDIX B. PLOTS FOR SIMPLIFIED CORRELATION ANALYSIS}

Simplified j-factor correlation for $80<\mathbf{R e}_{L p} \leq \mathbf{2 0 0}$

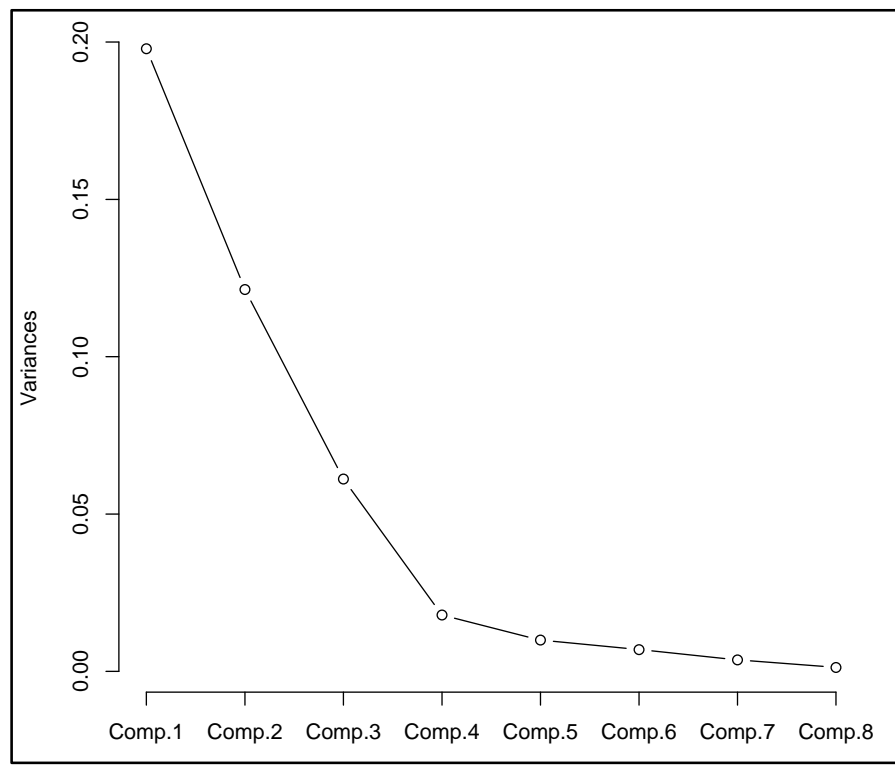

Analysis of principal components in j-factor

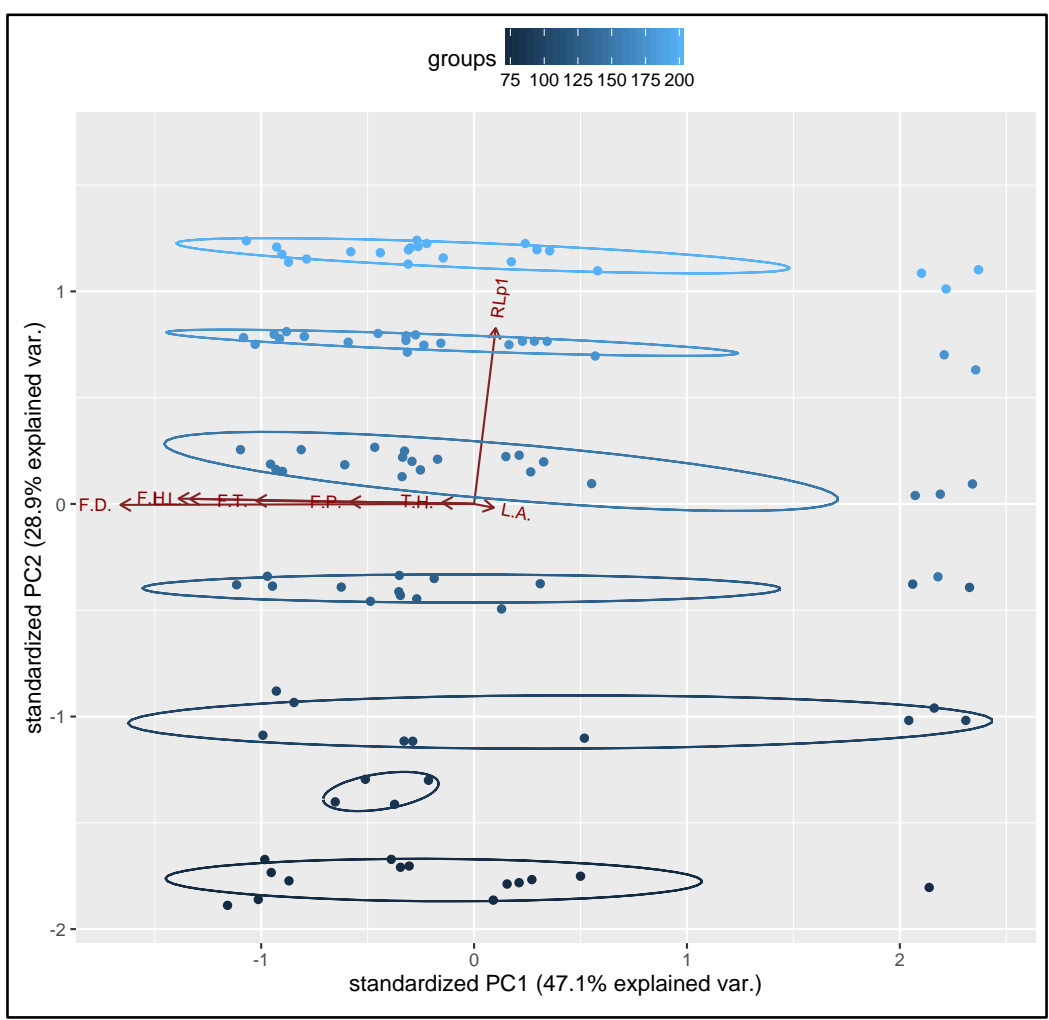

Covariance of the two principal components representing the dataset 


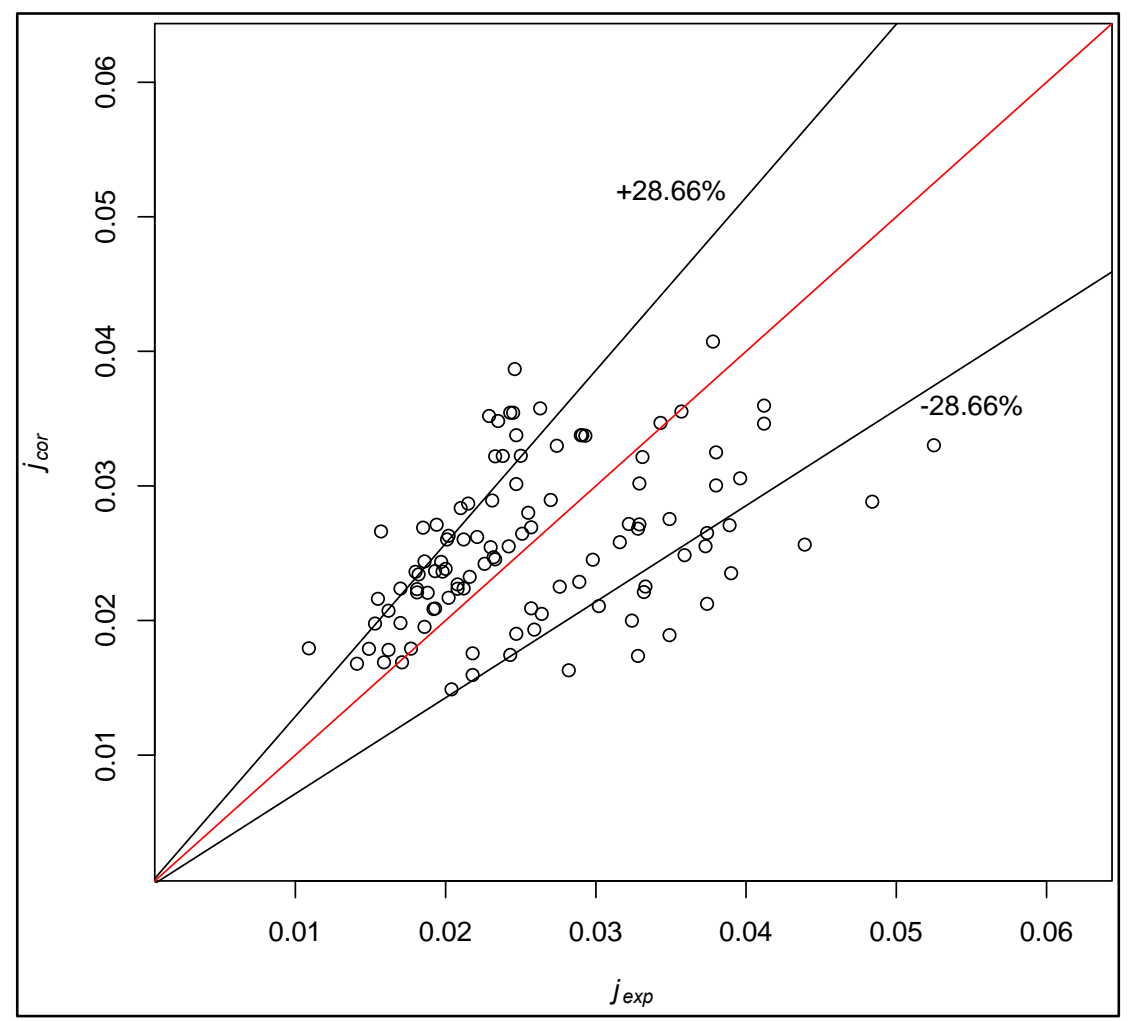

Correlated Simplified j Factor vs. Experimental j Factor

Simplified f-factor correlation for $20<\operatorname{Re}_{\mathrm{Lp}} \leq \mathbf{8 0}$

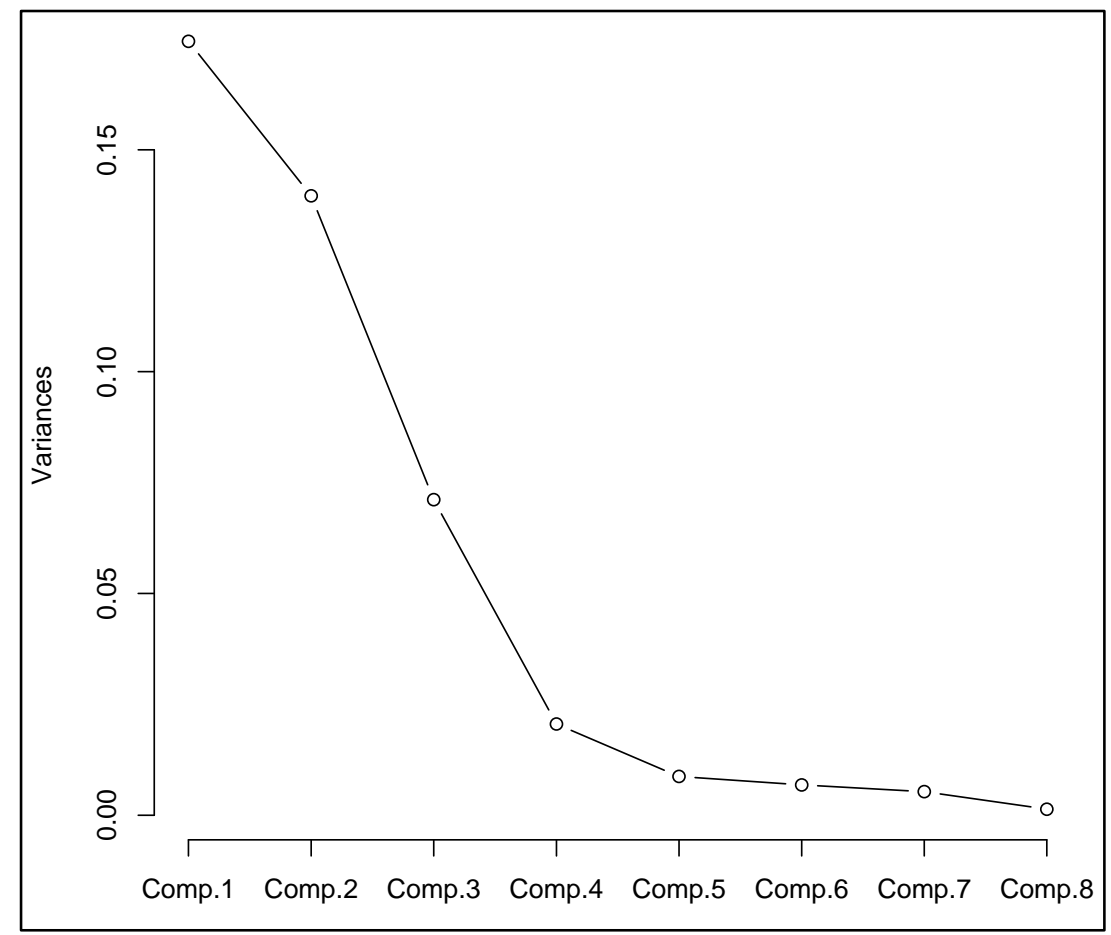

Analysis of principal components in f-factor 


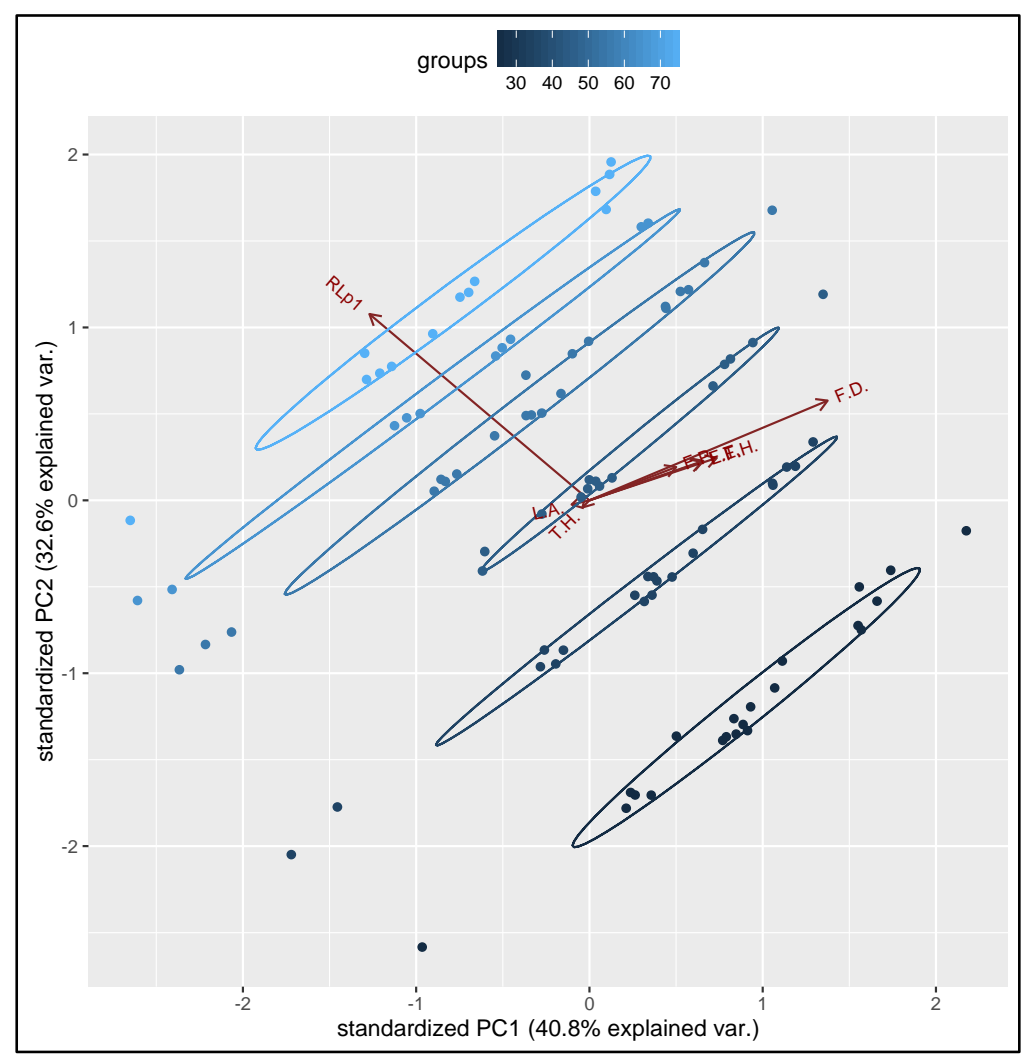

Covariance of the two principal components the dataset

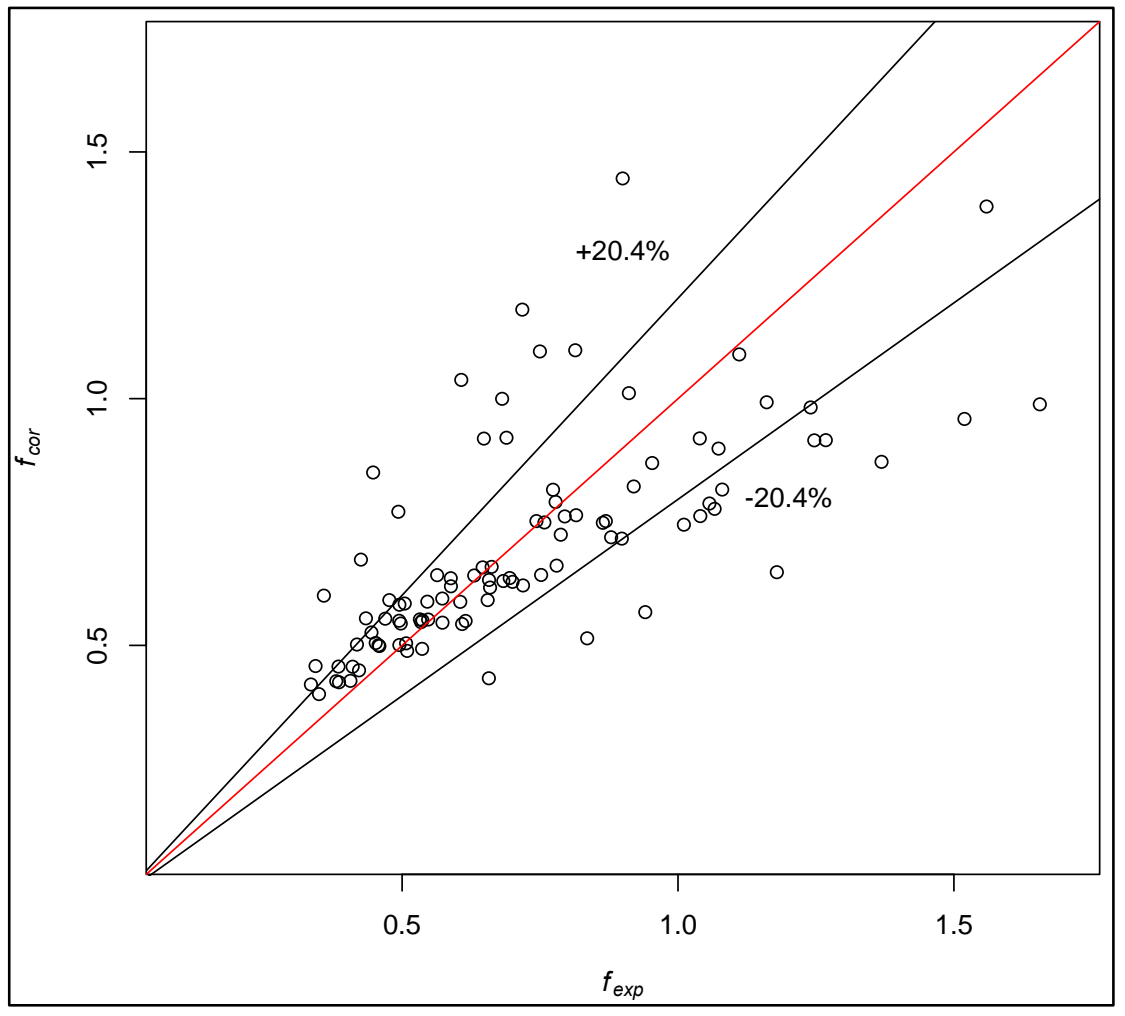

Correlated Simplified f Factor vs. Expe rimental f Factor 
Simplified f-factor correlation for $80<\operatorname{Re}_{L p} \leq \mathbf{2 0 0}$

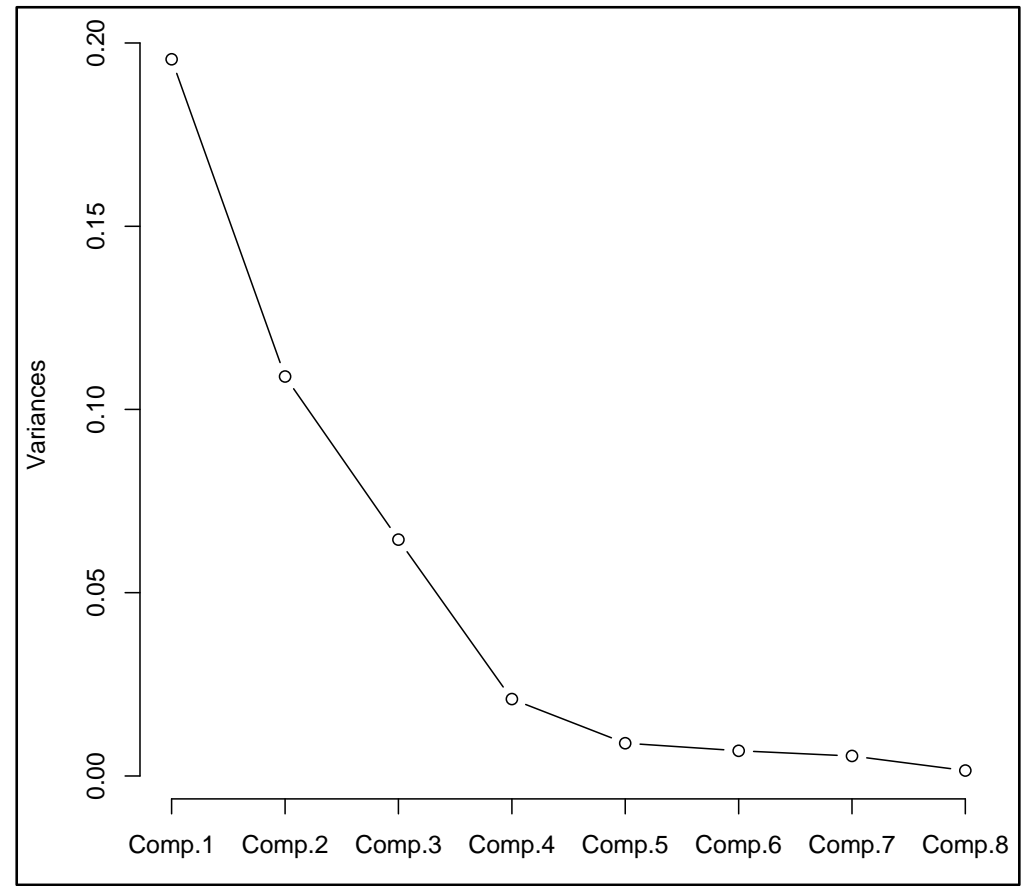

Analysis of principal components in f-factor

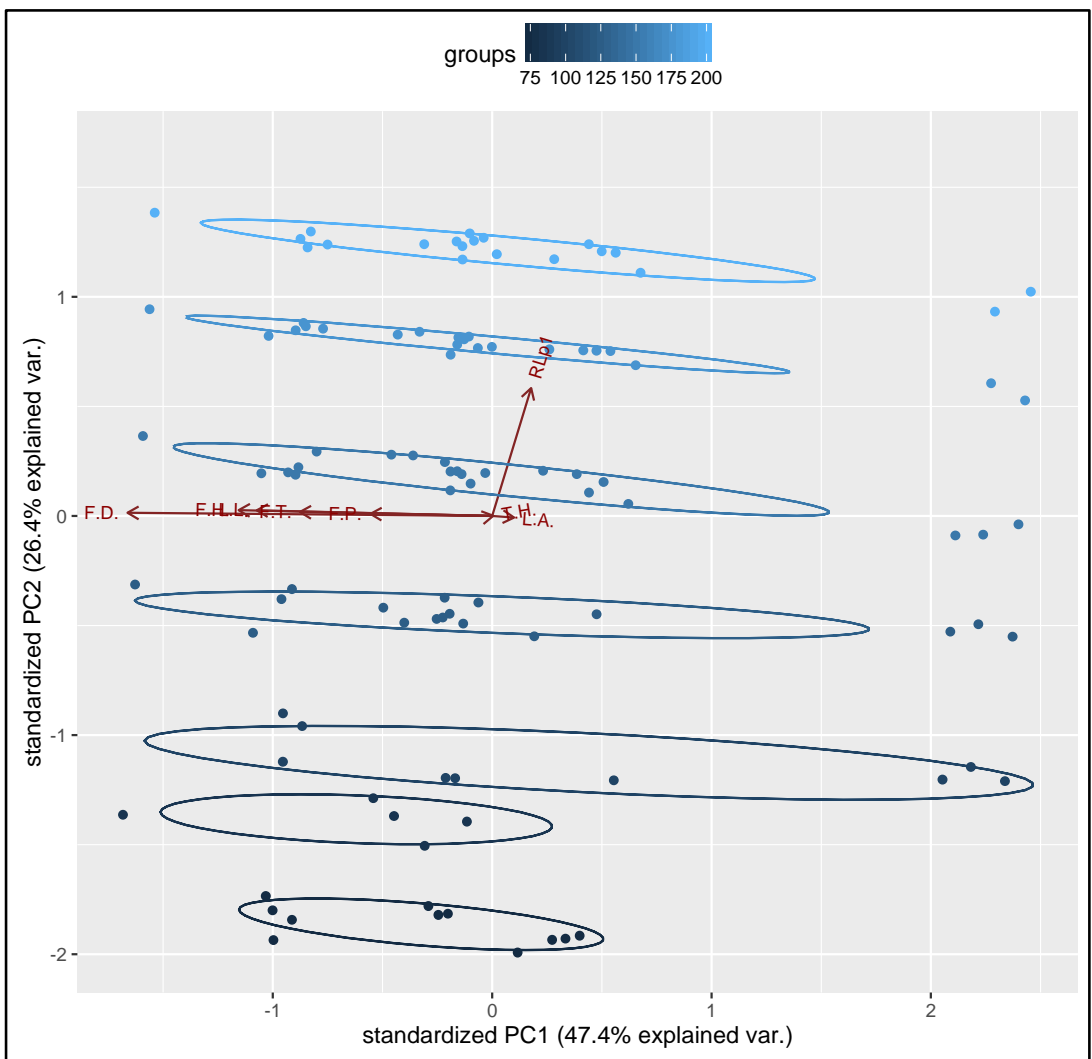

Covariance of the two principal components the dataset 


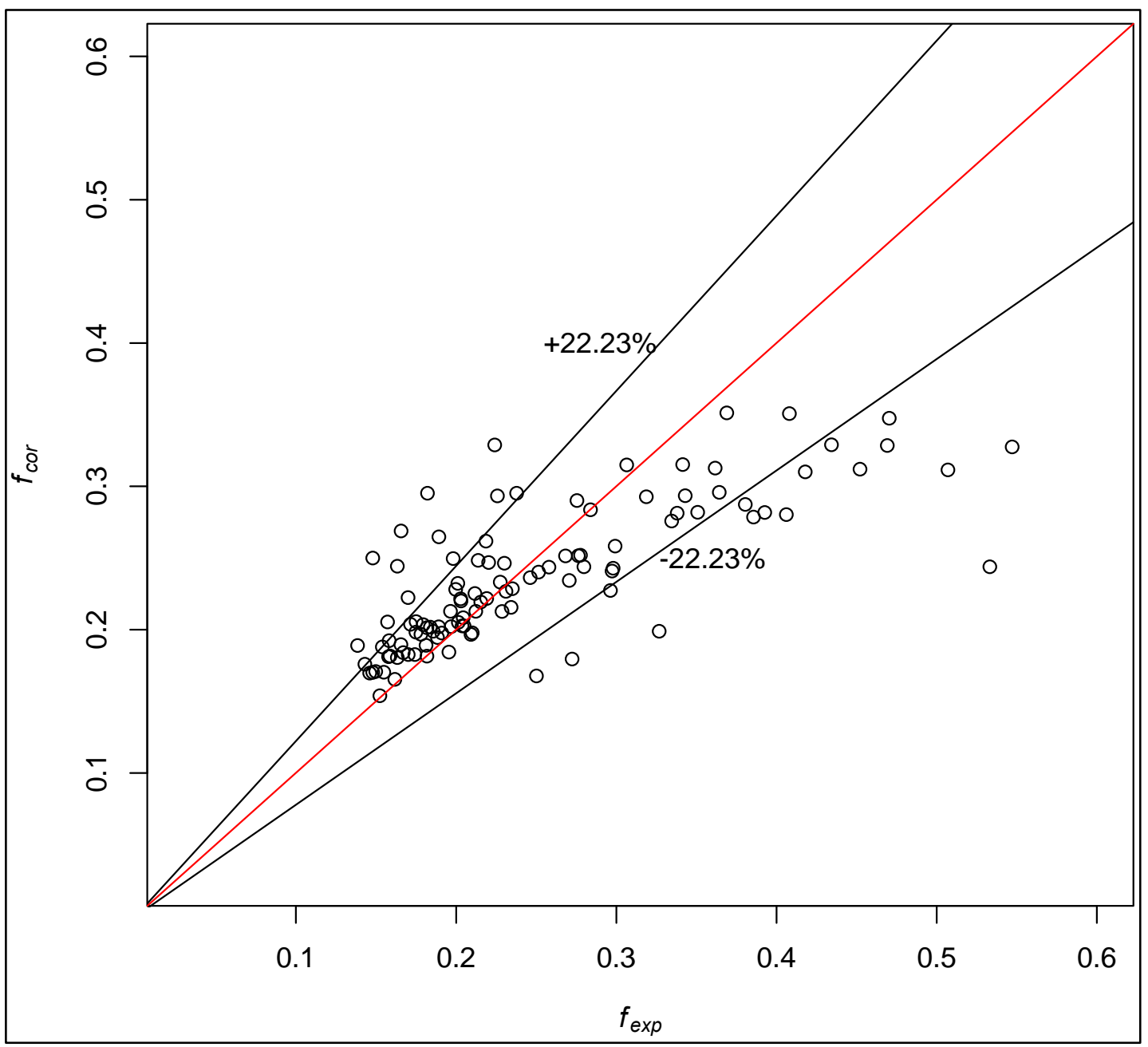

Correlated Simplified f Factor vs. Experimental f Factor 


\section{APPENDIX C. VELOCITY, TEMPERATURE, AND PRESSURE DROP PLOTS}

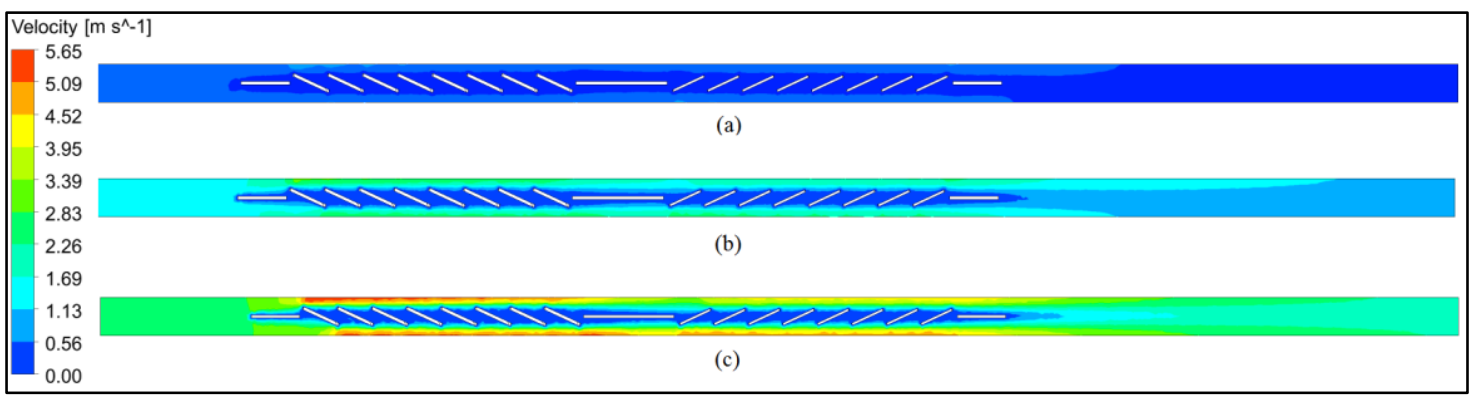

Velocity (m/s) contours for (a) $R e_{L p}=25$, (b) $R e_{L p}=100$, (c) $R e_{L p}=200$ for Sample\#2

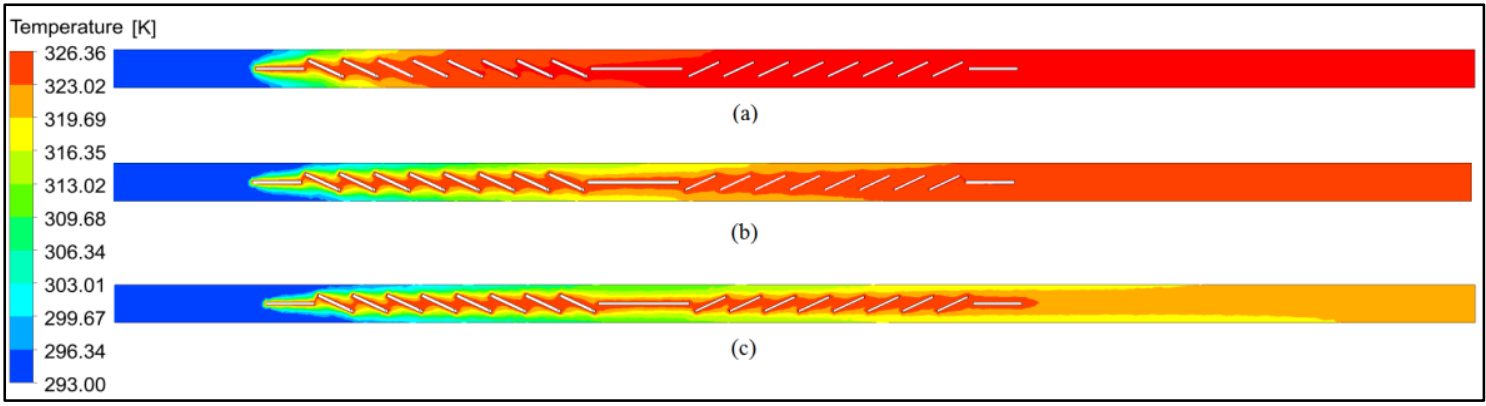

Temperature (K) contours for (a) $R e_{L p}=25$, (b) $R e_{L p}=100$, (c) $R e_{L p}=200$ for Sample\#2

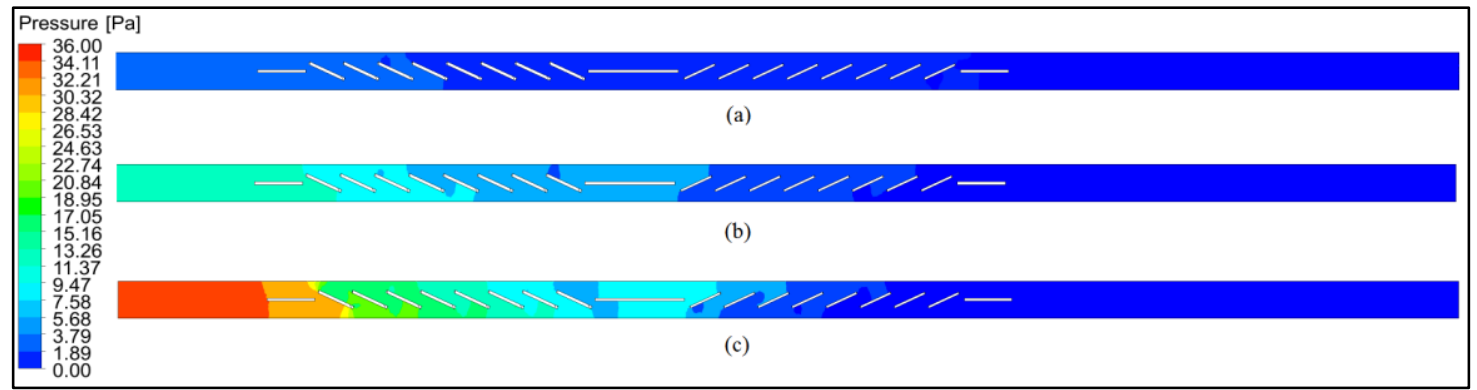

Pressure (Pa) contours for (a) $\operatorname{Re} L p=25$, (b) $\operatorname{Re} L p=100$, (c) $\operatorname{Re} L p=200$ for Sample\#2 


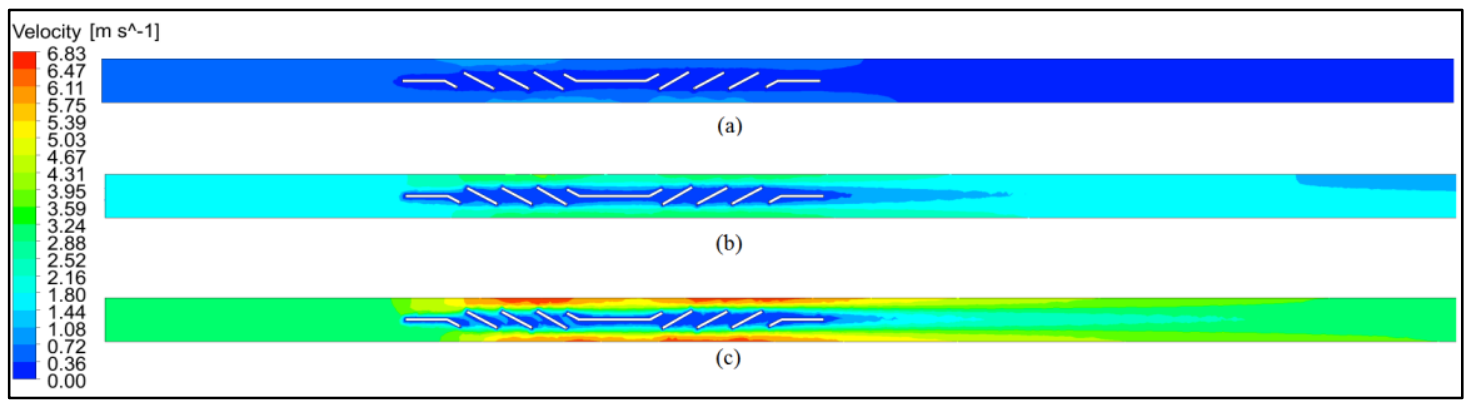

Velocity (m/s) contours for (a) $R e_{L p}=25$, (b) $R e_{L p}=100$, (c) $R e_{L p}=200$ for Sample\#5

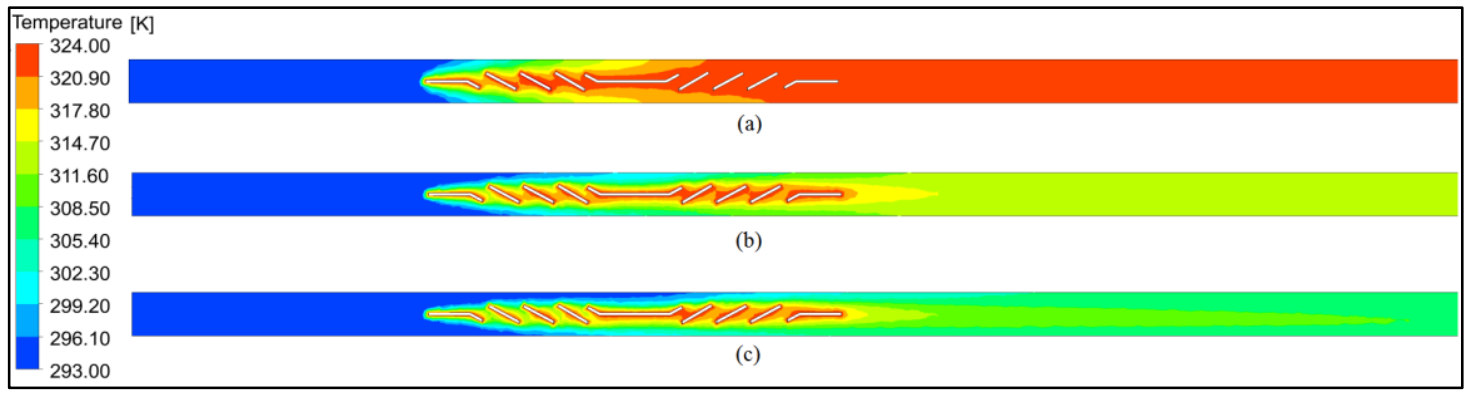

Temperature (K) contours for (a) $R e_{L p}=25$, (b) $R e_{L p}=100$, (c) $R e_{L p}=200$ for Sample\#5

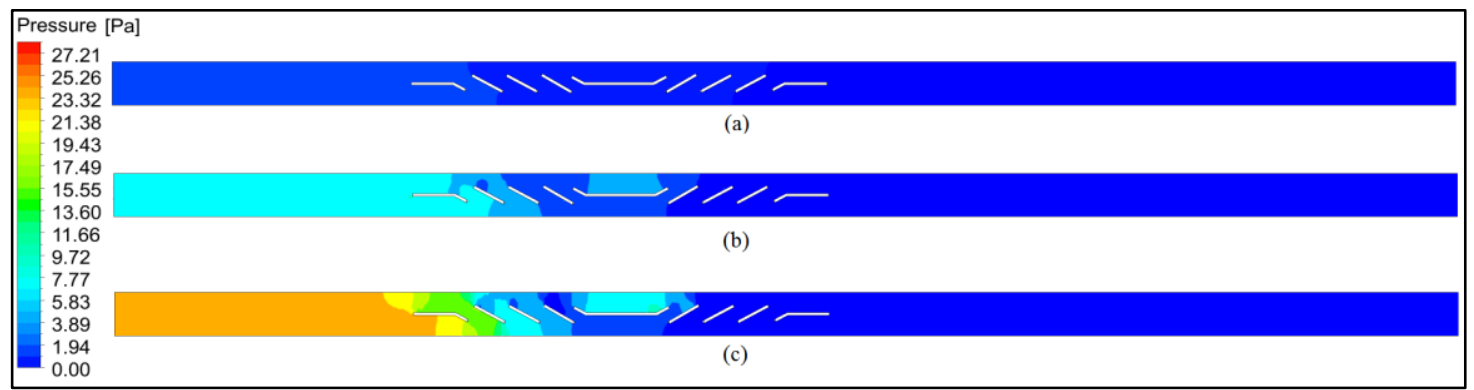

Pressure (Pa) contours for (a) $\operatorname{ReLp}=25$, (b) $\operatorname{ReLp}=100$, (c) $\operatorname{ReLp}=200$ for Sample\#5 


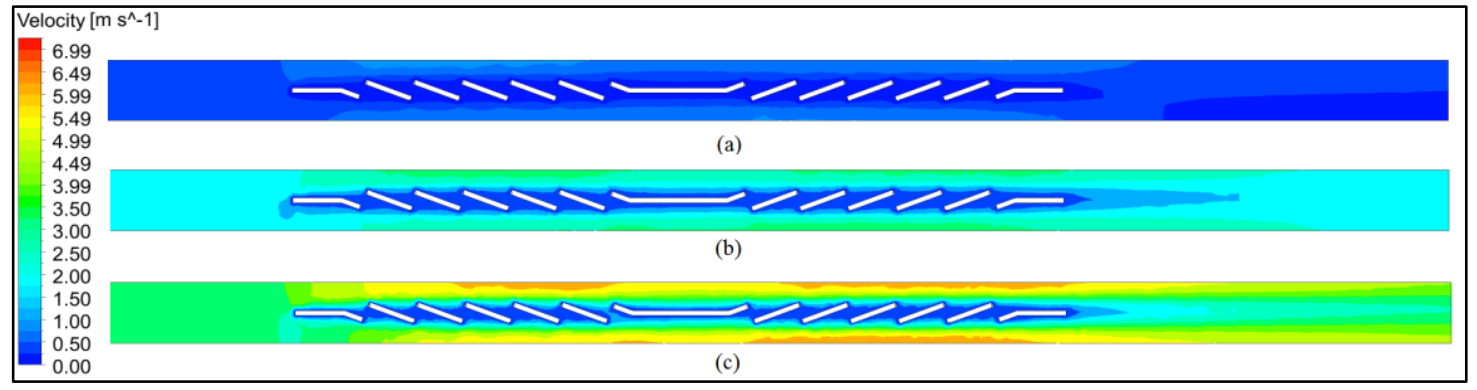

Velocity (m/s) contours for (a) $R e_{L p}=25$, (b) $R e_{L p}=100$, (c) $R e_{L p}=200$ for Sample\#7

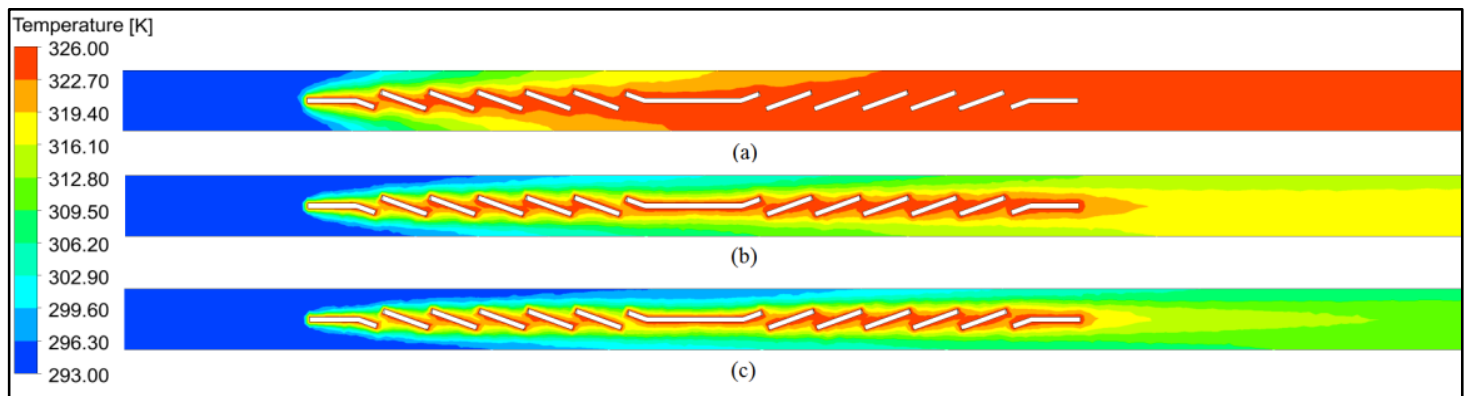

Temperature (K) contours for (a) $R e_{L p}=25$, (b) $R e_{L p}=100$, (c) $R e_{L p}=200$ for Sample\#7

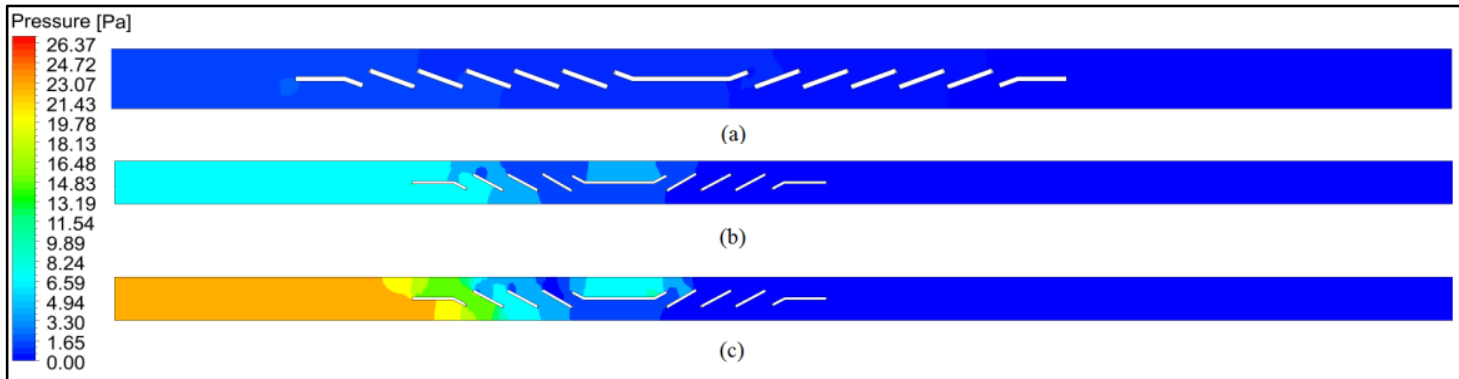

Pressure (Pa) contours for (a) $\operatorname{Re} L p=25$, (b) $\operatorname{Re} L p=100$, (c) $\operatorname{Re} L p=200$ for Sample\#7 


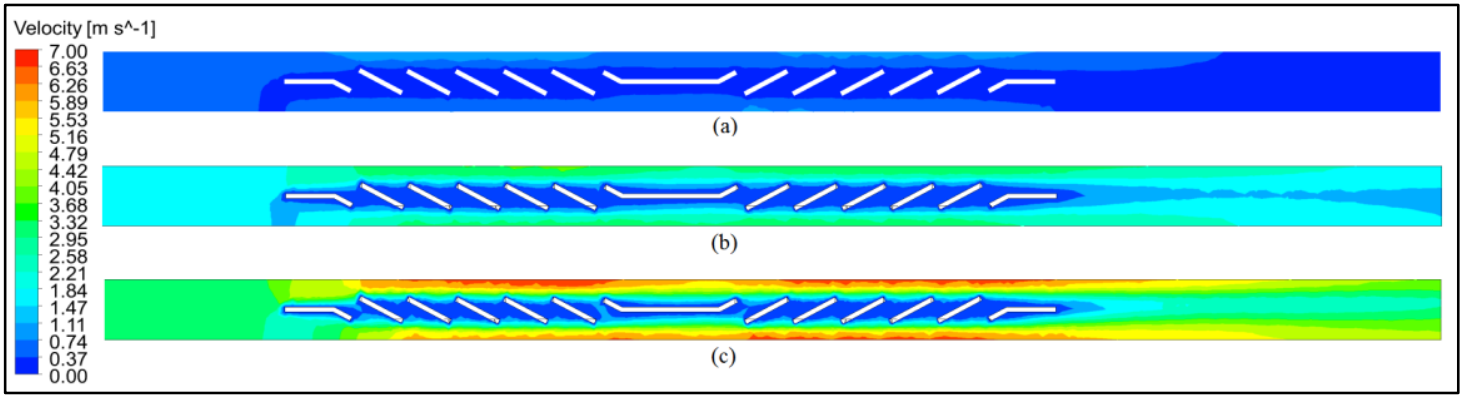

Velocity (m/s) contours for (a) $R e_{L p}=25$, (b) $R e_{L p}=100$, (c) $R e_{L p}=200$ for Sample\#15

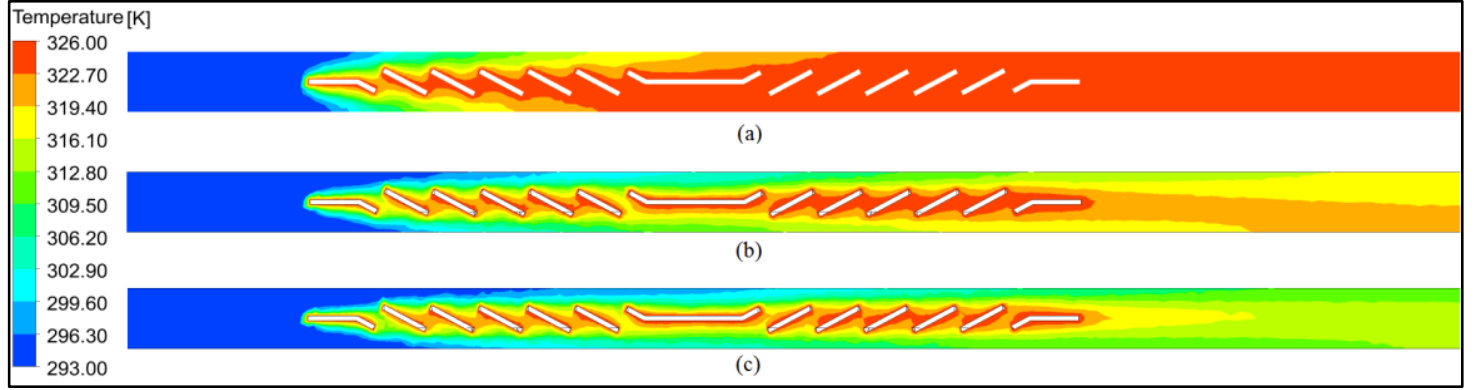

Temperature (K) contours for (a) $R e_{L p}=25$, (b) $R e_{L p}=100$, (c) $R e_{L p}=200$ for Sample\#15

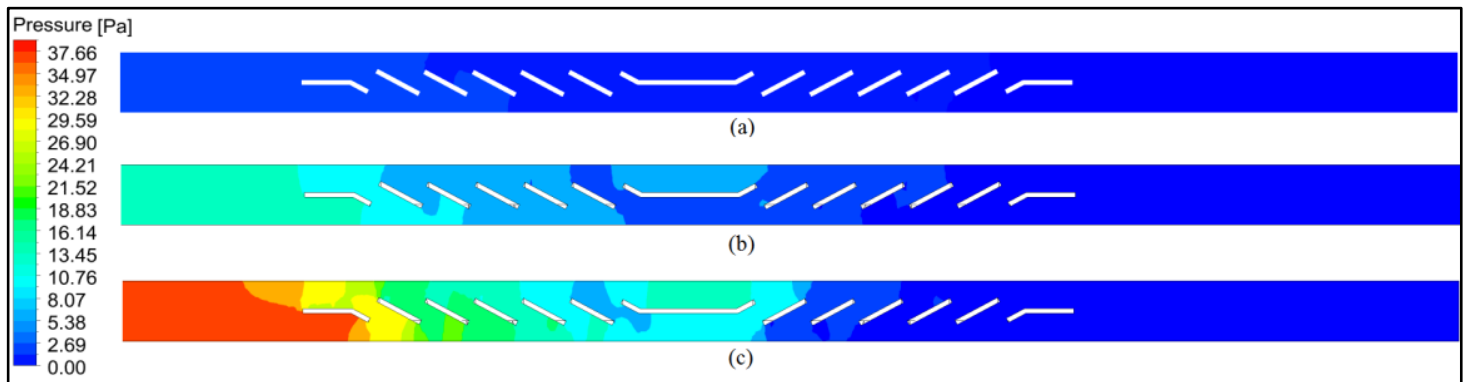

Pressure (Pa) contours for (a) $\operatorname{ReLp}=25$, (b) $\operatorname{ReLp}=100$, (c) $\operatorname{ReLp}=200$ for Sample\#15 


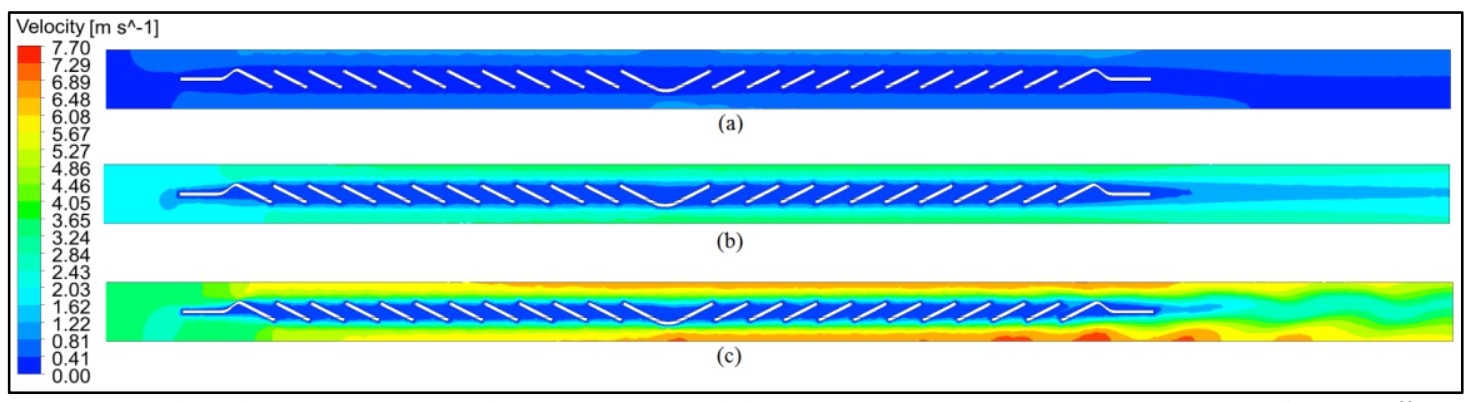

Velocity $(\mathrm{m} / \mathrm{s})$ contours for (a) $R e_{L p}=25$, (b) $R e_{L p}=100$, (c) $R e_{L p}=200$ for Sample\#25

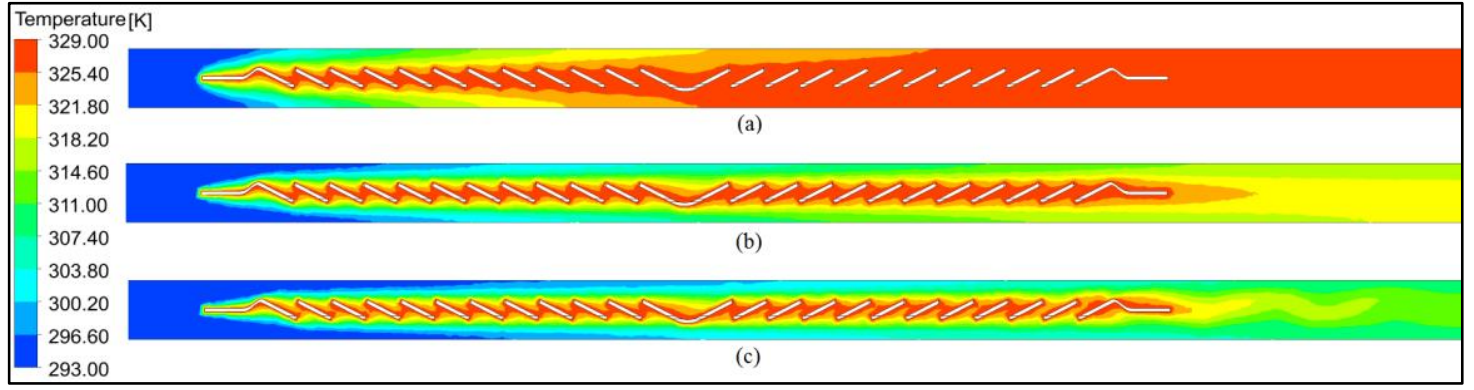

Temperature (K) contours for (a) $R e_{L p}=25$, (b) $R e_{L p}=100$, (c) $R e_{L p}=200$ for Sample\#25

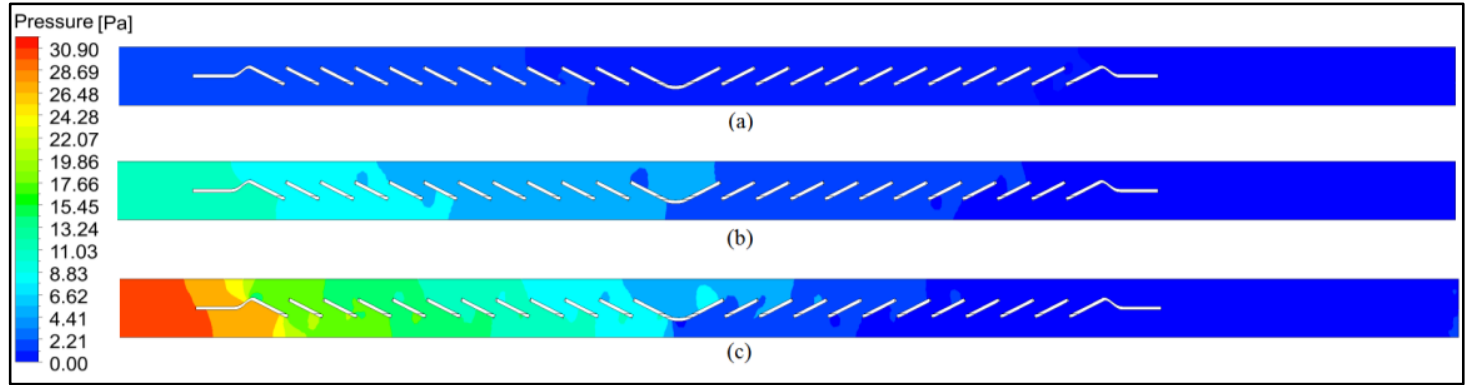

Pressure (Pa) contours for (a) $\operatorname{Re} L p=25$, (b) $\operatorname{Re} L p=100$, (c) $\operatorname{ReLp}=200$ for Sample\#25 


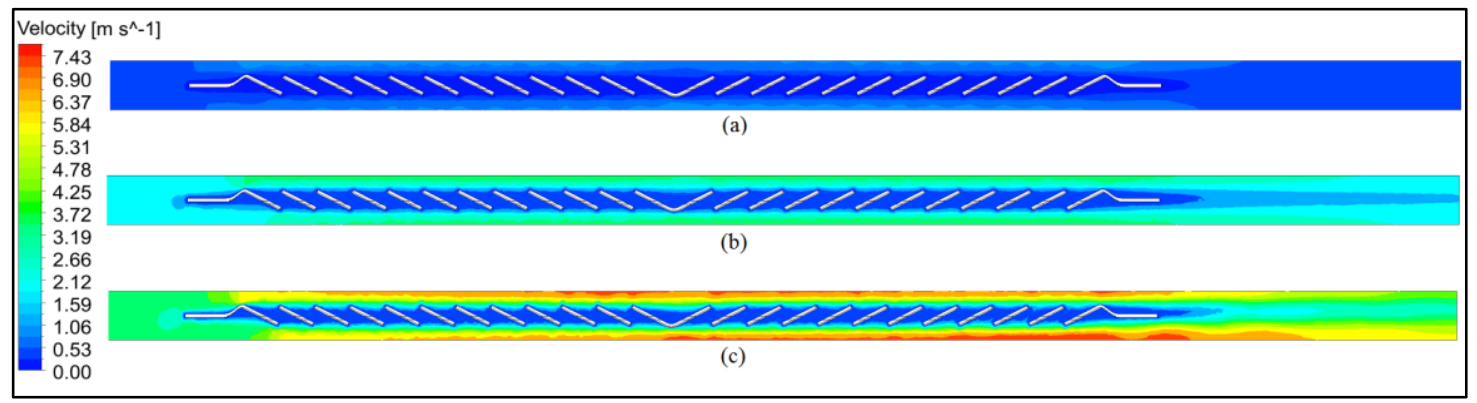

Velocity $(\mathrm{m} / \mathrm{s})$ contours for (a) $R e_{L p}=25$, (b) $R e_{L p}=100$, (c) $R e_{L p}=200$ for Sample\#26

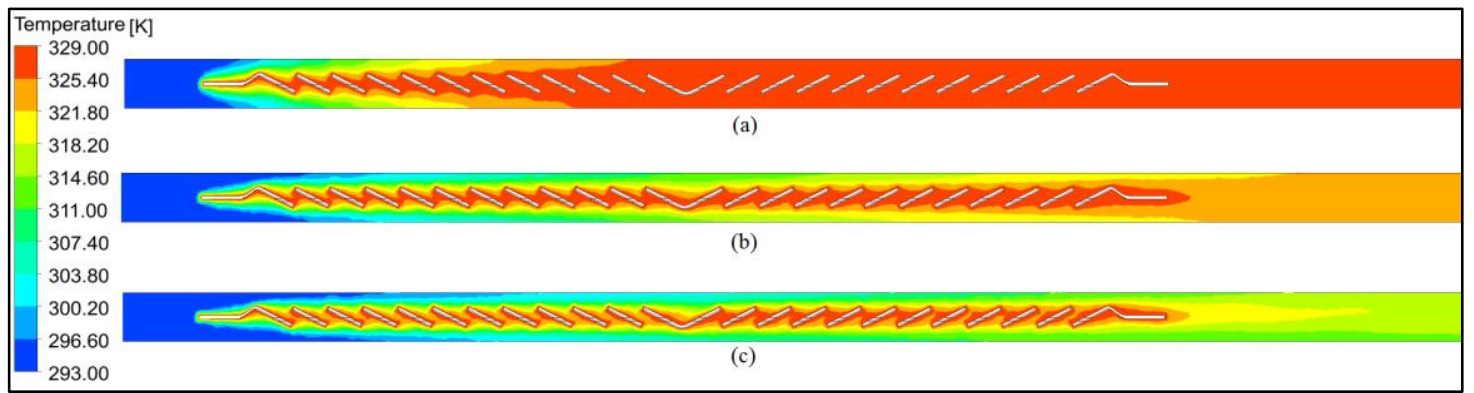

Temperature (K) contours for (a) $R e_{L p}=25$, (b) $R e_{L p}=100$, (c) $R e_{L p}=200$ for Sample\#26

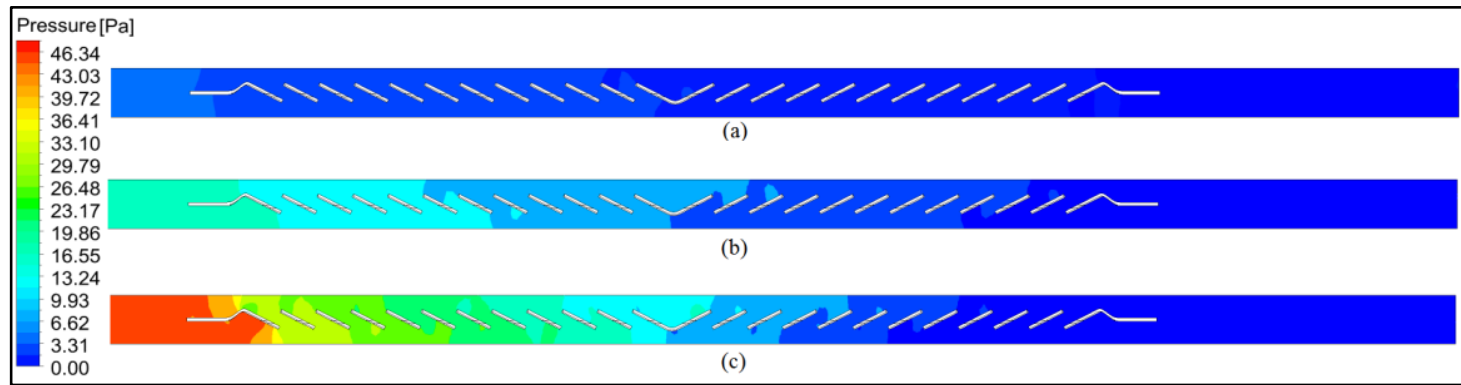

Pressure (Pa) contours for (a) $\operatorname{Re} L p=25$, (b) $\operatorname{ReLp}=100$, (c) $\operatorname{ReLp}=200$ for Sample\#26 
VITA

PRADEEP RAMESH SHINDE

Born, Nashik, Maharashtra (MH), India

2000-2004

2005-2006

Bachelor of Engineering, Mechanical Engineering Pune University, India

Precision Forging \& Stamping, Nashik, MH, India

2006-2007

2007-2009

2009

2010-2011

2011- 2015

2012-2016

2012-2014

2013

2013-2016

2014-2016

2016

2016

Founder \& President of Near Earth Explorers Club, FIU

2016

Dissertation Year Fellowship Award, FIU 


\section{PUBLICATIONS}

Shinde, P. \& Lin, C.-X., 2016. A heat transfer and friction factor correlation for low airside Reynolds number applications of compact heat exchangers (1535-RP). Science and Technology for the Built Environment, 0, pp.1-19.

Shinde, P., Schäfer, M. \& Lin, C.-X, 2016. Numerical Investigation of Micro-Channe led Louver Fin Aluminum Heat Exchangers At Low Reynolds Number. In Proceedings of the ASME 2016 Summer Heat Transfer Conference, HTFEICNMM2016. Washington, DC, USA, pp. 1-6.

Shinde, P.\& Lin, C.-X, 2016. Numerical Study of Micro-Channeled Louver Fin Aluminum Heat Exchangers at Very Low Reynolds Number. In Proceedings of the First Pacific Rim Thermal Engineering Conference, PRTEC-14695. Hawaii's Big Island, USA.

Shinde, P., Newman, E., Tansel, I. and Tosunoglu, S., 2016. Design of FIU FUNSAT System: Attitude Control for the 3U CubeSat. In Proceedings of FCRAR 2016. Florida International University, Miami, FL, USA.

Hernandez, S., Phillippe, C., Salas, W., Shinde, P., Tansel, I. and Tosunoglu, S., 2016. of the 29th Conference on Recent Advances in Robotics Fcrar 2016. In Proceedings of FCRAR 2016. Florida International University, Miami, FL, USA.

Shinde, P. \& Lin, C.-X., 2016. Experimental Investigation of geometry effects on the performance of Micro-Channeled Louver Fin Aluminum Heat Exchangers At Low Reynolds Number. AppliedThermalEngineering, In Process.

Shinde, P. \& Lin, C.-X., 2016. Numerical Investigation of Flow Behavior At Low Reynolds Number. Applied Thermal Engineering, In Process.

Synalovski, L., Francisque, C., Meza, L., Shinde, P. and Tremante, A., 2015. Uni-Body Structure For Prototype Vehicle. In 13th LACCEI Annual International Conference. Santo Domingo, Dominican Republic, pp. 29-32.

Shinde, P. \& Lin, C.-X, 2014. Uncertainty Analysis in Louver Fin Aluminum Heat Exchangers. In ASME International Mechanical Engineering Congress and Exposition. Montreal, Quebec, Canada, pp. 1-9.

Schäfer, M., Detzer, R., Hesselbach, J., Böhm, S., Shinde, P. and Lin, C.-X., 2013. CO2 and thermal gradient based demand-driven stratified ventilation - Experimental and simulation study. HVAC\&R Research, 19, pp.37-41.

Shinde, P., Korla, S., Ajrawat T. and Tosunoglu, S., 2008. Design and Development of a Flipping Biped Robot. ASME Early Career Technical Journal, 7, No.1. 